\title{
FOURTEEN NEW, ENDEMIC SPECIES OF SHREW (GENUS CROCIDURA) FROM SULAWESI REVEAL A SPECTACULAR ISLAND RADIATION
}

\author{
JACOB A. ESSELSTYN, ANANG S. ACHMADI, \\ HERU HANDIKA, MARK T. SWANSON, \\ THOMAS C. GIARLA, AND KEVIN C. ROWE
}

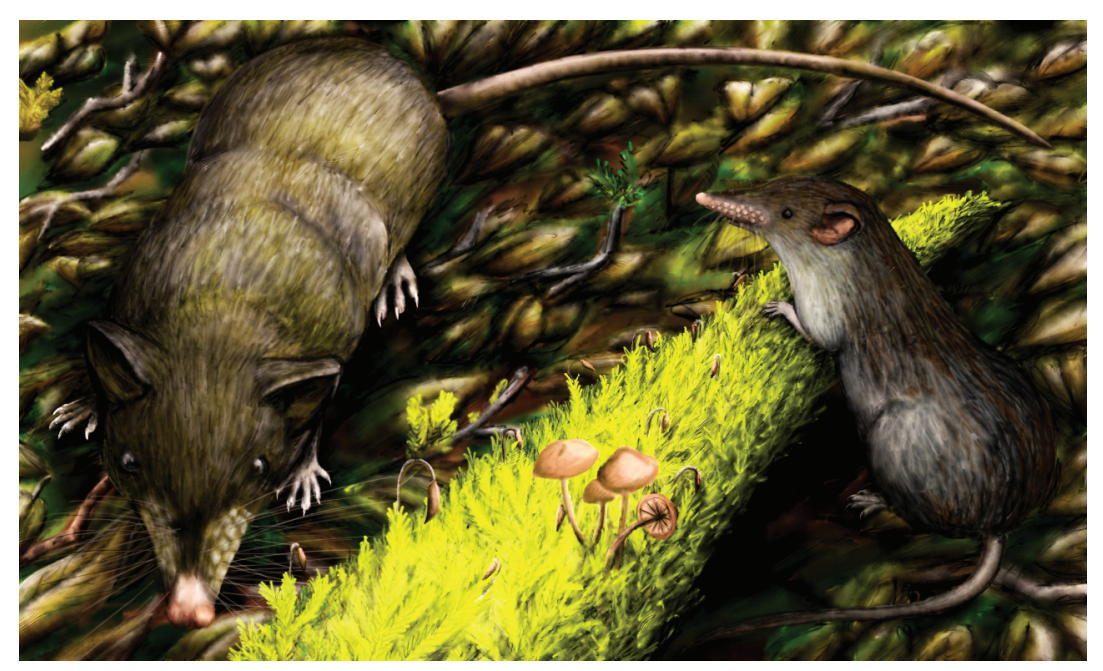

BULLETIN OF THE AMERICAN MUSEUM OF NATURAL HISTORY 


\title{
FOURTEEN NEW, ENDEMIC SPECIES OF SHREW (GENUS CROCIDURA) FROM SULAWESI REVEAL A SPECTACULAR ISLAND RADIATION
}

\author{
JACOB A. ESSELSTYN \\ Museum of Natural Science and Department of Biological Sciences,
} Louisiana State University, Baton Rouge, LA

ANANG S. ACHMADI

Museum Zoologicum Bogoriense, Indonesian Institute of Sciences, Cibinong, West Java, Indonesia

HERU HANDIKA

Museum of Natural Science and Department of Biological Sciences, Louisiana State University, Baton Rouge, LA

MARK T. SWANSON

Museum of Natural Science and Department of Biological Sciences, Louisiana State University, Baton Rouge, LA

THOMAS C. GIARLA

Department of Biology, Siena College, Loudonville, NY

KEVIN C. ROWE

Sciences Department, Museums Victoria, Melbourne, Victoria, Australia

BULLETIN OF THE AMERICAN MUSEUM OF NATURAL HISTORY

Number 454, 108 pp., 43 figures, 18 tables

Issued December 15, 2021 


\section{CONTENTS}

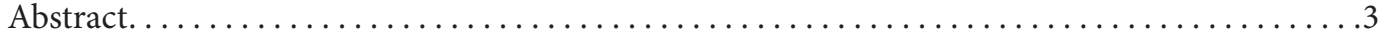

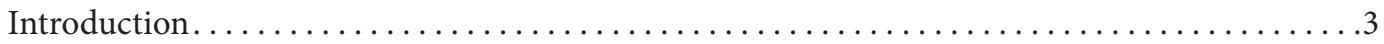

Materials and Methods ..........................................

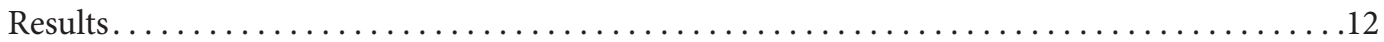

Field Collections, Identifications, and Morphological Variation $\ldots \ldots \ldots \ldots \ldots \ldots \ldots \ldots \ldots$

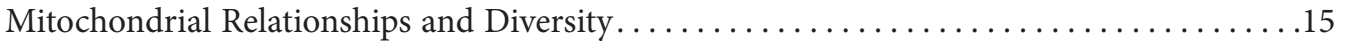

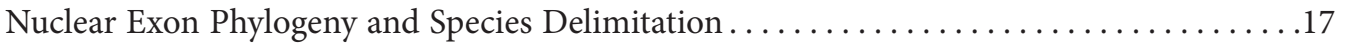

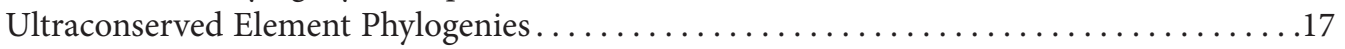

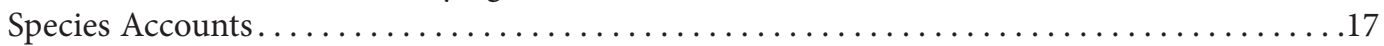

Long-Tailed Group and Elongata Subgroup .............................. 19

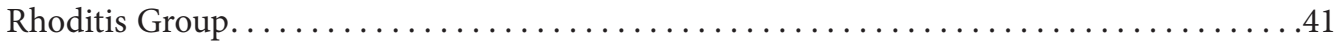

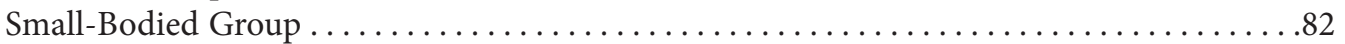

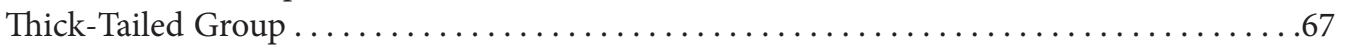

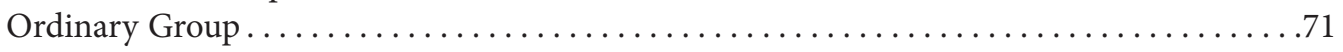

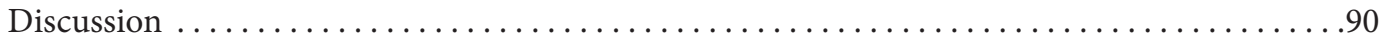

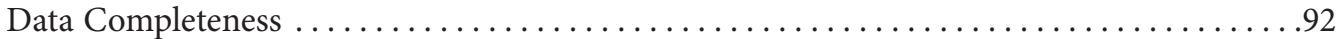

Phylogenetic Relationships and the Tempo of Diversification . . . . . . . . . . . . . . 92

Local Species Richness and Species Geographic Ranges..................... 93

Geographic Patterns of Morphological Diversity and Sympatry . . . . . . . . . . . . . . 94

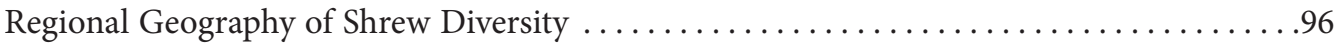

Within-Island Diversification Processes. ..............................

Conclusion ................................................ 97

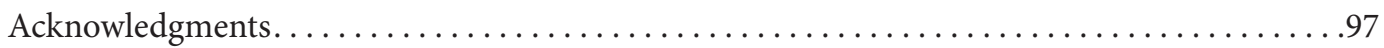

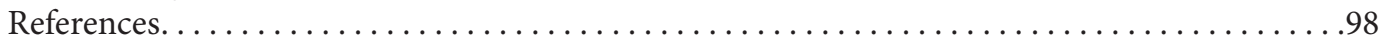

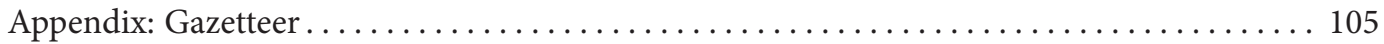




\begin{abstract}
After nearly a decade of field inventories in which we preserved voucher specimens of the small terrestrial mammals of Sulawesi, we combined qualitative and quantitative analyses of morphological traits with molecular phylogenetics to better understand the diversity of shrews (Soricidae: Crocidura) on the island. We examined the morphology of 1368 specimens and obtained extensive molecular data from many of them, including mitochondrial DNA sequences from 851 specimens, up to five nuclear exons from 657 specimens, and thousands of ultraconserved elements from 90 specimens. By iteratively testing species limits using distinct character datasets and appropriate taxon sampling, we found clear, mostly consistent evidence for the existence of 21 species of shrews on Sulawesi, only seven of which were previously recognized. We divide these 21 species into five morphogroups, provide emended diagnoses of the seven previously named species, and describe 14 new species. The Long-Tailed Group contains Crocidura caudipilosa, C. elongata, C. microelongata, new species, and C. quasielongata, new species; the Rhoditis Group contains C. rhoditis, C. pseudorhoditis, new species, C. australis, new species, and C. pallida, new species; the Small-Bodied Group contains C. lea, C. levicula, C. baletei, new species, C. mediocris, new species, C. parva, new species, and C. tenebrosa, new species; the Thick-Tailed Group contains C. brevicauda, new species and C. caudicrassa, new species; and the Ordinary Group contains C. musseri, C. nigripes, C. normalis, new species, C. ordinaria, new species, and C. solita, new species. Documenting these endemic species reveals a local radiation ( 20 of the 21 species are members of an endemic clade) in which elevational gradients played a prominent role in either promoting speciation, or at a minimum, fostering the cooccurrence of phenotypically similar species. As now understood, the species-level diversity of Crocidura on Sulawesi is nearly three times the known diversity of any other insular shrew fauna. This study highlights the fact that if we wish to understand the true extent of biodiversity on Earth, large-scale, vouchered organismal inventories followed up with thorough examinations of genetic, morphological, and geographic traits are sorely needed in montane tropical regions, even for purportedly well-studied groups such as mammals.
\end{abstract}

This publication has been registered in ZooBank: urn:lsid:zoobank.org:pub:7982B923-4CDC-44ED-A598-8651009DC7CC

\section{INTRODUCTION}

As the foundation of biodiversity knowledge, taxonomy is essential to our understanding of evolutionary and ecological processes (Mace, 2004; Patterson et al., 2010; Thomson et al., 2018). Species are recognized and counted when they are named by nomenclatural acts, and as a whole, these names represent the fundamental units of much biological research. Errors in taxonomy obscure processes such as trait evolution, population dynamics, community ecology, and beyond. Despite the great need, the taxonomy of many groups of organisms in most biogeographic regions remains woefully inadequate. Taxonomic resolution and accuracy are especially limited in tropical regions, where biodiversity inventories have not resulted in the preservation of enough specimens sampled across existing ecogeographic variation to allow for comprehensive taxonomic revisions. Although these limitations might surprise the nonspecialist, they are painfully apparent to taxonomists and exist even for many mammalian groups (e.g., bats, rodents, and shrews) and biogeographic regions (especially mountainous tropical domains like Madagascar, Wallacea, and the Andes; Burgin et al., 2018).

Shrews (family Soricidae) are a diverse group of mammals (461 species; Burgin et al., 2018), with a nearly global distribution. They are found on all continents except Australia and Antarctica. Within this family, the genus Crocidura is distributed across Africa and Eurasia, reaching 
its eastern limit in the Philippines and Indonesia. Crocidura currently contains 205 species, far more than any other mammalian genus (Burgin et al., 2018). This unusual level of richness is an implicit recognition of the conservative morphology of these animals. Over the approximately 6-8 million years since the origin of this genus (Dubey et al., 2007; Hutterer et al., 2018), little morphological diversity has accumulated. As such, constructing a taxonomy for these shrews that adequately estimates the true number of species and their limits has proven difficult (e.g., Giarla and Esselstyn, 2015; Stanley et al., 2015; Demos et al., 2017).

In Indonesia, near the eastern geographical limit of Crocidura, lies the oceanic island of Sulawesi. This island is large $\left(174,600 \mathrm{~km}^{2}\right)$, tropical $\left(1.7^{\circ} \mathrm{N}\right.$ to $5.8^{\circ} \mathrm{S}$ latitude), and mountainous (six peaks exceed $3000 \mathrm{~m}$ ). Perhaps Sulawesi's most conspicuous feature is its peculiar shape, which comprises a central area and four peninsulas that give it a $\mathrm{K}$-like shape (fig. 1). The island's fauna is remarkably rich in murine rodents (Rowe et al., 2016a, 2019), macaques (Fooden, 1969), and many other animal groups (e.g., Riedel and Narakusumo, 2019). The complexity of Sulawesi's geological history (Nugraha and Hall, 2018), its extensive ecogeographic variation (Whitten et al., 1987), and its tropical location are all factors that helped foster high levels of biodiversity. Researchers have also documented consistent geographical patterns of genetic partitioning among several ecologically and phylogenetically disparate animal taxa (e.g., toads, primates, and mice; Evans et al., 2003, 2008; Merker et al., 2009; Giarla et al., 2018; Handika et al. 2021). The consistent locations of inter- and intraspecific genetic breaks on Sulawesi have led biologists to delineate several areas of endemism (Evans et al., 2003), which are largely defined by the boundaries between the central part of the island and the peninsulas. In total, seven areas of endemism are recognized: the north-east, north-central, and north-west areas of endemism are all located on the northern peninsula; the central portion of the island is referred to as the west-central area of endemism; and the eastern, southeastern, and southwestern peninsulas are the east-central, south-east, and south-west areas of endemism, respectively (fig. 1). Some research has suggested that the westcentral area of endemism could be divided into two areas separated by the Palu-Koro Fault (Merker et al., 2009), but here we follow the more standard definition of seven areas of endemism (Evans et al., 2003).

As with several other groups, the shrew fauna on Sulawesi is diverse. Only the genus Crocidura is naturally present (the nonnative Suncus murinus may be found around human habitations), and seven species are currently recognized, but that figure is an underestimate; several studies have reported or suggested the presence of undescribed and unidentified species (e.g., Musser, 1982, 1987; Ruedi, 1995; Eldridge et al., 2018; Esselstyn et al., 2019). Among the seven currently documented species, six form a clade, while the remaining taxon (C. nigripes) is more closely related to species on other islands to the west (Ruedi et al., 1998; Esselstyn et al., 2009, 2019; Hinckley et al., 2021). This suggests that most of Sulawesi's shrew diversity arose through in situ diversification after the arrival of a single colonizing ancestor (Ruedi et al., 1998). The apparent dominance of in situ diversification as the main process generating diversity raises questions regarding what within-island mechanisms (e.g., geographic, ecological, behavioral, genetic, etc.) might have fostered speciation. Previous studies of Sulawesi's fauna have suggested that geological events, marine incursions, and climatic variation associated with elevational gradients offer plausible explanations for the high diversity and consistent genetic partitioning of a variety of organisms, including shrews (Evans et al., 2003, 2008; Merker et al., 2009; Hawkins et al., 2016; Eldridge et al., 2018; Giarla et al., 2018).

In this paper we investigate the diversity of shrews from Sulawesi using a large set of new collections made between 2010 and 2018. We combine extensive genetic data with qualitative 

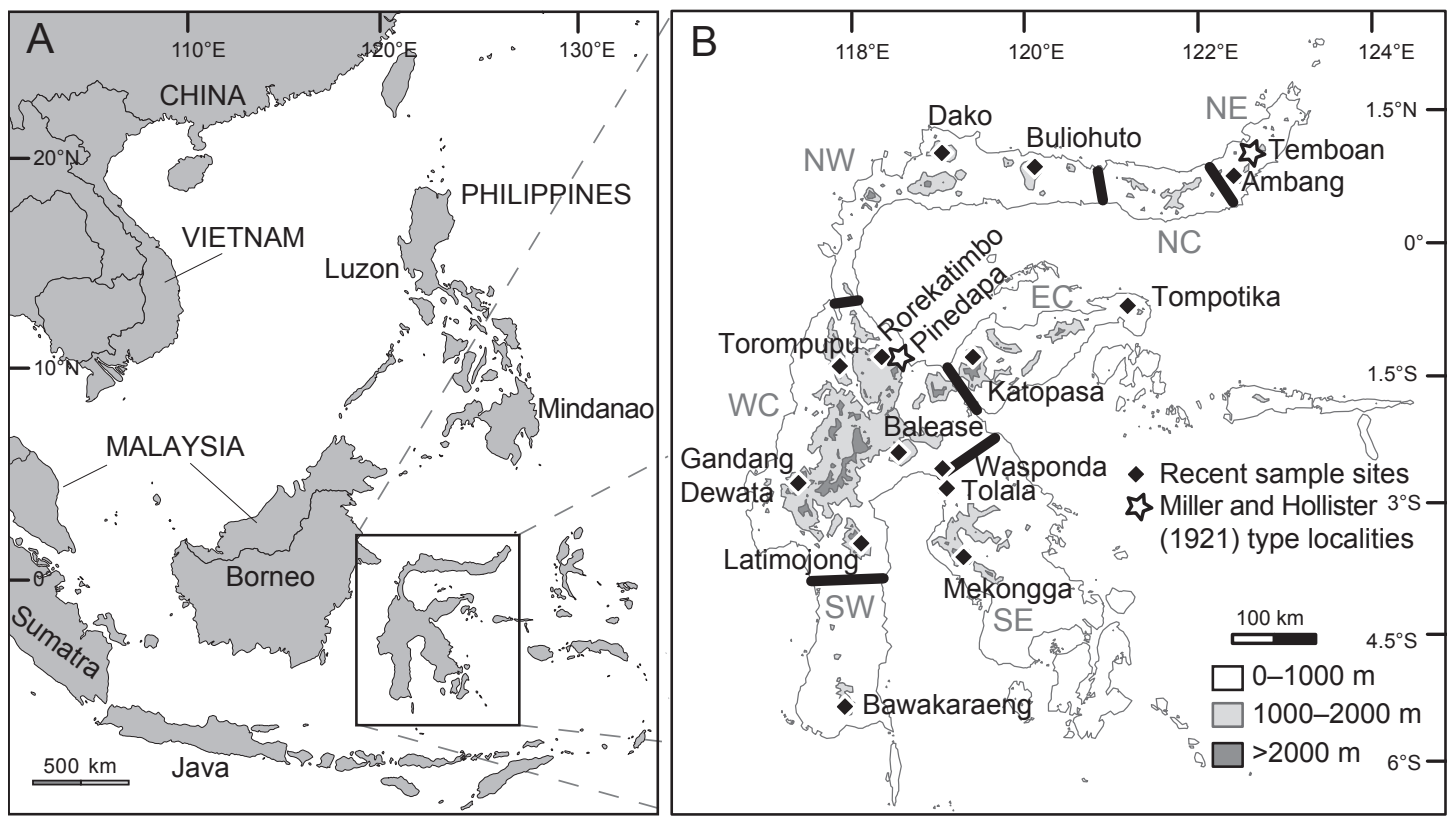

FIG. 1. Maps of A, Southeast Asia and B, Sulawesi showing topographical relief and the approximate boundaries (thick black lines) between areas of endemism (sensu Evans et al., 2003). Two-letter abbreviations in dark gray typeface identify the north-east (NE), north-central (NC), north-west (NW), west-central (WC), eastcentral (EC), south-west (SW), and south-east (SE) areas of endemism. Diamonds label localities where we, or others, have collected shrew specimens since 2010 with the mountain (or locality) name. Stars indicate type localities (Temboan and Pinedapa) from Miller and Hollister (1921). The type localities for the only two Crocidura described from the island since 1921 are Mt. Rorekatimbo (west-central area of endemism) for C. musseri Ruedi (1995) and Mt. Dako (north-west area of endemism) for C. caudipilosa Esselstyn et al. (2019).

and quantitative phenotypic information from new and old specimens alike to resolve species limits and describe new taxa. In revising the taxonomy, we identify patterns associated with species geographic ranges, local species richness, and phylogenetic relationships that highlight opportunities for a better understanding of the ecological and evolutionary processes that promote and maintain biological diversity.

\section{Materials AND Methods}

Species delimitation: Many pages have been written on the topic of species concepts, but relatively little of it is directly applicable to empirical problems (Sites and Marshall, 2003; Cadena et al., 2017). In an applied sense, and consistent with a variety of theoretical concepts, we anticipate that, more often than not, species will have genetic or morphological autapomorphies and cohesive geographic ranges. Therefore, we examined variation in morphology, mitochondrial DNA, and nuclear DNA, while considering the geographic distribution of specimens that are similar genetically and morphologically. When the preponderance of data suggests that a group of specimens is geographically, genetically, and morphologically cohesive, we recognize these specimens as representing a species. The species we identified should be consistent with many theoretical concepts, including the biological (Mayr, 1942, 1957), evolutionary (Simpson, 1961; Wiley, 1981), and general lineage (de Queiroz, 2007) concepts, because their definitions all rely on isolation in one form or another and predict the origin of unique traits and trait combinations. 
Specimen ACquisition: Beginning in 2010, we and others collected specimens of small terrestrial mammals in the vicinities of 12 mountains and two lowland areas that together represent six of the seven areas of endemism on Sulawesi (all but the north-central area of endemism were sampled). While these 14 sampling areas varied widely in the extent of trapping effort and elevational sampling range, we hereafter refer to them as "localities." We use "sites" to refer to specific places within localities where relevant. The surveyed mountains include three on the northern peninsula (Mt. Ambang of the northeast area of endemism, and Mts. Buliohuto and Dako of the north-west area of endemism), two on the eastern peninsula (Mts. Tompotika and Katopasa of the east-central area of endemism), one on the southeastern peninsula (Mt. Mekongga of the south-east area of endemism), one on the southwestern peninsula (Mt. Bawakaraeng of the south-west area of endemism), and five that are spread across the central core of the island (Mts. Latimojong, Gandang Dewata, Rorekatimbo, Balease, and Torompupu of the west-central area of endemism; fig. 1). Most of the specimens we studied are from these 12 mountains, but we also obtained a few samples from two lowland areas that are not connected to large mountains. Both lowland localities (Wasponda and Tolala) are near the boundary between the west-central and south-east areas of endemism. We included samples from Salu Tiwo, a partially forested lowland area northwest of Mt. Gandang Dewata, with that mountain locality (fig. 1). The specimen material from these 14 localities is deposited at the Museum Zoologicum Bogoriense, Bogor (MZB), Field Museum of Natural History, Chicago (FMNH), Louisiana State University Museum of Natural Science, Baton Rouge (LSUMZ), University of California Museum of Vertebrate Zoology, Berkeley (MVZ), Museum of Wildlife and Fish Biology at the University of California, Davis (MWFB), and Museums Victoria, Melbourne (NMV). Some specimens have had parts shared between institutions and thus are cataloged at multiple institutions.
All animal handling was conducted consistent with the guidelines of the American Society of Mammalogists (Sikes et al., 2016) and approved by our relevant institutional committees. All field research was also approved by relevant Indonesian authorities. Most shrew specimens were taken in pitfall traps. Buckets were usually 20 or $30 \mathrm{~L}$ in volume and connected by drift fence assembled from strips of sheet plastic and placed in lines of 5-15 traps along traversable terrain, nearly always in forested habitat. At Mt. Balease, we also used smaller buckets (3 L) placed such that natural objects, such as downed logs and large rocks, served as drift fences. Trapping at all sites also incorporated extensive use of other trap types (e.g., Victor snap traps, Museum Specials, and Sherman live traps), which produced a few additional shrew specimens at each locality. Most specimens were prepared as fluid vouchers, fixed initially in formalin, and subsequently stored in $70 \%$ ethanol, or as traditional museum study skins with cleaned skulls and skeletons. Skulls were often removed from fluid carcasses prior to fixation with formalin. Skeletal material was cleaned by dermestid beetles at the various museums. Tissue samples were preserved for genetic analysis by either freezing in liquid nitrogen or fixation in ethanol or RNALater (SigmaAldrich), followed by storage at $-80^{\circ} \mathrm{C}$.

We examined 1368 Crocidura specimens from Sulawesi, a total that includes the new specimens we collected, as well as older material available at some of the museums named above (MZB and FMNH) and at the National Museum of Natural History, Washington D.C. (USNM); American Museum of Natural History, New York (AMNH); Museum of Southwestern Biology, Albuquerque (MSB); and the Naturalis Biodiversity Center, Amsterdam (RMNH). These collections added several localities to our geographic sampling, but most involved relatively limited numbers of shrew specimens. The exceptions are the extensive shrew holdings at AMNH, collected by G.G. Musser, Boeadi of Museum Zoologicum Bogoriense, and others during the 1970s on Mt. Nokilalaki and vicinity (ca. $15 \mathrm{~km}$ west of Mt. 
Rorekatimbo, which is included in our more recent sampling) as well as those housed primarily at USNM and collected by H.C. Raven and colleagues in 1916 and 1918 at Temboan, Gimpoe, and Pinedapa (fig. 1). The early Raven collections include the types of five (Crocidura elongata, C. lea, C. levicula, C. nigripes, and C. rhoditis) of the seven currently recognized species of Sulawesi shrew (Miller and Hollister, 1921). The remaining two species (C. musseri and C. caudipilosa) were described by Ruedi (1995) and Esselstyn et al. (2019). A complete, georeferenced list of localities from which we examined specimens for this study is provided in the appendix.

GENERAL APPROACH TO DETERMINING SPECIES DIVERSITY, LIMITS, AND RELATIONSHIPS: We sought to maximize information content and dataset independence, while keeping research costs (time and money) manageable. We used independent datasets to compare and reconcile conclusions based on each set. As such, our DNA sequencing goal was to obtain one mitochondrial locus and several nuclear genes from multiple individuals of every species found at each locality, while also obtaining thousands of loci from at least two representatives of each potential species of shrew. This data-collection strategy allowed us to formulate initial hypotheses of species boundaries using mitochondrial sequences and morphological variation, evaluate whether analyses of these two datasets lead to similar conclusions, reconcile any differences between them and, finally, test the resulting putative species limits using a few nuclear genes from hundreds of specimens and thousands of loci from several dozen specimens. Our estimates of species limits focused on the specimens we collected because these represent relatively large series with both phenotypic and genetic data from individual localities. After formulating hypothesized species limits using our recently collected material, we then attempted to identify older specimens collected by others, and these comparisons relied almost entirely on morphological traits and geography. However, to determine which species represented among our new collections were synonymous with previously named taxa, we also attempted to collect genetic information from the type series of four species named by Miller and Hollister (1921). We did not include Crocidura nigripes in this sequencing effort because it is phenotypically distinctive and phylogenetically distant from other Sulawesi taxa. More recently described species (C. musseri and C. caudipilosa) have published genetic data available from the type series (Ruedi et al., 1998; Esselstyn et al., 2019), and we used those published sequences in our inferences.

Morphological DATA COLlection AND ANALYSIS: Our workflow started with identifying the morphospecies represented at each of the 14 localities sampled in this study and assigning as many specimens as possible to these putative, preliminary taxa. Morphospecies were distinguished using a combination of qualitative and quantitative morphometric traits from skulls and external anatomy. We then sought to understand whether these morphospecies were consistent with mtDNA clades (see methods below) within each locality and which morphospecies from different localities are potentially conspecific (i.e., genetically similar members of the same mtDNA clade). Whenever our initial morphospecies differed from the possible species suggested by mtDNA clusters, we reexamined the morphology. These reexaminations led us to identify a few additional, morphologically similar or cryptic putative species within localities.

For input to this workflow, we gathered standard external measurements (in millimeters, $\mathrm{mm}$ : total length, tail length, hind-foot length including the claws, ear length) and mass (in grams, g) from museum databases, specimen tags, and the field notes of collectors for all shrew specimens we could find from Sulawesi. We calculated head-and-body length by subtracting tail length from total length for all specimens. For specimens with clean, undamaged skulls, J.A.E. measured 12 craniodental dimensions to the nearest $0.01 \mathrm{~mm}$ using digital calipers. These measurements comprise con- 


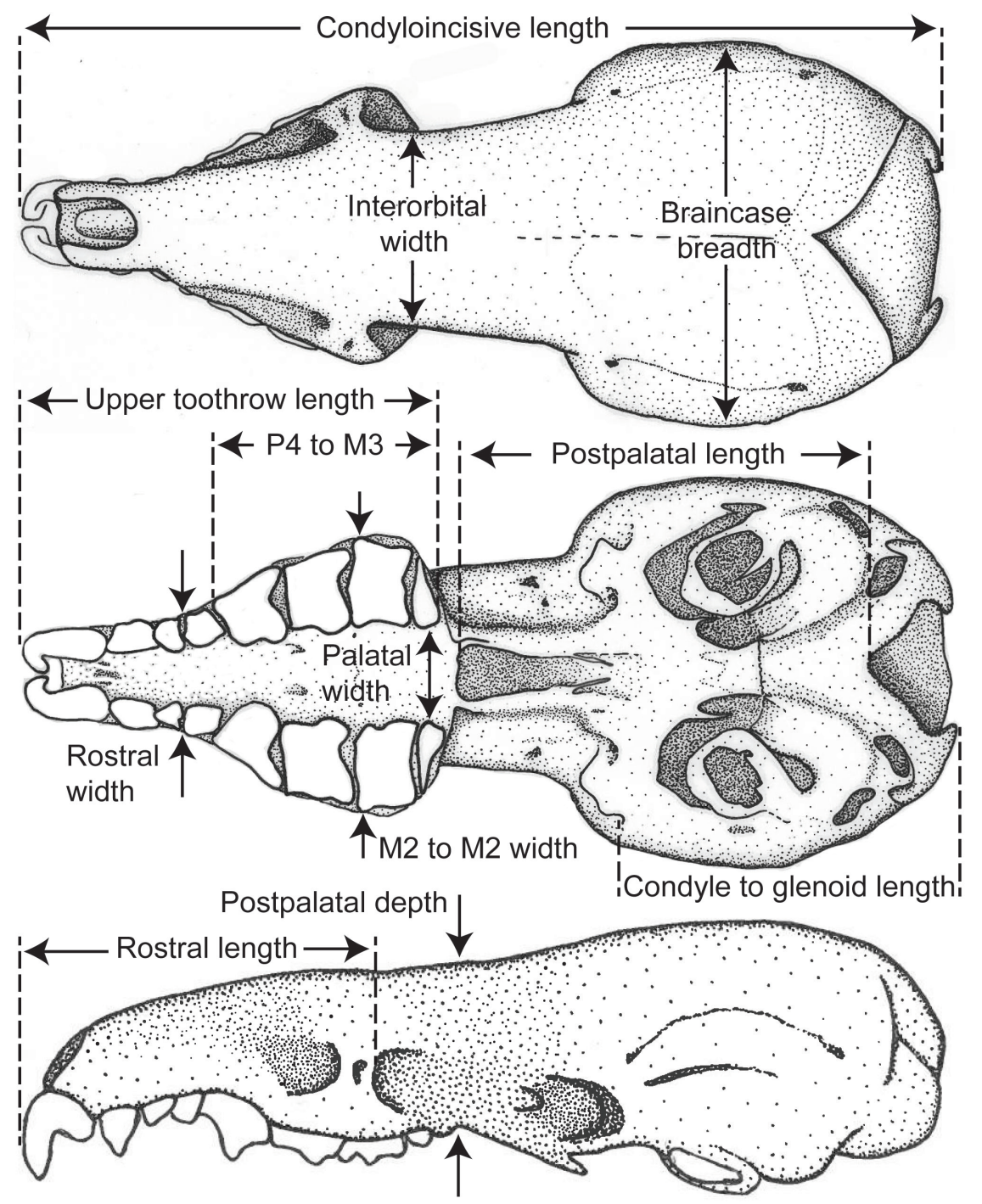

FIG. 2. Drawings of the skull of a Crocidura from a dorsal (upper), occlusal (middle), and lateral (lower) view showing the 12 cranial dimensions we analyzed.

dylo-incisive length (CIL), braincase breadth (BB), interorbital width (IOW), rostral length $(\mathrm{RL})$, postpalatal depth (PPD), rostral width (RW), postpalatal length (PPL), condyle to glenoid fossa length (CGL), length of upper tooth row at crown (UTR), P4 to M3 crown length (P4-M3), labial M2 to M2 crown width (M2W), and palatal width (PW). Measurements were taken as in Ruedi (1995) and are illustrated in figure 2. We follow the dental homology hypothesized by Hutterer (2005) regarding the upper three unicuspids of Crocidura as I2, I3, and $\mathrm{C}$ and the lower unicuspid as i2. Accordingly, the dental formula of Crocidura is I3 C1 $\mathrm{P} 1 \mathrm{M} 3 / \mathrm{i} 2 \mathrm{c} 1 \mathrm{p} 0 \mathrm{~m} 3=28$. Our quantitative analyses employed the measurements listed above, while our qualitative examinations focused on the overall shape and proportions of the skull and the color, texture, and pilosity of the tail, feet, and body. 
For our quantitative morphological comparisons, we made a variety of univariate and bivariate plots to visualize and identify the morphometric traits potentially most useful for distinguishing putative species. We also used principal components analyses (PCAs) to reduce the dimensionality of morphometric data, to explore whether putative species were distinguishable by the first two orthogonal axes of variation, and to identify morphometric similarities between potentially conspecific allopatric populations. In Results, we present the univariate, bivariate, and PCA plots that proved useful in separating the species we recognize, as well as a few others that highlight interspecific similarities and intraspecific geographic variation. Most PCAs were conducted on the 12 cranial measurements (untransformed), using the correlation matrix and only adult specimens (i.e., those with fully erupted teeth and fused basisphenoidbasioccipital sutures). In a few cases, we also explored variation in external measurements using PCAs, as for cranial data. In all morphometric analyses, males and females were pooled. To justify this decision, we tested for sexual dimorphism in the five species with the largest available sample sizes of skulls. We used Welch's two-sample $t$-tests (i.e., unequal variances $t$-test) conducted in R (R Core Team, 2019) to determine whether males and females differed in condyloincisive length or braincase breadth. Each test included at least 16 individuals of each sex.

To test whether our qualitative impressions of morphometric traits were realistic, we fit simple linear regression models to many bivariate plots of raw morphometric data (cranial and external measurements) that appeared useful for distinguishing species. Linear regressions used data only from adult specimens, and they generally included specimens from across the island. We then generated boxplots of the residuals from these analyses to visualize how individual species differ from the expectation for Sulawesi shrews. As such, our qualitative characterizations of morphological traits (e.g., "the interorbital region is wide") are made in comparison to all the species of shrews we document from Sulawesi, unless stated otherwise. PCAs were conducted using core functions in $\mathrm{R}$ ( $\mathrm{R}$ Core Team, 2019) and summary statistics were calculated using the package skimr (Waring et al., 2020), sometimes in combination with dplyr (Wickham et al., 2020). Plots were generated using ggplot2 (Wickham, 2016), sometimes in combination with patchwork (https://github. com/thomasp85/patchwork).

Mitochondrial DNA SEQUencing AND GENE-TREE ESTIMATION: Genomic DNA was isolated from frozen and buffer-preserved tissue samples using Qiagen DNEasy Blood and Tissue (Germantown, MD) or Promega Wizard (Madison, WI) kits. For obtaining genetic material from the type series of species named by Miller and Hollister (1921), we cut an approximately 2 $\times 2 \mathrm{~mm}$ sample from the belly incision of skin specimens. These samples were extracted following the Tsai et al. (2020) phenol-chloroform protocol, with modifications made by Swanson et al. (2019). We sampled the holotypes or paratypes from the type locality for Crocidura elongata, $C$. lea, C. levicula, and C. rhoditis. We successfully obtained DNA sequences from each species except for C. levicula.

We used standard polymerase chain reaction procedures to amplify and sequence fragments of one mitochondrial gene (cytochrome $b$ ) from recently collected specimens with frozen tissue samples. Protocols for amplifying, sequencing, and editing these sequences followed those from Esselstyn et al. (2009, 2013). To obtain cytochrome $b$ sequences from type series collected in the early 20 th century, we relied on by-catch from our ultraconserved-element library preparations (see below). Most of the sequence data we use here is newly generated, but we also downloaded from GenBank published cytochrome $b$ sequences from Ruedi et al. (1998), Esselstyn et al. (2009, 2019), and Eldridge et al. (2018). Using Geneious R7 we aligned cytochrome $b$ sequences (using the MUSCLE algorithm with default settings; Edgar, 2004) and inspected the result manually to ensure align- 
ment quality and confirm that no premature stop codons were present. All new cytochrome $b$ sequences were published to GenBank with accession numbers MZ856464-MZ857148.

After we settled on a reconciled mito-morphological hypothesis of species limits, we completed phylogenetic analyses of the final mitochondrial DNA alignment, which contained 851 samples and 1111 characters. The matrix is $71 \%$ complete. Most of the missing data derive from the fact that about half the specimens were sequenced for nearly the entirety of cytochrome $b$ ( 1100 bp), while the other half were sequenced for only $\sim 700$ bp from the $3^{\prime}$ end of the gene. About halfway through this project, we shifted from using two PCR reactions to amplify and sequence nearly all of cytochrome $b$ to using a single pair of primers that target the $3^{\prime}$ end of the gene for the sake of efficiency. We did not include any non-Sulawesi shrews as outgroups in this alignment because Crocidura nigripes is known to be a distant relative of the other shrews on Sulawesi (Ruedi et al., 1998; Esselstyn et al., 2009), and thus it served as the outgroup (see below for details of analyses of genomewide markers that included multiple outgroups).

We estimated the cytochrome $b$ gene tree using maximum likelihood (ML). We first selected the single best model of sequence evolution for the entire alignment using linked branch lengths and the Akaike Information Criterion with small sample correction (AICc) to compare all possible models in PartitionFinder 2.1.1 (Guindon et al., 2010; Lanfear et al., 2017). The ML analysis was conducted using RAxML 8.2.12 (Kozlov et al., 2019) on the CIPRES portal (Miller et al., 2010). The analysis employed the model chosen by AICc (GTR $+\mathrm{I}+\Gamma$ with four rate categories) and $10 \mathrm{ML}$ searches. Support was quantified by bootstrapping with automatic stopping.

We calculated inter- and intraspecific mitochondrial Jukes-Cantor distances using the "ape" package (Paradis and Schliep, 2019) in R. For these calculations, we first reduced the cytochrome $b$ alignment to eliminate all missing data while maximizing the number of remaining specimens. The resulting alignment contained 812 samples and 321 nucleotides with zero missing characters.

In addition to our cytochrome $b$ data sampled from hundreds of individuals, we obtained mitochondrial genome sequences as by-catch from our target enrichment of ultraconserved elements (detailed below). Mitogenomes were obtained by running MitoFinder 1.4 (Allio et al., 2020) on quality-filtered Illumina read pools for each sample. Within MitoFinder, we used metaSPAdes (Nurk et al., 2017) to assemble the reads against a reference mitochondrial genome from Crocidura fuliginosa (GenBank accession NC_042762). We extracted both partial and complete protein-coding gene sequences and rRNA sequences from each mitochondrial genome assembly and aligned sequences from each locus in MAFFT 7.309 (Katoh and Standley, 2013). We concatenated the 13 protein-coding gene alignments along with the two rRNA gene alignments. Possible partitioning schemes (by codon position and gene) and nucleotide substitution models were tested using ModelFinder (Kalyaanamoorthy et al., 2017) within IQ-TREE 2.1.1 (Minh et al., 2020) using the "TESTNEWMERGE" option, which first invokes PartitionFinder2 (Lanfear et al., 2017). After applying the best-fitting partitioning scheme and substitution models, IQ-TREE inferred a single ML tree for the mitochondrial data. Nodal support was estimated via 1000 ultrafast bootstrap replicates (Hoang et al., 2018).

NuCleAR EXON SEQUENCING, PHYLOGENETIC INFERENCE, AND SPECIES DELIMITATION: The hypotheses of species limits derived from iteratively reconciling morphological variation with mitochondrial variation needed to be tested with an independent dataset. As such, we sequenced five nuclear protein-coding loci (apolipoprotein b, breast cancer susceptibility 1 , brain derived neurotrophic factor, growth hormone receptor exon 10, and prostaglandin E4 receptor) from representatives of all putative species. Lab protocols followed Esselstyn et al. (2009, 2013). As 
with mitochondrial sequences, we aligned nuclear exons and checked them for premature stop codons using Geneious R7. Most nuclear exon sequences are newly generated, but some were obtained from Eldridge et al. (2018) and Esselstyn et al. (2019). Individual loci were 414588 nucleotides long, and a concatenated matrix of all five genes contained 2595 characters and 657 specimens. Every sample represented in this alignment is also represented in the cytochrome $b$ alignment. All new nuclear exon sequences were published to GenBank with accession numbers MZ923987-MZ926690.

For phylogenetic inference, we wanted to avoid spurious inferences caused by missing data. We therefore eliminated a few individuals from the 657 individual alignment that had fewer than three loci or 1500 nucleotides. However, one species, Crocidura caudicrassa, was represented by only one specimen at this threshold (it has all five loci). We therefore retained an additional seven individuals at a lower threshold (two loci, 1137 nucleotides) so that this taxon would be represented by multiple individuals. The resulting alignment contains 642 individuals and $7 \%$ of characters are missing. Each species is represented by $2-77$ individuals (mean $=30.6$, sd $=22.1$ ). This alignment was analyzed using RAxML 8.2.12 (Kozlov et al., 2019) on the CIPRES portal, employed the GTRCAT model, and support was quantified by 1000 rapid bootstraps.

Also using the five-exon dataset, we conducted species-delimitation analyses in BPP v. 4, which uses a multispecies coalescent model (Yang and Rannala, 2010; Rannala and Yang, 2013; Yang, 2015). Because testing a species-limit hypothesis with 20 putative species and sequences from hundreds of individuals is intractable, we divided the dataset into a series of smaller problems with 2-4 potential taxa each that targeted the species groups that seemed most likely to fail delimitation tests. The groups we tested included morphologically similar mtDNA sister pairs and groups of putative taxa with similar phenotypes, whether or not they formed a clade in mtDNA analyses. For each BPP analysis, all species were represented by sequences from most or all of the localities from which the taxon is known. When only two species were involved, we used the A01 analysis of BPP (fixed species tree). When more species were involved, we used the A11 analysis (explores possible topologies and species limits). For most of these analyses, we used all available nuclear DNA from our Sanger sequencing. But in a few cases, large numbers of individuals (e.g., $>50$ ) per putative species caused BPP to crash. In these cases, we reduced sampling to $\sim 20$ individuals per putative species but made sure that all available localities were represented for each potential taxon in any reduced alignments. Mitochondrial data were not used in these analyses to maintain analytical independence.

All BPP analyses used unphased sequences, algorithm 1 for the reversible-jump Markov chain Monte Carlo (rjMCMC) analysis, and the default inverse gamma priors $(\alpha=3 ; \beta=0.002)$ for $\theta$ (population size). We explored the possible influence of our priors by testing the default value ( $\alpha=3 ; \beta=0.002)$ on $t$ (root age) as well as priors that make divergence time older $(\alpha=3$; $\beta$ $=0.004)$ and younger $(\alpha=3 ; \beta=0.0005)$. Each analysis was conducted with two independent runs of 10,000 pre-burn-in rjMCMC steps, 50,000 post-burn-in steps, and a sampling frequency of every five steps. In total, we analyzed 10 data subsets (some of them nested subsets of potential species) six times each (three prior settings by two runs).

Because the multispecies coalescent model that BPP uses has been criticized as delimiting population structure rather than species (Sukumaran and Knowles, 2017), we consider the BPP delimitation results in their geographic context (e.g., sympatric versus allopatric putative species) and in conjunction with conclusions from other datasets (e.g., morphology and mitochondrial DNA).

Ultraconserved ELEMENTS SEquencING AND ANALYSIS: To obtain an independent, genomewide dataset, we enriched and sequenced ultraconserved elements (UCEs; Faircloth et al., 
2012) in 90 specimens from Sulawesi selected to represent each of the putative species hypothesized using the above methods. We also enriched and sequenced UCEs in 12 outgroup taxa, including members of the crocidurine genera Crocidura, Suncus, Scutisorex, Palawanosorex, and Paracrocidura and the myosoricine genera Myosorex and Congosorex. UCE data from some outgroups were previously published in Hutterer et al. (2018). UCE library preparation and enrichment were conducted by Rapid Genomics (Gainesville, FL), as in Hutterer et al. (2018), for some of the samples. Others were prepared by us using a custom UCE probe set designed to capture the standard Tetrapods $5 \mathrm{k}$ UCE loci (Faircloth et al., 2012) and 27 exons commonly sequenced for mammals. Probes for the 27 exons were designed and manufactured (in combination with the standard UCE probes) by Arbor Biosciences (Ann Arbor, MI) using alignments from a phylogenetically dispersed sample of mammal diversity. For the samples we enriched, laboratory protocols followed Esselstyn et al. (2017) and Swanson et al. (2019) with two exceptions: (1) we treated skin-clip extracts from type series with a New England BioLabs (Ipswich, MA) PreCR Repair Kit following the manufacturer's instructions, and (2) we pooled unenriched libraries of skin-clip samples with the enriched libraries prior to sequencing to enhance our chances of obtaining mitochondrial reads. Pools were sequenced by Novogene USA (Sacramento, CA) using an Illumina HiSeq 4000 platform and 150 bp paired-end reads. Novogene demultiplexed raw reads from BCL files using bcl2fastq 1.8.4 (Illumina, Inc.) and returned FASTQ-formatted files to us. Low-quality bases and adapter sequences were trimmed from the raw reads using illumiprocessor ver. 2.0.7 (Faircloth, 2013), which incorporates trimmomatic (Bolger et al., 2014). We processed these data by assembling cleaned reads into contigs using Trinity v. r2013.08.14 (Grabherr et al., 2011) implemented in the Python package phyluce (Faircloth, 2016). We obtained mitochondrial sequences from the type series described by
Miller and Hollister (1921) using phyluce_ assembly_match_contigs_to_barcodes command and a Niviventer niviventer cytochrome $b$ template sequence (NCBI Genbank Accession AB973113.1). Cytochrome $b$ sequences from skin samples were added to the mitochondrial alignment and gene tree analyses described above. All new UCE data were published under NCBI BioProject PRJNA757975 with BioSample numbers SAMN20991356-SAMN20991445.

Phylogenetic analyses of UCEs employed concatenation and species-tree approaches. UCE sequences were aligned in phyluce using the MAFFT algorithm (Katoh and Standley, 2013). Alignments were then filtered in phyluce according to how many specimens were sampled per locus. Concatenated inference was conducted in IQ-TREE on a $75 \%$ complete dataset (i.e., only loci that included data from at least $75 \%$ of the 102 specimens were included). Nine hundred and eighty-three loci met this threshold. Different partitioning schemes and nucleotide substitution models were tested within IQ-TREE using the "TESTNEWMERGE" option. To reduce computation time for this large dataset, we used PartitionFinder2's relaxed hierarchical clustering ("rcluster") algorithm (Lanfear et al., 2014) under the default settings. Nodal support was estimated via 1000 ultrafast bootstrap replicates.

Species-tree inference first entailed estimating gene trees for each locus. We used IQ-TREE to infer a substitution model and then a gene tree for each UCE locus that had at least $10 \%$ of the 102 specimens included (3940 loci). We then used the resultant gene trees to build a species tree in ASTRAL 5.7.3 (Zhang et al., 2018) with the default settings.

\section{RESULTS}

Field COLLECTIONS, identificATIONS, AND MORPHOLOGICAL VARIATION: We obtained specimens from 14 localities distributed across all but the north-central area of endemism (fig. 1) and we used previously collected specimens from additional locations (including a couple speci- 
mens from the north-central area of endemism). Within localities, the majority of sites we sampled were in mature forest with human impact mostly limited to trails, hunting, and some harvesting of minor forest products such as rattan and resin from mature Agathis trees. The exceptions were some lowland areas where we collected shrews from secondary forests (Tolala, Wasponda, Salu Tiwo of Mt. Gandang Dewata, and Mts. Dako, Balease, Katopasa, and Tompotika) and brushy areas of early-successional vegetation (Salu Tiwo). Across all localities we sampled shrews from approximately 150 to 2600 $\mathrm{m}$ elevation. However, the extent of elevational sampling varied widely among mountains (fig. 3) and was affected primarily by the lowest elevational extent of minimally disturbed forest and the accessibility of higher-elevation areas. Most of the elevational bands within localities were surveyed for one or more weeks, with sampling at two or more elevational bands on most mountains. At most localities, this resulted in the collection of many shrew specimens (fig. 3).

Our examination of morphological traits revealed some consistent patterns in both how local communities are structured and which morphological features are useful for distinguishing species. Each well-surveyed site (elevational bands within localities) housed a shrew community comprising at least four species. The richest locality (Mt. Gandang Dewata) was home to 10 species of Crocidura over the entirety of our elevational sampling. Generally, each site (within localities) contained 1-3 species with a tail longer than its head and body, one very small species $(<5 \mathrm{~g})$, at least one large species $(>12 \mathrm{~g})$, and one or more species with intermediate body sizes. Raw external and cranial measurements that reflect overall size were valuable for distinguishing many species morphologically. For separating similarly sized taxa, we found that cranial and external proportions were often most useful. For instance, comparing widths at different points along the anteroposterior axis (e.g., braincase and interorbital width), relative to skull length (as measured by condyloincisive length) proved valuable. Similarly, but to a lesser degree, the relative lengths of individual skull components, such as the rostrum were also helpful. Ratios of external measurements, such as tail to head-and-body length and mass relative to headand-body length, also contributed to our ability to identify species. Compared to the value of these proportional differences, we found variation in dental morphology to be minimally useful. This is at least in part caused by the complicating effect of ontogenetic variation. Tooth shape is altered as wear reduces cusp height and shape over an animal's lifetime, whereas skull shape seems more or less constant through adulthood. Aside from differences in shape (external and cranial proportions), species often differed in the color of the pelage and areas of exposed skin, and to a lesser degree in the length and density of their fur. For instance, at some sites, we found similarly sized and proportioned but genetically distinct species that differed primarily in the color of their feet. Overall, combinations of these types of morphological features allowed us to morphologically distinguish nearly all the species we detail below.

In total, we identified 1238 specimens as members of one of seven existing species or 14 new species (see supplementary data S1, available online: https://doi.org/10.5531/sd.sp.52). We did not assign another 130 specimens to species primarily because of a lack of genetic data, but secondarily due to small sample sizes for some areas surveyed in the past and overlapping morphological traits for multiple plausible species identities. Among the 12 localities we surveyed extensively, we examined between 31 (Mt. Tompotika) and 275 (Mt. Gandang Dewata, including the lowland Salu Tiwo site) specimens from each, with a mean of 105 and a standard deviation of 66 specimens per locality. We assigned an average of $93 \%$ of these specimens per locality (range $77 \%-100 \%$ ) to species. In addition, we included samples from two sites that were geographically significant, but where our cursory trapping efforts yielded only a few specimens (five specimens from Wasponda and two from 


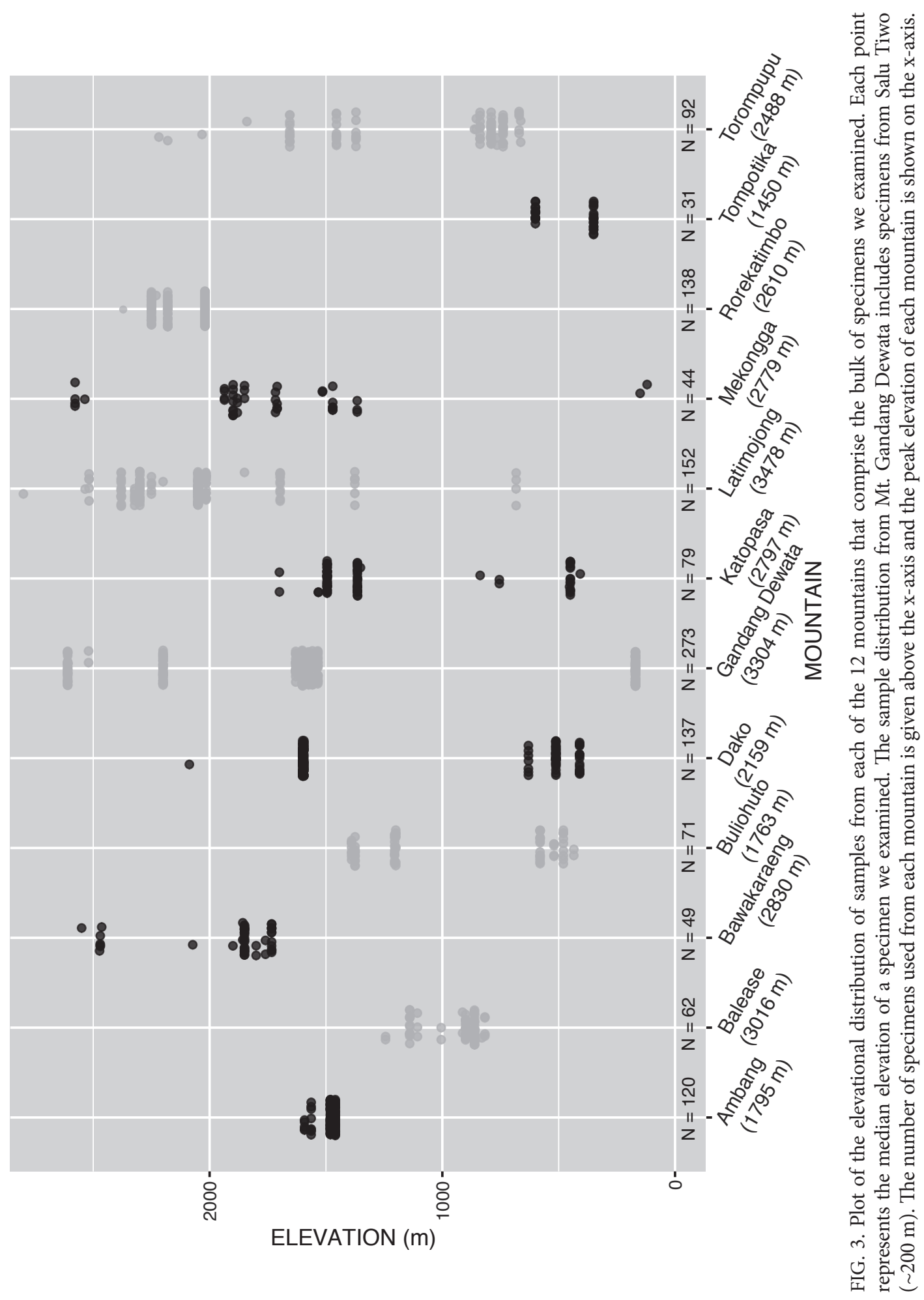


TABLE 1

Tests for Sexual Dimorphism in Five Species of Crocidura

\begin{tabular}{|c|c|c|c|c|c|c|c|}
\hline & \multirow{2}{*}{$\mathrm{N}(\mathrm{m}) / \mathrm{N}(\mathrm{f})^{\mathrm{a}}$} & \multicolumn{3}{|c|}{ Condyloincisive length ${ }^{\mathrm{b}}$} & \multicolumn{3}{|c|}{ Braincase breadth $^{c}$} \\
\hline & & $\mathrm{t}$ & $\mathrm{df}$ & $\mathrm{p}$ & $\mathrm{t}$ & $\mathrm{df}$ & $\mathrm{p}$ \\
\hline C. pseudorhoditis & $36 / 38$ & -0.747 & 71 & 0.46 & -0.649 & 72 & 0.52 \\
\hline C. solita & $21 / 19$ & -2.288 & 35 & 0.03 & -1.887 & 37 & 0.06 \\
\hline C. caudipilosa & $30 / 22$ & -0.704 & 38 & 0.48 & -0.841 & 46 & 0.41 \\
\hline C. quasielongata & $24 / 16$ & -0.38 & 28 & 0.71 & -0.108 & 32 & 0.92 \\
\hline C. nigripes & $37 / 38$ & -0.666 & 73 & 0.51 & -0.667 & 73 & 0.51 \\
\hline
\end{tabular}

a Number of males/number of females.

b Results from Welch's two-sample $t$-tests for condyloincisive length.

${ }^{c}$ Results from Welch's two-sample $t$-tests for braincase breadth.

Tolala; fig. 1), all of which were assigned to species. Among the 1238 assigned specimens, each species was represented by between six and 156 specimens $(59 \pm 42)$.

We found little evidence of sexual dimorphism in the well-sampled species, justifying our decision to combine the sexes in all morphometric analyses. Among 10 tests for sexual dimorphism, only one was significant at $\alpha=0.05$ (table 1 ).

MitochONDRIAL RELATIONSHIPS AND DIVERSITY: Our mitochondrial gene tree containing 851 specimens showed clear clustering of tips that are largely consistent with the discontinuities we initially observed in morphological characters within localities. Examples where cytochrome $b$ suggested we had mistakenly lumped cryptic species in our intitial morphological delimitations include taxa subsequently recognized in this report as Crocidura rhoditis and C. pseudorhoditis on Mt. Ambang; C. solita and C. ordinaria on Mt. Gandang Dewata; C. lea and C. baletei on Mt. Dako ("pale lea" and "dark lea" in Esselstyn et al., 2019); and between Elongata Subgroup members (defined below) at multiple localities.

While the tip-level clusters in the cytochrome $b$ gene tree are generally well supported, older relationships are almost entirely unsupported (fig. 4; supplementary data S2, available online: https://doi.org/10.5531/sd.sp.52). Our other mitochondrial gene tree, which was inferred from 14,007 nucleotides, but only 83 individuals (82 from Sulawesi; 1-8 per species), is similar in overall shape and topology, with tip clusters well supported, but again, the backbone relationships are largely unresolved (fig. 5).

Intra- and interspecific mitochondrial distances provide clear evidence of a barcode gap (e.g., Hebert et al., 2003; Puillandre et al., 2012) in our data. Although interspecific distances are far more numerous, distinct intra- and interspecific peaks in frequency are evident (fig. 6). Most intraspecific Jukes-Cantor distances are $<0.04$, but seven species contain maximum intraspecific distances $>0.05$ (fig. 4; supplementary data S3S5, available online: https://doi.org/10.5531/sd. sp.52). The lowest mean interspecific distance in our dataset is 0.047 , found between both Crocidura mediocris and C. parva, and C. caudipilosa and C. baletei. All other mean interspecific distances are $>0.05$ and the vast majority are $>0.07$ (fig. 6; supplementary data S3, available online: https://doi.org/10.5531/sd.sp.52). Among the species with the lowest interspecific mitochondrial distances, C. mediocris and C. parva have similar phenotypes and allopatric distributions, but C. caudipilosa and C. baletei have quite different morphologies and occur together on Mts. Dako and Buliohuto.

Most species we define are monophyletic in both the cytochrome $b$ and mitogenome gene trees. However, two species, Crocidura mediocris 


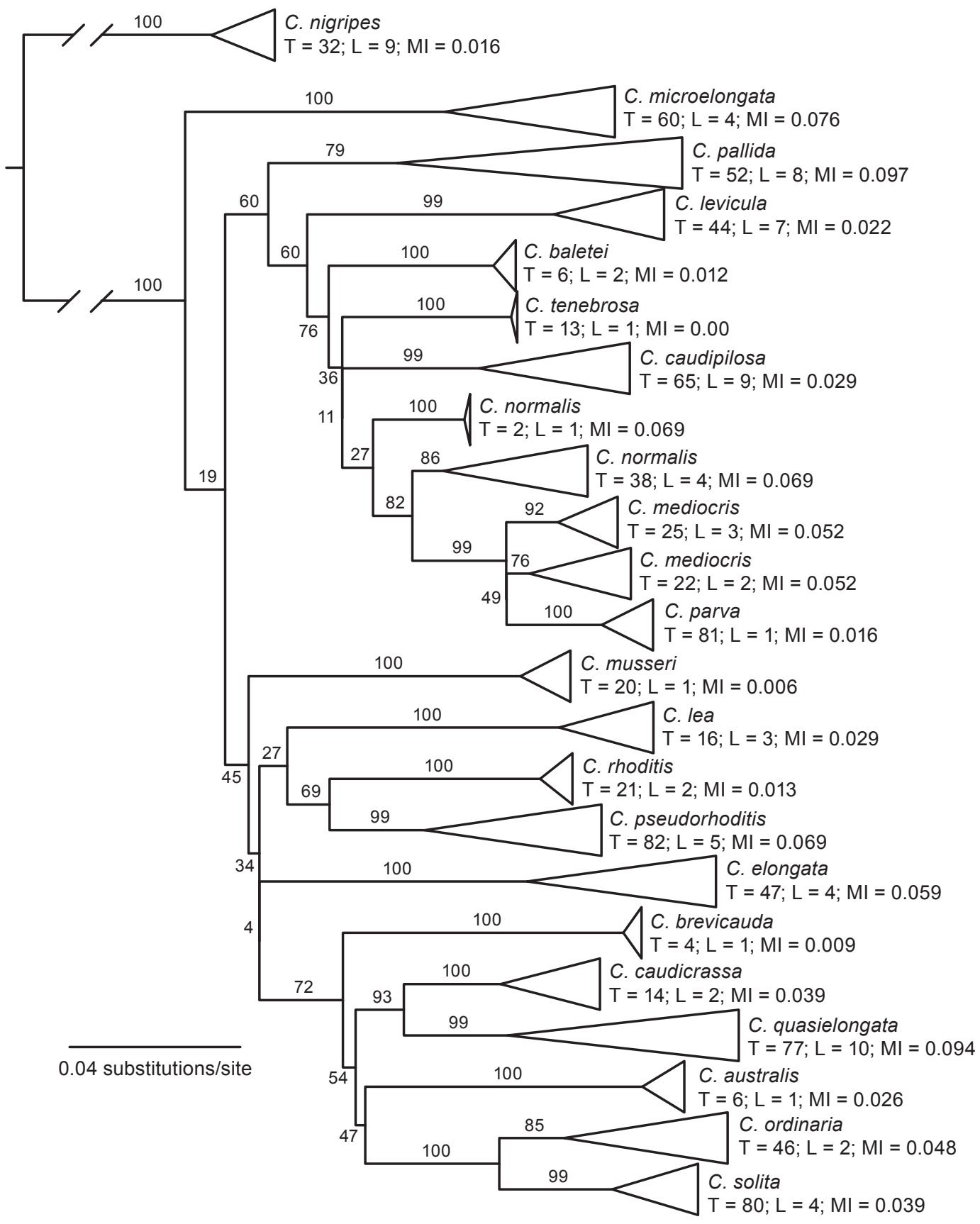


and C. normalis, are paraphyletic. The paraphyly of $C$. normalis is well supported in both mitochondrial inferences, but these populations form a clade in our UCE inferences (see below). In contrast, the separation of $C$. mediocris into two allopatric clades received essentially no support $(\mathrm{BS}=$ 49 ) in the cytochrome $b$ tree, but these divergent populations are united in a poorly supported clade in the mitogenome tree. The lack of monophyly in the mitochondrial gene trees for C. normalis and $C$. mediocris gave us some hesitation with regard to how we have delimited species. However, in both cases, the morphology of each allopatric intraspecific clade is similar. If these species are young, we might expect some ancestral polymorphisms to be retained, and this can lead to the inference of paraphyly (Maddison, 1997). As such, gene-tree paraphyly is not necessarily inconsistent with our species concept.

NuClEAR EXON PHYLOGENY AND SPECIES DELIMITATION: Our inference of phylogenetic relationships from the concatenated alignment of five exons and 642 individuals produced a tree with coherent tip clusters but a lack of resolution for most interspecific relationships (supplementary data S6, available online: https://doi.org/10.5531/ sd.sp.52), similar to the branch-length and nodesupport patterns derived from mitochondrial sequences. In this tree, all but four species are monophyletic. Crocidura mediocris and C. parva are reciprocally paraphyletic, as are C. solita and $C$. ordinaria. Crocidura normalis, which is paraphyletic in the cytochrome $b$ inference is monophyletic and well supported by nuclear exons. Most of the species that are monophyletic in this analysis (17 taxa) are well supported, with bootstrap values $>90$ (supplementary data, S6).
Multispecies coalescent tests of our hypothesized species limits using BPP on our five-locus nuclear dataset supported every putative species we tested with a posterior probability of 1.0 for each combination of parameter settings and taxon samples. Details of these analyses are presented in the species accounts below.

UlTRACONSERVED ELEMENT PHYLOGENIES: Phylogenetic inferences using sequences from either 983 UCEs (75\% threshold: average alignment length $719 \mathrm{bp}$, range 171-1524 bp) or 3940 UCEs (10\% threshold: average alignment length $613 \mathrm{bp}$, range 101-1615 bp) from 90 samples from Sulawesi provided similar levels of resolution to our mitochondrial inferences (figs. 4, 5) near the tips of the tree and somewhat better resolution of interspecific relationships (figs. 7, 8). For instance, in our species-tree estimate (fig. 7), which treated individuals as "species" so that we could see which tips formed natural groups, we found that all species except Crocidura ordinaria, C. solita, C. mediocris, and C. parva are monophyletic, as we inferred from our analysis of five concatenated exons. Our concatenated UCE maximum likelihood inference produced the same result, except that C. parva is monophyletic in this tree (fig. 8). The monophyly of 17 or 18 of the delimited species supported their distinction, while the paraphyly noted in the remaining four or three species is consistent with multiple taxonomic hypotheses.

\section{SPECIES ACCOUNTS}

In the accounts that follow, we diagnose the seven species named by Miller and Hollister (1921), Ruedi (1995), and Esselstyn et al. (2019), and we describe 14 new species. Our results from

FIG. 4. Maximum-likelihood estimate of the gene tree of Sulawesi Crocidura derived from an alignment of 851 individuals and 1111 characters from the mitochondrial gene cytochrome $b$. Bootstrap support is shown along branches. Clades corresponding to species are collapsed for ease of presentation. Tips are labeled with the species name, the number of tips (T), and number of localities (L), as labeled in figure 1, and the maximum intraspecific (MI) Jukes-Cantor distance calculated from a reduced alignment. Two species are paraphyletic and their respective, within-clade MI values are shown separately. For species described by Miller and Hollister (1921), the holotype or paratypes are included for C. elongata, C. lea, and C. rhoditis. Branch lengths between C. nigripes and other taxa are shortened for presentation. See supplementary data $S 2$ for the full tree. 


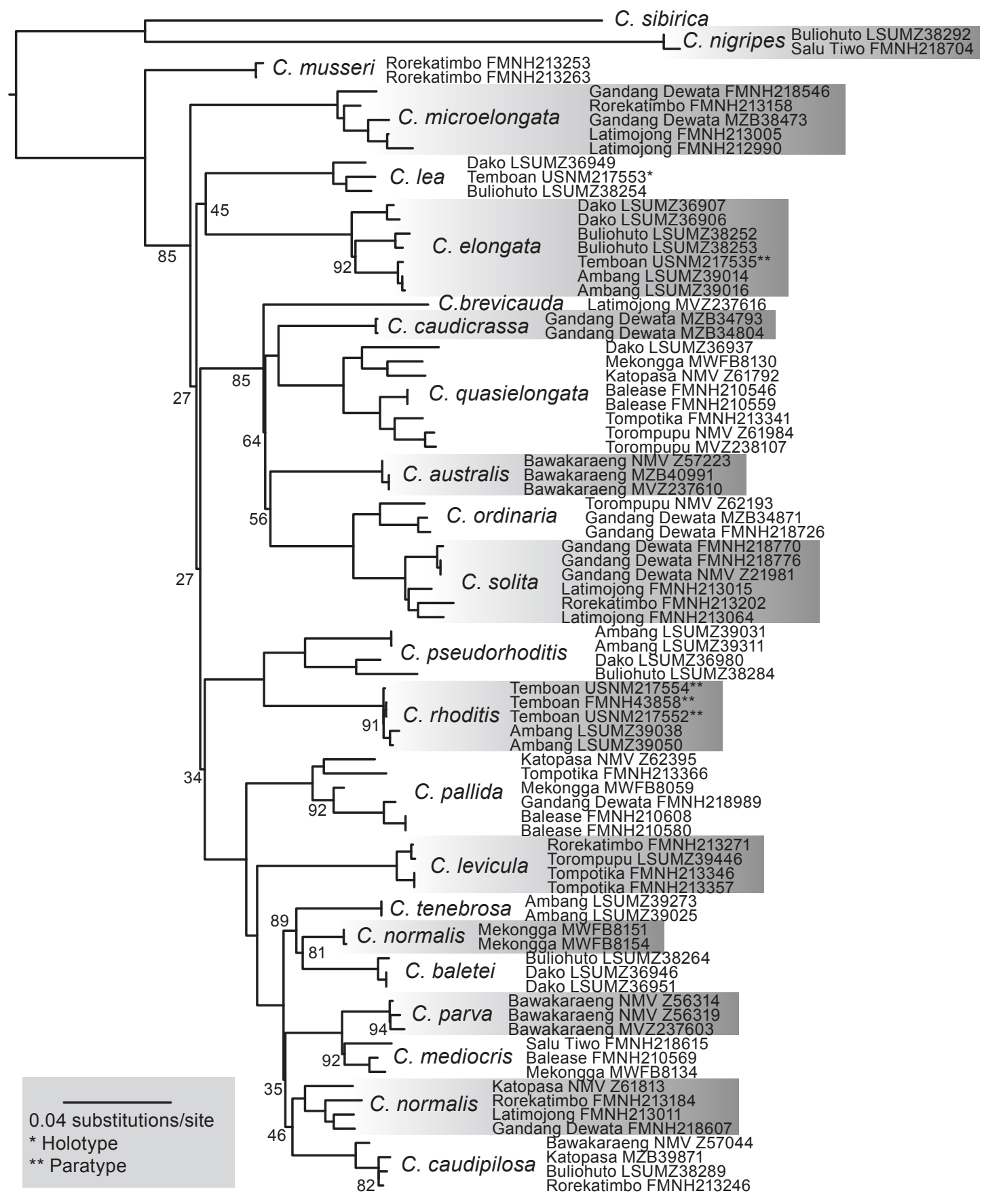

FIG. 5. Maximum likelihood estimate of the mitochondrial gene tree derived from an analysis of 14,007 characters (representing protein-coding and rRNA genes) from 83 samples. Bootstrap support values $<95$ are shown at nodes. Tips are labeled with the species, locality, and voucher number. 
morphometric and coalescent species delimitation analyses are also presented here, together with relevant nomenclatural details and explanations of species groupings.

To facilitate taxonomic comparisons, we group taxa based on external morphology, providing a means to focus on the species that are the most challenging to distinguish in the field. Whereas these groups provide a consistent method for referring to morphologically similar taxa, most of them do not represent clades. Within groups, we first discuss previously described species, emending the original diagnoses of Miller and Hollister (1921), which were brief and for some species based on very few specimens. We then describe the new species we have identified, noting external and cranial traits as much as possible. When we make comparative statements without explicit reference to another species or group of species, these are made relative to all other congeneric species from Sulawesi. In each account, we present external measurements and weight recorded from the holotype in the format of "total length $\times$ tail length $\times$ hind-foot length $\times$ ear length $=$ weight." For each species, we list the most useful morphological traits for identifying species in supplementary data S7 (available online: https://doi.org/10.5531/sd.sp.52).

We report type localities for each species verbatim (e.g., as reported in the original descriptions of previously recognized species, or as recorded in museum databases and field notes for the newly described species). As a result, we report the English province name for some species but the Indonesian province name for others. In our descriptions of geographic ranges, however, we consistently use English names for Indonesian provinces as follows: Sulawesi Utara (North Sulawesi), Gorontalo (Gorontalo), Sulawesi Tengah (Central Sulawesi), Sulawesi Barat (West Sulawesi), Sulawesi Selatan (South Sulawesi), and Sulawesi Tenggara (Southeast Sulawesi). The type localities published in Miller and Hollister (1921) lack details of provinces and lower administrative units. We therefore provide, following the verbatim

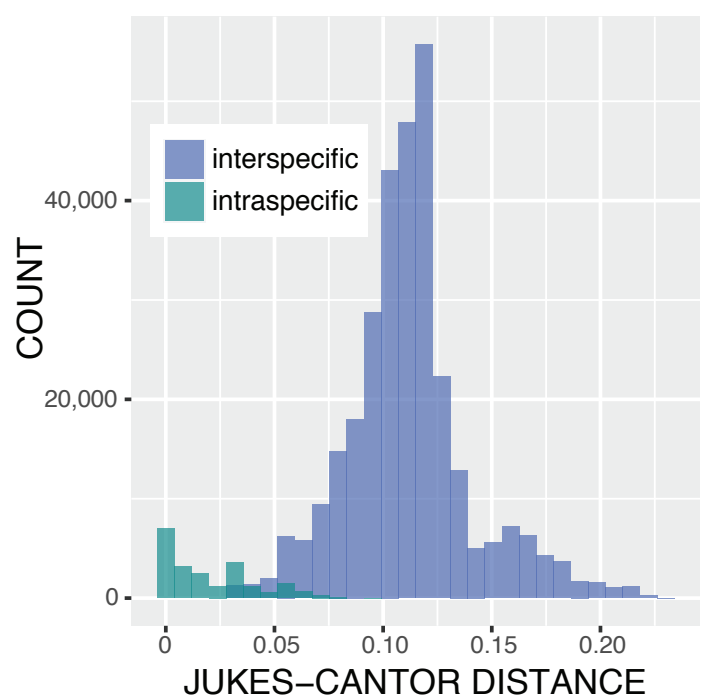

FIG. 6. Distribution of Jukes-Cantor distances from a character matrix with 812 samples, 312 nucleotides of cytochrome $b$, and no missing data. Character sampling, and to a lesser extent taxon sampling, was reduced to eliminate missing data.

type locality, additional details of current geopolitical units. In each species account, we also report the known elevational range with the minimum and maximum rounded to the nearest $100 \mathrm{~m}$.

\section{LONG-TAILED GRoup AND Elongata Subgroup}

Four species on Sulawesi have tail lengths (75$145 \mathrm{~mm}$ ) greater than their head-and-body lengths (65-105 mm; fig. 9; table 2). We group these taxa (Crocidura caudipilosa, C. elongata, C. microelongata, and C. quasielongata) together for ease of description, not because of any close phylogenetic relationships (supplementary data S6). Crocidura caudipilosa differs from the other members of the Long-Tailed Group by its uniquely hirsute tail and its skull with typical width-to-length ratios (fig. 10; Esselstyn et al., 2019). The other species have long and narrow skulls, varying degrees of a long postpalatal region relative to skull length, unusually long and slender hind feet (HF nearly always between 17 and $23 \mathrm{~mm}$ ), and a very long tail (usually $>100 \mathrm{~mm}$ ) largely lacking in bristles. We refer 


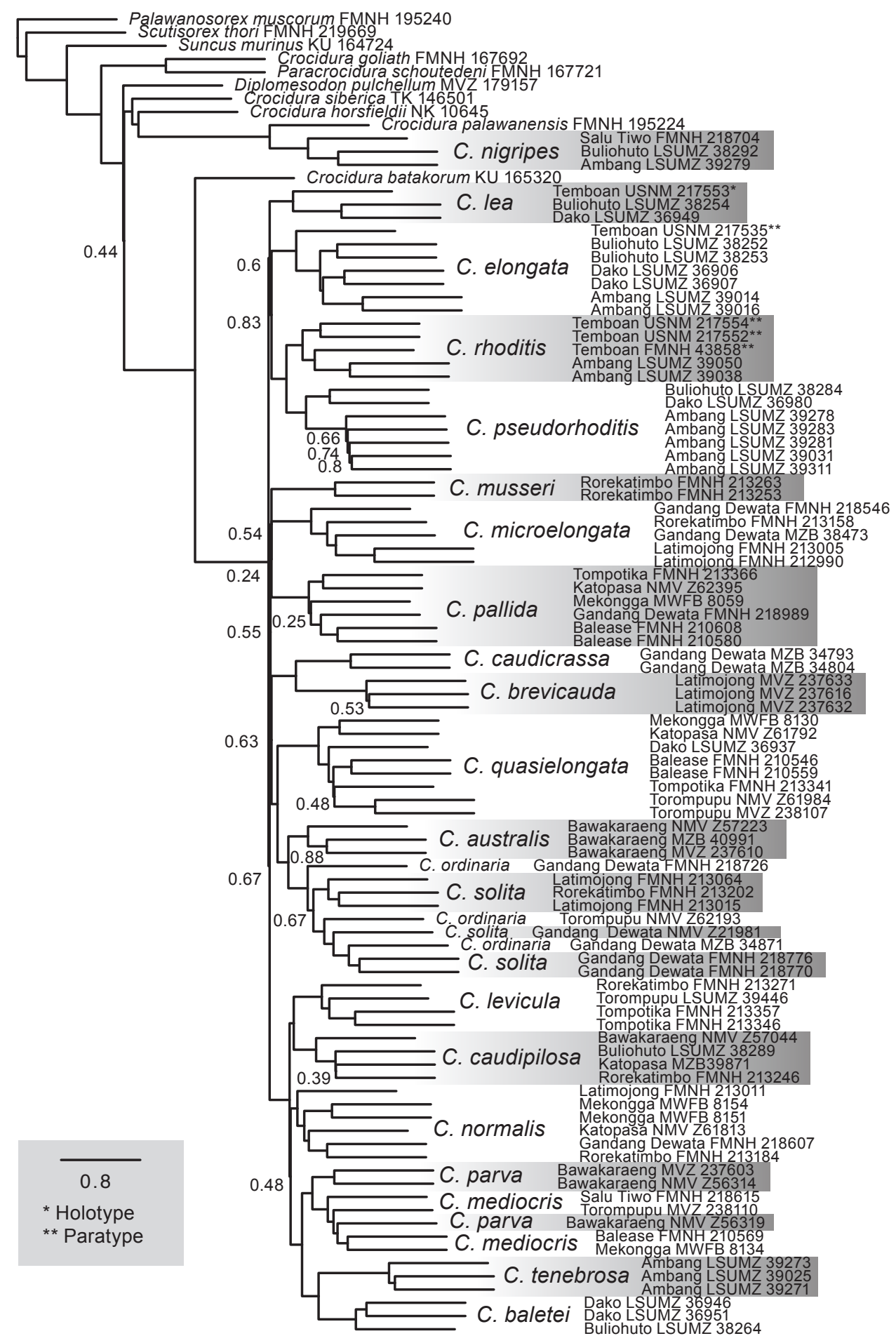


to these three species as the Elongata Subgroup of the Long-Tailed Group. This subgroup designation reflects previous suggestions of the possible existence of multiple taxa contained within C. elongata (Ruedi, 1995; Eldridge et al., 2018; Esselstyn et al., 2019). However, despite their phenotypic similarities, none of these three species form a sister relationship in any of our phylogenetic analyses, nor are any sister to C. caudipilosa (figs. 4, 5, 7, 8). Backbone relationships, however, are unresolved and it remains plausible that some Elongata Subgroup members are sister species. Crocidura caudipilosa is broadly sympatric with Elongata Subgroup members and two members of the subgroup occur sympatrically at some sites (table 3). A principal components analysis of 12 cranial dimensions shows that one of the Elongata Subgroup members (C. microelongata) fills morphospace distinct from that occupied by the other two more similar species (fig. 11; table 4). Plots of individual cranial dimensions show a similar pattern (fig. 12).

\section{Crocidura caudipilosa Esselstyn et al., 2019}

Crocidura caudipilosa Esselstyn et al., 2019:

1718. Original description.

HoLOTyPe: MZB 41456 (= LSUMZ 36945), an adult male collected 8 March 2013 by J.L. Patton. The skin, skull, skeleton, and a tissue are held at MZB, while an additional frozen tissue is curated at LSUMZ. External measurements and weight recorded from the holotype are $182 \mathrm{~mm}$ $\times 98 \mathrm{~mm} \times 19 \mathrm{~mm} \times 9 \mathrm{~mm}=12 \mathrm{~g}$.

Type Locality: Indonesia, Sulawesi Tengah, Toli Toli, Malangga Selatan, Mt. Dako; $1.10642^{\circ}$ $\mathrm{N}, 120.9106^{\circ} \mathrm{E}, 512 \mathrm{~m}$ elevation.

Geographic Distribution: Widespread on Sulawesi across most areas of endemism, with records from the west-central (Mts. Rorekatimbo and Torompupu, Central Sulawesi Province; Mt. Gandang Dewata, West Sulawesi Province; Mt.
Latimojong, South Sulawesi Province), northwest (Mt. Dako, Central Sulawesi Province; Mt. Buliohuto, Gorontalo Province), north-east (Mt. Ambang, North Sulawesi Province), south-west (Mt. Bawakaraeng, South Sulawesi Province), east-central (Mt. Katopasa, Central Sulawesi Province), and south-east (Mt. Mekongga, Southeast Sulawesi Province) areas of endemism. The lack of records from the north-central area of endemism is almost certainly due to the lack of collecting effort in this region. Occurs over a wide elevational range from approximately 500 $\mathrm{m}$ on Mt. Buliohuto to at least $2600 \mathrm{~m}$ on Mt. Gandang Dewata (fig. 13; table 3).

Abbreviated Diagnosis: Esselstyn et al. (2019) made detailed comparisons to other Sulawesi species found on Mt. Dako, of the north-west area of endemism. Briefly, Crocidura caudipilosa is a slender grayish to brownish shrew with a hairy tail (fig. 14A) that is moderately longer than the head and body (table 2). The feet are brown in dorsal view, with paler digits. The skull is gracile, with rounded features and a weakly developed dentition (fig. 15). Summary statistics for measurements of material we refer to this species are provided in tables 2 and 5.

Comparisons: This species is readily distinguished from all other Crocidura on Sulawesi by the density (combined number and length) of applied hairs on the tail (short hairs that lie close to the tail, not the longer bristles that typically project away from the tail on many species of Crocidura), but it is also distinguishable by various combinations of its body size, tail length relative to head-and-body length (fig. 9), gray to brown pelage, slight bicoloration (darker dorsum, paler venter), slender skull, and relatively small teeth. Its tail is shorter relative to headand-body length than in any of the Elongata Subgroup members, but longer (absolutely and relatively) than in any other congeneric species

FIG. 7. Estimated species tree from analysis of 3940 ultraconserved element loci in ASTRAL. Samples from Sulawesi are labeled with the species name, locality, and catalog number. Asterisks indicate type specimens from Miller and Hollister (1921). Local posterior probabilities $<0.95$ are shown. Tip branch lengths are arbitrary. 
Congosorex phillipsorum FMNH 177682

Myosorex geata FMNH 158299

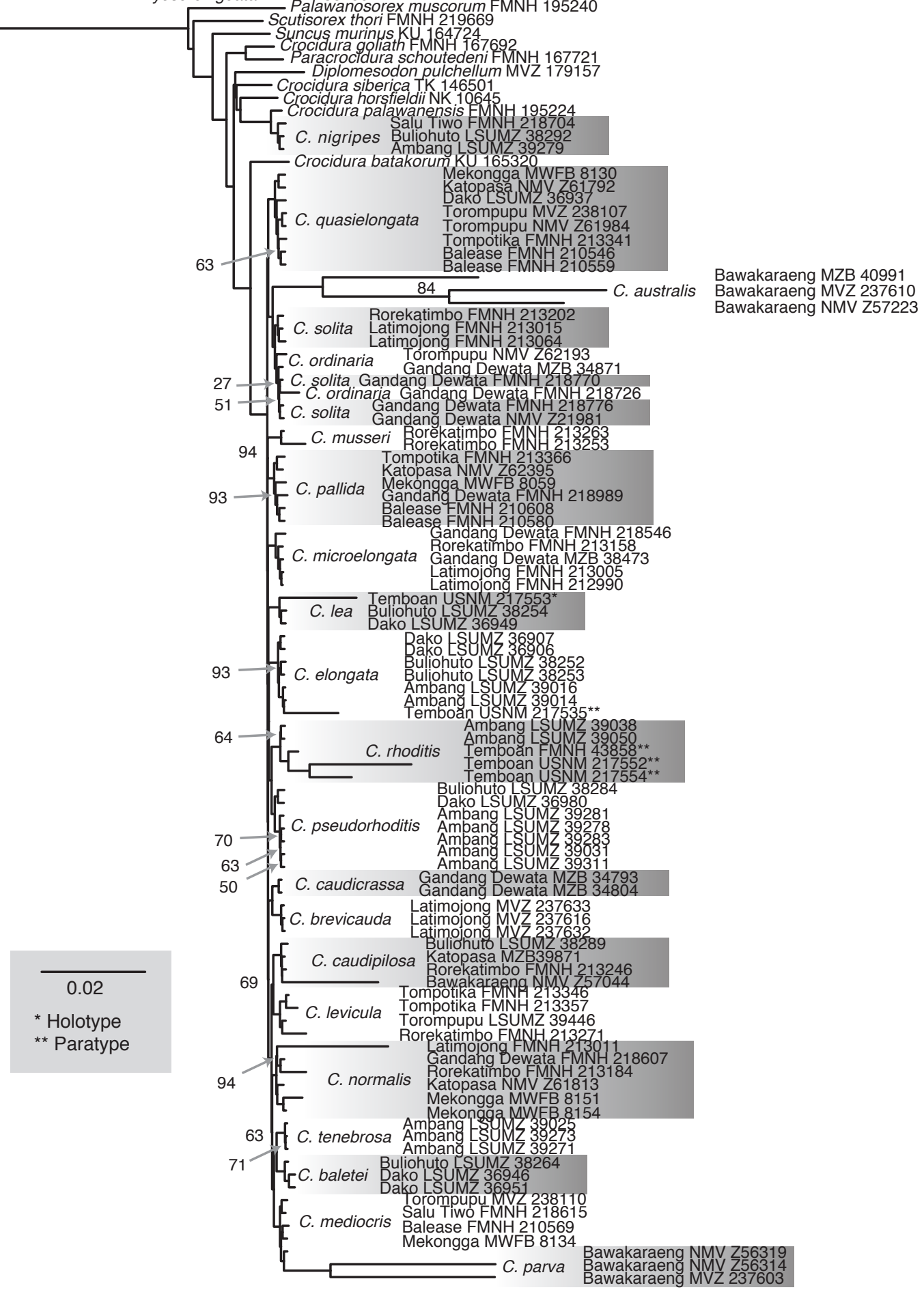


on Sulawesi (fig. 9). Body size is considerably smaller than in C. elongata and C. quasielongata, but only slightly smaller than in C. microelongata (fig. 9). The skull and hind feet are not particularly elongate, as they are in members of the Elongata Subgroup. The ratio of braincase breadth to interorbital width is greater, on average, than in any other shrew species on Sulawesi, and considerably so compared to any of the Elongata Subgroup members (fig. 10).

Comments: Individuals of Crocidura caudipilosa have been caught (NMV Z56802) and observed (NMV Z62413) climbing trees (Esselstyn et al., 2019). The extent of time this species spends in trees is unknown, but the possibility that some shrews on Sulawesi exploit arboreal resources is a potentially promising explanation for how so many species coexist on the island. Musser (1982: 81) reported collecting an undescribed species of Crocidura "in moss growing 8 feet above ground around a tree trunk." However, he never described this species, and it is unclear whether he was referencing a member of the Long-Tailed Group or some other species.

Crocidura caudipilosa is unusually widespread across Sulawesi, but Jukes-Cantor distances calculated from mtDNA sequences were $<0.024$ (fig. 4; supplementary data S3), suggesting recent, widespread movement of at least maternally inherited markers. Nuclear loci sampled from across the island show the same pattern, with variation detected at only five of 549 nucleotides among 56 sequences of apolipoprotein $b$, for instance.

This species is sister to Crocidura levicula in our UCE- (figs. 7, 8) and nuclear exon-based phylogenies, although statistical support from the latter estimate was absent (supplementary data S6). Our mitochondrial estimates placed $C$. caudipilosa in an unresolved clade of several small, darkly colored species of shrew, among which C. levicula is included (figs. 4, 5). This clade, which was well supported by our UCE analyses, contained no other member species of the Long-Tailed Group (figs. 7, 8).

Specimens eXamined: Mt. Ambang (LSUMZ 39243-39247), Mt. Bawakaraeng (MVZ 237625237627; NMV Z57152, Z57013, Z57043, Z57044), Mt. Buliohuto (LSUMZ 38288-38291, 38296, 38588, 38656; NMV C37746, C37815), Mt. Dako (LSUMZ 36940, 36942, 36945; NMV C37267, C37304, C37305, C37330, C37351), Mt Gandang Dewata (FMNH 218759-218762, 218768, 218983218986; MZB 34746, 34747, 34951, 34952), Mt. Katopasa (LSUMZ 39355-39357; MZB 39840, 39871, 39922; NMV C40186, C40219, C40220, Z61815, Z62413, Z62415), Mt. Latimojong (FMNH 213020-213028, 213427; MVZ 237612237615; MZB 41649; NMV C38591), Mt. Mekongga (MWFB 8158, 13512), Mt. Rorekatimbo (FMNH 213246-213248, 213441), Mt. Torompupu (LSUMZ 39358, 39359).

\section{Crocidura elongata Miller and Hollister, 1921}

Crocidura elongata Miller and Hollister, 1921: 101. Original description.

Crocidura "dark elongata" Esselstyn et al., 2019:

1715. Informal name.

HolOtyPe: USNM 217534, an adult male obtained by H.C. Raven on 1 August 1916. The specimen comprises a skin and skull. External measurements recorded from the type are 214 $\mathrm{mm} \times 120 \mathrm{~mm} \times 22 \mathrm{~mm}$; no ear length or weight was recorded.

TyPe LOCALity: "Temboan (southwest from Tondano Lake), northeastern Celebes” (Miller and Hollister, 1921: 101; fig. 1). We estimate that the type locality is at $0.979^{\circ} \mathrm{N}, 124.605^{\circ} \mathrm{E}, 650$ $\mathrm{m}$ elevation, which differs from other interpretations (e.g., Musser, 2014). See the gazetteer for a full explanation (appendix).

Geographic Distribution: Apparently restricted to the northern peninsula of Sulawesi,

FIG. 8. Estimated phylogenetic relationships from a maximum likelihood analysis of 983 concatenated ultraconserved elements. Samples from Sulawesi are labeled with the species name, locality, and catalog number. Asterisks indicate type specimens from Miller and Hollister (1921). Ultrafast bootstrap values <95 are shown. 


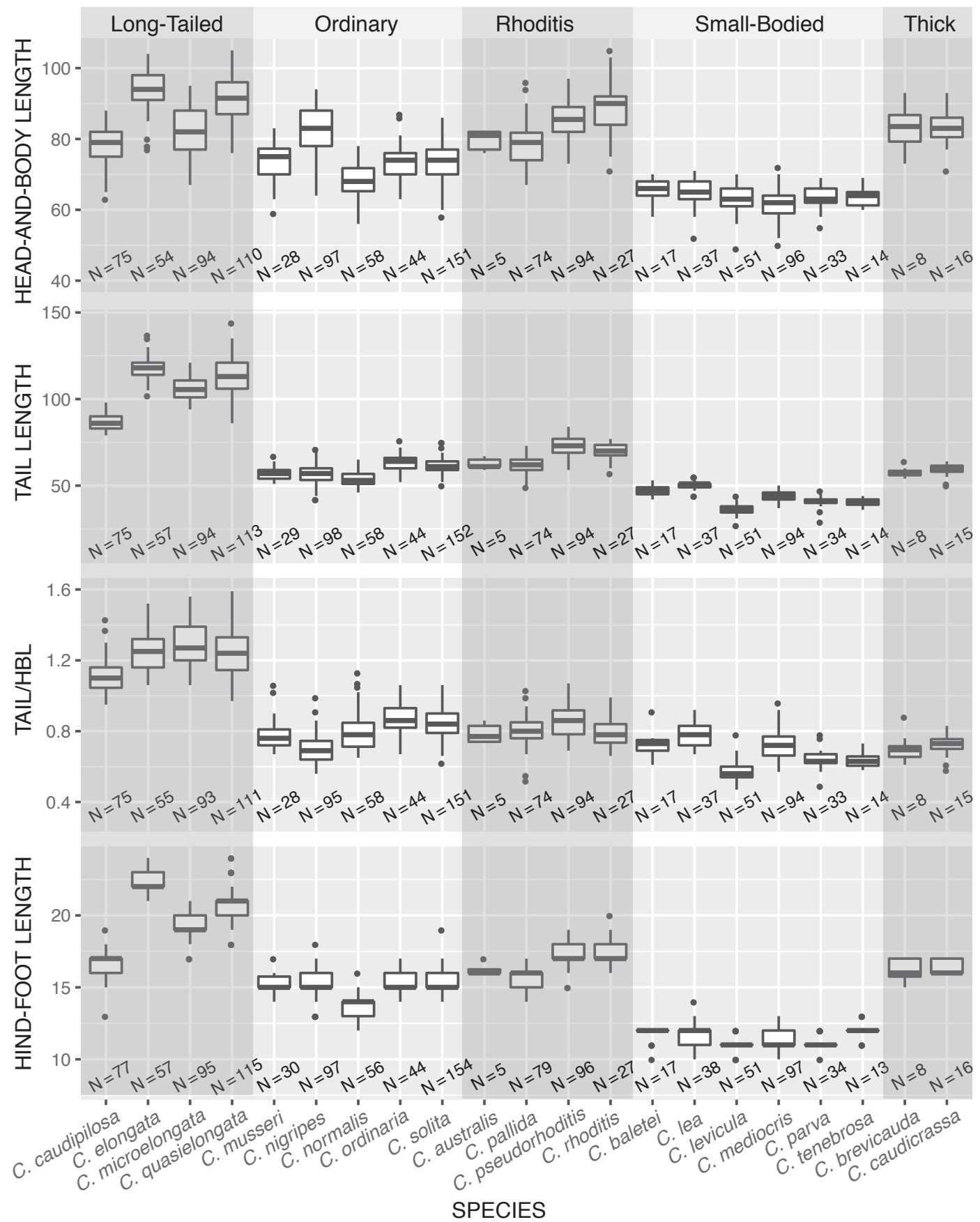

FIG. 9. Box plots showing variation in external measurements from all species of Sulawesi shrew. Plots show the median, 1 st and 3 rd quartiles, the maximum value within $1.5 \times$ interquartile range (distance between 1 st and 3rd quartiles; IQR), the minimum value within $1.5 \times \mathrm{IQR}$, and outliers (black circles). Sample sizes are shown along the $\mathrm{x}$-axis. Species are grouped according to the species groups used in the text (Thick $=$ ThickTailed Group). All measurements in mm. HBL = head-and-body length. 
TABLE 2

Descriptive Statistics ${ }^{\mathrm{a}}$ for External Measurements (mm) and Mass (g) for Species of Sulawesi Crocidura

\begin{tabular}{|c|c|c|c|c|c|}
\hline & Total & Tail & Hind foot & Ear & Mass \\
\hline C. australis & $\begin{array}{c}142 \pm 4.3 \\
(136-148) 5\end{array}$ & $\begin{array}{c}63 \pm 3.3 \\
(59-67) 5\end{array}$ & $\begin{array}{c}16 \pm 0.4 \\
(16-17) 5\end{array}$ & $\begin{array}{l}11 \pm 0.5 \\
(10-11) 5\end{array}$ & $\begin{array}{c}10.9 \pm 1.83 \\
(8.5-12.7) 5\end{array}$ \\
\hline C. baletei & $\begin{array}{c}112 \pm 5.24 \\
(102-121) 17\end{array}$ & $\begin{array}{c}47 \pm 3.1 \\
(42-53) 17\end{array}$ & $\begin{array}{c}12 \pm 0.6 \\
(10-12) 17\end{array}$ & $\begin{array}{c}8 \pm 0.6 \\
(7-9) 17\end{array}$ & $\begin{array}{c}5.3 \pm 0.58 \\
(4.3-6.4) 17\end{array}$ \\
\hline C. brevicauda & $\begin{array}{c}141 \pm 6.1 \\
(130-150) 8\end{array}$ & $\begin{array}{c}58 \pm 3.1 \\
(54-64) 8\end{array}$ & $\begin{array}{c}16 \pm 0.8 \\
(15-17) 8\end{array}$ & $\begin{array}{c}9 \pm 0.7 \\
(8-10) 8\end{array}$ & $\begin{array}{c}12.4 \pm 1.63 \\
(10.6-15.2) 8\end{array}$ \\
\hline C. caudicrassa & $\begin{array}{c}141 \pm 5.5 \\
(130-150) 15\end{array}$ & $\begin{array}{c}59 \pm 4.3 \\
(50-64) 15\end{array}$ & $\begin{array}{c}16 \pm 0.5 \\
(16-17) 16\end{array}$ & $\begin{array}{c}10 \pm 0.5 \\
(9-10) 16\end{array}$ & $\begin{array}{c}15.5 \pm 1.34 \\
(13.5-18.5) 16\end{array}$ \\
\hline C. caudipilosa & $\begin{array}{c}164 \pm 7.7 \\
(145-183) 75\end{array}$ & $\begin{array}{c}86 \pm 4.6 \\
(79-98) 74\end{array}$ & $\begin{array}{c}17 \pm 0.9 \\
(15-19) 76\end{array}$ & $\begin{array}{c}10 \pm 1.0 \\
(8-13) 77\end{array}$ & $\begin{array}{c}8.8 \pm 1.27 \\
(5.8-12) 75\end{array}$ \\
\hline C. elongata & $\begin{array}{c}213 \pm 8.6 \\
(192-229) 54\end{array}$ & $\begin{array}{c}118 \pm 6.9 \\
(102-137) 57\end{array}$ & $\begin{array}{c}22 \pm 0.9 \\
(21-24) 57\end{array}$ & $\begin{array}{c}13 \pm 1.2 \\
(10-15) 53\end{array}$ & $\begin{array}{c}14.5 \pm 1.57 \\
(9.5-17.7) 55\end{array}$ \\
\hline C. lea & $\begin{array}{c}115 \pm 51 \\
(100-124) 37\end{array}$ & $\begin{array}{c}50 \pm 2.5 \\
(44-55) 37\end{array}$ & $\begin{array}{c}12 \pm 0.8 \\
(10-14) 38\end{array}$ & $\begin{array}{c}8 \pm 0.7 \\
(7-9) 37\end{array}$ & $\begin{array}{c}5.0 \pm 0.73 \\
(3.4-6.6) 34\end{array}$ \\
\hline C. levicula & $\begin{array}{c}99 \pm 5.3 \\
(85-109) 51\end{array}$ & $\begin{array}{c}36 \pm 2.9 \\
(27-44) 51\end{array}$ & $\begin{array}{c}11 \pm 0.5 \\
(10-12) 51\end{array}$ & $\begin{array}{c}8 \pm 0.8 \\
(6-10) 49\end{array}$ & $\begin{array}{c}4.4 \pm 0.77 \\
(3-7) 49\end{array}$ \\
\hline C. mediocris & $\begin{array}{c}106 \pm 5.0 \\
(89-117) 93\end{array}$ & $\begin{array}{c}44 \pm 2.9 \\
(37-50) 93\end{array}$ & $\begin{array}{c}11 \pm 0.6 \\
(10-13) 97\end{array}$ & $\begin{array}{c}8 \pm 0.7 \\
(6-9) 97\end{array}$ & $\begin{array}{c}4.4 \pm 0.72 \\
(2.9-5.9) 97\end{array}$ \\
\hline C. microelongata & $\begin{array}{c}188 \pm 9.7 \\
(165-209) 98\end{array}$ & $\begin{array}{c}106 \pm 6.4 \\
(94-121) 93\end{array}$ & $\begin{array}{c}19 \pm 0.9 \\
(17-21) 98\end{array}$ & $\begin{array}{c}10 \pm 0.8 \\
(8-13) 96\end{array}$ & $\begin{array}{c}11.1 \pm 1.59 \\
(7.5-14.25) 93\end{array}$ \\
\hline C. musseri & $\begin{array}{c}131 \pm 6.8 \\
(112-144) 27\end{array}$ & $\begin{array}{c}57 \pm 3.6 \\
(51-67) 28\end{array}$ & $\begin{array}{c}15 \pm 0.7 \\
(14-17) 30\end{array}$ & $\begin{array}{c}9 \pm 0.7 \\
(8-11) 30\end{array}$ & $\begin{array}{c}9.1 \pm 1.27 \\
(6.2-12.0) 27\end{array}$ \\
\hline C. nigripes & $\begin{array}{c}140 \pm 9.2 \\
(106-156) 95\end{array}$ & $\begin{array}{c}57 \pm 5.7 \\
(42-71) 97\end{array}$ & $\begin{array}{c}15 \pm 1.1 \\
(13-18) 97\end{array}$ & $\begin{array}{c}10 \pm 1.4 \\
(7-15) 79\end{array}$ & $\begin{array}{c}11.2 \pm 1.86 \\
(7.9-16.0) 74\end{array}$ \\
\hline C. normalis & $\begin{array}{c}122 \pm 5.1 \\
(110-140) 58\end{array}$ & $\begin{array}{c}54 \pm 4.6 \\
(46-65) 58\end{array}$ & $\begin{array}{c}14 \pm 0.8 \\
(12-16) 56\end{array}$ & $\begin{array}{c}8 \pm 0.7 \\
(7-10) 58\end{array}$ & $\begin{array}{c}6.1 \pm 0.86 \\
(4.3-8.2) 58\end{array}$ \\
\hline C. ordinaria & $\begin{array}{c}137 \pm 7.8 \\
(122-163) 44\end{array}$ & $\begin{array}{c}63 \pm 4.8 \\
(52-76) 44\end{array}$ & $\begin{array}{c}15 \pm 0.6 \\
(14-17) 44\end{array}$ & $\begin{array}{c}9 \pm 0.6 \\
(8-10) 44\end{array}$ & $\begin{array}{c}9.7 \pm 1.35 \\
(5-12.8) 43\end{array}$ \\
\hline C. pallida & $\begin{array}{c}140 \pm 7.7 \\
(122-160) 74\end{array}$ & $\begin{array}{c}62 \pm 4.7 \\
(49-73) 74\end{array}$ & $\begin{array}{c}16 \pm 0.7 \\
(14-17) 82\end{array}$ & $\begin{array}{c}10 \pm 1.0 \\
(7.5-13) 77\end{array}$ & $\begin{array}{l}10.4 \pm 1.50 \\
(7.4-16) 75\end{array}$ \\
\hline C. parva & $\begin{array}{c}104 \pm 5.36 \\
(88-112) 33\end{array}$ & $\begin{array}{c}41 \pm 3.0 \\
(29-47) 34\end{array}$ & $\begin{array}{c}11 \pm 0.5 \\
(10-12) 34\end{array}$ & $\begin{array}{c}8.0 \pm 0.46 \\
(7-9) 34\end{array}$ & $\begin{array}{c}4.3 \pm 0.62 \\
(3.2-5.9) 34\end{array}$ \\
\hline C. pseudorhoditis & $\begin{array}{c}158 \pm 8.7 \\
(135-180) 98\end{array}$ & $\begin{array}{c}73 \pm 6.0 \\
(59-84) 93\end{array}$ & $\begin{array}{c}17 \pm 0.8 \\
(15-19) 96\end{array}$ & $\begin{array}{l}10.7 \pm 1.1 \\
(8-13) 97\end{array}$ & $\begin{array}{c}13.2 \pm 1.72 \\
(10.3-18.5) 93\end{array}$ \\
\hline C. quasielongata & $\begin{array}{c}205 \pm 13.9 \\
(171-240) 112\end{array}$ & $\begin{array}{c}114 \pm 10.5 \\
(86-144) 115\end{array}$ & $\begin{array}{c}21 \pm 1.2 \\
(18-24) 115\end{array}$ & $\begin{array}{c}12 \pm 1.2 \\
(9-14) 112\end{array}$ & $\begin{array}{c}13.6 \pm 2.20 \\
(8.6-19.5) 110\end{array}$ \\
\hline C. rhoditis & $\begin{array}{c}158 \pm 11.0 \\
(131-182) 26\end{array}$ & $\begin{array}{c}70 \pm 5.2 \\
(57-77) 26\end{array}$ & $\begin{array}{c}18 \pm 1.1 \\
(16-20) 26\end{array}$ & $\begin{array}{c}11 \pm 1.1 \\
(10-13) 18\end{array}$ & $\begin{array}{c}16.9 \pm 2.64 \\
(11.5-21.9) 18\end{array}$ \\
\hline C. solita & $\begin{array}{c}135 \pm 7.1 \\
(118-154) 152\end{array}$ & $\begin{array}{c}62 \pm 4.1 \\
(50-75) 152\end{array}$ & $\begin{array}{c}15 \pm 0.8 \\
(14-19) 154\end{array}$ & $\begin{array}{c}9 \pm 0.9 \\
(7-11) 155\end{array}$ & $\begin{array}{c}8.5 \pm 1.34 \\
(5.4-12.5) 154\end{array}$ \\
\hline C. tenebrosa & $\begin{array}{c}104 \pm 4.2 \\
(96-111) 14\end{array}$ & $\begin{array}{c}41 \pm 2.4 \\
(36-44) 14\end{array}$ & $\begin{array}{c}12 \pm 0.7 \\
(11-13) 13\end{array}$ & $\begin{array}{c}10 \pm 1.0 \\
(8-11) 14\end{array}$ & $\begin{array}{c}5.6 \pm 0.67 \\
(4.3-6.6) 14\end{array}$ \\
\hline
\end{tabular}

a The sample mean \pm one standard deviation, the observed range in parentheses, and the sample size. 


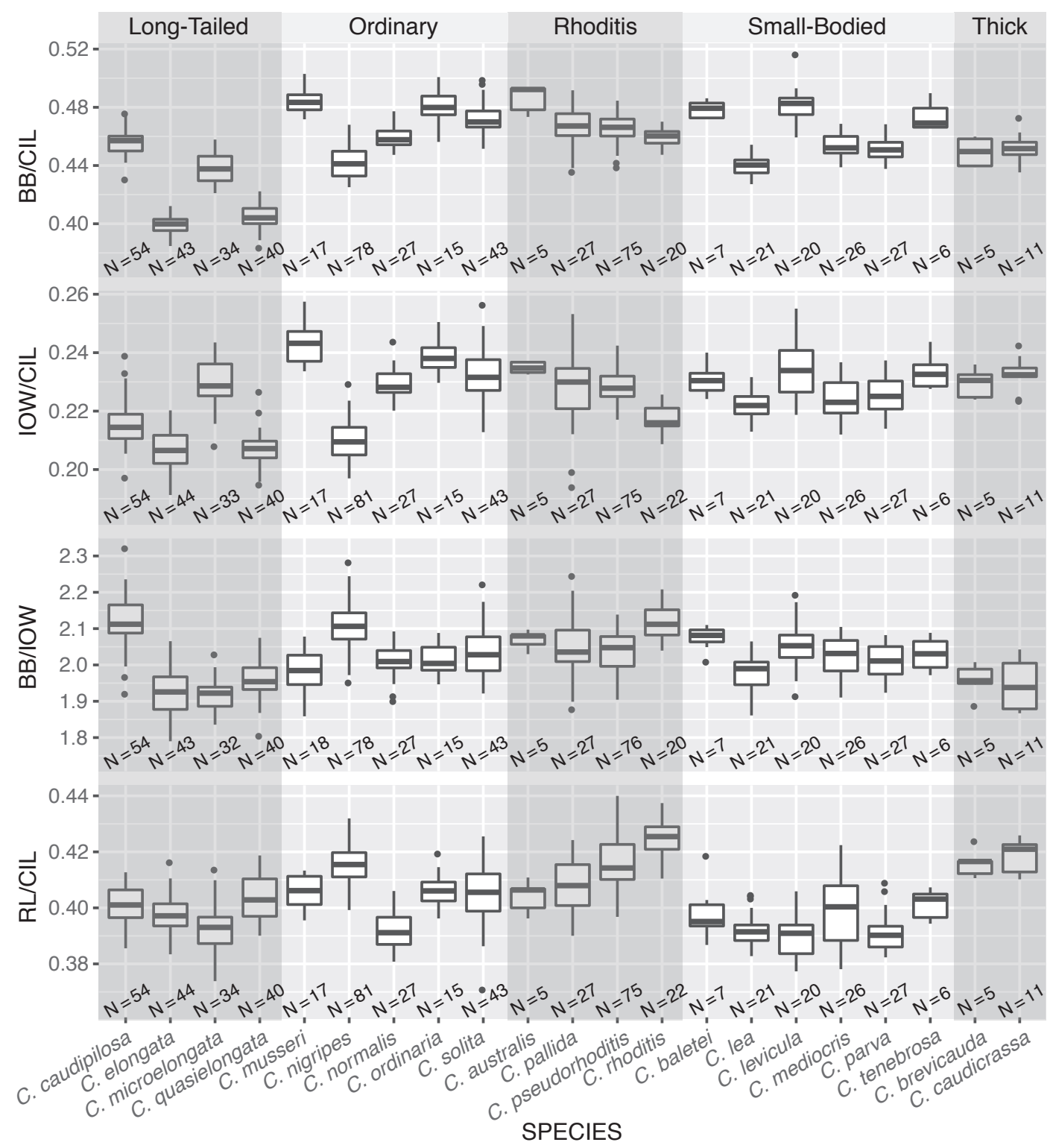

FIG. 10. Box plots of relative skull measures showing braincase breadth (BB), interorbital width (IOW), and rostral length (RL) divided by condyloincisive length (CIL) and BB divided by IOW for all species of Sulawesi shrew. Plots show the median, 1st and 3rd quartiles, the maximum value within $1.5 \times$ interquartile range (distance between 1st and 3rd quartiles; IQR), the minimum value within $1.5 \times \mathrm{IQR}$, and outliers (black circles). Sample sizes are shown along the $\mathrm{x}$-axis. Species are ordered according to the species groups used in the text (Thick $=$ Thick-Tailed Group). 
TABLE 3

Elevational Ranges (m) and Species Richness of Crocidura on Mountains of Sulawesi ${ }^{a}$

\begin{tabular}{|c|c|c|c|c|c|c|c|c|c|c|c|c|}
\hline & \multicolumn{3}{|c|}{ North Peninsula } & \multicolumn{5}{|c|}{ West-Central } & \multirow{2}{*}{$\frac{\text { SW }}{\text { Bawa }}$} & \multicolumn{2}{|c|}{ East-Central } & \multirow{2}{*}{$\frac{\mathrm{SE}}{\mathrm{Mek}}$} \\
\hline & $\mathrm{Amb}$ & Bulio & Dako & Gand & Lati & Bal & Rore & Torom & & Kato & Tomp & \\
\hline \multicolumn{13}{|c|}{ Long-tailed group: } \\
\hline caudipilosa & $\begin{array}{c}1460- \\
1655\end{array}$ & $\begin{array}{l}480- \\
1390\end{array}$ & $\begin{array}{l}512- \\
1630\end{array}$ & $\begin{array}{c}1535- \\
2640\end{array}$ & $\begin{array}{c}1697- \\
2500\end{array}$ & - & $\begin{array}{c}2020- \\
2250\end{array}$ & $\begin{array}{c}793- \\
862\end{array}$ & $\begin{array}{c}1660- \\
2550\end{array}$ & $\begin{array}{c}1352- \\
1610\end{array}$ & - & $\begin{array}{c}1710- \\
2536\end{array}$ \\
\hline elongata & $\begin{array}{c}1460- \\
1592\end{array}$ & $\begin{array}{l}580- \\
1390\end{array}$ & $\begin{array}{l}512- \\
1630\end{array}$ & - & - & - & - & - & - & - & - & - \\
\hline microelongata & - & - & - & $\begin{array}{c}1535- \\
2640\end{array}$ & $\begin{array}{l}683- \\
2535\end{array}$ & - & $\begin{array}{c}2020- \\
2250\end{array}$ & $\begin{array}{c}1584- \\
2218\end{array}$ & - & - & - & - \\
\hline quasielongata & - & - & 410 & 170 & 683 & $\begin{array}{l}830- \\
1140\end{array}$ & - & $\begin{array}{l}663- \\
1727\end{array}$ & $\begin{array}{c}1660- \\
2040\end{array}$ & $\begin{array}{l}365- \\
1700\end{array}$ & 350 & $\begin{array}{c}1366- \\
1717\end{array}$ \\
\hline \multicolumn{13}{|l|}{ Ordinary group: } \\
\hline musseri & - & - & - & - & - & - & $\begin{array}{c}2020- \\
2250\end{array}$ & - & - & - & - & - \\
\hline nigripes & $\begin{array}{c}1460- \\
1481\end{array}$ & $\begin{array}{l}480- \\
1390\end{array}$ & $\begin{array}{l}410- \\
1630\end{array}$ & 170 & - & $\begin{array}{l}900- \\
1140\end{array}$ & 2020 & $\begin{array}{l}790- \\
1371\end{array}$ & - & $\begin{array}{c}414- \\
875\end{array}$ & - & - \\
\hline normalis & - & - & - & $\begin{array}{c}1535- \\
2640\end{array}$ & $\begin{array}{c}1770- \\
2500\end{array}$ & - & $\begin{array}{c}2020- \\
2250\end{array}$ & - & - & $\begin{array}{c}1380- \\
1610\end{array}$ & - & 1366 \\
\hline ordinaria & - & - & - & $\begin{array}{l}170- \\
2640\end{array}$ & - & - & - & $\begin{array}{c}724- \\
790\end{array}$ & - & - & - & - \\
\hline solita & - & - & - & $\begin{array}{c}1535- \\
2640\end{array}$ & $\begin{array}{l}683- \\
2518\end{array}$ & - & $\begin{array}{c}2020- \\
2250\end{array}$ & - & - & - & - & - \\
\hline \multicolumn{13}{|l|}{ Rhoditis group: } \\
\hline australis & - & - & - & - & - & - & - & - & $\begin{array}{c}1660- \\
2550\end{array}$ & - & - & - \\
\hline pallida & - & - & - & $\begin{array}{c}1535- \\
1620\end{array}$ & 1376 & $\begin{array}{l}860- \\
1244\end{array}$ & - & $\begin{array}{c}1584- \\
1727\end{array}$ & - & $\begin{array}{l}450- \\
1610\end{array}$ & $\begin{array}{c}350- \\
600\end{array}$ & $\begin{array}{l}120- \\
2578\end{array}$ \\
\hline pseudorhoditis & $\begin{array}{c}1460- \\
1655\end{array}$ & $\begin{array}{l}480- \\
1210\end{array}$ & $\begin{array}{l}512- \\
1630\end{array}$ & - & - & - & 2230 & $\begin{array}{c}1584- \\
1727\end{array}$ & - & - & - & - \\
\hline rhoditis & $\begin{array}{c}1460- \\
1655\end{array}$ & - & - & - & - & - & - & - & - & - & - & - \\
\hline \multicolumn{13}{|c|}{ Small-bodied group: } \\
\hline mediocris & - & - & - & 170 & 1697 & $\begin{array}{l}817- \\
1107\end{array}$ & - & $\begin{array}{c}663- \\
859\end{array}$ & - & - & - & $\begin{array}{c}1471- \\
1936\end{array}$ \\
\hline balete & - & $\begin{array}{c}1375- \\
1390\end{array}$ & $\begin{array}{c}1560- \\
1630\end{array}$ & - & - & - & - & - & - & - & - & - \\
\hline lea & - & $\begin{array}{l}400- \\
1210\end{array}$ & $\begin{array}{l}512- \\
1600\end{array}$ & - & - & - & - & - & - & - & - & - \\
\hline levicula & - & - & - & - & - & - & 2020 & $\begin{array}{c}1371- \\
1890\end{array}$ & - & $\begin{array}{c}1365- \\
1700\end{array}$ & $\begin{array}{c}350- \\
600\end{array}$ & - \\
\hline parva & - & - & - & - & - & - & - & - & $\begin{array}{c}1660- \\
2550\end{array}$ & - & - & - \\
\hline
\end{tabular}


TABLE 3 continued

\begin{tabular}{|c|c|c|c|c|c|c|c|c|c|c|c|c|}
\hline & \multicolumn{3}{|c|}{ North Peninsula } & \multicolumn{5}{|c|}{ West-Central } & \multirow{2}{*}{$\frac{\text { SW }}{\text { Bawa }}$} & \multicolumn{2}{|c|}{ East-Central } & \multirow{2}{*}{$\frac{\mathrm{SE}}{\text { Mek }}$} \\
\hline & $\mathrm{Amb}$ & Bulio & Dako & Gand & Lati & Bal & Rore & Torom & & Kato & Tomp & \\
\hline tenebrosa & $\begin{array}{c}1460- \\
1481\end{array}$ & - & - & - & - & - & - & - & - & - & - & - \\
\hline \multicolumn{13}{|l|}{ Thick-tailed group: } \\
\hline brevicauda & - & - & - & - & $\begin{array}{c}2260- \\
2518\end{array}$ & - & - & - & - & - & - & - \\
\hline caudicrassa & - & - & - & $\begin{array}{c}2120- \\
2640\end{array}$ & - & - & - & - & - & - & - & - \\
\hline SPECIES RICHNESS & 6 & 6 & 7 & 10 & 8 & 4 & 8 & 9 & 3 & 6 & 3 & 5 \\
\hline
\end{tabular}

${ }^{a}$ Mountains are grouped by peninsula or area of endemism. Some mountain names are abbreviated: Amb = Ambang, Bulio = Buliohuto, Gand $=$ Gandang Dewata, Lati $=$ Latimojong, $\mathrm{Bal}=$ Balease, Rore $=$ Rorekatimbo, Torom $=$ Torompupu, Bawa $=$ Bawakaraeng, Kato = Katopasa, Tomp = Tompotika, and Mek = Mekongga). When museum databases recorded an elevational range for an individual specimen, we used the median of that range as the elevation for that specimen. Specimens from Salu Tiwo are grouped under Mt. Gandang Dewata.

where clear records are known from the northeast (the type locality, Temboan and Mt. Ambang, North Sulawesi Province) and north-west (Mt. Dako, Central Sulawesi Province, and Mt. Buliohuto, Gorontalo Province) areas of endemism (fig. 16). The absence of records from the north-central area of endemism are almost certainly due to the general lack of mammal collecting from this region. Miller and Hollister's (1921) paratypes from "Pinedapa, eastern Middle Celebes" and the two specimens from Mt. Rorekatimbo reported by Ruedi (1995) almost certainly represent Crocidura microelongata (see below). Crocidura elongata is known from a moderately broad range of elevations, with the low elevation records between 500 and $600 \mathrm{~m}$ from Mts. Buliohuto and Dako and high-elevation records reaching $1600 \mathrm{~m}$ on Mt. Dako (table 3). The type locality at Temboan is around $650 \mathrm{~m}$ elevation.

EMENDED DIAGNosis: A long-bodied, somewhat heavily built, moderately bicolored shrew with a very long tail and unusually long, pale hind feet (figs. 9, 14C, 17; tables 2, 5). The dorsal pelage is gray-brown overall; individual dorsal hairs are gray at the base and brown at the tip. The ventral pelage is paler, with individual hairs gray-based like those on the dorsum, except that the hair tips are silvery. The silvery appearance of the venter is most pronounced on the throat and chest area. In some specimens, however, this area has a reddish tint, due to variation in the color of the tips of some hairs. The mystacial vibrissae are dark proximally but white distally. The ears are prominent and pale. Dorsally, the feet are pale, transitioning from light brown near the wrist and ankle to nearly white on the digits. Ventrally, the feet show the same transition, but pigment is concentrated around the base of the pads (fig. 14C). The claws are translucent. The hind feet are long, even relative to head-and-body length (fig. 17). The long tail is subtly bicolored, with a brown dorsum and pale brown venter. Tiny applied hairs are present along the entire length of the tail, but they are barely visible to the naked eye (fig. 14C). However, these hairs are slightly longer and white near the tip of the tail, creating a very small white distal tuft. The long bristle hairs that are common at the base of the tail of many Crocidura are nearly absent in this species. The skull is long and slender, with a notably narrow braincase, interorbital region, and palate (figs. 10, 18A). Although the interorbital region is narrow relative to skull length, it is less constricted than the braincase. The long skull of $C$. elongata is attributable primarily to elongation of the postpalatal region; the rostral length is short 


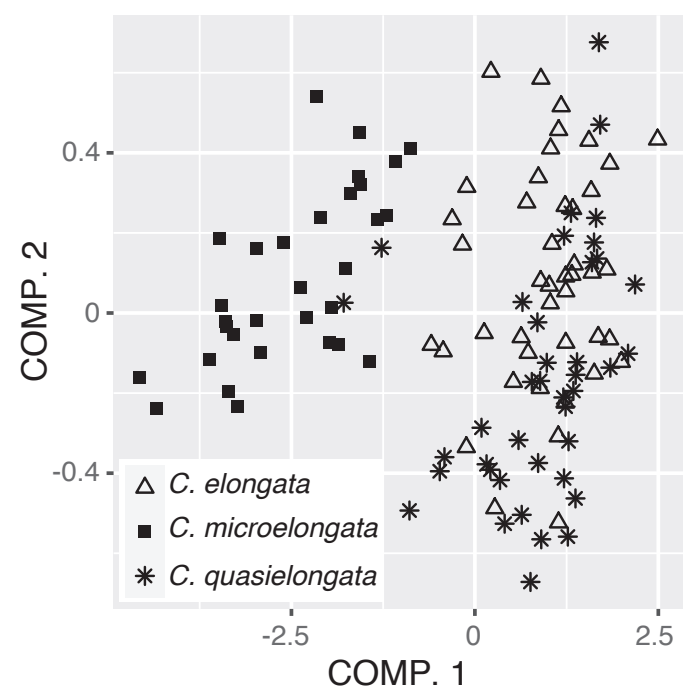

FIG. 11. Bivariate plot of the first two principal components from an analysis of 12 cranial measurements from the Elongata Subgroup. Loadings and variance explained are given in table 4.

relative to skull length (fig. 10). The lambdoidal ridge is prominent for a shrew of this size. The interorbital region is relatively straight (i.e., not strongly tapered) when viewed from the dorsal aspect. The dentition is prominent relative to the palatal breadth (fig. 18A).

COMPARISONS: Crocidura elongata is readily distinguished from most shrew species on Sulawesi by its long body and even longer tail, relatively pale color, and long and narrow hind feet and skull (tables 2, 5). Its head-and-body length is considerably longer than all species except C. rhoditis and C. quasielongata. Absolute hind-foot and ear lengths are on average greater in C. elongata than in any other shrew on Sulawesi (fig. 9; table 2). However, the other members of the Elongata Subgroup, first described below, can be difficult to distinguish (fig. 11; table 4). Compared to C. elongata, C. microelongata is smaller bodied, with a darker pelage and shorter average tail length. The thenar pad on the hind foot of C. elongata (fig. 14C) is considerably longer than in either C. microelongata (fig. 14D) or C. quasielongata (fig. 14B). The skull of $C$. microelongata is also shorter but
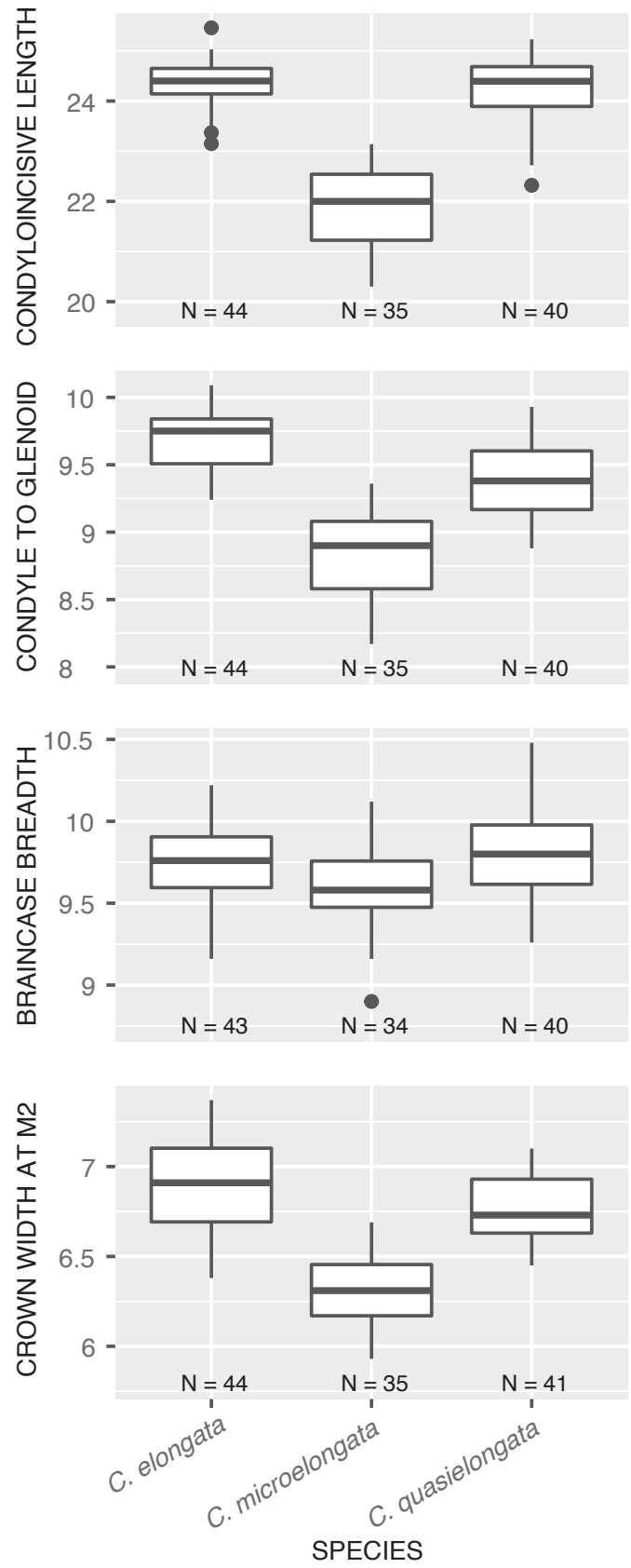

FIG. 12. Box plots of skull measurements useful for distinguishing species of the Elongata Subgroup. Plots show the median, 1 st and 3rd quartiles, the maximum value within $1.5 \times$ interquartile range (distance between 1 st and 3rd quartiles; IQR), the minimum value within $1.5 \times \mathrm{IQR}$, and outliers (black circles). Sample sizes are shown along the $\mathrm{x}$-axis. All measurements in $\mathrm{mm}$. 
TABLE 4

Results of Principal Components Analysis of Craniodental Measurements of the Elongata Subgroup of Crocidura

\begin{tabular}{lcc}
\hline & Component 1 & Component 2 \\
Variables $^{\mathrm{a}}$ & & \\
\hline Condyloincisive length & 0.7310 & 0.0787 \\
Braincase breadth & 0.0950 & 0.3000 \\
Interorbital width & 0.0345 & 0.2089 \\
Rostral length & 0.3256 & -0.5244 \\
Postpalatal width & 0.0533 & 0.0238 \\
Rostral width & 0.0654 & -0.0098 \\
Postpalatal length & 0.3520 & 0.3492 \\
Condyle to glenoid fossa & 0.2238 & 0.5233 \\
Upper toothrow length & 0.3401 & -0.3828 \\
P4 to M3 length & 0.1675 & -0.1932 \\
M2 to M2 labial width & 0.1531 & -0.0187 \\
Palatal width & 0.0336 & 0.0667 \\
Proportion of variance & 0.9089 & 0.0261 \\
Cumulative variance & 0.9089 & 0.9350 \\
\hline
\end{tabular}

a Table entries for variables are component loadings.

nearly as wide at the braincase and interorbital region, hence its relative width $(\mathrm{BB} / \mathrm{CIL}$ and IOW/CIL) is greater than that of C. elongata (figs. 10, 12). Compared to C. elongata, $C$. quasielongata has a similar head-and-body length, but, on average, a shorter tail and paler pelage (fig. 12, table 2). The skull of C. elongata is very similar in length to that of $C$. quasielongata (figs. 12, 18). However, in C. elongata the rostrum makes up a smaller proportion and the postpalatal region makes up a greater proportion of skull length than in C. quasielongata (figs. 10, 12). In addition, relative braincase breadth (BB/ CIL and $\mathrm{BB} / \mathrm{IOW}$ ) is, on average, slightly less in C. elongata than in C. quasielongata. A principal components analysis of 12 cranial measurements shows that these two species have broad, though not complete, overlap in multivariate morphometric space (fig. 11).

Comments: A nearly complete cytochrome $b$ sequence (1109 bp) from a topotypical paratype (USNM 217535) is nearly identical to those from specimens we collected on Mt. Ambang (fig. 4), which is approximately $32 \mathrm{~km}$ to the southwest. Our inference based on mitogenomes also place USNM 217535 as a close relative to specimens from Mt. Ambang (fig. 5). These animals' mitochondrial sequences are also closely related to a series from Mt. Buliohuto and to specimens from Mt. Dako referred to as "dark elongata" by Esselstyn et al. (2019). Maximum Jukes-Cantor distances between these sample localities is 0.05 (fig. 4; supplementary data S5). Samples of this species from Temboan and Mts. Ambang, Buliohuto, and Dako formed a well-supported clade in our analyses of UCEs (figs. 7, 8) and concatenated nuclear exons (supplementary data S6).

The phylogeographic study of Eldridge et al. (2018), which examined the correspondence of genetic diversity in Elongata Subgroup shrews to the area of endemism paradigm expectations, conflated the three species of this subgroup with Crocidura elongata. More recently, specimens of $C$. elongata from Mt. Dako were referred to as "dark 


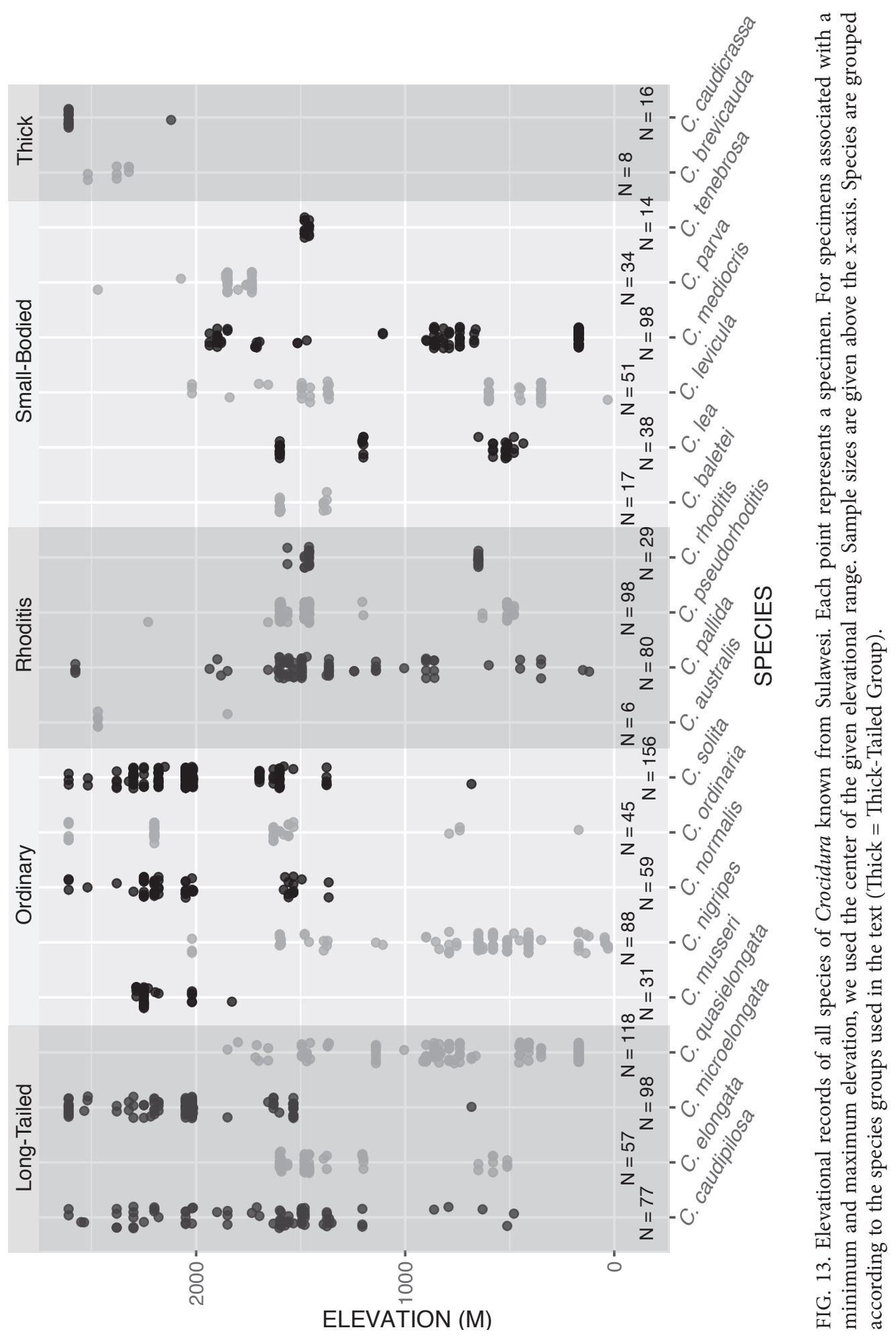




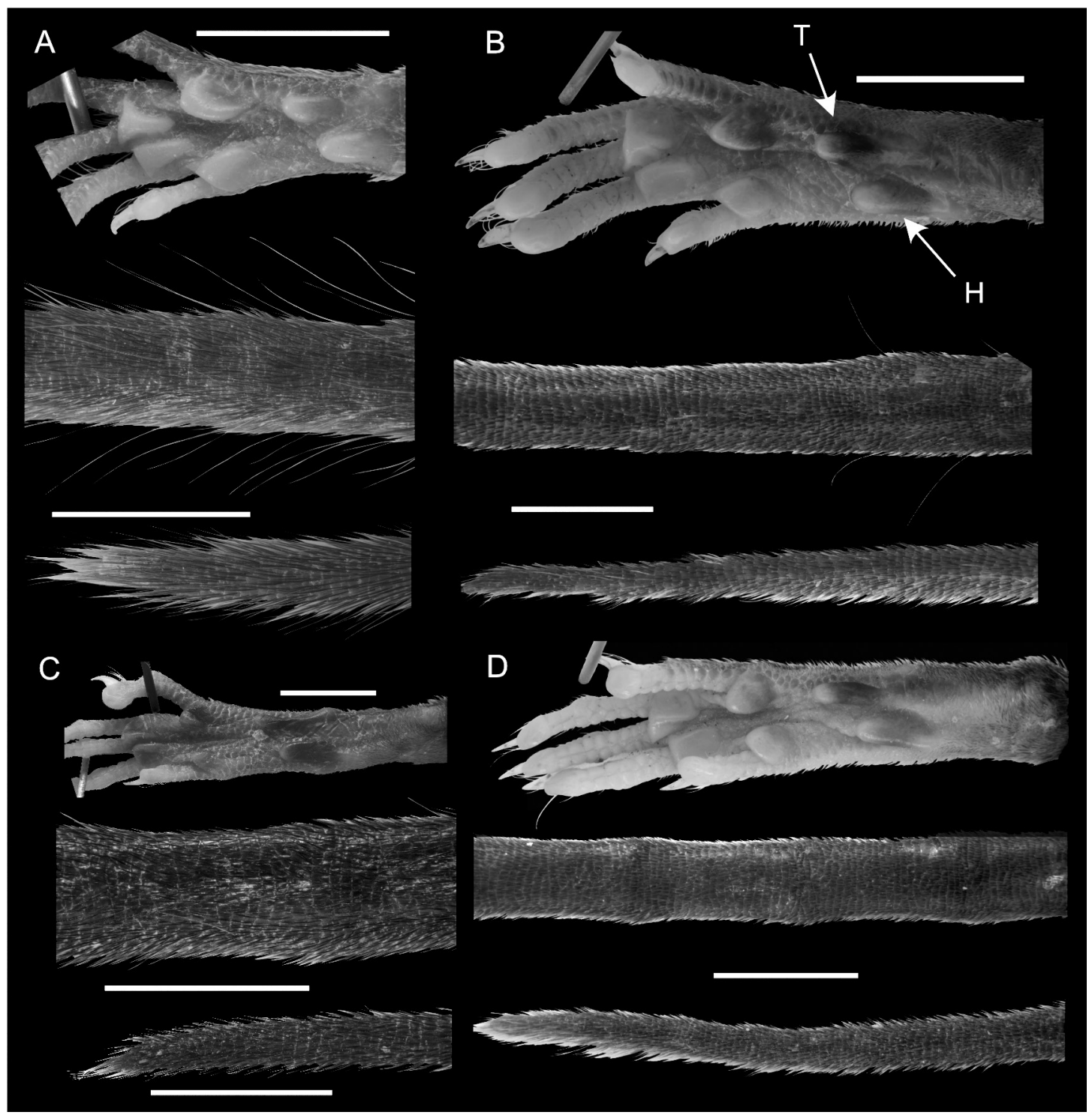

FIG. 14. Images showing the ventral surface of the left hind foot and dorsal surfaces of the tail base (approximately $1 \mathrm{~cm}$ from rump) and tail tip from the four members of the Long-Tailed Group: A, Crocidura caudipilosa, LSUMZ 36940; B, C. quasielongata, FMNH 218551; C, C. elongata, LSUMZ 39009; and D, C. microelongata, FMNH 212998. Scale bars represent $5 \mathrm{~mm}$ and apply to their nearest images within each panel. The thenar $(\mathrm{T})$ and hypothenar $(\mathrm{H})$ pads are labeled on panel $\mathrm{B}$. 
elongata" by Esselstyn et al. (2019) because the authors were unable to determine if either of two long-tailed species on Mt. Dako represented true $C$. elongata. Mt. Dako is the only area where we found C. elongata occurring in syntopy with another member of the Elongata Subgroup (C. quasielongata). Despite the confusing history of specimens in this subgroup, none of our analyses suggested a sister relationship between any two of these species. In our UCE species-tree inference, C. elongata was moderately supported as the sister to $C$. rhoditis and C. pseudorhoditis (fig. 7), but in our mitogenome estimate it was placed as sister to C. lea, although without statistical support (fig. 5).

Ruedi (1995) suggested a scansorial lifestyle for this species based on its long, naked-appearing tail and long hind feet. While this is certainly possible, direct evidence for a scansorial lifestyle is lacking, and these traits could be linked alternatively to a saltatorial locomotory style (Brosset, 1988). Some very limited evidence indicates that Crocidura caudipilosa, which has a long, but less extreme tail combined with a more typical hind-foot length, is a skilled climber (Esselstyn et al., 2019).

For coalescent species delimitation results, see the Crocidura quasielongata account below.

SPECIMENS EXAMINED: Mt. Ambang (LSUMZ 39008-39013, 39015-39018, 39057, 39058, 39061, 39248-39251, 39257-39264, 39318; NMV C38009, C38032), Mt. Buliohuto (LSUMZ 38238, 38240, 38243-38247, 38251-38253; NMV C37742, C37752, C37760), Mt. Dako (LSUMZ 36905-36907, 36909, 36916, 36919, 36921, 36923, 36924, 36932; NMV C37248, C37249, C37303), Temboan (USNM 217534, 217535).

Crocidura microelongata, new species

LSID: urn:lsid:zoobank. org:act:015EFE9D-8AAC-433D-B563-

\section{DD8855C43B00}

Crocidura elongata Ruedi, 1995: 251.

Misidentification.

HoLOTyPe: MZB 43000 (= FMNH 213426), an adult male, collected on 1 March 2011 by J.A.

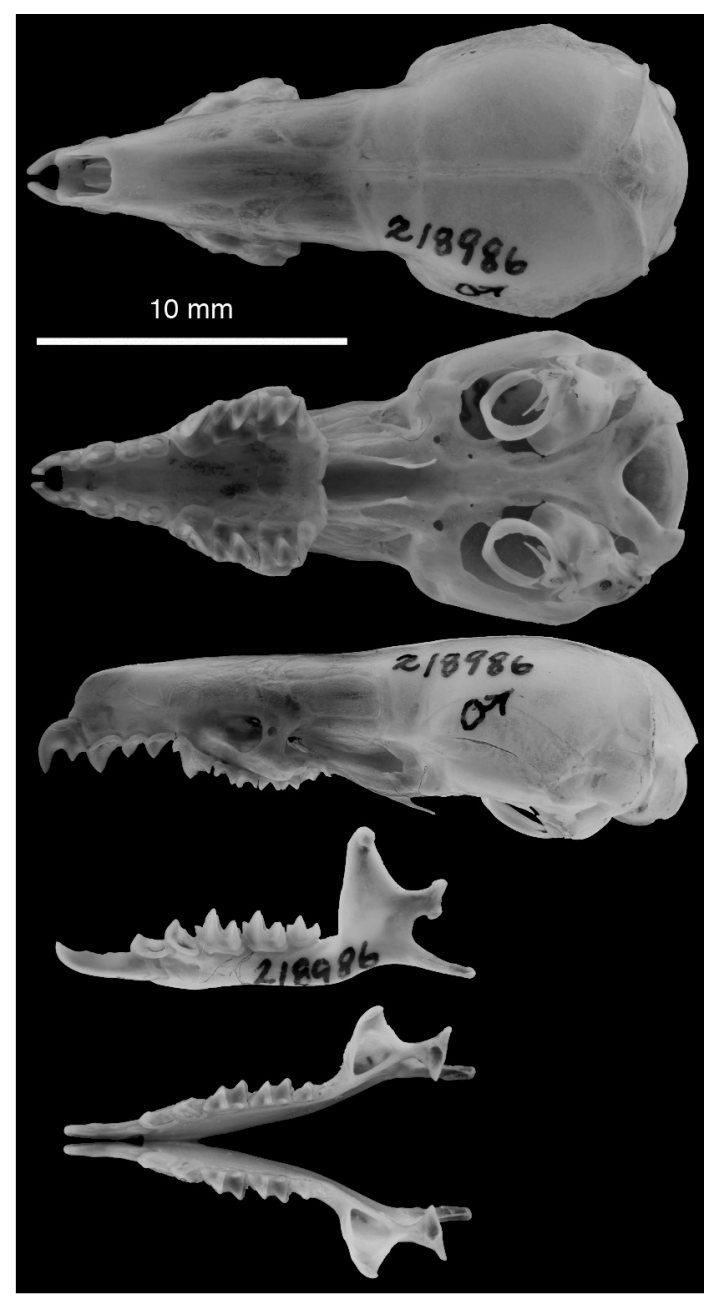

FIG. 15. Images showing dorsal, ventral, and lateral views of the skull and occlusal and lateral views of the dentary of Crocidura caudipilosa (FMNH 218986).

Esselstyn. The specimen comprises a study skin, cleaned skull and skeleton, and frozen tissue samples. External measurements from the holotype are $206 \mathrm{~mm} \times 111 \mathrm{~mm} \times 20 \mathrm{~mm} \times 10 \mathrm{~mm}$ $=12.5 \mathrm{~g}$. The voucher specimen and a tissue sample will be permanently curated at MZB, with another tissue sample retained at FMNH.

Type LOCALITy: Indonesia, Sulawesi Selatan, Enrekang, Buntu Bato, Latimojong Village, Karangan, Mt. Latimojong, Bantanase; $3.40755^{\circ}$ S, $120.0078^{\circ} \mathrm{E}, 2050 \mathrm{~m}$. 
TABLE 5

Descriptive Statistics ${ }^{\mathrm{a}}$ for Craniodental Measurements ( $\mathrm{mm}$ ) for Species of the Long-Tailed Group of Sulawesi Crocidura

\begin{tabular}{|c|c|c|c|c|}
\hline & C. caudipilosa & C. elongata & C. microelongata & C. quasielongata \\
\hline Condyloincisive length & $\begin{array}{c}20.76 \pm 0.624 \\
(19.54-22.2) 44\end{array}$ & $\begin{array}{c}24.35 \pm 0.502 \\
(23.15-25.46) 44\end{array}$ & $\begin{array}{c}21.9 \pm 0.749 \\
(20.3-23.14) 35\end{array}$ & $\begin{array}{c}24.25 \pm 0.663 \\
(22.32-25.23) 40\end{array}$ \\
\hline Braincase breadth & $\begin{array}{c}9.46 \pm 0.232 \\
(9.0-9.99) 44\end{array}$ & $\begin{array}{c}9.73 \pm 0.263 \\
(9.16-10.22) 42\end{array}$ & $\begin{array}{c}9.59 \pm 0.229 \\
(8.9-10.12) 33\end{array}$ & $\begin{array}{c}9.81 \pm 0.272 \\
(9.26-10.48) 40\end{array}$ \\
\hline Interorbital width & $\begin{array}{c}4.47 \pm 0.151 \\
(4.1-4.84) 44\end{array}$ & $\begin{array}{c}5.04 \pm 0.17 \\
(4.67-5.35) 44\end{array}$ & $\begin{array}{c}5.01 \pm 0.182 \\
(4.69-5.35) 33\end{array}$ & $\begin{array}{c}5.01 \pm 0.179 \\
(4.63-5.45) 41\end{array}$ \\
\hline Rostral length & $\begin{array}{c}8.32 \pm 0.313 \\
(7.59-9.05) 44\end{array}$ & $\begin{array}{c}9.69 \pm 0.276 \\
(9.16-10.16) 44\end{array}$ & $\begin{array}{c}8.59 \pm 0.263 \\
(7.91-9.03) 33\end{array}$ & $\begin{array}{c}9.79 \pm 0.307 \\
(8.71-10.27) 41\end{array}$ \\
\hline Postpalatal width & $\begin{array}{c}3.77 \pm 0.125 \\
(3.52-4.05) 44\end{array}$ & $\begin{array}{c}4.33 \pm 0.13 \\
(4.1-4.64) 44\end{array}$ & $\begin{array}{c}4.21 \pm 0.118 \\
(4.0-4.48) 33\end{array}$ & $\begin{array}{l}4.41 \pm 0.156 \\
(4.1-4.8) 41\end{array}$ \\
\hline Rostral width & $\begin{array}{c}2.92 \pm 0.146 \\
(2.63-3.22) 44\end{array}$ & $\begin{array}{c}3.22 \pm 0.116 \\
(2.98-3.47) 44\end{array}$ & $\begin{array}{c}3.03 \pm 0.163 \\
(2.62-3.4) 35\end{array}$ & $\begin{array}{c}3.29 \pm 0.178 \\
(3.04-3.74) 41\end{array}$ \\
\hline Postpalatal length & $\begin{array}{c}9.44 \pm 0.321 \\
(8.82-10.24) 43\end{array}$ & $\begin{array}{c}11.1 \pm 0.265 \\
(10.44-11.84) 44\end{array}$ & $\begin{array}{c}9.89 \pm 0.329 \\
(9.18-10.44) 35\end{array}$ & $\begin{array}{c}11.0 \pm 0.387 \\
(10.29-11.75) 40\end{array}$ \\
\hline Condyle to glenoid fossa & $\begin{array}{c}8.25 \pm 0.214 \\
(7.89-8.76) 44\end{array}$ & $\begin{array}{c}9.68 \pm 0.211 \\
(9.24-10.09) 44\end{array}$ & $\begin{array}{c}8.85 \pm 0.316 \\
(8.17-9.36) 35\end{array}$ & $\begin{array}{c}9.38 \pm 0.26 \\
(8.88-9.93) 40\end{array}$ \\
\hline Upper toothrow length & $\begin{array}{c}9.07 \pm 0.283 \\
(8.49-9.66) 44\end{array}$ & $\begin{array}{c}10.6 \pm 0.261 \\
(10.07-11.15) 44\end{array}$ & $\begin{array}{c}9.46 \pm 0.296 \\
(8.78-9.88) 35\end{array}$ & $\begin{array}{c}10.6 \pm 0.30 \\
(9.65-11.03) 41\end{array}$ \\
\hline P4 to M3 length & $\begin{array}{c}4.77 \pm 0.15 \\
(4.44-5.07) 44\end{array}$ & $\begin{array}{c}5.82 \pm 0.154 \\
(5.42-6.14) 44\end{array}$ & $\begin{array}{c}5.28 \pm 0.179 \\
(4.95-5.62) 35\end{array}$ & $\begin{array}{c}5.86 \pm 0.195 \\
(5.21-6.15) 41\end{array}$ \\
\hline M2 to M2 labial width & $\begin{array}{c}5.79 \pm 0.194 \\
(5.42-6.26) 44\end{array}$ & $\begin{array}{c}6.9 \pm 0.251 \\
(6.38-7.37) 44\end{array}$ & $\begin{array}{c}6.32 \pm 0.182 \\
(5.93-6.69) 35\end{array}$ & $\begin{array}{c}6.78 \pm 0.181 \\
(6.45-7.1) 41\end{array}$ \\
\hline Palatal width & $\begin{array}{c}2.46 \pm 0.123 \\
(2.2-2.75) 44\end{array}$ & $\begin{array}{c}2.68 \pm 0.125 \\
(2.44-3.03) 44\end{array}$ & $\begin{array}{c}2.58 \pm 0.1 \\
(2.4-2.84) 35\end{array}$ & $\begin{array}{c}2.69 \pm 0.138 \\
(2.42-2.96) 41\end{array}$ \\
\hline
\end{tabular}

a The sample mean \pm one standard deviation, the observed range in parentheses, and the sample size.

Eтymology: We combine "micro" with "elongata" because this species looks like a small version of C. elongata.

GeOgRAPHIC Distribution: This species is broadly distributed across western portions of the west-central area of endemism of Sulawesi. We identified populations from Mt. Latimojong, South Sulawesi Province; Mt. Gandang Dewata, West Sulawesi Province; and Mts. Torompupu and Rorekatimbo, Central Sulawesi Province (fig. 16). Recorded from approximately $700 \mathrm{~m}$ on Mt. Latimojong to $2600 \mathrm{~m}$ on Mt. Gandang Dewata. Most specimens are from areas $>1500 \mathrm{~m}$ (fig. 13; table 3).

DiAgnosis: Crocidura microelongata is a somewhat large Crocidura with a long tail and long, slen- der hind feet and skull (tables 2, 5). The dorsal pelage is gray-brown overall, with individual hairs having a gray-brown base and brown tip (fig. 14D). The ventral pelage is more silver, comprising individual hairs with a dark gray base and silver tip. The mystacial vibrissae are dark proximally for a third of their length but white distally. The hind feet are long in absolute terms and relative to head-andbody length (figs. 9, 17). Dorsally, the feet are brown, abruptly transitioning to pinkish white near the base of the phalanges (in some specimens, it is a gradual transition). Ventrally, the hind feet are nearly white, but brown pigment is present around the lateral, posterior margin of the hind foot and around the base of the thenar and hypothenar pads 
(fig. 14D). In some specimens, the 1 st and 4 th interdigital pads are also pigmented around the base. The palmar surface is entirely pinkish white. The claws are translucent. The tail is subtly bicolored, with a brown dorsum and pale brown venter. Tiny applied hairs are present along the entire length of the tail, but they are barely visible to the naked eye along most of the length of the tail (fig. 14D). These hairs are slightly longer and white near the tip of the tail, creating a very small distal white tuft. In a minority of specimens, the integument is also white for the distal $\leq 20 \mathrm{~mm}$ of the tail. The tail bristles that are common at the base of the tail of many Crocidura are nearly absent in this species (fig. 14D). The skull is somewhat long and slender, with a tapering interorbital region, and moderately robust dentition (fig. 18B). The braincase is dorsoventrally inflated and bulges outward in the parietal region as compared with the more posterior interparietal. Relative to skull length the rostrum is quite short (fig. 10). The braincase is somewhat narrow relative to skull length, but the interorbital region is wide (fig. 10).

Comparisons: This species is readily distinguished by its ratio of tail length to head-and-body length (fig. 9; table 2) from all Crocidura species on Sulawesi except other members of the Long-Tailed Group. Within the Long-Tailed Group, C. caudipilosa is smaller and has a much hairier tail, shorter hind foot, paler pelage, and lower relative interorbital width (IOW/CIL) but greater relative braincase breadth (BB/CIL) (figs. 9, 10). Within the Elongata Subgroup, C. microelongata has a smaller body size, shorter tail, shorter and slightly darker hind feet, and shorter skull than C. elongata and $C$. quasielongata (fig. 12; table 5). The thenar pad on the hind foot is shorter than in C. elongata, but comparable to that of C. quasielongta (fig. 14). Although the skull is shorter, its breadth is similar to that of the other two species, whether measured at the braincase, interorbital area, or rostral region (figs. 10, 12). The interorbital region, however, is more tapered than in either of the two most similar species (fig. 18). The dentition of C. microelongata is slightly smaller in proportion to the skull than in either C. elongata or C. quasielongata (fig. 18).
Comments: Although we have not examined the specimens Ruedi (1995) identified as Crocidura elongata from Mt. Rorekatimbo (IZEA 4365 and 4396), a published cytochrome $b$ sequence from IZEA 4396 is indistinguishable from mitochondrial sequences we obtained from Mt. Rorekatimbo samples of C. microelongata. Our mitochondrial gene trees placed C. microelongata as either sister to the other 19 species that make up Sulawesi's endemic radiation (all species except $C$. nigripes) or to all members of the endemic radiation except $C$. musseri. However, statistical support for these hypotheses was nonexistent (fig. 4) or modest (fig. 5). Our analyses of nuclear DNA placed C. microelongata as part of the basal comb with no clear sister relationship (figs. 7, 8; supplementary data S6). See the next account for results of nuclear DNA species delimitation analyses.

Specimens examined: Mt. Gandang Dewata (MZB 34736-34741, 34743-34745, 34748, 34749, 34751,34753 , 34755-34757, 38463, 38472, 38473; FMNH 218544-218547, 218584, 218593218603, 218969, 218972; NMV Z21764), Mt. Latimojong (MZB 40935, 40937, 40938, 43000; FMNH 212990-213005; MVZ 237567, 237569237572, 237594, 238121; NMV C38534), Mt. Rorekatimbo (FMNH 213146-213162, 213164213173, 213435, 213436), Mt. Torompupu (MZB 43013, 43014; NMV C40139).

\section{Crocidura quasielongata, new species}

LSID: urn:lsid:zoobank. org:act:551F4F6E-2983-4C71-923A047FB0E24B74

Crocidura "pale elongata" Esselstyn et al., 2019: 1715. Informal name.

HoLOTyPe: MZB 43001 (= LSUMZ 36939), an adult male, collected on 15 March 2013 by J.L. Patton. The specimen was prepared as a study skin, cleaned skull and skeleton, and frozen tissues. External measurements from the holotype are $215 \mathrm{~mm} \times 126 \mathrm{~mm} \times 22 \mathrm{~mm} \times 11 \mathrm{~mm}=16 \mathrm{~g}$. The voucher specimen and a tissue sample will be 


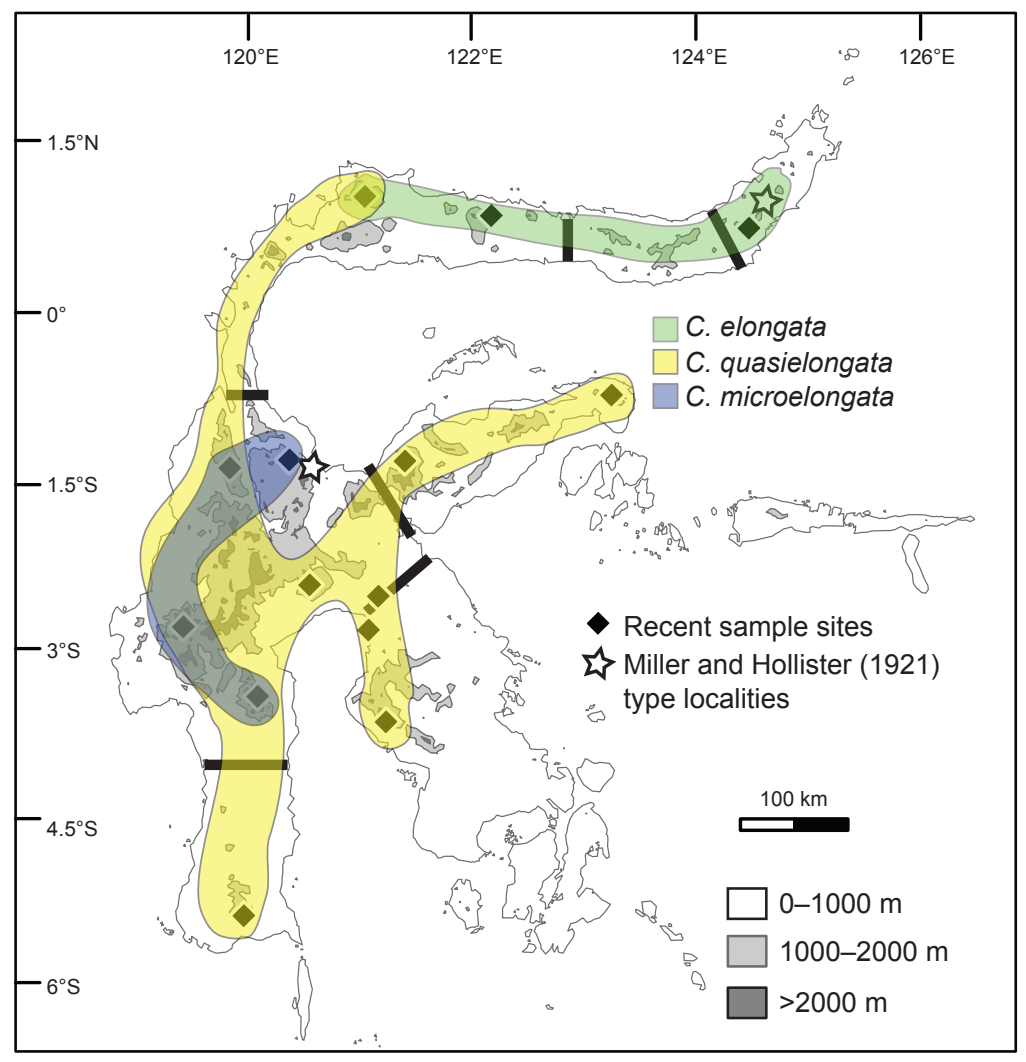

FIG. 16. Map of Sulawesi showing localities sampled for shrews. Colored areas enclose localities with known records of members of the Elongata Subgroup. Although we excluded Pinedapa from the estimated geographic ranges, we suspect the two USNM specimens referred to Crocidura elongata by Miller and Hollister (1921) from this site represent C. microelongata.

permanently curated at MZB, with another tissue sample retained at LSUMZ.

Type Locality: Indonesia, Sulawesi Tengah, Toli Toli, Mt. Dako; $1.10998^{\circ}$ N, $120.90339^{\circ}$ E, $410 \mathrm{~m}$.

Eтymology: We combine "quasi" with "elongata" because this species resembles $C$. elongata.

Geographic Distribution: Widespread on Sulawesi and recorded from all areas of endemism except the north-central and north-east (fig. 16). Populations identified here are from the westcentral (Wasponda and Mts. Balease and Torompupu, Central Sulawesi Province; Salu Tiwo of Mt. Gandang Dewata, West Sulawesi Province; Mt. Latimojong, South Sulawesi Province), south-west (Mt. Bawakaraeng, South Sulawesi Province), south-east (Mt. Mekongga, Southeast Sulawesi
Province), east-central (Mts. Katopasa and Tompotika, Central Sulawesi Province), and northwest (Mt. Dako, Central Sulawesi Province) areas of endemism (fig. 16). We found this species from approximately $200 \mathrm{~m}$ at Salu Tiwo (low elevation Mt. Gandang Dewata site) to $1700 \mathrm{~m}$ on Mts. Mekongga and Katopasa and $1800 \mathrm{~m}$ on Mt. Bawakaraeng (fig. 13; table 3).

DiAgnosis: A long-bodied, somewhat heavily built, moderately bicolored shrew with a long tail and long, pale hind feet (table 2). The dorsal pelage ranges from gray-tan to gray-brown overall, with individual dorsal hairs having a gray base and tan to brown tip. Some specimens also have a narrow, tan band between the gray proximal section and brown tip of each hair. The ventral pelage has silver highlights, the visual effect of 


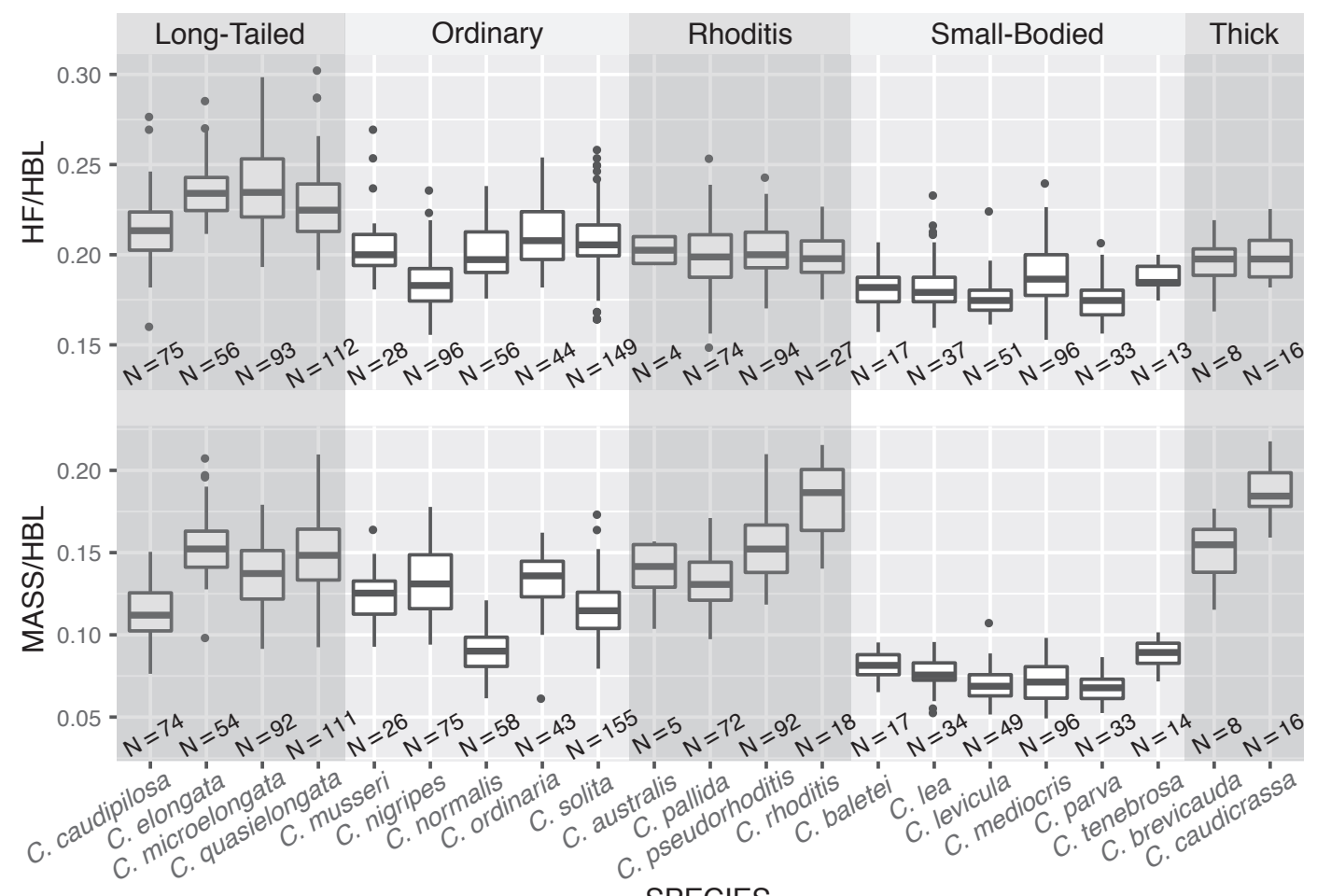

SPECIES

FIG. 17. Box plots showing the length of the hind foot (HF) relative to the head-and-body length (HBL) and the ratio of mass to HBL. Plots show the median, 1st and 3rd quartiles, the maximum value within $1.5 \times$ interquartile range (distance between 1st and 3rd quartiles; IQR), the minimum value within $1.5 \times \mathrm{IQR}$, and outliers (black circles). Sample sizes are shown along the $\mathrm{x}$-axis. Species are ordered along the $\mathrm{x}$-axis according to the species groups used in the text (Thick = Thick-Tailed Group). Lengths are in mm and mass is in grams.

individual hairs each with a pale tip. In many specimens, the chest and throat area has a slight red tint due to variation in the color of the hair tips. The ears are large and pale. The mystacial vibrissae are dark proximally, but white distally, with the dark portion occupying $20 \%-80 \%$ of vibrissa length. The hind feet are long absolutely (table 2) and relative to head-and-body length (fig. 17). Dorsally, the feet range from entirely white, to brown at the ankle and wrist, slowly transitioning toward the white digits. Ventrally, the feet show the same transition (except in specimens where they are entirely white), but pigment is concentrated around the base of each foot pad. The claws are translucent (fig. 14B). The tail is subtly bicolored, with a brown dorsum and pale brown venter. Tiny applied hairs are present along the entire length of the tail, but they are barely visible to the naked eye along most of the tail. However, these hairs are slightly longer and white near the tip of the tail, creating a very small, sometimes white, distal tuft. Tail bristles are nearly absent (fig. 14B). The skull is long, primarily due to elongation of the postpalatal region, but not the rostral region (figs. 10, 18C). Relative to skull length, the braincase is especially narrow $(\mathrm{BB} / \mathrm{CIL})$ and the interorbital region somewhat narrow (IOW/CIL; fig. 10) and relatively untapered. The lambdoidal crest is prominent. The dentition is robust (fig. 18C).

Comparisons: This species is easily distinguished by the ratio of tail length to head-andbody length (most specimens $>110 \%$; fig. 9) from all Crocidura species on Sulawesi except 
TABLE 6

Results of Principal Components Analysis of Craniodental Measurements of the Rhoditis Group of Crocidura

\begin{tabular}{|c|c|c|c|c|}
\hline \multirow[b]{2}{*}{ Variables $^{\mathrm{a}}$} & \multicolumn{2}{|c|}{ Mt. Ambang } & \multicolumn{2}{|c|}{ All Sulawesi } \\
\hline & Component 1 & Component 2 & Component 1 & Component 2 \\
\hline Condyloincisive length & 0.6855 & 0.0425 & 0.6873 & 0.1399 \\
\hline Braincase breadth & 0.2106 & 0.3206 & 0.2279 & 0.2567 \\
\hline Interorbital width & 0.0683 & 0.1852 & 0.0988 & 0.2657 \\
\hline Rostral length & 0.3426 & -0.6866 & 0.3510 & -0.4988 \\
\hline Postpalatal width & 0.1140 & 0.0094 & 0.0830 & 0.0558 \\
\hline Rostral width & 0.1050 & 0.3168 & 0.0881 & 0.1321 \\
\hline Postpalatal length & 0.3406 & 0.2742 & 0.2633 & 0.4475 \\
\hline Condyle to glenoid fossa & 0.2126 & 0.3072 & 0.1774 & 0.3981 \\
\hline Upper toothrow length & 0.3146 & -0.2646 & 0.3413 & -0.3654 \\
\hline P4 to M3 length & 0.1744 & -0.1050 & 0.1960 & -0.2046 \\
\hline M2 to M2 labial width & 0.2104 & 0.1102 & 0.2473 & -0.1987 \\
\hline Palatal width & 0.0692 & 0.1625 & 0.1062 & 0.0320 \\
\hline Proportion of variance & 0.8994 & 0.0281 & 0.8731 & 0.0336 \\
\hline Cumulative proportion & 0.8994 & 0.9275 & 0.8731 & 0.9067 \\
\hline
\end{tabular}

a Table entries for variables are component loadings.

other members of the Long-Tailed Group. Within this group, C. quasielongata is considerably larger, much stockier, has a much narrower relative braincase breadth (BB/CIL), and has a much less hairy tail than C. caudipilosa. Within the Elongata Subgroup, C. quasielongata is, on average, intermediate in size, tail length, and hind-foot length between the smaller C. microelongata and the slightly larger $C$. elongata (fig. 9; tables 2, 5). Crocidura quasielongata has long ears, second in length only to C. elongata (table 2). Although these measurements overlap between the species, the averages differ. On the hind foot, the thenar pad is shorter than in $C$. elongata (fig. 14), despite the similar hind-foot lengths shared by these species. Also, on average, $C$. quasielongata is paler than either $C$. elongata or C. microelongata, but there is substantial color variation across the range of the species. The pelage varies in overall color from tan to dark brown. The palest specimens of $C$. quasielongata are from Mt. Tompotika and Salu Tiwo of Mt. Gandang Dewata, while animals from Mt. Dako are slightly darker, and specimens from Mts. Balease, Katopasa, and Torompupu are darker still. These color differences may reflect a tendency for low-elevation animals to be paler than those sampled at higher elevations, perhaps an elevational version of Gloger's Rule (Gloger, 1833). The palest specimens have a middle color band that is light gray on individual hairs. The skull of C. quasielongata is long, with a very narrow braincase and interorbital region. The interorbital region is also rather straight, barely tapering anteriorly. In this regard, the skull is very similar to, but slightly shorter than that of C. elongata, and it is much more elongate than in C. microelongata (fig. 12). In proportion to skull length, rostral length is greater, but postpalatal length is lesser in C. quasielongata than in C. elongata and $C$. microelongata (fig. 10). The dentition is slightly more robust than in C. microelongata but comparable to that of C. elongata (fig. 18).

Comments: Although Crocidura microelongata is mostly separated in our PCA (fig. 11) and 


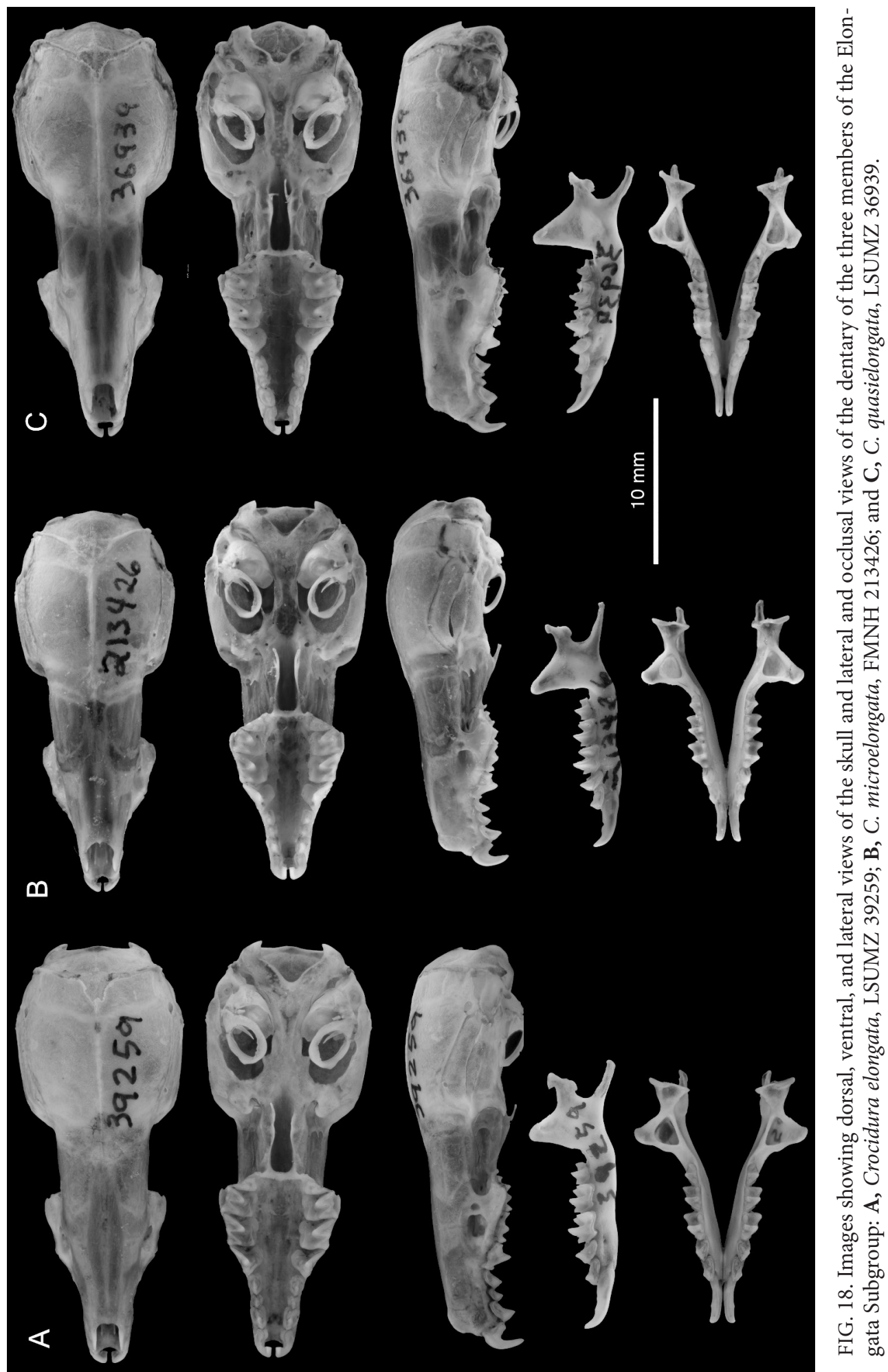



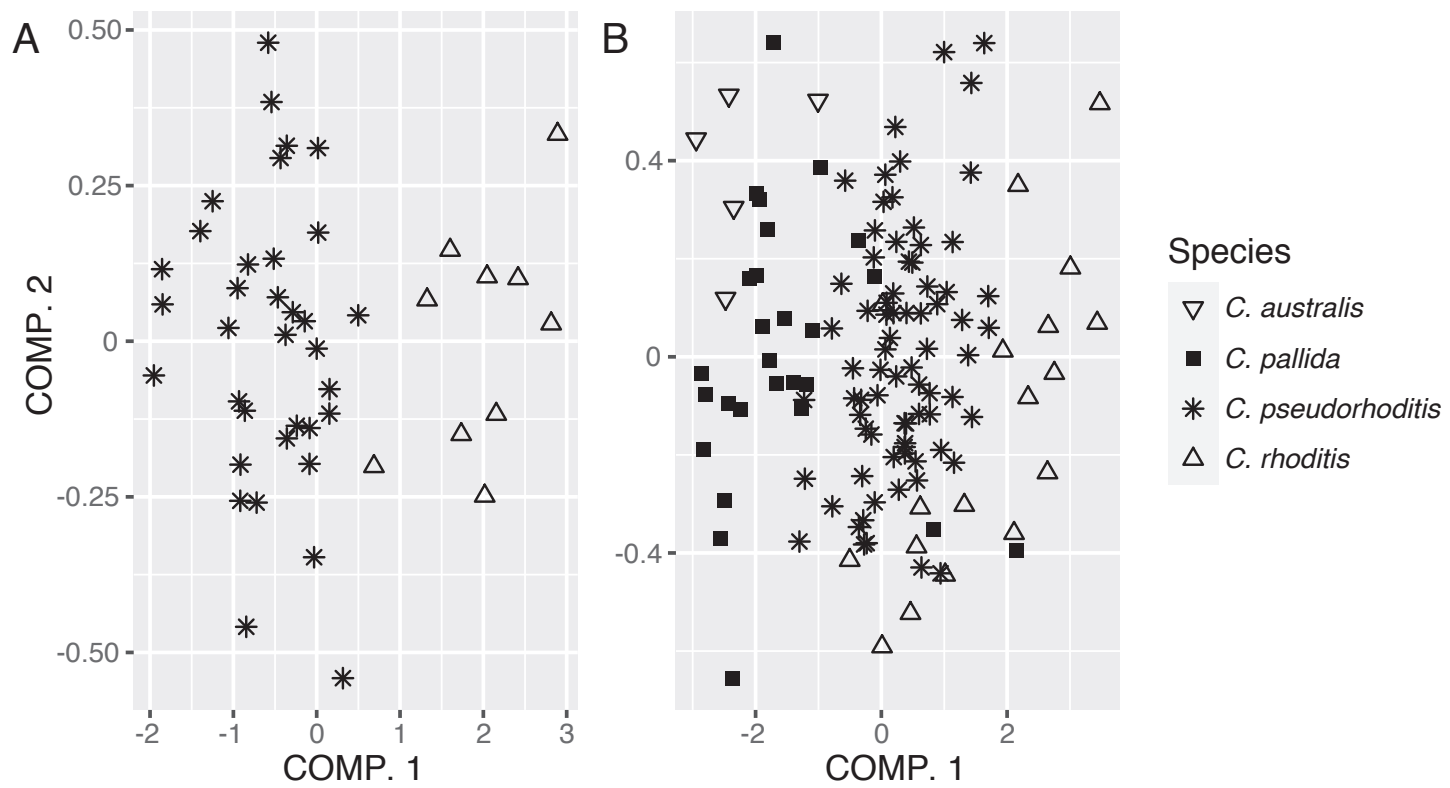

FIG. 19. Bivariate plots showing the first two principal components from analyses of 12 cranial variables in the Rhoditis Group. Panel A shows analysis of individuals sampled syntopically on Mt. Ambang (C. pseudorhoditis and C. rhoditis) and panel B shows individuals sampled across the island. Loadings and variance explained by component axes are presented in table 6 .

in univariate measures (fig. 12), C. elongata and C. quasielongata are much more difficult to distinguish, with average differences apparent only from large series of specimens identified with molecular data. Based on current sampling, geography can be a reliable predictor except that we found both species occurring on Mt. Dako and there remains a large sampling gap between Mt. Dako and the west-central area of endemism (i.e., the base of the northern peninsula; fig. 16). On Mt. Dako, we trapped C. elongata around 512 and $1600 \mathrm{~m}$, whereas we captured C. quasielongata only around $410 \mathrm{~m}$. We found C. quasielongata at higher elevations in other parts of the island and C. elongata at lower elevations at other localities (fig. 13; table 3). Thus, these two species may have a parapatric distribution partitioned by elevation on the one mountain where we found them together. Because these two species are so different morphologically from all the other species on the island, it would not be surprising if they fill similar functional niches and thus one excludes the other wherever they interact.
Despite the morphological similarities of Elongata Subgroup members, genetic evidence is clear that these three species are distinct from each other and do not form a clade. None of our phylogenetic analyses (mtDNA, nuclear exons, or UCEs) even hinted at a sister relationship between any of the three species. Our mitochondrial inferences placed Crocidura quasielongata as sister to C. caudicrassa (figs. 4, 5), but this seems unlikely because C. caudicrassa is sister to the phenotypically similar $C$. brevicauda in UCE trees (figs. 7, 8). In our UCE species tree, C. quasielongata is sister to a mix of Ordinary Group and Rhoditis Group species (fig. 7). Despite these mixed signals, the lack of basal resolution among species in our phylogenetic estimates leaves the door open to possible sister relationships among Elongata Subgroup members. The similarities in cranial proportions (e.g., relative widths; fig. 10) between C. elongata and $C$. quasielongata suggest either inherited similarity, or remarkable convergence. If any of these three species ever show a sister relationship in future analyses, we suspect it will be this pair. 


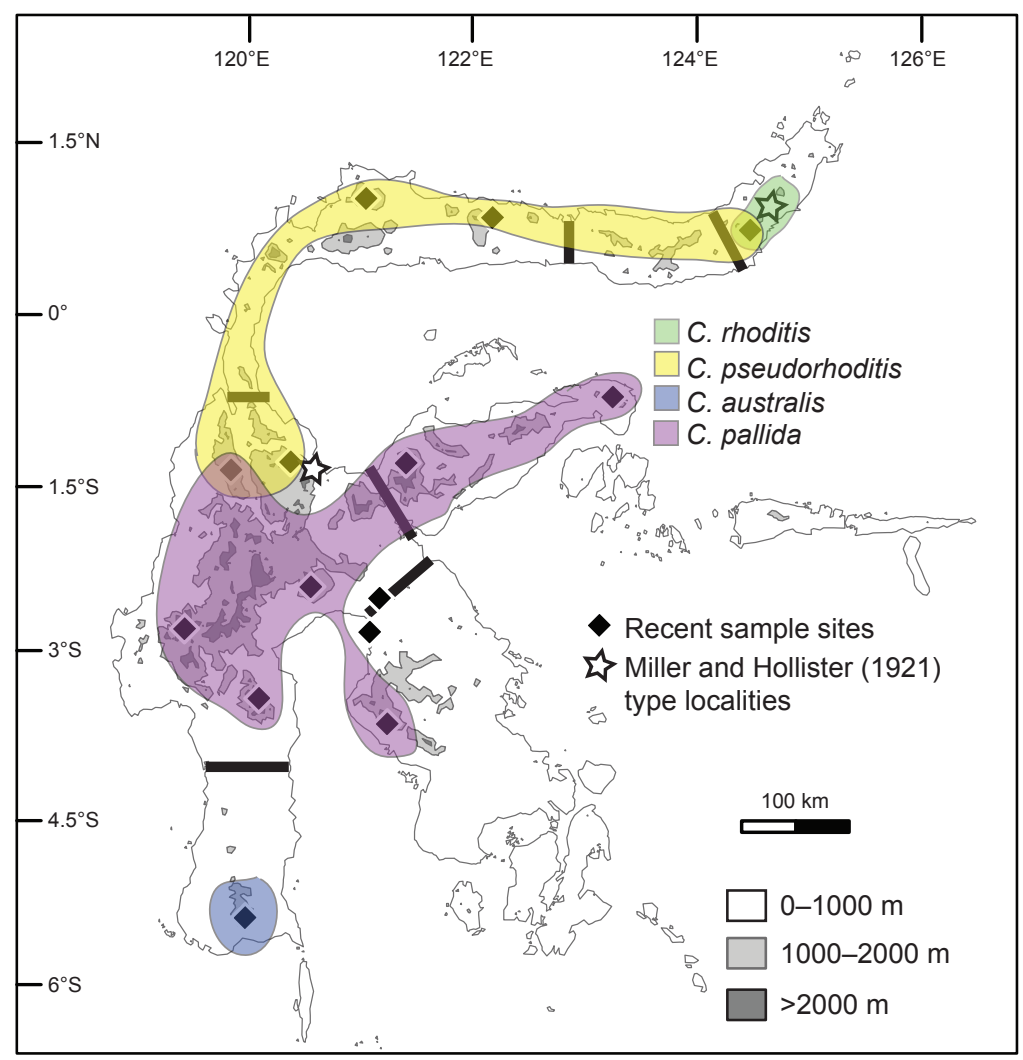

FIG. 20. Map of Sulawesi showing localities sampled for shrews. Colored areas enclose localities with known records of members of the Rhoditis Group of Sulawesi Crocidura.

Our BPP analyses compared the three members of the Elongata Subgroup, even though we did not infer them to form a clade in any of our phylogenetic analyses. The samples of each species were chosen to represent the full extent of our geographic sampling for the range of each species. Samples included comprise Crocidura elongata from three mountains $(\mathrm{N}=17), C$. microelongata from four mountains $(\mathrm{N}=24)$, and C. quasielongata from eight mountains $(\mathrm{N}=28)$. The matrix is $92 \%$ complete and all analyses supported all three species with 1.0 posterior probability.

Specimens examined: Mt. Balease (FMNH 210542-210559, 210596-210601), Mt. Bawakaraeng (NMV Z57377, Z57061), Mt. Dako (MZB 43001; LSUMZ 36935-36938), Mt. Katopasa (LSUMZ 39483, 39486-39490, 39492; NMV C40177, C40201, C40202, Z62311, Z61792), Mt.
Latimojong (MZB 40936, MVZ 237573), Mt. Mekongga (MWFB 8091, 8094, 8113, 8114, 8122, 8130, 13507, 13509, 13511), Salu Tiwo (FMNH 218548-218557, 218559-218561, 218563218579; MZB 38448, 38452), Mt. Tompotika (FMNH 213339-213342), Mt. Torompupu (LSUMZ 39418-39422, 39426-39430; MVZ 238107, 238108, NMV C40240, C40241, C40243-C40245, C40247, C40254, C40259C40262, C40281, C40282, C40288, C40293), Wasponda (FMNH 210560-210562).

\section{RHODITIS Group}

We place Crocidura rhoditis and three new species in the Rhoditis Group, combined here because of their relatively large body sizes (most individuals $>10 \mathrm{~g}$ ), tail lengths (50-80 


\section{TABLE 7}

Descriptive Statistics $^{\mathrm{a}}$ for Craniodental Measurements $(\mathrm{mm})$ for Species of the Rhoditis Group of Sulawesi Crocidura

\begin{tabular}{|c|c|c|c|c|}
\hline & C. australis & C. pallida & C. pseudorhoditis & C. rhoditis \\
\hline $\begin{array}{l}\text { Condyloincisive } \\
\text { length }\end{array}$ & $\begin{array}{c}20.69 \pm 0.541 \\
(20.19-21.61) 5\end{array}$ & $\begin{array}{c}21.12 \pm 0.872 \\
(20.03-23.91) 53\end{array}$ & $\begin{array}{c}22.37 \pm 0.503 \\
(21.16-23.57) 74\end{array}$ & $\begin{array}{c}23.25 \pm 0.856 \\
(21.61-24.59) 22\end{array}$ \\
\hline Braincase breadth & $\begin{array}{c}10 \pm 0.178 \\
(9.79-10.23) 5\end{array}$ & $\begin{array}{c}9.85 \pm 0.299 \\
(9.24-10.42) 53\end{array}$ & $\begin{array}{c}10.4 \pm 0.189 \\
(10.05-10.85) 76\end{array}$ & $\begin{array}{c}10.7 \pm 0.386 \\
(10.04-11.4) 20\end{array}$ \\
\hline Interorbital width & $\begin{array}{l}4.86 \pm 0.111 \\
(4.76-5.04) 5\end{array}$ & $\begin{array}{c}4.81 \pm 0.218 \\
(4.53-5.37) 53\end{array}$ & $\begin{array}{c}5.11 \pm 0.153 \\
(4.76-5.56) 76\end{array}$ & $\begin{array}{c}5.06 \pm 0.199 \\
(4.76-5.46) 22\end{array}$ \\
\hline Rostral length & $\begin{array}{l}8.36 \pm 0.29 \\
(8.0-8.79) 5\end{array}$ & $\begin{array}{c}8.6 \pm 0.373 \\
(8.22-9.99) 53\end{array}$ & $\begin{array}{c}9.3 \pm 0.278 \\
(8.67-9.86) 74\end{array}$ & $\begin{array}{c}9.89 \pm 0.349 \\
(9.27-10.4) 22\end{array}$ \\
\hline Postpalatal width & $\begin{array}{l}3.94 \pm 0.181 \\
(3.78-4.23) 5\end{array}$ & $\begin{array}{c}3.96 \pm 0.149 \\
(3.74-4.32) 53\end{array}$ & $\begin{array}{c}4.04 \pm 0.121 \\
(3.72-4.29) 76\end{array}$ & $\begin{array}{c}4.29 \pm 0.15 \\
(4.01-4.49) 22\end{array}$ \\
\hline Rostral width & $\begin{array}{l}2.97 \pm 0.097 \\
(2.84-3.09) 5\end{array}$ & $\begin{array}{l}2.99 \pm 0.203 \\
(2.6-3.29) 53\end{array}$ & $\begin{array}{c}3.16 \pm 0.164 \\
(2.74-3.76) 76\end{array}$ & $\begin{array}{c}3.32 \pm 0.215 \\
(2.82-3.68) 22\end{array}$ \\
\hline Postpalatal length & $\begin{array}{l}9.39 \pm 0.217 \\
(9.23-9.76) 5\end{array}$ & $\begin{array}{c}9.46 \pm 0.336 \\
(8.84-10.19) 53\end{array}$ & $\begin{array}{c}9.88 \pm 0.284 \\
(9.15-10.67) 76\end{array}$ & $\begin{array}{c}10.4 \pm 0.403 \\
(9.8-11.06) 22\end{array}$ \\
\hline $\begin{array}{l}\text { Condyle to glenoid } \\
\text { fossa }\end{array}$ & $\begin{array}{l}8.17 \pm 0.215 \\
(7.94-8.46) 5\end{array}$ & $\begin{array}{l}8.21 \pm 0.241 \\
(7.83-8.9) 53\end{array}$ & $\begin{array}{l}8.51 \pm 0.212 \\
(7.89-9.0) 76\end{array}$ & $\begin{array}{c}8.66 \pm 0.411 \\
(7.86-9.34) 22\end{array}$ \\
\hline $\begin{array}{l}\text { Upper toothrow } \\
\text { length }\end{array}$ & $\begin{array}{c}8.93 \pm 0.23 \\
(8.64-9.26) 5\end{array}$ & $\begin{array}{c}9.39 \pm 0.444 \\
(8.88-10.83) 53\end{array}$ & $\begin{array}{c}9.98 \pm 0.246 \\
(9.5-10.54) 74\end{array}$ & $\begin{array}{c}10.4 \pm 0.375 \\
(9.65-11.03) 22\end{array}$ \\
\hline P4 to M3 length & $\begin{array}{c}5.05 \pm 0.181 \\
(4.87-5.35) 5\end{array}$ & $\begin{array}{l}5.42 \pm 0.246 \\
(5.1-6.15) 53\end{array}$ & $\begin{array}{c}5.75 \pm 0.144 \\
(5.39-6.07) 76\end{array}$ & $\begin{array}{c}6.03 \pm 0.228 \\
(5.54-6.34) 22\end{array}$ \\
\hline M2 to M2 labial width & $\begin{array}{l}6.05 \pm 0.0434 \\
(5.97-6.08) 5\end{array}$ & $\begin{array}{c}6.37 \pm 0.3 \\
(6.03-7.21) 53\end{array}$ & $\begin{array}{c}6.9 \pm 0.171 \\
(6.44-7.38) 76\end{array}$ & $\begin{array}{c}7.3 \pm 0.193 \\
(6.91-7.61) 20\end{array}$ \\
\hline Palatal width & $\begin{array}{l}2.61 \pm 0.159 \\
(2.47-2.86) 5\end{array}$ & $\begin{array}{c}2.59 \pm 0.122 \\
(2.34-2.82) 53\end{array}$ & $\begin{array}{c}2.92 \pm 0.117 \\
(2.64-3.34) 76\end{array}$ & $\begin{array}{c}3.04 \pm 0.11 \\
(2.8-3.24) 20\end{array}$ \\
\hline
\end{tabular}

a The sample mean \pm one standard deviation, the observed range in parentheses, and the sample size.

$\mathrm{mm}$ ) shorter than head-and-body lengths (70$105 \mathrm{~mm}$ ), sparse tail bristles, pale pelages, and white or nearly white feet (fig. 9; table 2; supplementary data S7). Two of the taxa in this group are sister species in all of our phylogenetic analyses, while the other two appear more closely related to species in other morphological groupings. The two sister species (C. rhoditis and C. pseudorhoditis) differ primarily in size traits, but their syntopy on $\mathrm{Mt}$. Ambang and genetic differentiation strongly support our treating them as separate taxa. The other two species placed in this group are smaller than C. rhoditis and C. pseudorhoditis, but similar in size to each other. They are however allopatrically distributed, not closely related in any of our phylogenetic analyses, and differ slightly in relative braincase breadths (BB/CIL) and coloration. A principal components analysis of cranial measurements shows that all four species occupy somewhat overlapping morphometric space and differ primarily in size (fig. 19; table 6).

\section{Crocidura rhoditis Miller and Hollister, 1921}

Crocidura rhoditis Miller and Hollister, 1921:

102. Original description.

Holotype: USNM 217550, an adult male collected 3 August 1916 by H.C. Raven. Prepared as a skin and skull. External measurements from the type are $153 \mathrm{~mm} \times 70 \mathrm{~mm} \times 17 \mathrm{~mm}$; ear length and weight were not recorded. 


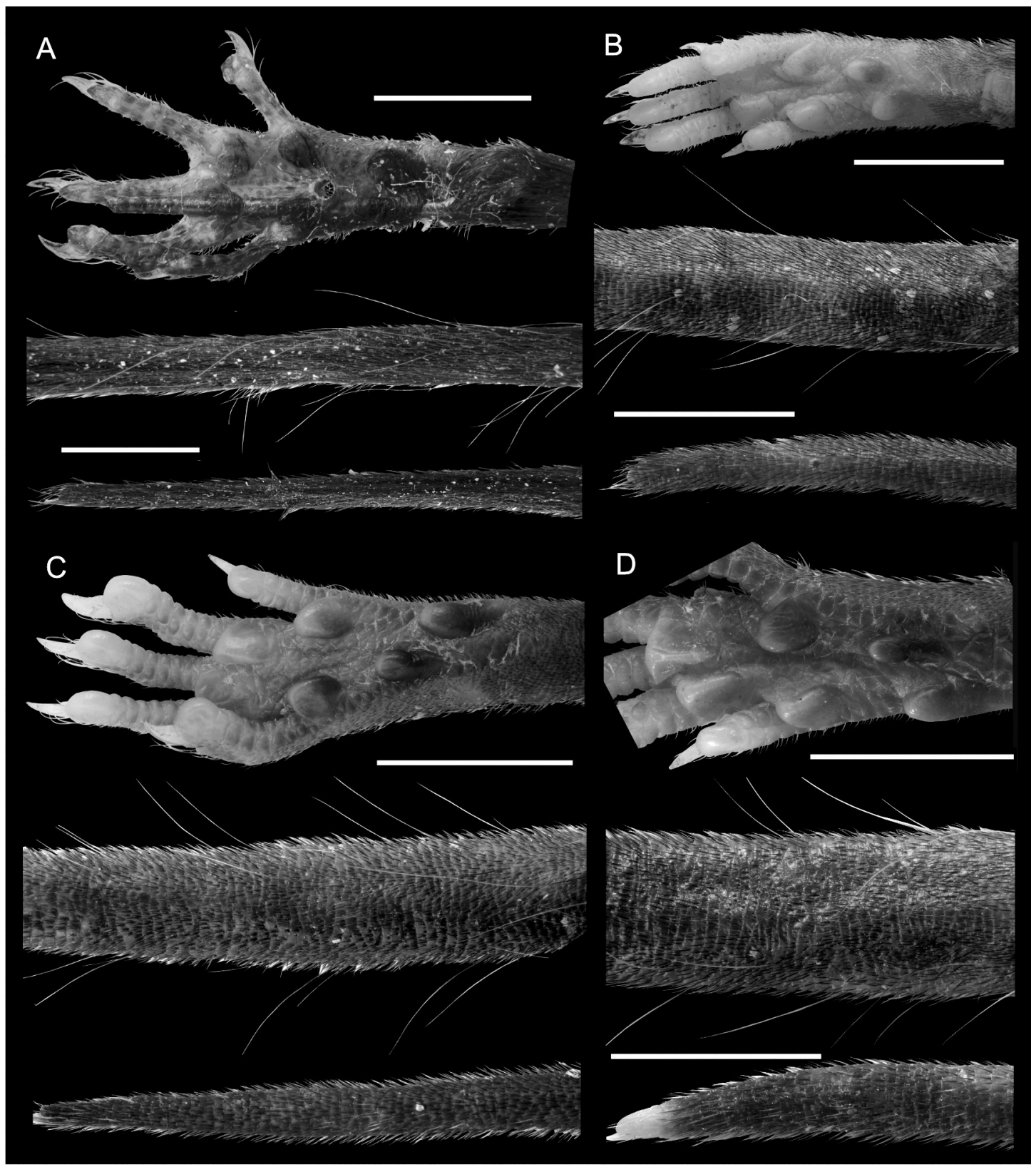

FIG. 21. Images showing the ventral surface of the hind foot and dorsal surfaces of the tail base (approximately $1 \mathrm{~cm}$ from rump) and tail tip from the four members of the Rhoditis Group: A, Crocidura australis, MVZ 237610 (right hind foot); B, C. pallida, FMNH 210582 (left hind foot); C, C. pseudorhoditis, LSUMZ 39040 (right hind foot); and D, C. rhoditis, LSUMZ 39296 (left hind foot). Scale bars represent $5 \mathrm{~mm}$. When two scale bars are present in a panel, the upper applies to the foot and the lower to the tail. 


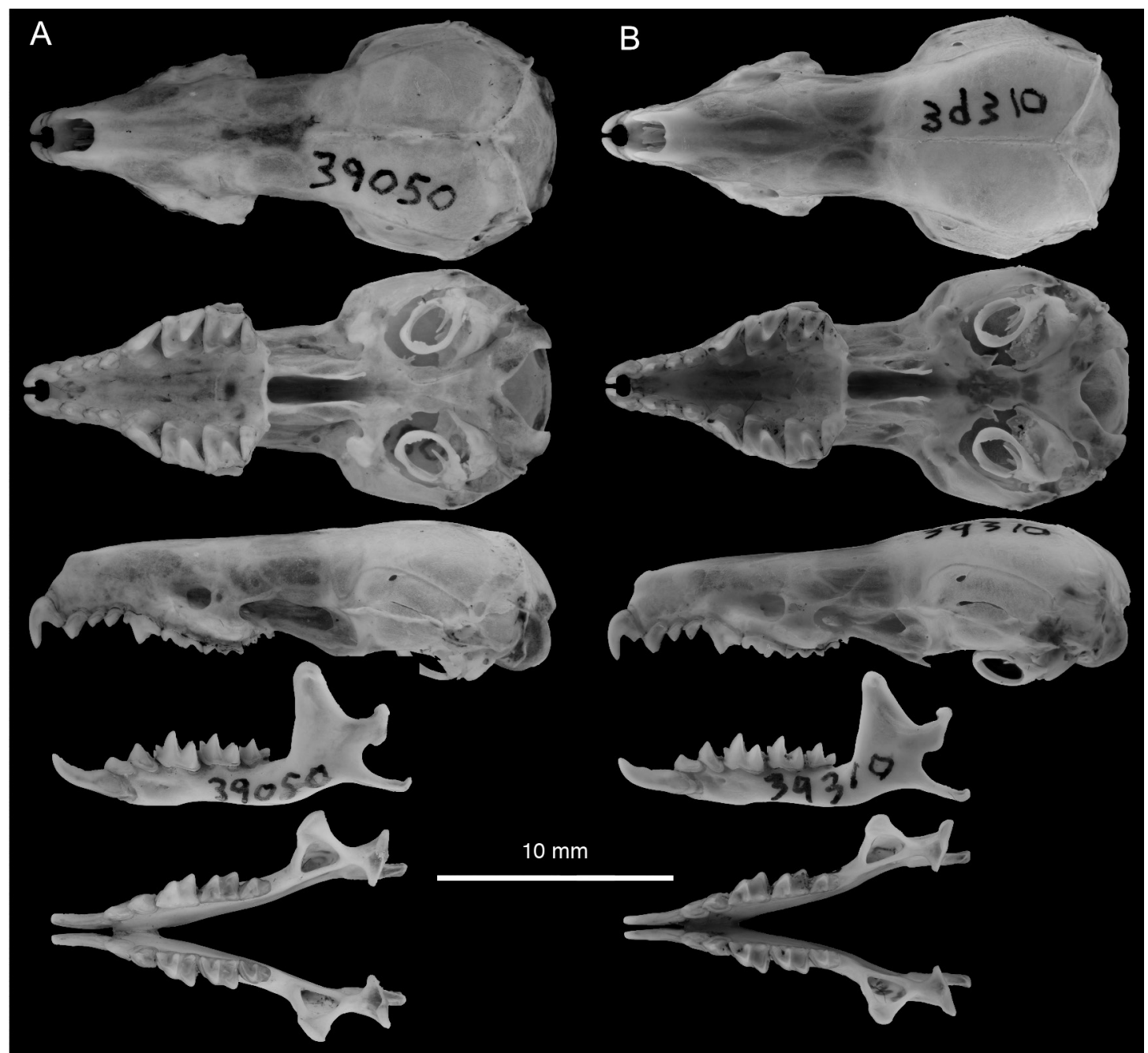

FIG. 22. Images showing dorsal, ventral, and lateral views of the skull and lateral and occlusal views of the dentary from two members of the Rhoditis Group: A, Crocidura rhoditis, LSUMZ 39050 and B, C. pseudorhoditis, LSUMZ 39310.

Type LOCAlity: "Temboan, northeastern Celebes" (Miller and Hollister, 1921: 102; fig. 20). Temboan is located at $0.979^{\circ} \mathrm{N}, 124.605^{\circ} \mathrm{E}, 650 \mathrm{~m}$ elevation in the Southeast Minahasa Regency, North Sulawesi Province, $6 \mathrm{~km}$ south of Kalait. See the gazetteer (appendix) for a detailed explanation of our interpretation of Raven's type locality.

GeOgraphic Distribution: Known only from the north-east area of endemism (Temboan and Mt. Ambang, North Sulawesi Province; fig. 20). Ruedi (1995) reported specimens from Mt.
Rorekatimbo, but mitochondrially (Ruedi et al., 1998), these match the sister taxon, Crocidura pseudorhoditis. Musser (1987) reported C. rhoditis from southwestern and central Sulawesi, but those records likely represent other taxa. We recorded this species between 1400 and $1700 \mathrm{~m}$ on Mt. Ambang (fig. 13; table 3). Specimens from Temboan are from low elevation habitat, probably around $650 \mathrm{~m}$.

Emended Diagnosis: Crocidura rhoditis is one of the larger shrews on Sulawesi (tables 2, 7), 
with a stocky build (fig. 17). Its overall color is paler than most species on the island, with a medium gray dorsal pelage and slightly paler venter, often with cinnamon highlights. The feet are pale, especially the forefeet. The digits of the hand are nearly white or pale pink colored, but those of the hind feet are off-white. The tail is slightly shorter than head-and-body length, thick at the base, and similar in color to the pelage. Tail bristles are present, but sparse along the proximal half of the tail (fig. 21D). The lips are paler than the surrounding pelage and the rhinarium is also generally pale, but the upper margins of each nostril have a dark rim. The skull of C. rhoditis is large, with the rostral length making up an unusually large proportion of skull length (RL/CIL; fig. 10). The braincase is wider than expected for a shrew of this size, but the interorbital region is narrow relative to the braincase breadth (figs. 10, 22A). The lambdoidal ridge is fairly prominent and the squamosalparietal suture also forms a ridge that extends horizontally from above the internal ear to above the glenoid fossa. This ridge is visible from a dorsal aspect and highlights the tapering shape of the anterior portion of the braincase margin. The angle at which the braincase narrows anteriorly is similar to the tapered shape of the interorbital region. The dentition is robust, occupying a large portion of the palate (fig. 22A).

Comparisons: Crocidura rhoditis is larger than all Sulawesi Crocidura except C. elongata, $C$. quasielongata, C. nigripes, and the two ThickTailed Group members, C. brevicauda and $C$. caudicrassa. Its mass-to-HBL ratio is greater than in all other species except C. caudicrassa (fig. 17) and its relative rostral length (RL/CIL) is greater than in all other species (fig. 10). The tail of $C$. rhoditis is much shorter absolutely and relative to body length than in members of the Long-Tailed Group, but longer absolutely than in all other species except $C$. pseudorhoditis (fig. 9). The dorsal pelage of $C$. rhoditis is similar in color to $C$. elongata, darker than C. quasielongata, and paler than $C$. nigripes. The feet of $C$. rhoditis are paler than those of most other species, with the excep- tions of C. lea (much smaller), C. pallida (smaller), C. elongata (longer tail), and $C$. quasielongata (longer tail). Within the Rhoditis Group, C. rhoditis is easily confused with $C$. pseudorhoditis, its apparent sister species, but it is larger in all dimensions than the other two members of the Rhoditis Group, C. australis and C. pallida. Both C. rhoditis and C. pseudorhoditis have a pale integument, but C. rhoditis is larger, slightly paler, and has a narrower thenar pad on the hind foot (fig. 21). Although differences in body length are modest (fig. 23), C. rhoditis is stockier than C. pseudorhoditis (fig. 17) and size differences are apparent in condyloincisive length and braincase breadth (fig. 23; table 7). In addition to the greater relative rostral length mentioned above, C. rhoditis also has a lesser relative interorbital width (IOW/CIL) than all other members of the Rhoditis Group (fig. 10). The narrowness of the interorbital region is also reflected in that it is lesser relative to braincase breadth (IOW/BB) in C. rhoditis compared to $C$. pseudorhoditis, whereas braincase breadth relative to skull length (BB/CIL) does not differ appreciably between the two species (figs. 10, 22). The skull of C. rhoditis has a prominent ridge at the suture of the squamosal and parietal bones. This ridge is present, but less conspicuous in C. pseudorhoditis. A PCA of cranial measurements largely separates these two taxa along the first axis, which represents size (fig. 19; table 6). The differences in size measurements between $C$. rhoditis and its sister species are somewhat more pronounced when only syntopically sampled specimens from Mt. Ambang are considered (fig. 23), perhaps indicating a role for character displacement in these species.

Comments: Mitochondrial sequences from the type series (USNM 217550, 217552, and 217554, and FMNH 43858) are all very similar to cytochrome $b$ sequences from our Mt. Ambang specimens, with maximum intraspecific Jukes-Cantor distances $\leq 0.011$ (fig. 4; supplementary data S5). Parapatrically distributed, phenotypically similar specimens with distinct mitochondrial sequences (mean Jukes-Cantor 

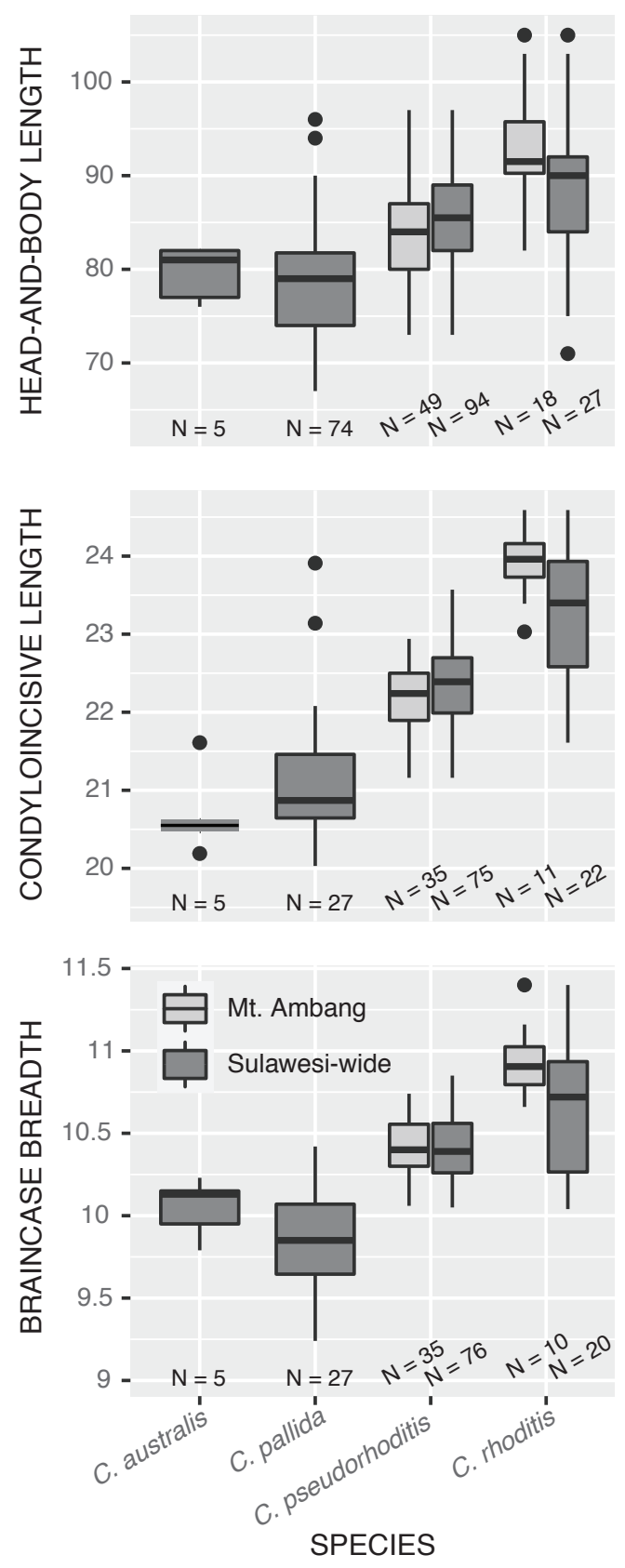

distance $=0.08)$ and smaller skulls are described below as Crocidura pseudorhoditis. Although the morphological differences between these two species are slight, the fairly large mitochondrial divergence, corroborating inferences from nuclear exons and UCEs (figs. 7, 8; supplementary data S6), and their syntopy on Mt. Ambang (fig. 20) strongly support their recognition as distinct taxa. See the account of C. pseudorhoditis for results of BPP analyses.

Specimens examined: Mt. Ambang (LSUMZ 39032, 39033, 39037, 39038, 39050, 3905339055, 39062, 39064, 39065, 39068, 39284, 39296, 39319, 39321; NMV C38022, C38031), Temboan (USNM 217550, 217552, 217554, FMNH 43858).

Crocidura pseudorhoditis, new species

LSID: urn:lsid:zoobank. org:act:980DF37A-D8F0-4DBF-877CA11C04F55FC1

Crocidura rhoditis Ruedi, 1995: 255.

Misidentification.

Crocidura rhoditis Esselstyn et al., 2019: 1716.

Misidentification.

Holotype: MZB 43002 (= LSUMZ 39310), an adult female, collected on 22 February 2016 by $\mathrm{H}$. Handika. The specimen was prepared as a cleaned skull and skeleton, study skin, stomach,

FIG. 23. Box plots summarizing head-and-body length, condyloincisive length, and braincase breadth measurements for members of the Rhoditis Group. Data from Crocidura rhoditis and C. pseudorhoditis are divided into two boxes. Dark gray boxes show all available measurements from across the species range while light gray boxes show only samples taken on Mt. Ambang, where the two species occur in syntopy. Note that the differences between these two species are greater on Mt. Ambang than they are for the islandwide sample. Plots show the median, 1st and 3 rd quartiles, the maximum value within $1.5 \times$ interquartile range (distance between 1st and 3rd quartiles; $\mathrm{IQR})$, the minimum value within $1.5 \times \mathrm{IQR}$, and outliers (black circles). Sample sizes are shown along the $\mathrm{x}$-axis. All measurements in $\mathrm{mm}$. 
intestine, and frozen tissues. External measurements from the type are $148 \mathrm{~mm} \times 70 \mathrm{~mm} \times 16$ $\mathrm{mm} \times 11 \mathrm{~mm}=11 \mathrm{~g}$. The voucher specimen and a tissue sample will be permanently curated at $M Z B$, with another tissue sample retained at LSUMZ.

TyPe LOCALity: Indonesia; Sulawesi Utara; Bolaang Mondgondow, Passi Timur; Insil; Mt. Ambang, near Lake Aliyah; $0.76385^{\circ} \mathrm{N}$, $124.41188^{\circ} \mathrm{E}, 1481 \mathrm{~m}$ elevation.

Етумоlogy: We combine "pseudo" with "rhoditis" because this species looks very similar to C. rhoditis.

Geographic Distribution: We recorded this species from the northwestern portion of the west-central area of endemism (Mts. Torompupu and Rorekatimbo, Central Sulawesi Province), and the north-west and north-east areas of endemism of the northern peninsula (fig. 20; Mt. Dako, Central Sulawesi Province; Mt. Buliohuto, Gorontalo Province; and Mt. Ambang, North Sulawesi Province). The absence of records from the north-central area of endemism is almost certainly due to the lack of general mammal surveys and specimens from this region. Both specimens we report from Mt. Rorekatimbo were trapped by Ruedi (1995); we did not collect any Crocidura pseudorhoditis on Mt. Rorekatimbo, despite working at similar elevations. We found this species at a range of elevations (fig. 13), the low on Mt. Buliohuto $(500 \mathrm{~m})$ and the high on Mt. Rorekatimbo (2200 m; table 3).

Diagnosis: Crocidura pseudorhoditis is a moderately large shrew (tables 2, 7) with a somewhat stocky build, medium gray, moderately bicolored pelage, a tail that is shorter than headand-body length, and dorsal foot surfaces that range from light gray-brown to pinkish white. The forefeet are paler than the hind feet and the claws are unpigmented and accompanied by a small tuft of white hairs on the hands, but on the hind feet, some of these hairs are dark. The tail is barely dorsoventrally bicolored proximally, but this transitions to a uniformly colored tail for the distal half of tail length. The tail has only sparse bristles over the proximal half of its length (fig. 21C). The lips are gray-brown, but the nose is distinctly paler. The palmar surface ranges from gray-brown to white, being palest on the digits. The color of the plantar surface also transitions from darker to paler colors toward the digits (fig. 21C), but all aspects are darker than on the forefeet. The skull is long (table 7) and broader at the braincase and interorbital region than expected given its length (figs. 10, 22B). The rostrum is long relative to the postpalatal portion of skull length, reflected in the RL/CIL (fig. 10). The suture between the squamosal and parietal bones is often open and in the shape of a sickle blade just below the opening of the sinus canal (fig. 22B). The maxillary bridge is wide.

Comparisons: Crocidura pseudorhoditis is smaller than C. rhoditis, C. elongata, and $C$. quasielongata, but larger than C. caudipilosa, Rhoditis Group members C. australis and C. pallida, all members of the Small-Bodied Group, and all members of the Ordinary Group except C. nigripes, which is similarly sized (fig. 19; tables 2, 7). The body of C. pseudorhoditis is more robust than those of $C$. microelongata, C. australis, and C. pallida, but less stocky than in C. rhoditis and C. caudicrassa (fig. 17). Crocidura pseudorhoditis is slightly darker (both pelage and feet) than C. rhoditis and tail bristles, though not abundant, are still more prevalent than in C. rhoditis (fig. 21). The thenar and hypothenar pads on the hind foot are both more rounded than the oblong pads of C. rhoditis (fig. 21). Crocidura pseudorhoditis is similar in pelage color to $C$. australis and C. pallida. Braincase breadth relative to skull length is greater than in many of the species with somewhat similar body sizes, including C. rhoditis, and all Elongata Subgroup and Thick-Tailed Group species. However, $C$. pallida is comparable in this regard, and C. australis has an even greater relative skull breadth no matter where it is measured (fig. 10). The braincase is a bit more angular in C. pseudorhoditis than in C. rhoditis, with the widest part of the cranium in C. pseudorhoditis forming an obtuse point (fig. 22). However, the angularity of the braincase does not reach the degree seen in 
C. nigripes. The ratio of rostral length to skull length is large in C. pseudorhoditis and exceeded only by that of $C$. rhoditis; the other Rhoditis Group members have comparatively short relative rostral lengths (RL/CIL) and outside the Rhoditis Group, C. nigripes and the two ThickTailed species (defined below) are comparable (fig. 10). Crocidura pseudorhoditis is larger in head-and-body length, foot length, and all cranial dimensions than C. australis and C. pallida (fig. 19; tables 2, 7). The slight difference in size between C. pseudorhoditis and C. rhoditis appears to be enhanced where the two species cooccur (Mt. Ambang; fig. 20), especially condyloincisive length (fig. 23). A principal components analysis of 12 cranial measurements that only included these two species readily separated them on the first axis, which represents size (fig. 19; table 6).

Comments: While Crocidura pseudorhoditis is on average smaller than $C$. rhoditis, the two species are easily confused phenotypically and they occur in sympatry in the north-east area of endemism (fig. 20; table 3). The large mitochondrial distances between C. rhoditis and C. pseudorhoditis, along with the slight but consistent differences in size, which appear to be enhanced where they are syntopic (fig. 23), strongly suggest these are independently evolving populations. Our BPP analyses tested species limits with an alignment that contains 15 C. rhoditis and 58 C. pseudorhoditis and is $96 \%$ complete. The analyses supported these species' distinction with 1.0 posterior probability with all prior combinations in all runs.

One of the few cases of clarity from our phylogenetic analyses is the consistent and well-supported sister relationship between Crocidura rhoditis and C. pseudorhoditis (figs. 4, 5, 7, 8; supplementary data S6). Given their phenotypic similarity, this makes sense from a morphological perspective. In our UCE species tree, we found these two species sister to C. elongata (fig. 7).

SPECIMENS EXAMINED: Mt. Ambang (LSUMZ 39030, 39031, 39034-39036, 39039-39043, 39045 , 39048, 39049, 39051, 39052, 39056, 39059, 39060, 39063, 39066, 39067, 39278, 39280-39283, 39293, 39297, 39298, 39300-
39309, 39311-39314, 39316, 39317, 39322; MZB 43002; NMV C37985, C37992, C37996, C38017), Mt. Buliohuto (LSUMZ 38275-38278, 38284; NMV C37793), Mt. Dako (LSUMZ 36973, 36978, 36979, 36986, 36990, 36991, 36993, 36995, $36998,37000,37002,37005,37007,37008$, 37011-37016, 37033, 37034; MZB 38564-38566; NMV C37252, C37254, C37264, C37268, C37292, C37297, 37308, 37315, C37328, 37329, C37363, C37367), Mt. Torompupu (NMV C40308), Mt. Rorekatimbo (RMNH 38409 (= IZEA 4406), IZEA 4407).

\section{Crocidura australis, new species}

$$
\begin{gathered}
\text { LSID: urn:lsid:zoobank. } \\
\text { org:act:3ABC433E-7C35-47DD-B52B- } \\
\text { D33CC37F8F62 }
\end{gathered}
$$

Holotype: MZB 43003 (= MVZ 237610), an adult of unknown sex collected by K.C. Rowe on 30 October 2016. The specimen was preserved as a study skin, cleaned skull (fig. 24) and skeleton, and frozen tissues. External measurements from the holotype are: $141 \mathrm{~mm} \times 65 \mathrm{~mm} \times 16 \mathrm{~mm} \times$ $11 \mathrm{~mm}=9.8 \mathrm{~g}$. The voucher specimen and a tissue sample will be permanently curated at MZB, with another tissue sample retained at MVZ.

Type locality: Indonesia, Sulawesi Selatan, Sinjai, Sinjai Barat, Gunung Perak Village, Mt. Bawakaraeng; $5.308463^{\circ} \mathrm{S}, 119.948661^{\circ} \mathrm{E}, 2390-$ 2550 m elevation.

Eтymology: We use the Latin for "southern," as this species is the most southern member of the Rhoditis Group.

Geographic Distribution: This species is known only from the south-west area of endemism and was only collected from Mt. Bawakaraeng, South Sulawesi Province (fig. 20) on traplines placed around 1660-2040 and 23902550 m elevation (fig. 13; table 3).

DiAgnosis: Crocidura australis is a mediumsized shrew (tables 2, 7) with a thick, mediumbrown dorsal pelage and slightly paler venter. Hairs of the middorsum are 6-7 $\mathrm{mm}$ long. The color of the tail matches that of the dorsal pelage, 
but the feet are paler than the surrounding fur, particularly on the digits (fig. 21A). The tail is slightly shorter than the head-and-body length and not distinctly bicolored. Applied hairs on the tail are inconspicuous and bristles are sparsely distributed along the proximal half of tail length. The claws are translucent and surrounded by small tufts of white hairs. On the hind foot, the claws are long and the tufts more prominent than on the forefoot. The foot pads are more darkly pigmented than the surrounding plantar and palmar surfaces, but the difference is greater on the hind foot than on the forefoot. The external ears, though not small, are indistinct from the surrounding fur, due to the matching color, length, and density of the pelage. The mystacial vibrissae are relatively short, and mostly unpigmented. A few pigmented vibrissae are found posterior to the shorter, unpigmented vibrissae. Those with pigment are pigmented only proximally, typically for no more than half of their length. The braincase is wide relative to skull length (fig. 10), high, and somewhat angular, with a lateral point in the mastoid region and relatively prominent lambdoidal ridges (fig. 24A). The ridge formed by the parietal-squamosal suture is indistinct. The interorbital region is also wide relative to skull length (fig. 10), but it is strongly tapered. Despite the strongly tapered interorbital region, the maxillary process is not prominent when viewed from the dorsal aspect. The dentition is somewhat prominent relative to palatal width (fig. 24A).

COMPARISONS: Crocidura australis is substantially larger in body size than all members of the Small-Bodied Group and somewhat larger than C. musseri, C. ordinaria, and C. solita of the Ordinary Group (fig. 9). It is smaller than members of the Thick-Tailed Group and Elongata Subgroup. Relative to members of the Rhoditis Group, it is smaller than C. rhoditis and C. pseudorhoditis in all dimensions except ear length, but similar in size to C. pallida (figs. 19, 23; tables 2, 7). In color, C. australis is darker than all other members of the Rhoditis Group, particularly on the feet. Crocidura ordinaria and
C. solita of the Ordinary Group are similar in color and only a little smaller, but their braincases are more rounded than in C. australis. The somewhat angular shape of the braincase, however, is nevertheless more rounded than in $C$. pseudorhoditis. The great relative breadth of the braincase (BB/CIL) in C. australis distinguishes it from all other species except $C$. baletei (much smaller and darker), C. levicula (much smaller and darker), C. musseri (smaller and darker), and C. ordinaria (smaller). In comparison to other Rhoditis Group species, C. australis is substantially smaller in condyloincisive length and braincase breadth than the much larger skull of $C$. rhoditis and the somewhat larger skull of C. pseudorhoditis (fig. 19). Condyloincisive length is somewhat smaller than in $C$. pallida, although these two species are quite similar in head-and-body length. The interorbital region and labial breadth at M2 are also narrower than noted in C. rhoditis or C. pseudorhoditis (table 7). Relative rostral length (RL/ CIL) in C. australis is less than in any other member of the Rhoditis Group, though only slightly so compared to C. pallida.

Comments: Published references to C. rhoditis from the southwestern peninsula (Musser, 1987; Ruedi, 1995) probably refer to this species. Crocidura australis was consistently inferred as sister to the clade containing C. ordinaria and C. solita of the Ordinary Group with varying degrees of support (figs. 4, 5, 7, 8; supplementary data 6).

Specimens eXAmined: Mt. Bawakaraeng (MZB 40991, 41027, 43003; NMV Z56801, NMV Z57200, NMV Z57223).

\section{Crocidura pallida, new species}

$$
\begin{aligned}
& \text { LSID: urn:lsid:zoobank. } \\
& \text { org:act:1249AC44-0D01-4060-B5FD- } \\
& \text { 3000D9C4D29D }
\end{aligned}
$$

Holotype: MZB 43004 (= FMNH 210607), an adult female collected by J.A. Esselstyn on 18 October 2010. The specimen consists of a 


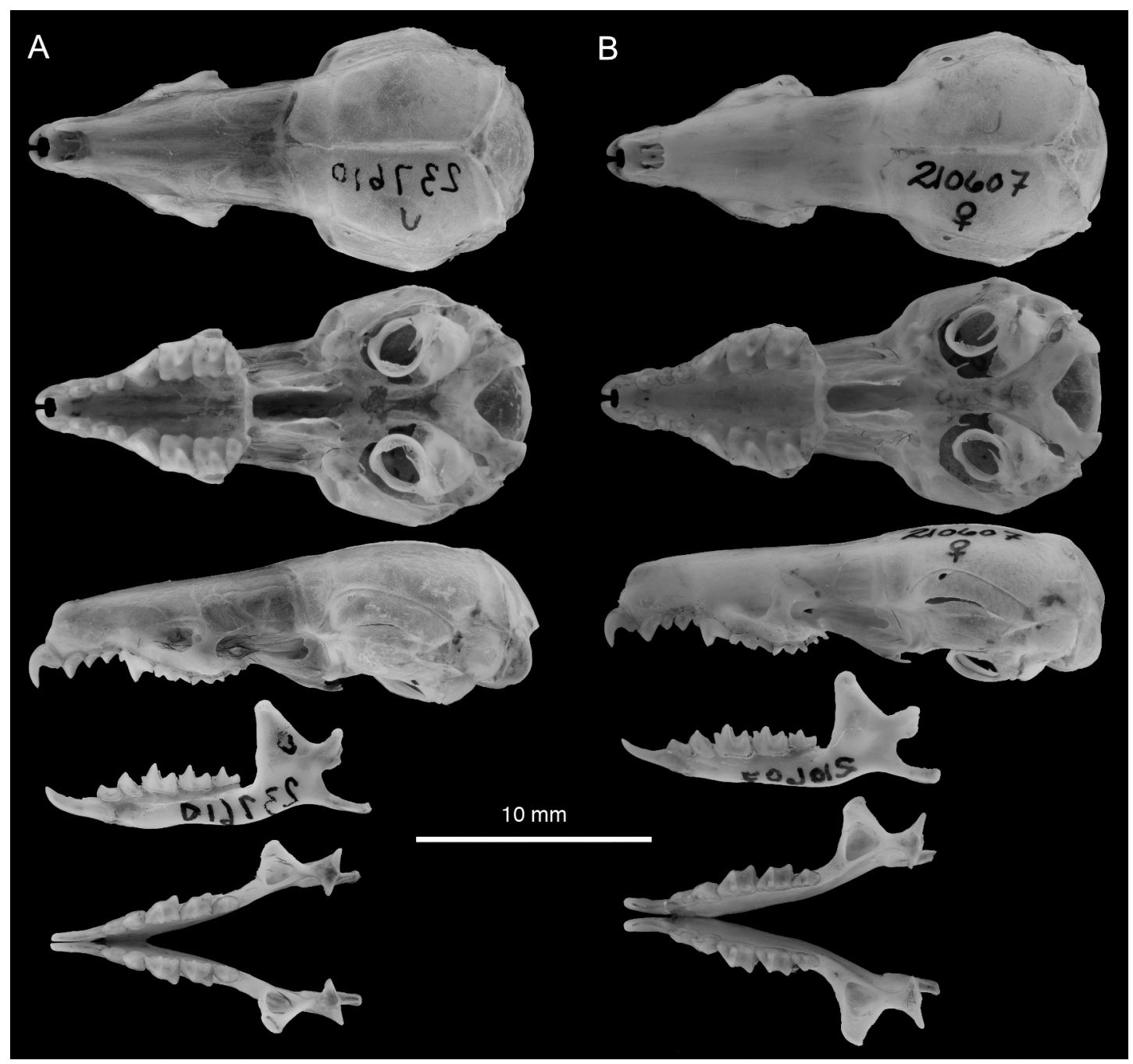

FIG. 24. Images showing dorsal, ventral, and lateral views of the skull and lateral and occlusal views of the dentary of two members of the Rhoditis Group: A, Crocidura australis, MVZ 237610 and B, C. pallida, FMNH 210607.

dried skin, cleaned skull (fig. 24B) and skeleton, and tissue sample. It carried one embryo measuring $18 \mathrm{~mm}$ in crown-rump length. External measurements from the holotype are: $140 \mathrm{~mm} \times 62 \mathrm{~mm} \times 15 \mathrm{~mm} \times 8 \mathrm{~mm}=11 \mathrm{~g}$. The voucher specimen and a tissue sample will be permanently curated at MZB, with another tissue sample retained at FMNH.

Type Locality: Indonesia, Sulawesi Selatan, Luwu Utara, Sukamaju, Mt. Balease; $2.4995^{\circ} \mathrm{S}$, $120.4874^{\circ} \mathrm{E}, 900 \mathrm{~m}$ elevation.
Eтymology: We use the Latin pallida to highlight the pale color of the feet of this species.

GEOGRAPHIC DISTRIBUtion: Recorded from the west-central (Mt. Gandang Dewata, West Sulawesi Province; Mts.Torompupu and Balease, Central Sulawesi Province; Mt. Latimojong and Rindingallo, South Sulawesi Province), east-central (Mts. Katopasa and Tompotika, Central Sulawesi Province), and south-east areas of endemism (Mt. Mekongga, Southeast Sulawesi Province; fig. 20). 
Across these areas, we found this species over a broad elevational range, from approximately 100 to over $2500 \mathrm{~m}$ (fig. 13; table 3).

Diagnosis: Crocidura pallida is a moderately sized shrew (figs. 9, 23; tables 2,7 ) with very pale feet (fig. 21B) and a somewhat pale ventral side of the tail. The tail is shorter than the head-andbody length (fig. 9; table 2). The dorsal pelage is gray to gray-brown while the ventral pelage is pale gray. The pinna and the dorsal side of the tail match the dorsal pelage, but the dorsal side of the feet are distinctly paler. The dorsal surface of the hand is nearly white, but some pigment is present near the wrist. The hind feet show a similar pattern but are modestly darker. Ventrally, the feet are also pale, especially on the digits, which are usually white. The darkest parts of the hind foot are usually the thenar and hypothenar pads (fig. 21B). The pads of the forefeet are rarely pigmented. Tail bristles are sparse to nearly absent (fig. 21B), extending along no more than the proximal third of the tail length. The tail varies from uniformly colored to moderately bicolored with a paler ventral side. The skull is typical of Crocidura of this size. The braincase is generally rounded, but a subtle lateral point is evident at the mastoid region when viewed from a dorsal aspect (fig. 24B). The braincase is somewhat inflated dorsoventrally, and it is wide relative to skull length (fig. 24B), as are the interorbital region and rostrum (fig. 10; table 7 ). The wide interorbital region gives the maxillary process a relatively weak appearance. In some individuals, the nasal passage is particularly inflated and laterally bulging, further obscuring the maxillary process. The rostrum is somewhat long, relative to skull length (fig. 10). The maxillary bridge is usually narrow, with an anteriorly placed lacrimal foramen. The posterior portion of the hard palate is narrow, sandwiched between broad molars.

COMPARIsons: Crocidura pallida is smaller than C. rhoditis, C. pseudorhoditis, C. nigripes, and members of the Elongata Subgroup and Thick-Tailed Group. It is considerably larger than all members of the Small-Bodied Group and somewhat larger than all members the Ordinary
Group except $C$. nigripes. In absolute terms and relative to head-and-body length, the tail length is comparable to members of the Ordinary, Thick-Tailed, and Rhoditis groups, but substantially shorter than in all members of the LongTailed Group and considerably longer than in any member of the Small-Bodied Group (fig. 9). Outside of the Rhoditis Group, most species have much darker feet than C. pallida. These include C. caudipilosa and C. microelongata of the Long-Tailed Group, C. normalis, C. musseri, and C. nigripes of the Ordinary Group, both Thick-Tailed Group members, and all members of the Small-Bodied Group except C. lea. Within the Rhoditis Group, C. pallida is smaller in absolute measurements (fig. 9) and more delicately built than C. rhoditis and C. pseudorhoditis (fig. 17 ); it is paler with a relatively narrower braincase and interorbital region than the otherwise similarly proportioned C. australis. Rostral length makes up a smaller proportion of skull length (RL/CIL) in C. pallida than in either $C$. rhoditis or C. pseudorhoditis, but this trait is comparable in C. australis (fig. 10).

Comments: Substantial mitochondrial genetic divergence is evident between populations from Mt. Katopasa, Mt. Tompotika, and the remaining sites (up to 0.089 Jukes-Cantor distance; fig. 4; supplementary data S3). However, these populations form a cohesive set of morphological specimens, form a clade in our phylogenetic analyses of nuclear genes (figs. 7, 8; supplementary data S6), and all of the mitochondrial variation is partitioned geographically (i.e., no sympatry between divergent mitochondrial clades). We therefore did not divide them further.

We identified a single specimen of Crocidura pallida from Mt. Latimojong (MVZ 237618), a locality where C. solita is abundant. Although $C$. pallida is slightly larger, these two can be difficult to distinguish. As such, it is possible that this specimen is a slightly large individual of C. solita with mtDNA introgressed from C. pallida. Unfortunately, we did not obtain nuclear loci (exons or UCEs) from this specimen and there- 
fore cannot test for introgression. Contamination of this cytochrome $b$ sequence is unlikely because it is unique in our alignment. We favor the hypothesis that MVZ 237618 is C. pallida because its cytochrome $b$ sequence differs slightly from C. pallida sequences from nearby localities (i.e., Mts. Gandang Dewata and Balease) and phenotypically, it is nearer the averages for $C$. pallida than C. solita.

Phylogenetic estimates were not consistent regarding the relationships of Crocidura pallida. Our mitochondrial gene trees put it as sister to a clade of Small-Bodied species, C. caudipilosa, and $C$. normalis (figs. 4, 5). However, our nuclearbased inferences placed C. pallida as part of the large basal polytomy (figs. 7, 8; supplementary data S6).

Specimens examined: Mt. Balease (FMNH 210580-210592, 210608, 210609, MZB 43004), Mt. Gandang Dewata (FMNH 218687-218702, 218989; MZB 34872, 34886, 34888, 34889), Mt. Katopasa (LSUMZ 39527, 39529-39538; MVZ 238115-238118; NMV C40187, C40192, C40199, C40206, C40214, C40217, C40307, Z56723, Z62366, Z61754, Z62414), Mt. Latimojong (MVZ 237618), Mt. Mekongga (MWFB 8059, $8115,8125,8139,8150,8161,8162,8195,8196$, 8438, 8439), Rindingallo, Tana Toraja (MSB 93256), Mt. Tompotika (FMNH 213366-213369), Mt. Torompupu (NMV C40307).

\section{SMALl-Bodied Group}

We place the six smallest species into the Small-Bodied Group. All members have average head-and-body lengths between 61 and $65 \mathrm{~mm}$ and hind-foot lengths $<13 \mathrm{~mm}$ (supplementary data S7). Two of these taxa, Crocidura lea and C. levicula, were described by Miller and Hollister (1921), while the remaining four species are new taxa described below. Three of the six species are endemic to portions of the northern peninsula. No phylogenetic analyses suggested all six species form a clade, but two probable sister relationships within this group do suggest a role for small-scale geographic isolation in speciation. Every locality we surveyed holds at least one member of this species group and three localities had two members, but no localities had more than two species (fig. 25). Bivariate plots of raw cranial measurements and results from a principal components analysis of cranial measurements show that these species largely, but incompletely, occupy distinct morphometric space (fig. 26). In this section, we first document the three species from the northern peninsula and then we diagnose taxa from the rest of the island.

Crocidura lea Miller and Hollister, 1921

Crocidura lea Miller and Hollister, 1921: 102.

Original description.

Crocidura "pale lea" Esselstyn et al., 2019: 1715.

Informal name.

Holotype: USNM 217553, an adult male collected by H.C. Raven on 3 August 1916. Prepared as a skin and skull. External measurements from the holotype are $111 \mathrm{~mm} \times 51 \mathrm{~mm} \times 14 \mathrm{~mm}$; ear length and weight were not recorded.

TyPe locality: "Temboan, northeastern Celebes" (Miller and Hollister, 1921: 102; fig. 25). Temboan is located at $0.979^{\circ} \mathrm{N}, 124.605^{\circ} \mathrm{E}, 650$ $\mathrm{m}$ elevation in the Southeast Minahasa Regency, North Sulawesi Province, $6 \mathrm{~km}$ south of Kalait. See the gazetteer (appendix) for details of our interpretation of Raven's field notes.

Geographic Distribution: Probably endemic to the northern peninsula. We identified specimens of this species from the northwest area of endemism (Mt. Dako, Central Sulawesi Province and Mt. Buliohuto, Gorontalo Province) and the type locality is in the north-east area of endemism (Temboan, North Sulawesi Province). We did not find this species on Mt. Ambang (north-east area of endemism), where its ecological position is apparently held by another tiny, but not closely related shrew, Crocidura tenebrosa (fig. 25). We recorded $C$. lea at both high and low elevations on both Mts. Dako (512 and $1600 \mathrm{~m}$ ) and Buliohuto (400- 


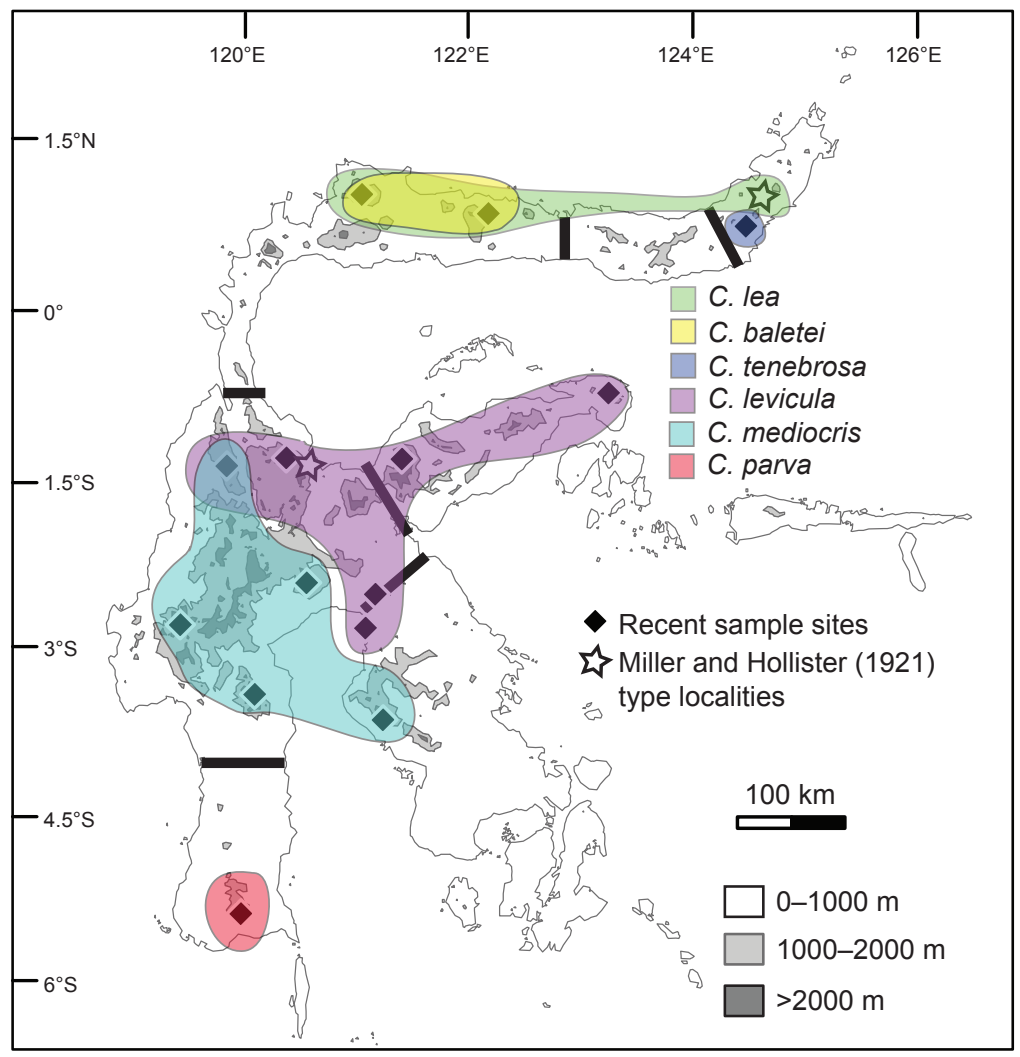

FIG. 25. Map of Sulawesi showing localities sampled for shrews. Colored areas enclose localities with known records of members of the Small-Bodied Group of Sulawesi Crocidura.

600 and $1200 \mathrm{~m}$; table 3). We did not collect any specimens of this species at our $410 \mathrm{~m}$ site on Mt. Dako. The type locality (Temboan) is at roughly $650 \mathrm{~m}$.

Emended Diagnosis: Crocidura lea is a very small shrew (tables 2, 8) with a brown dorsal pelage, gray-brown ventral pelage, and pale feet. The pinnae are prominent and slightly paler than the surrounding fur, especially at the lobe. The mystacial vibrissae are generally unpigmented, but a few, typically the longer ones, are brown or black proximally. Dorsally, foot color transitions from gray-brown at the wrist and ankle to pale pinkish white on the digits (fig. 27B). The claws are small, unpigmented, and sometimes lack the surrounding tuft of white hairs present in many other species. Ventrally, the forefeet mostly lack pigment, but the hind feet are darker. In the hind feet, color transitions from brown posteriorly from the heel, and to a lesser extent laterally, to white at the digits. However, pigment is concentrated in the pads, particularly around the base of the thenar, hypothenar, and in some cases the 4th (lateralmost) interdigital pad (fig. 27B). The tail is shorter than head-and-body length, sometimes dorsoventrally bicolored, and thinly covered with very small, dark brown applied hairs. A few sparse bristles are present along the proximal three-fourths of the tail (fig. 27B). The skull is short, narrow, and somewhat rounded in overall shape (fig. 28B). Relative to body size, the skull is slightly longer than expected, and relative to skull length, the braincase (BB/CIL) is especially narrow, but the interorbital region is not unusual in its relative width (IOW/CIL; fig. 10). The maxillary process is weak (fig. 28B). The I3 

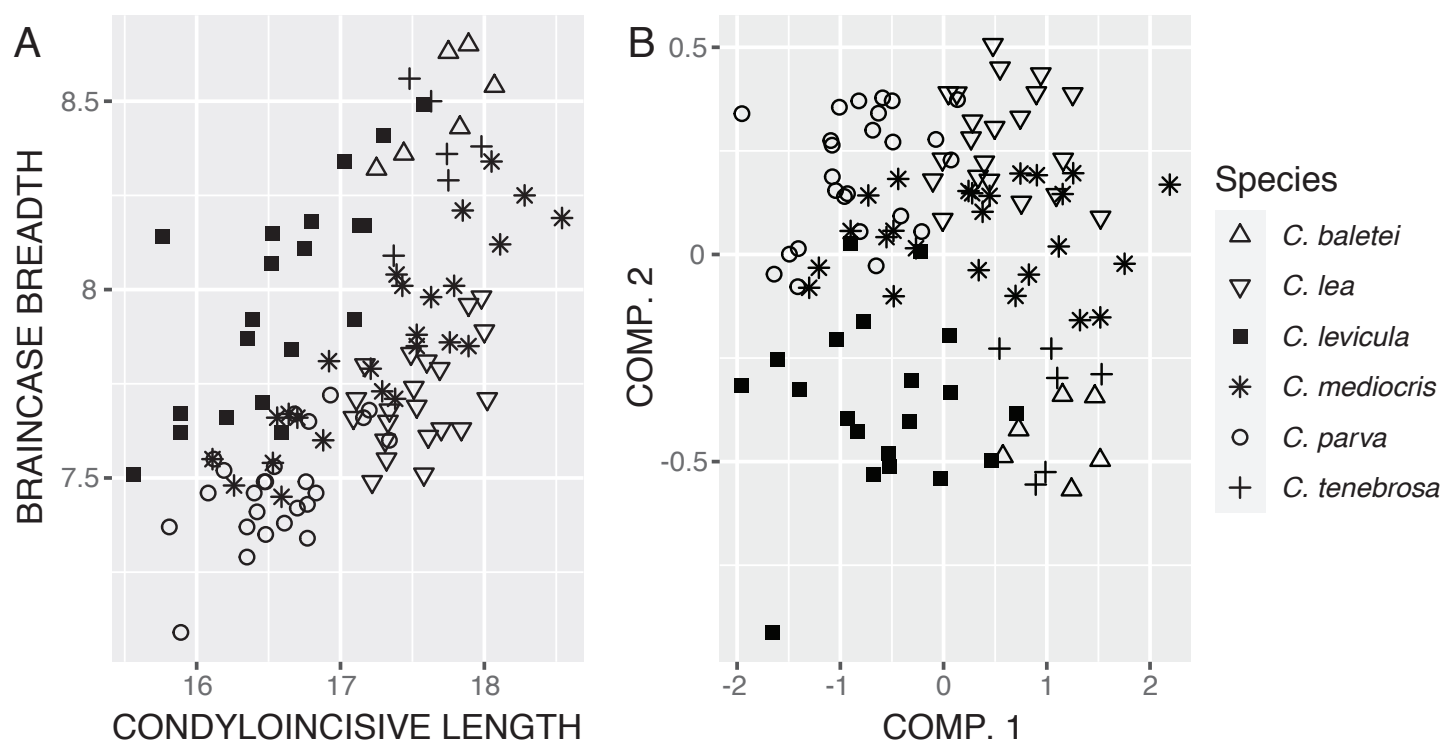

FIG. 26. Bivariate plots showing A, variation in the condyloincisive length and braincase breadth and $\mathbf{B}$, the first two axes from a principal components analysis of 12 cranial measurements among all members of the Small-Bodied Group. Loadings and variance explained are given in table 9.

(U2) is smaller than the C (U3). The parastyle of P4 is modest.

Comparisons: Crocidura lea is much smaller than all Sulawesi Crocidura outside of the SmallBodied Group (fig. 9). Among the Small-Bodied species, only C. baletei and C. tenebrosa are known from the northern peninsula. Crocidura levicula, C. parva, and C. mediocris are apparently restricted to the central core and eastern and southwestern peninsulas (fig. 25). We therefore focus our comparisons on the cooccurring, northern peninsula species. However, first we note that the allopatric $C$. levicula has a broader skull (figs. 10, 26; tables 8, 9), shorter tail, shorter hind feet, and more tail bristles than does C. lea (figs. 27, 29; table 2). Among the Small-Bodied shrews of the northern peninsula, C. lea has a slightly paler and more strongly dorsoventrally bicolored pelage than C. baletei or C. tenebrosa. Both of the latter species are relatively uniform in color, C. baletei being medium brown and $C$. tenebrosa dark brown. Crocidura lea also has paler skin wherever it is exposed than either $C$. baletei (somewhat darker) or C. tenebrosa (much darker). Dorsally, the feet of both C. baletei and C. tenebrosa are uniformly dark, whereas the foot color transitions posteriorly from brown at the heel to white or pink at the digits in C. lea (fig. 27). Similarly, the tails of both C. baletei and $C$. tenebrosa are not obviously bicolored, and both are darker. Tail bristles are present on approximately three-fourths of the tail length in all three species, but they are much more abundant and longer on the tails of C. baletei and C. tenebrosa than in C. lea (fig. 27). Applied hairs on the tail are also much more visible in the two new species than in C. lea. Tail length in C. lea is greater, on average, than in C. baletei, and substantially so compared to C. tenebrosa (fig. 9; table 2). The skulls of $C$. lea are comparable in length, but significantly narrower at the braincase, interorbital region, maxillary process, and to a lesser extent at the rostrum than those of $C$. baletei and $C$. tenebrosa (figs. 10, 30; table 8). Crocidura lea occupies distinct morphometric space from the other northern peninsula endemics in bivariate plots of skull length and width and the first two principal components from an analysis of $12 \mathrm{cra}$ - 

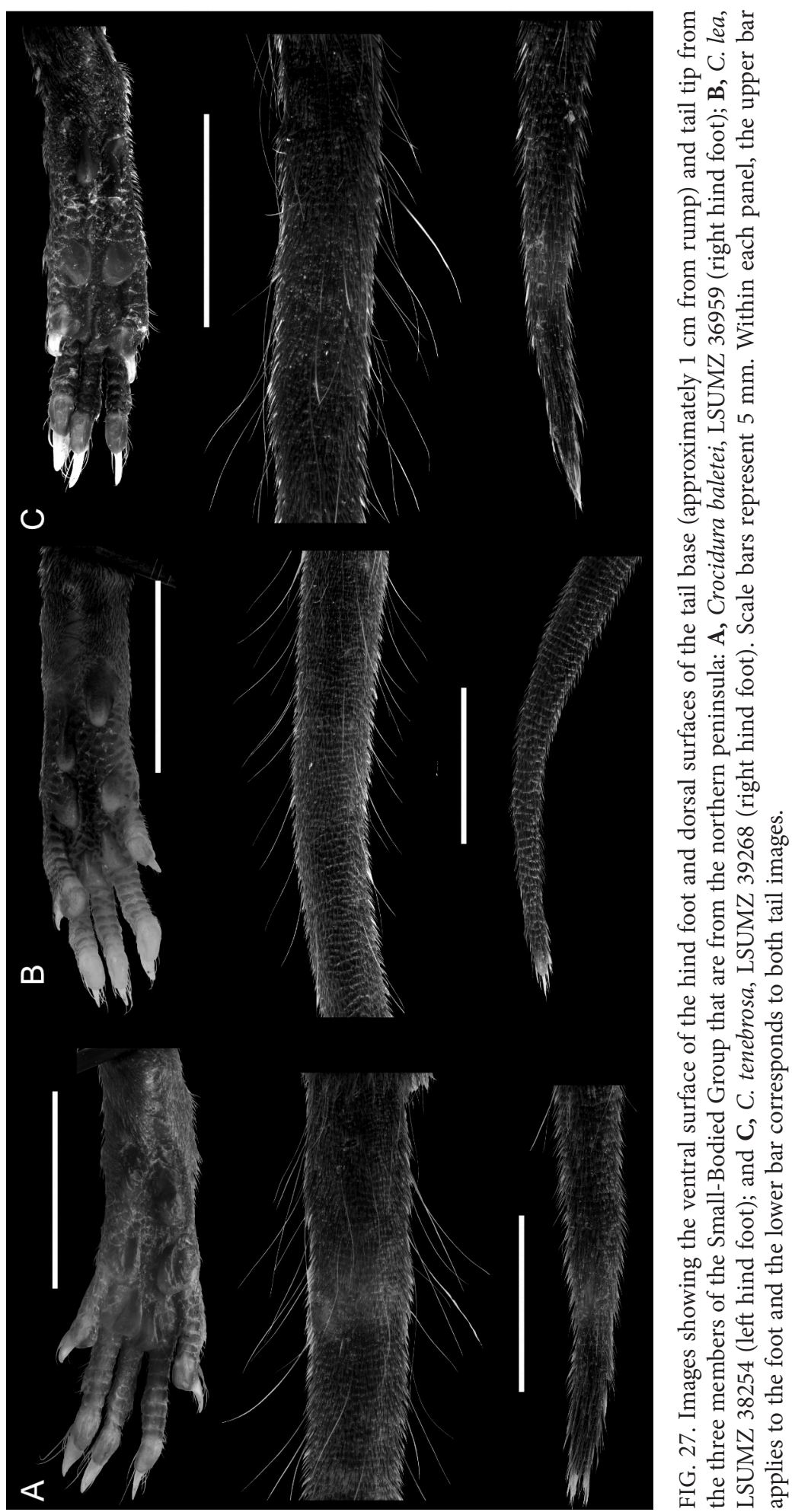


\section{TABLE 8}

Descriptive Statistics ${ }^{a}$ for Craniodental Measurements (mm) for Species of the Small-Bodied Group of Sulawesi Crocidura

\begin{tabular}{|c|c|c|c|c|c|c|}
\hline & C. baletei & C. lea & C. levicula & C. mediocris & C. parva & C. tenebrosa \\
\hline Condyloincisive & $\begin{array}{l}17.68 \pm 0.285 \\
(17.25-18.07)\end{array}$ & $\begin{array}{l}17.54 \pm 0.293 \\
(17.09-18.02)\end{array}$ & $\begin{array}{l}16.58 \pm 0.545 \\
(15.56-17.58)\end{array}$ & $\begin{array}{l}17.31 \pm 0.643 \\
(16.11-18.54)\end{array}$ & $\begin{array}{l}16.55 \pm 0.372 \\
(15.81-17.34)\end{array}$ & $\begin{array}{l}17.66 \pm 0.216 \\
(17.37-17.98)\end{array}$ \\
\hline length & 7 & 21 & 19 & 25 & 26 & 8 \\
\hline Braincase breadth & $\begin{array}{c}8.46 \pm 0.152 \\
(8.27-8.65) 7\end{array}$ & $\begin{array}{c}7.71 \pm 0.135 \\
(7.49-7.98) 21\end{array}$ & $\begin{array}{c}7.98 \pm 0.287 \\
(7.51-8.49) 19\end{array}$ & $\begin{array}{c}7.85 \pm 0.246 \\
(7.45-8.34) 25\end{array}$ & $\begin{array}{c}7.47 \pm 0.145 \\
(7.09-7.72) 26\end{array}$ & $\begin{array}{c}8.36 \pm 0.166 \\
(8.09-8.56) 8\end{array}$ \\
\hline Interorbital width & $\begin{array}{c}4.08 \pm 0.058 \\
(3.98-4.15) 7\end{array}$ & $\begin{array}{c}3.89 \pm 0.123 \\
(3.69-4.14) 21\end{array}$ & $\begin{array}{c}3.88 \pm 0.136 \\
(3.71-4.11) 19\end{array}$ & $\begin{array}{c}3.88 \pm 0.125 \\
(3.68-4.14) 25\end{array}$ & $\begin{array}{c}3.73 \pm 0.109 \\
(3.42-3.89) 28\end{array}$ & $\begin{array}{c}4.12 \pm 0.104 \\
(4.04-4.26) 8\end{array}$ \\
\hline Rostral length & $\begin{array}{c}7.05 \pm 0.242 \\
(6.78-7.49) 7\end{array}$ & $\begin{array}{c}6.86 \pm 0.208 \\
(6.48-7.27) 22\end{array}$ & $\begin{array}{c}6.48 \pm 0.22 \\
(6.05-6.92) 19\end{array}$ & $\begin{array}{c}6.91 \pm 0.396 \\
(6.37-7.7) 25\end{array}$ & $\begin{array}{c}6.48 \pm 0.182 \\
(6.08-6.86) 28\end{array}$ & $\begin{array}{l}7.09 \pm 0.136 \\
(6.85-7.22) 8\end{array}$ \\
\hline Postpalatal width & $\begin{array}{l}3.19 \pm 0.088 \\
(3.0-3.26) 7\end{array}$ & $\begin{array}{c}3.13 \pm 0.10 \\
(2.95-3.33) 21\end{array}$ & $\begin{array}{c}3.01 \pm 0.101 \\
(2.86-3.22) 19\end{array}$ & $\begin{array}{l}3.09 \pm 0.106 \\
(2.8-3.3) 25\end{array}$ & $\begin{array}{c}2.96 \pm 0.113 \\
(2.67-3.18) 28\end{array}$ & $\begin{array}{c}3.2 \pm 0.077 \\
(3.12-3.33) 8\end{array}$ \\
\hline Rostral width & $\begin{array}{c}2.41 \pm 0.162 \\
(2.17-2.61) 7\end{array}$ & $\begin{array}{c}2.4 \pm 0.146 \\
(2.13-2.68) 21\end{array}$ & $\begin{array}{c}2.28 \pm 0.125 \\
(2.07-2.53) 19\end{array}$ & $\begin{array}{c}2.34 \pm 0.169 \\
(2.13-2.67) 25\end{array}$ & $\begin{array}{c}2.32 \pm 0.147 \\
(2.09-2.63) 28\end{array}$ & $\begin{array}{l}2.55 \pm 0.117 \\
(2.44-2.74) 8\end{array}$ \\
\hline Postpalatal length & $\begin{array}{c}8.01 \pm 0.124 \\
(7.79-8.14) 7\end{array}$ & $\begin{array}{c}8.08 \pm 0.15 \\
(7.81-8.42) 21\end{array}$ & $\begin{array}{l}7.56 \pm 0.265 \\
(7.05-8.1) 19\end{array}$ & $\begin{array}{c}7.9 \pm 0.255 \\
(7.34-8.54) 25\end{array}$ & $\begin{array}{c}7.62 \pm 0.197 \\
(7.12-7.95) 24\end{array}$ & $\begin{array}{c}8.06 \pm 0.13 \\
(7.89-8.26) 8\end{array}$ \\
\hline $\begin{array}{l}\text { Condyle to glenoid } \\
\text { fossa }\end{array}$ & $\begin{array}{c}7.25 \pm 0.156 \\
(7.03-7.43) 7\end{array}$ & $\begin{array}{c}7.21 \pm 0.162 \\
(7.01-7.56) 21\end{array}$ & $\begin{array}{l}6.83 \pm 0.211 \\
(6.5-7.2) 19\end{array}$ & $\begin{array}{c}7.06 \pm 0.22 \\
(6.5-7.45) 25\end{array}$ & $\begin{array}{c}6.94 \pm 0.151 \\
(6.71-7.17) 26\end{array}$ & $\begin{array}{l}7.24 \pm 0.077 \\
(7.11-7.35) 8\end{array}$ \\
\hline $\begin{array}{l}\text { Upper toothrow } \\
\text { length }\end{array}$ & $\begin{array}{c}7.67 \pm 0.118 \\
(7.49-7.82) 7\end{array}$ & $\begin{array}{c}7.52 \pm 0.235 \\
(7.13-7.98) 22\end{array}$ & $\begin{array}{c}7.15 \pm 0.222 \\
(6.73-7.62) 19\end{array}$ & $\begin{array}{c}7.54 \pm 0.369 \\
(6.81-8.28) 25\end{array}$ & $\begin{array}{l}7.07 \pm 0.187 \\
(6.7-7.45) 28\end{array}$ & $\begin{array}{l}7.62 \pm 0.178 \\
(7.34-7.84) 8\end{array}$ \\
\hline P4 to M3 length & $\begin{array}{c}4.41 \pm 0.077 \\
(4.33-4.52) 7\end{array}$ & $\begin{array}{c}4.23 \pm 0.135 \\
(3.98-4.56) 22\end{array}$ & $\begin{array}{c}4.09 \pm 0.132 \\
(3.87-4.33) 19\end{array}$ & $\begin{array}{c}4.24 \pm 0.201 \\
(3.85-4.58) 25\end{array}$ & $\begin{array}{l}3.98 \pm 0.121 \\
(3.73-4.3) 28\end{array}$ & $\begin{array}{c}4.36 \pm 0.098 \\
(4.23-4.52) 8\end{array}$ \\
\hline $\begin{array}{l}\text { M2 to M2 labial } \\
\text { width }\end{array}$ & $\begin{array}{c}5.22 \pm 0.063 \\
(5.14-5.32) 6\end{array}$ & $\begin{array}{c}5.03 \pm 0.165 \\
(4.61-5.37) 22\end{array}$ & $\begin{array}{c}4.83 \pm 0.174 \\
(4.56-5.23) 19\end{array}$ & $\begin{array}{c}5.0 \pm 0.224 \\
(4.58-5.48) 25\end{array}$ & $\begin{array}{c}4.66 \pm 0.137 \\
(4.41-4.92) 28\end{array}$ & $\begin{array}{c}5.25 \pm 0.128 \\
(5.15-5.49) 8\end{array}$ \\
\hline Palatal width & $\begin{array}{l}2.14 \pm 0.074 \\
(2.04-2.24) 6\end{array}$ & $\begin{array}{c}1.98 \pm 0.115 \\
(1.8-2.32) 22\end{array}$ & $\begin{array}{c}2.02 \pm 0.105 \\
(1.78-2.24) 19\end{array}$ & $\begin{array}{c}1.98 \pm 0.068 \\
(1.85-2.1) 25\end{array}$ & $\begin{array}{c}1.89 \pm 0.102 \\
(1.73-2.11) 26\end{array}$ & $\begin{array}{c}2.08 \pm 0.115 \\
(1.92-2.24) 8\end{array}$ \\
\hline
\end{tabular}

a The sample mean \pm one standard deviation, the observed range in parentheses, and the sample size.

nial measurements (fig. 26). The C (U3) is larger than $\mathrm{I} 3$ (U2) in C. lea, but they are usually subequal in occlusal surface area in C. baletei and $C$. tenebrosa. The parastyle of $\mathrm{P} 4$ is more prominent in C. tenebrosa than in C. lea or C. baletei.

Comments: An 1111 bp cytochrome $b$ sequence from the holotype (USNM 217553) provides strong evidence that the tiny shrews we collected on Mts. Buliohuto and Dako (samples from Mt. Dako were referred to as "Crocidura pale lea" by Esselstyn et al., 2019) represent this species. Interestingly, we did not find C. lea on Mt. Ambang, our sample site nearest the type locality. Rather, the tiny shrews we collected from Mt. Ambang represent an undescribed spe- cies (C. tenebrosa) that does not appear to be a close relative of $C$. lea. We suspect that C. lea is widespread at relatively low elevations on the northern peninsula, but is displaced by smallerrange, darker-colored endemics in some higherelevation areas (fig. 13; table 3). Our only surveys on Mt. Ambang were centered on $1500 \mathrm{~m}$ elevation (fig. 3). For BPP species delimitation results, see the $C$. tenebrosa account below.

Ruedi (1995) reported Crocidura lea from Mt. Rorekatimbo, but we refer those specimens to $C$. normalis (see below) based on a cytochrome $b$ sequence from Ruedi et al. (1998).

None of our phylogenetic estimates found strong support for the closest relative(s) of Croc- 
TABLE 9

Results of Principal Components Analysis of Craniodental Measurements of the Small-Bodied Group of Crocidura

\begin{tabular}{lcc}
\hline & Component 1 & Component 2 \\
Variables $^{\mathrm{a}}$ & & \\
\hline Condyloincisive length & 0.6818 & 0.2724 \\
Braincase breadth & 0.2456 & -0.8299 \\
Interorbital width & 0.1167 & -0.2702 \\
Rostral length & 0.3441 & 0.0190 \\
Postpalatal width & 0.1036 & -0.0849 \\
Rostral width & 0.0779 & -0.0082 \\
Postpalatal length & 0.2750 & 0.2500 \\
Condyle to glenoid fossa & 0.2073 & 0.1481 \\
Upper toothrow length & 0.3440 & 0.0510 \\
P4 to M3 length & 0.1880 & -0.0904 \\
M2 to M2 labial width & 0.2256 & -0.1674 \\
Palatal width & 0.0534 & -0.1820 \\
Proportion of variance & 0.8056 & 0.0817 \\
Cumulative proportion & 0.8056 & 0.8873 \\
\hline
\end{tabular}

a Table entries for variables are component loadings.

idura lea, but some consistencies are nevertheless apparent. Our mitochondrial analyses placed $C$. lea as the sister to C. rhoditis and C. pseudorhoditis (fig. 4) or C. elongata (fig. 5), while our UCE species tree placed C. lea as sister to the clade containing C. elongata, C. rhoditis, and C. pseudorhoditis (fig. 7). Other nuclear-based inferences lacked support (fig. 8; supplementary data S6).

Specimens exAmined: Mt. Buliohuto (LSUMZ 38254-38262, 38271-38274; NMV C37692, C37715, C37716, C37720, C37721, C37735, C37744, C37829), Mt. Dako (LSUMZ 3694736950, 36952, 36954-36956, 36958, 36960, 36964, 36968-36972), Temboan (USNM 217553).

\section{Crocidura baletei, new species}

LSID: urn:lsid:zoobank. org:act:6D7C389E-00FB-4D18-B6D9889279B66FE1

Crocidura “dark lea” Esselstyn et al., 2019: 1715. Informal name.
Holotype: MZB 43005 (= LSUMZ 36959), an adult male, collected by J.A. Esselstyn on 10 March 2013. Specimen consists of a cleaned skull (fig. 28A), a fluid-preserved body, and frozen tissues. External measurements from the holotype are: $119 \mathrm{~mm} \times 50 \mathrm{~mm} \times 12 \mathrm{~mm} \times 8 \mathrm{~mm}=4.9 \mathrm{~g}$. The voucher and a tissue sample will be permanently curated at MZB, with another tissue sample retained by LSUMZ.

TyPe LOCAlity: Indonesia, Sulawesi Tengah, Toli Toli, Galang, Malangga Selatan, Mt. Dako; $1.10607^{\circ} \mathrm{N}, 120.93853^{\circ} \mathrm{E}, 1600 \mathrm{~m}$.

Eтymology: Named in honor of Danilo S. Balete, an accomplished mammal systematist who passed away much too early in 2017. Danny, as he is known, was a tireless collector, whose years of field research in the Philippines built the kind of museum collections needed for comprehensive catalogs of biodiversity. Without the focused, long-term efforts of people like Danny, the type of comprehensive taxonomic research we are attempting here would not be possible. 


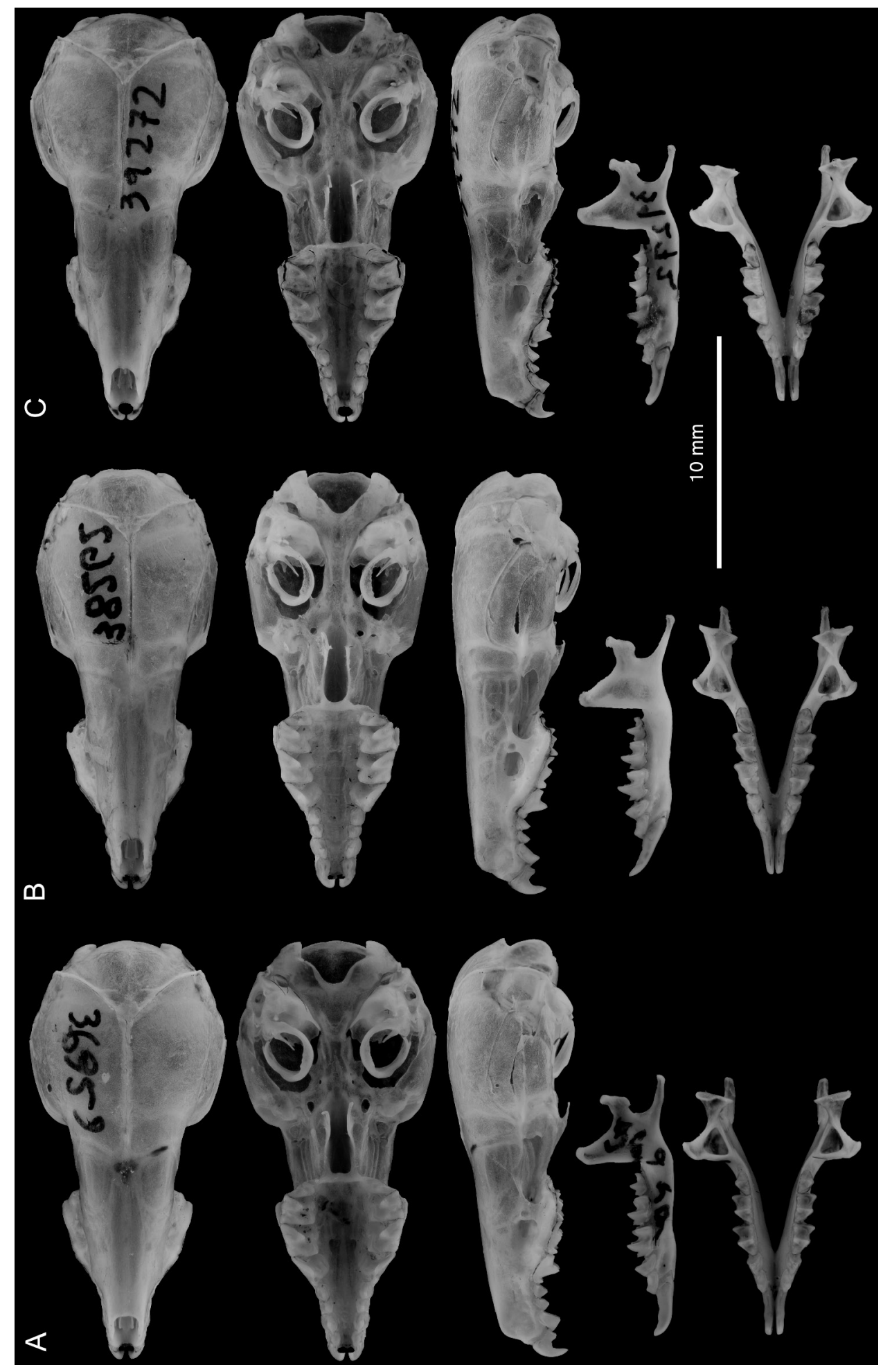

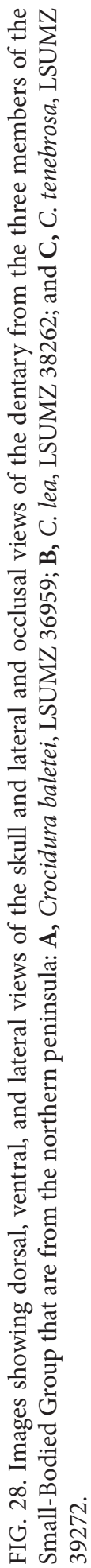




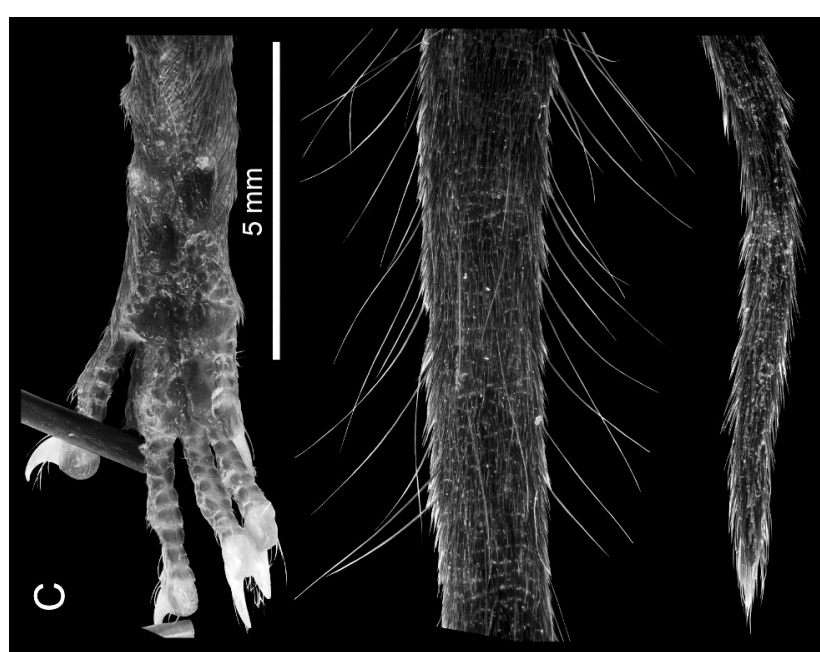

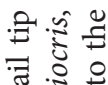

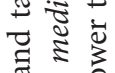

สิ

范

茫艺

घิ สี

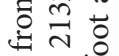

艺实

고용

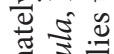

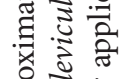

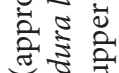

\&

జิ

تี

(1)

苛

㟧寻

यू ڤ.

莺苛

के एँ

芯

훙 ฮ

킁 ซี
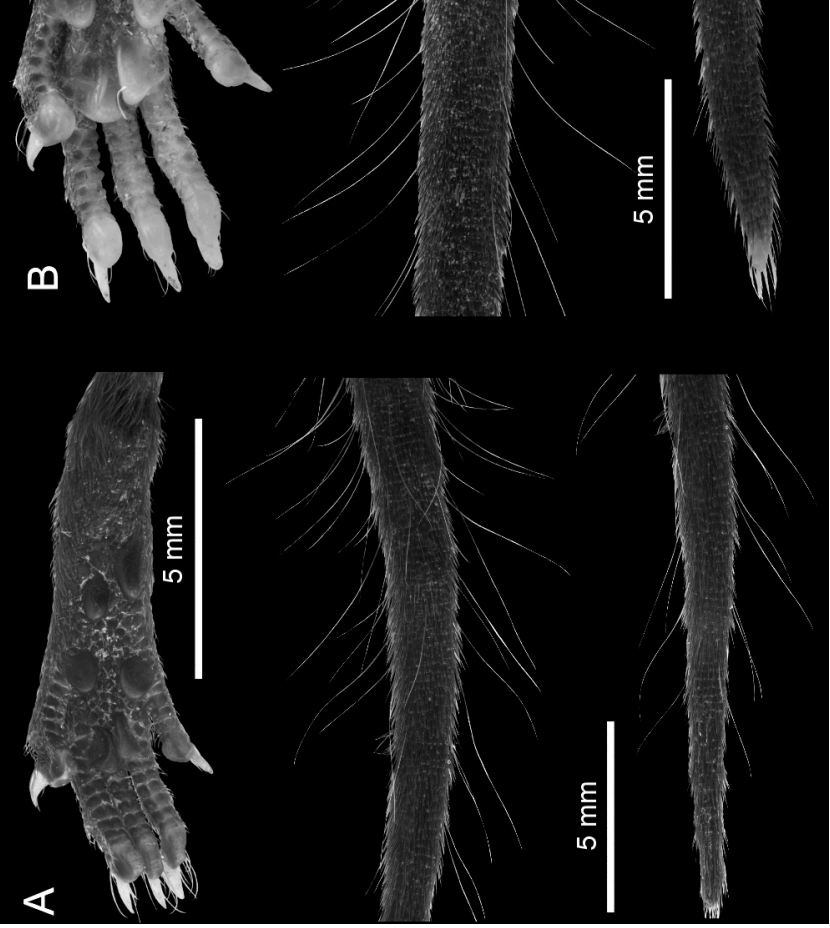

苍艺苞

范

类

푼

吾芯

पे जे

氙

$\breve{~}$

क

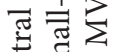

क्षे क ป ई

$\mp$ ज

000

.

के हี च

㟧

范苛

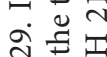

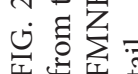


Geographic Distribution: Apparently endemic to montane forests of the north-west area of endemism. We recorded this species only on Mts. Dako and Buliohuto (fig. 25) at elevations around 1600 and $1400 \mathrm{~m}$, respectively (fig. 13). Our sampling efforts at lower elevations (400-600 m; fig. 3) on both mountains did not find this species (table 3). Surveys in the mountains west and south of Mt. Dako (i.e., the base of the northern peninsula) and east of Mt. Buliohuto are needed to draw firmer conclusions regarding the geographic distribution of Crocidura baletei.

DiAgnosis: Crocidura baletei is a very small shrew (tables 2,8) with a brown pelage and skin color, where exposed. Overall, this species is quite uniform in color, with the feet, pinnae, and tail matching the surrounding fur. The venter and dorsum are similarly colored. The pinnae are, however, paler around their lower margin. The mystacial vibrissae are pigmented for about the proximal half of their length, but unpigmented distally. The color of the digits is only slightly paler than that of the rest of the foot (fig. 27A). Tail length is shorter than head-and-body length (fig. 9; table 2) and bristles are present for approximately three-fourths of tail length. Small, applied hairs are present on the tail, but difficult to see with the naked eye. The skull is short, particularly the rostral portion, relative to the overall body size of the species (fig. 28). Relative to skull length, the skull is broad overall, especially at the braincase (fig. 10). On the upper dentition, I3 (U2) and C (U3) are subequal and the parastyle of $\mathrm{P} 4$ is modest (fig. 28A).

Comparisons: This shrew is much smaller than all other Sulawesi Crocidura outside of the Small-Bodied Group (fig. 9). Within the SmallBodied Group, C. lea and C. tenebrosa are the only other taxa known from the northern peninsula. Among the tiny shrews of the northern peninsula, C. baletei and C. tenebrosa are more uniform in color than C. lea, with C. baletei being paler (medium brown) than $C$. tenebrosa (dark brown). Crocidura lea has a paler integument, wherever it is exposed, and it is more strongly bicolored than either C. baletei (somewhat darker) or C. tenebrosa (much darker). Dorsally, the feet of both C. baletei and C. tenebrosa are uniformly dark, whereas the foot color transitions posteriorly from brown at the heel to white or pink digits in C. lea. Similarly, the tails of both C. baletei and C. tenebrosa are not obviously bicolored, and both are darker. Tail bristles are present on approximately three-fourths of the tail length in all three species, but they are much more abundant and longer on the tails of $C$. baletei and C. tenebrosa than in C. lea (fig. 27). Applied hairs on the tail are also more visible in the two new species than in C. lea. Tail length in C. baletei is slightly shorter than in C. lea, but substantially longer than in C. tenebrosa (fig. 9). On the hind foot, the thenar pad is wider and more prominent than in C. lea, but comparable to that of $C$. tenebrosa (fig. 27). The skulls of all three species are similar in length, but that of $C$. baletei is considerably wider than that of C. lea (figs. 10, 26, 30). The braincase breadths relative to skull lengths $(\mathrm{BB} / \mathrm{CIL})$ are similar in C. baletei and $C$. tenebrosa, but the interorbital region is relatively wider (IOW/CIL) in C. tenebrosa (fig. 10). Relative rostral length (RL/CIL) is slightly less in C. baletei than in C. tenebrosa (fig. 10). The parastyle of $\mathrm{P} 4$ is less prominent in $C$. baletei than in C. tenebrosa.

Comments: See comments for Crocidura tenebrosa, below.

Specimens examined: Mt. Buliohuto (LSUMZ 38264, 38265, 38268, 38270; NMV C37777, C37794, C37800), Mt. Dako (LSUMZ 36946, 36951, 36953, 36961-36963, 36965, 36966; MZB 43005; NMV C37306).

\section{Crocidura tenebrosa, new species}

$$
\begin{gathered}
\text { LSID: urn:lsid:zoobank. } \\
\text { org:act:856C039C-7F2E-4E38-8F16- } \\
\text { 02E4376F8B11 }
\end{gathered}
$$

Holotype: MZB 43006 (= LSUMZ 39272), an adult male collected by $\mathrm{H}$. Handika on 21 February 2016. The specimen comprises a study 
skin, cleaned skull and skeleton, and frozen tissues. External measurements from the holotype are $100 \mathrm{~mm} \times 37 \mathrm{~mm} \times 11 \mathrm{~mm} \times 8 \mathrm{~mm}=6.28$ $\mathrm{g}$. The voucher specimen and a tissue sample will be permanently curated at MZB, with additional tissues retained by LSUMZ.

Type LOCALity: Indonesia, Sulawesi Utara, Bolaang Mondgondow, Passi Timur, Insil, Mt. Ambang, near Lake Aliyah; $0.76385^{\circ} \mathrm{N}$, $124.41188^{\circ} \mathrm{E}, 1481 \mathrm{~m}$ elevation.

Eтymology: Tenebrosa is Latin for "dark," describing the overall color of this animal.

Geographic Distribution: Recorded only on Mt. Ambang in the north-east area of endemism (North Sulawesi Province) between 1400 and $1500 \mathrm{~m}$ elevation (fig. 25; table 3). Future surveys of other mountains in the north-central area of endemism and at the eastern extreme of the north-east area of endemism may extend the known range of this species.

Diagnosis: Crocidura tenebrosa is a very small (fig. 9; tables 2, 8), very dark shrew. The pelage and all areas of exposed skin (feet, tail, pinna, lips, and nose) are uniformly dark brown (fig. 27C). The overall dark pelage of this animal appears to be primarily from a darker proximal base of individual hairs. The mystacial vibrissae are black for most of their length, but unpigmented at the tips. The soles of the feet are mostly dark brown, but the areas that tend to accumulate pigment (base of the foot pads) are black (fig. 27C). The claws are translucent. The tail is short, with a notable density of applied hairs and a comparative abundance of bristles extending for three-fourths of the tail length. The skull is short, particularly the postpalatal portion, relative to its width (figs. 10, 28C) and to overall body size. Posteriorly, the skull is rounded, with a smoothly inflated and broad braincase (fig. 28C). The lambdoidal ridge is thin, but relatively high for such a delicate skull. The interorbital region is smoothly tapered, and the maxillary process is relatively inconspicuous, a consequence of the broad interorbital region. The palate is narrow, with a somewhat prominent dentition. The C (U3) and I3 (U2) are sub- equal in occlusal surface area. The parastyle of P4 is prominent.

COMPARIsOns: Crocidura tenebrosa is smaller than all Sulawesi shrews except the other members of the Small-Bodied Group, which are all comparable in body size. Among these, only C. lea and $C$. baletei are found on the northern peninsula, near the range of $C$. tenebrosa. Crocidura tenebrosa is readily distinguished from $C$. lea by its more dark and uniform color, shorter tail (fig. 9), and wider skull (figs. 10, 26). Crocidura tenebrosa is distinguished from its sister species, $C$. baletei, by its shorter tail (fig. 30; table 2), darker integument, shorter relative hind-foot length (fig. 17), and slightly narrower braincase, but wider interorbital region and rostrum (fig. 30; table 8). The ratio of the braincase breadth to interorbital width is slightly lower for C. tenebrosa than $C$. baletei (fig. 10). For additional details, see comparisons sections of C. lea and C. baletei, above.

Comments: We tested species limits with BPP between Crocidura baletei and C. tenebrosa, among these two species and C. lea, and among these three species and C. levicula. The alignments we analyzed contain: 6 and 13; 6, 13, and 12 ; and $6,13,12$, and 34 individuals per species, respectively. Alignments are $91 \%, 87 \%$, and $93 \%$ complete. All analyses supported all species with a posterior probability of 1 .

Crocidura baletei and C. tenebrosa are probable sister species (figs. 7, 8) and phenotypically similar. We define them as distinct species because they have modest differences in color and skull shape, they are divergent in their mitochondrial DNA (mean 0.076 Jukes-Cantor distance; supplementary data S4), they are reciprocally monophyletic in our UCE, mitochondrial, and nuclear exon trees (figs. 4, 5, 7, 8; supplementary data S6), and finally since both species have been recorded only above $1000 \mathrm{~m}$ elevation (fig. 13), they are likely isolated from each other by the low, dry habitat of the Gorontalo Divide. These two small-bodied highland endemics may be replaced across the northern peninsula lowlands by the similarly sized but paler colored and distantly related C. lea. 

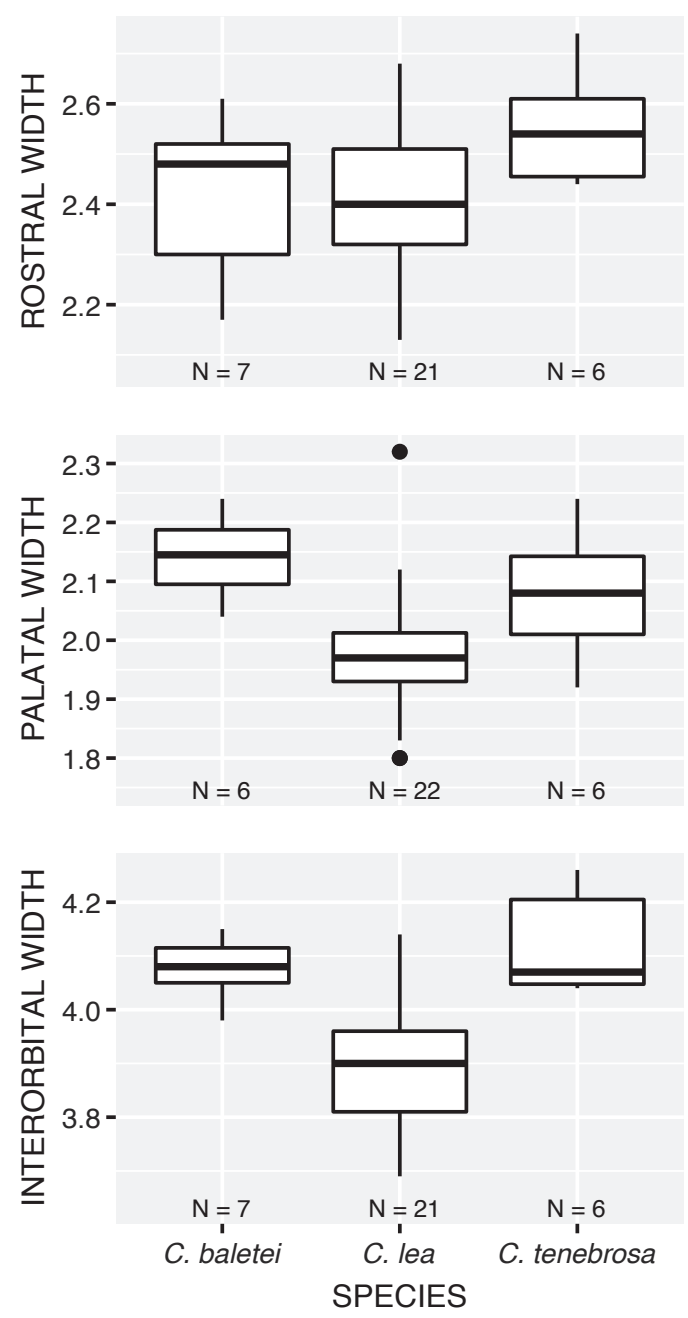

FIG. 30. Box plots showing variation in skull width and tail length from species of the Small-Bodied Group on the northern peninsula of Sulawesi. Plots show the median, 1st and 3rd quartiles, the maximum value within $1.5 \times$ interquartile range (distance between 1st and 3rd quartiles; IQR), the minimum value within $1.5 \times \mathrm{IQR}$, and outliers (black circles). Sample sizes are shown along the $\mathrm{x}$-axis. All measurements in $\mathrm{mm}$.
Specimens exAmined: Mt. Ambang (LSUMZ 39019-39023, 39025, 39267-39271, 39273, 39274; MZB 43006).

\section{Crocidura levicula Miller and Hollister, 1921}

Crocidura levicula Miller and Hollister, 1921: 103. Original description.

Holotype: USNM 219450, an adult female collected by H.C. Raven on 13 February 1918. Specimen prepared as a skin and skull. External measurements from the type are $108 \mathrm{~mm}$ $\times 44 \mathrm{~mm} \times 11 \mathrm{~mm}$; ear length and weight were not recorded.

Type locality: "Pinedapa, Middle Celebes" (fig. 25). Pinedapa is located near the north coast of Central Sulawesi Province, in Poso Regency, just west of the town of Mapane. Musser (2014) placed the locality at $1.4167^{\circ} \mathrm{S}, 120.5833^{\circ} \mathrm{E}, 31$ m elevation.

GeOgRAPHIC DISTRIBUtion: The type locality is near sea level in the northwestern part of Sulawesi's west-central area of endemism. We found this species to occur in the northern part of the west-central area of endemism (Mts. Rorekatimbo and Torompupu, Central Sulawesi Province), in two lowland areas near the boundary between the west-central and south-east areas of endemism (Wasponda and Tolala, Central Sulawesi Province), and in the east-central area of endemism (Mts. Katopasa and Tompotika, Central Sulawesi Province; fig. 25). These records span a broad elevational range, from approximately $400 \mathrm{~m}$ on Mt. Tompotika to 2000 m on Mt. Rorekatimbo (fig. 13; table 3).

Emended Diagnosis: A very small (tables 2, 8), medium- to dark-brown shrew, with almost uniformly colored pelage, feet, pinna, and tail. The ventral pelage is only slightly paler than the dorsal pelage. The digits are similarly pigmented as the other foot parts. The tail is unusually short (table 2), with an abundance of bristles (some of which are pigmented) extending along the proximal two-thirds of tail length (fig. 29A). The hind foot is short, with darkly pigmented pads. The 
claws are pale, perhaps lightly pigmented, and surrounded by a small tuft of brown hairs (fig. 29A). The skull is small but broad, more so at the braincase than at the interorbital region (figs. 10, 31A). Relative to body size and skull breadth, the skull is quite short, particularly the rostrum (fig. $10)$. The $C(\mathrm{U} 3)$ is equal to or larger in occlusal area than the I3 (U2).

Comparisons: Crocidura levicula is one of the smallest shrew species on Sulawesi, only being comparable to other members of the Small-Bodied Group (fig. 9). It has a shorter relative tail length than any other shrew species on Sulawesi (fig. 9). Its hind-foot length is shorter than in all Sulawesi shrews except one other member of the Small-Bodied Group, C. parva (fig. 9; table 2). Crocidura levicula is also darker in color than both C. lea and C. baletei, but not C. tenebrosa. Absolute tail length is slightly less in C. levicula than in C. parva. Tail bristles are more abundant on specimens of $C$. levicula than in C. lea, C. tenebrosa, and C. parva. The skull of C. levicula is small, delicate, and broad at the braincase and to a lesser degree at the interorbital region (fig. 10). Its skull width relative to length is greater than in C. lea, C. parva, and $C$. mediocris, and to a lesser degree, greater compared to C. tenebrosa (fig. 26). Crocidura levicula has a lesser skull length and breadth than $C$. baletei (fig. 26), but these two species have similar relative skull widths (fig. 10). Samples of Crocidura levicula are nearly nonoverlapping with other members of the Small-Bodied Group in morphometric space in bivariate plots of skull length versus width and along the first two axes from a PCA of 12 cranial measurements (fig. 26). In C. levicula, the C (U3) is equal to or greater in occlusal surface area than is I3 (U2) (fig. 31), which is similar to the conformation in C. lea.

Comments: Miller and Hollister (1921) named this species based solely on the holotype, and unfortunately, we failed to obtain DNA from this specimen. We followed the Tsai et al. (2020) phenol-chloroform extraction protocol and used two separate extractions. The addition of resalting the ethanol supernatants did not yield a quantity of DNA that could be detected with a Qubit 2.0 fluorometer using the dsDNA High Sensitivity Assay Kit (Thermo Fisher Scientific, Waltham, MA). As such, our identification of Crocidura levicula is based on the morphological similarity of the holotype to specimens we collected in areas nearest the type locality.

One specimen (NMV Z63390) from Mt. Torompupu appears to have an introgressed mitochondrion from syntopic Crocidura ordinaria, a member of the Ordinary Group detailed below. Our identification of this specimen is based on morphology alone; we did not sequence any nuclear DNA from this specimen and therefore cannot test our introgression hypothesis.

In our phylogenetic estimates, UCE data confidently placed Crocidura levicula as sister to $C$. caudipilosa (figs. 7, 8). However, our nuclearexon and mitochondrial inferences placed this species as a member of a clade of mostly SmallBodied species that also includes $C$. caudipilosa (fig. 5; supplementary data S6).

Crocidura levicula was delimited by all BPP analyses. See the C. tenebrosa account above for details.

SPECimens EXAMINED: Mt. Katopasa (LSUMZ 39512-39516; NMV C40180, C40181, C40200, C40203, C40207, Z55557), Pinedapa (USNM 219450), Mt. Rorekatimbo (FMNH 213192, 213193, 213271), Tolala (FMNH 210576, 210577), Mt. Tompotika (FMNH 213343213365), Mt. Torompupu (LSUMZ 39446-39449; NMV C40292, C40294, C40306, C40311, Z63365), Wasponda (FMNH 210578, 210579).

\section{Crocidura mediocris, new species}

$$
\begin{gathered}
\text { LSID: urn:lsid:zoobank. } \\
\text { org:act:1587FDA2-B27F-47C4-95DF- } \\
\text { E44A1081CCA4 }
\end{gathered}
$$

Holotype: MZB 43007 (= FMNH 210603), an adult female collected by J.A. Esselstyn on 22 October 2010. The specimen consists of a dried skin, cleaned skull and skeleton, and tissue samples. External measurements from the holotype 

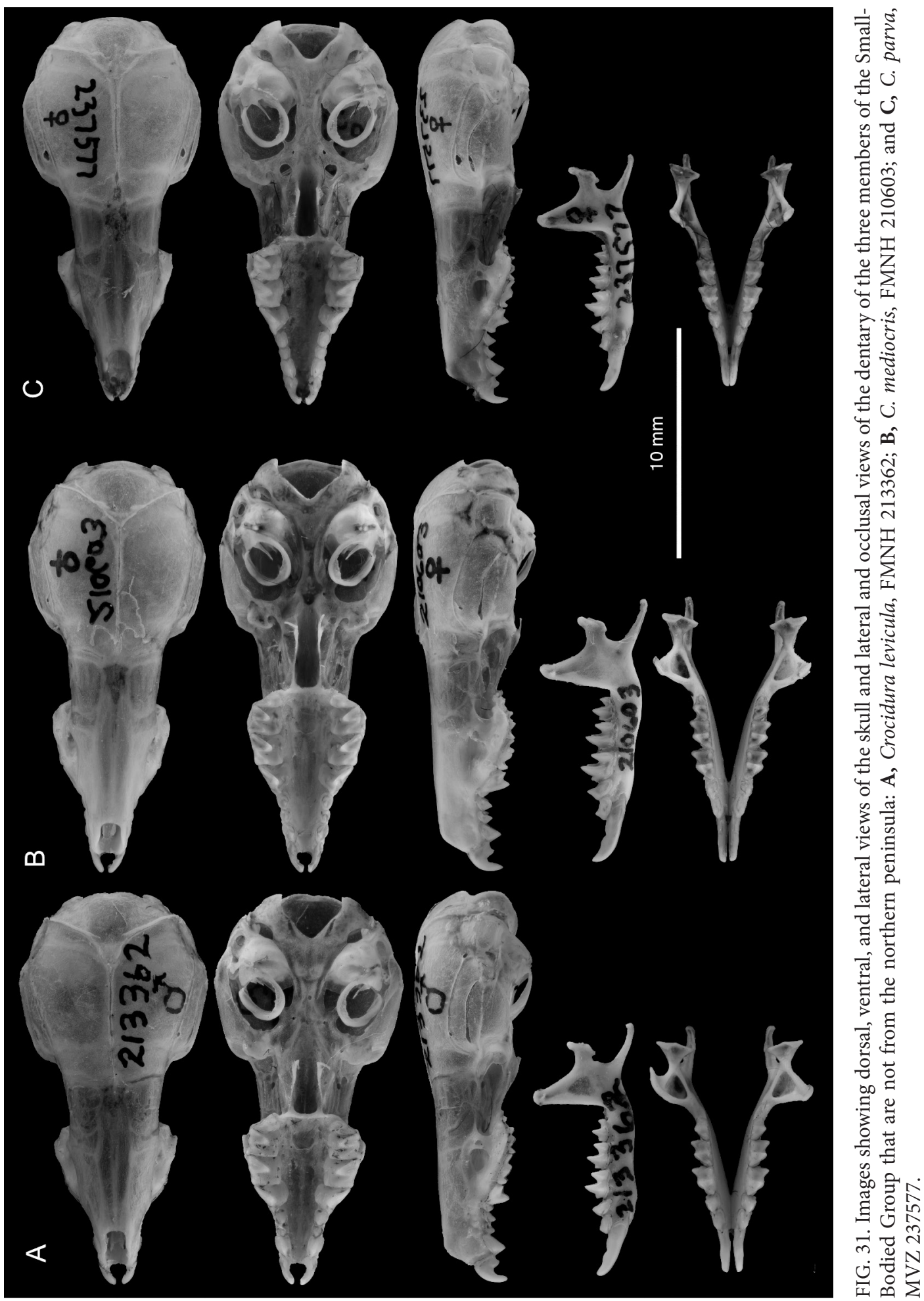
are: $102 \mathrm{~mm} \times 41 \mathrm{~mm} \times 11 \mathrm{~mm} \times 7 \mathrm{~mm}=3.7 \mathrm{~g}$. The voucher specimen and a tissue sample will be permanently curated at MZB, with an additional tissue sample retained by FMNH.

Type Locality: Indonesia, Sulawesi Selatan, Luwu Utara, Sukamaju, Mt. Balease; $2.50002^{\circ} \mathrm{S}$, $120.48726^{\circ} \mathrm{E}, 862 \mathrm{~m}$ elevation.

Eтyмоlogy: Mediocris is Latin for "average," applied in recognition that this is a species of shrew with no striking phenotypic traits worthy of hanging a descriptive name on.

Geographic Distribution: This species is found across the southern and western portions of the west-central area of endemism (Mts. Torompupu and Balease, Central Sulawesi Province; Salu Tiwo, West Sulawesi Province; and Mt. Latimojong, South Sulawesi Province) and in the south-east area of endemism (Mt. Mekongga, Southeast Sulawesi Province; fig. 25). We found this species from approximately 200 to $1900 \mathrm{~m}$ elevation (fig. 13). Although the species was present at Salu Tiwo (ca. $200 \mathrm{~m}$ ), we did not find it at higher elevations on Mt. Gandang Dewata (table 3).

Diagnosis: Crocidura mediocris is another small shrew (tables 2, 8), with a delicate build and dark gray to medium brown pelage that is only slightly paler on the venter. The tail is shorter than head-and-body length and moderately dorsoventrally bicolored. The feet are somewhat paler than the pelage, more so around the digits (fig. 29B). The pelage covers the body completely, but individual hairs are short $(2-3 \mathrm{~mm}$ at middorsum). Mystacial vibrissae are short relative to body size, and unpigmented along most of their length. The tail is covered in moderately dense bristles along the proximal two-thirds of its length and a relatively high density of short, dark, applied hairs along its entire length (fig. 29B). The dorsal surfaces of the digits and, in some specimens, the feet are light brown. The plantar and palmar surfaces are generally dark, but the ventral sides of the digits are white (fig. 29B). As is typical, more pigment is present on the posterior and lateral portions of the palmar and plantar surfaces. The skull is small and delicate, with a relatively robust dentition (fig. 31B). The braincase is somewhat narrow and the interobital region is narrow relative to skull length (fig. 10). The maxillary process is modest and the maxillary bridge is narrow (fig. 31B). The lambdoidal ridge is prominent for such a small species.

Comparisons: Crocidura mediocris is one of the smallest species on Sulawesi, easily distinguished on body size alone from all species outside the Small-Bodied Group (fig. 10). Crocidura normalis is the smallest member of the Ordinary Group and may be closely related to C. mediocris and C. parva, also of the Small-Bodied Group (figs. 5, 7). Compared to C. normalis, C. mediocris is smaller, paler colored, and has a shorter tail (fig. 10; table 2). Among the Small-Bodied species, $C$. mediocris has the shortest average head-and-body length. Its tail is also short, and relative tail length is comparable to C. baletei, greater than in $C$. levicula, C. tenebrosa, and C. parva, and only slightly less than in C. lea (fig. 9). In color, the feet of $C$. mediocris are darker than those of C. lea. Aside from the relative tail-length differences, $C$. mediocris is similar to C. levicula in overall proportions but differs in having a longer and slightly narrower skull (table 8), paler pelage and feet, more rounded hypothenar on the hind foot (fig. 29), and on average, fewer tail bristles. Crocidura mediocris is also paler than both C. tenebrosa (fig. 27C) and C. parva (fig. 29C). In cranial proportions, $C$. mediocris has a greater average condyloincisive length than C. levicula and C. parva, but is comparable in this regard to C. lea, C. baletei, and $C$. tenebrosa (table 8 ). The length of the rostrum, relative to skull length (RL/CIL), is greater on average than in C. lea, C. levicula, and C. parva (fig. 10). The relative breadth of the braincase (BB/ $\mathrm{CIL}$ ) is greater than in C. lea and slightly more than in C. parva, but less than in the other SmallBodied species. In morphometric space, a bivariate plot of condyloincisive length versus braincase breadth shows that $C$. mediocris occupies a widthto-length ratio between the narrow $C$. lea and $C$. parva and the wide C. levicula, C. baletei, and $C$. tenebrosa (fig. 26A). A PCA of cranial dimensions shows that specimens of $C$. mediocris occupy 
moderately distinct morphometric space, overlapping primarily with individuals of $C$. lea and $C$. parva (fig. 26A).

Comments: Crocidura mediocris is closely related to C. parva. See the C. parva account for a discussion of phylogenetic relationships between these two phenotypically similar species. For coalescent species delimitation results, see the C. normalis (Ordinary Group) and $C$. parva accounts below.

SPECimens eXAmined: Mt. Balease (FMNH 210563-210575, 210602, 210604-210606; MZB 43007), Mt. Gandang Dewata (FMNH 218617, 218619, 218620, 218622-218638, 218640218642, 218644-218649), Mt. Latimojong (MVZ 237574), Mt. Mekongga (MWFB 8092, 8104, $8121,8131-8136,8140-8142,8144,8145,8148$, $8149,8152,8153,13508,13510,13513,13514)$, Salu Tiwo (FMNH 218614-218616, 218618, 218621, 218639, 218643, 218650, 218651), Mt. Torompupu (LSUMZ 39452-39457, 39555; MVZ 238109-238114; NMV C40246, C40251, C40253, C40274, C40278, Z62199).

\section{Crocidura parva, new species}

\author{
LSID: urn:lsid:zoobank. \\ org:act:8C7D230C-7F04-4FE0-9896- \\ 5921A8574315
}

HoLOTyPe: MZB 43008 (= MVZ 237577), an adult female collected on 18 October 2016 by $\mathrm{H}$. Handika. The specimen is preserved as a study skin, cleaned skull (fig. 31C) and skeleton, and frozen tissues. External measurements recorded in the field from the type are: $101 \mathrm{~mm} \times 41 \mathrm{~mm}$ $\times 2 \mathrm{~mm} \times 7 \mathrm{~mm}=3.9 \mathrm{~g}$. Hind-foot length for the holotype was erroneously recorded as $2 \mathrm{~mm}$; the true value is almost certainly $12 \mathrm{~mm}$. The voucher specimen and a tissue sample will be permanently curated at MZB, while an additional tissue sample will be retained at MVZ.

Type LOCALITy: Indonesia, Sulawesi Selatan, Sinjai, Sinjai Barat, Gunung Perak Village, Mt. Bawakaraeng; $5.286815^{\circ} \mathrm{S}, 119.961406^{\circ} \mathrm{E}, 1713-$ 1754 m elevation.
Eтymology: Parva is Latin (feminine) for "tiny," used in recognition of the diminutive body size of this species.

Geographic Distribution: This animal was extremely abundant on Mt. Bawakaraeng of the south-west area of endemism (South Sulawesi Province; fig. 25). We did not encounter it anywhere else and it may be endemic to this region. All specimens were collected between 1700 and 2500 m elevation (table 3). Habitat destruction has eliminated low- and middle-elevation forests in South Sulawesi, which may have altered the natural elevational distribution of this species.

Diagnosis: Crocidura parva is among the smallest shrews on Sulawesi and it has the narrowest average braincase breadth of any species on the island (tables 2,8). For a shrew of its head-and-body length, it has a rather delicate build (fig. 17). Crocidura parva has a gray-brown to dark brown pelage, with a slightly grayer venter. The fur is not particularly dense, and individual hairs on the middorsum are only about 3 $\mathrm{mm}$ in length, despite all specimens coming from mid to high elevation. Overall, the color of the skin on the feet, ears, lips, and tail match that of the surrounding pelage. The mystacial vibrissae are short (most $<10 \mathrm{~mm}$ ) and pigmented proximally for no more than half of their length. The tail length is short absolutely, and less than head-and-body length (fig. 9; table 2). Tail bristles are relatively abundant and are present along about two-thirds of the proximal tail length (fig. 29C). The skull is short, but also quite narrow at the braincase, giving it an elongate and dorsoventrally compressed overall appearance. The lambdoidal ridge is indistinct. The width of the interorbital region is middling relative to skull length (fig. 10) and the maxillary process is not prominent. Rostral length forms a relatively small proportion of skull length (fig. 10). The molar row is crowded on the narrow palate (fig. $31 \mathrm{C})$. On the upper cheek teeth, the metacone is unusually prominent relative to the protocone, particularly on $\mathrm{P} 4$.

Comparisons: Crocidura parva is much smaller than all known Sulawesi shrews except 
other members of the Small-Bodied Group. Externally, C. parva is rather uniform in color, as are C. levicula, C. baletei, and C. tenebrosa, but other species have paler feet than bodies, including C. lea and to a lesser extent, C. mediocris. The overall color of $C$. parva is slightly darker than $C$. mediocris, and considerably darker than C. lea. The tail has more bristles than in C. mediocris, but fewer than C. levicula (fig. 29). The pelage is shorter than in other species, except that $C$. mediocris is similar. The skull of the tiny C. parva is slightly smaller overall than seen in any of the other very small taxa (table 8 ) and relative rostral length (RL/CIL) is less than in C. mediocris, $C$. baletei, and C. tenebrosa (fig. 10). Most distinctively, the braincases of the other species are more dorsoventrally inflated, particularly in the case of C. lea. The flat braincase of C. parva is narrower than in all other Small-Bodied species, but the range of values overlaps with those from C. lea, C. levicula, and C. mediocris (fig. 26). Bivariate plots of cranial length versus width and the first two axes from a PCA of 12 cranial dimensions show $C$. parva to occupy largely distinct morphometric space, but to overlap some with C. lea, C. levicula, and C. mediocris (fig. 26). Finally, in C. parva, on the upper molariform teeth, the protocone is relatively low, compared with those of the other Small-Bodied shrews (figs. 28, 31).

Comments: We found this species only on Mt. Bawakaraeng, but our nearest sample sites are on Mt. Latimojong (fig. 25), some $215 \mathrm{~km}$ away. Much of the intervening habitat between Mts. Bawakaraeng and Latimojong is low elevation and dry, with the lowest area (the Tempe Depression) considered a barrier to many vertebrate taxa. Nevertheless, sampling additional sites in the south-west area of endemism may extend the known range of Crocidura parva. We interpret this probable isolation as additional support for distinguishing C. parva from $C$. mediocris, which is phenotypically similar. These two species are sister taxa in our mitogenome phylogeny (fig. 5), but each is paraphyletic with respect to the other in our UCE (figs. 7,8 ) and nuclear exon phylogenies (supplementary data S6). Because of the slow evolutionary rate of UCEs and exons, we do not consider this to be strong evidence against their distinction.

We tested species limits in BPP between Crocidura parva and C. mediocris and among $C$. parva, C. mediocris, and C. normalis. The former analysis employed 20 individuals of each species and the matrix is $95 \%$ complete. The second analysis used the same dataset, but with the addition of 36 specimens of $C$. normalis. This matrix is $94 \%$ complete. All analyses supported each species with a posterior probability of 1 .

Specimens eXAmined: Mt. Bawakaraeng (MVZ 237575, 237576, 237578-237581, 237583, 237584, 237600-237609; MZB 43008; NMV Z57156, Z56280, Z56302, Z56314, Z56319, Z56995, Z57008, Z57012, Z57045, Z57046, Z57047, Z57057, Z57064, Z57103, Z57129, Z57208).

\section{Thick-Tailed Group}

We group two new species here that are more distinctive than most and are probably sister species. Both have somewhat large bodies (typically 80-90 mm head-and-body length), stocky body forms, and short, thick tails $(50-75 \mathrm{~mm}$ in length; figs. 9, 17; table 2; supplementary data S7). Each species also appears to be a high-elevation endemic restricted to a single mountainous area. Principal components analyses show that these two species occupy distinct cranial morphometric space, but overlap almost completely in external morphometric space (fig. 32; tables 10, 11).

\section{Crocidura brevicauda, new species}

$$
\begin{gathered}
\text { LSID: urn:lsid:zoobank. } \\
\text { org:act:62AA5599-D510-4AAB-B516- } \\
\text { 1D901C972A6E }
\end{gathered}
$$

Holotype: MZB 43009 (= MVZ 237632), an adult female collected on 12 August 2016 by $\mathrm{H}$. Handika, and prepared as a cleaned skull, forma- 

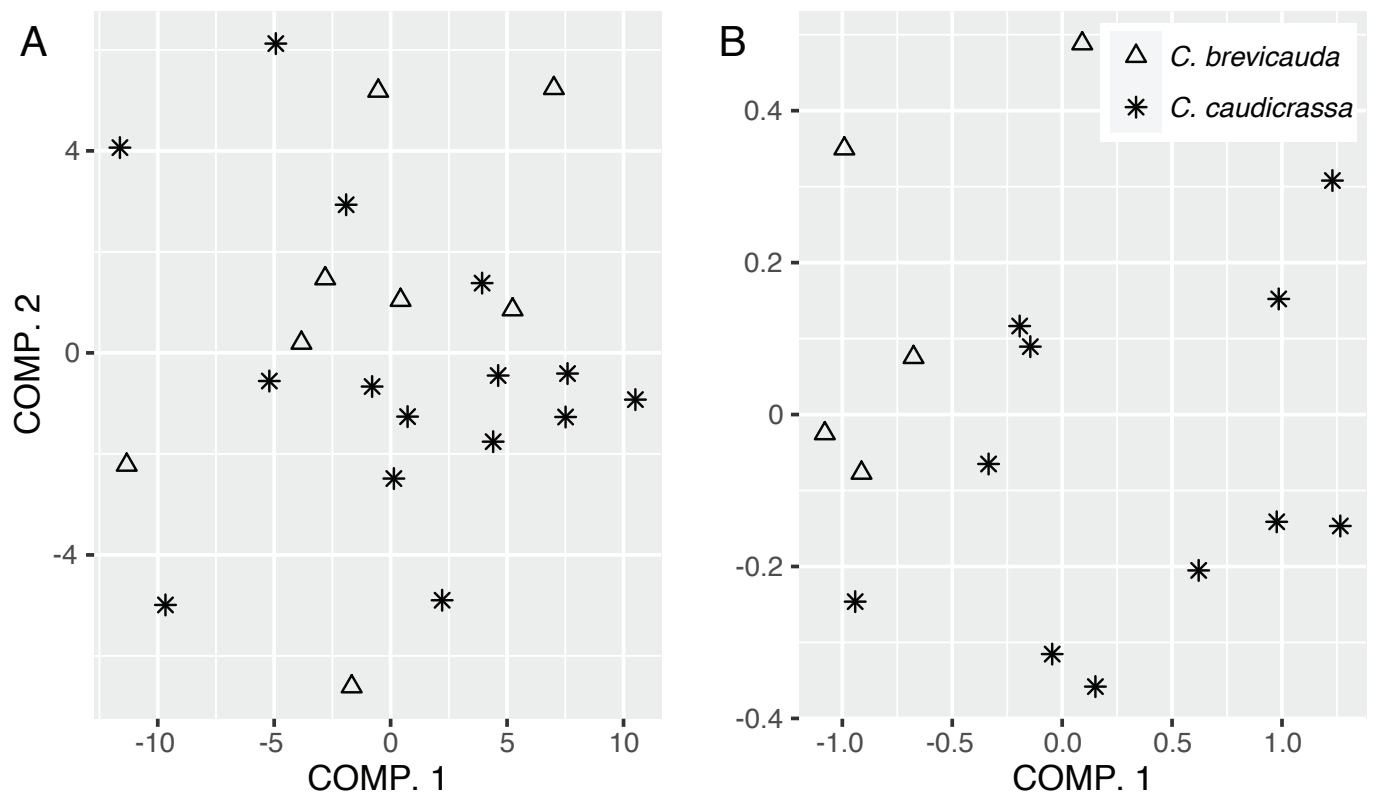

FIG. 32. Bivariate plots showing the results of principal components analyses of the two Thick-Tailed Group species using A, five external and B, 12 cranial measurements. Loadings and variance explained are given in tables 10 and 11 , respectively.

lin-fixed carcass, and tissue samples. External measurements of the holotype are $130 \mathrm{~mm} \times 56$ $\mathrm{mm} \times 15 \mathrm{~mm} \times 9 \mathrm{~mm}=12.0 \mathrm{~g}$. The voucher specimen and a tissue sample will be permanently curated at MZB and an additional tissue will be retained at MVZ.

Type LOCALity: Indonesia, South Sulawesi Province, Luwu Regency, Latimojong District, Ulusalu, Gamaru Village, Mt. Latimojong; $3.43103^{\circ} \mathrm{S}, 120.09457^{\circ} \mathrm{E}, 2518 \mathrm{~m}$ elevation.

Eтymology: Brevicauda is Latin for "short tail," indicating the relatively stubby tail that this species possesses.

Geographic distribution: Only known from Mt. Latimojong of the west-central area of endemism (fig. 1), between 2300 and $2500 \mathrm{~m}$ elevation (fig. 13). The surveys we conducted on Mt. Latimojong during 2011 between 2000 and $2300 \mathrm{~m}$ did not find this species (table 3 ).

Diagnosis: Crocidura brevicauda is a fairly large shrew (tables 2,12) with a stocky build (fig. 17) and relatively short tail (fig. 9). The tail is somewhat thick and dark brown with many applied hairs. It has sparse, but long bristles along nearly its entire length (fig. 33A). The long dorsal fur $(7-8 \mathrm{~mm}$ at middorsum) is gray-brown to dark brown, with a gray base and short brown tip. The fur coat is sufficiently thick and long that it somewhat obscures the ears. The hind feet are darker than the forefeet, the former being brown to dark brown dorsally, while the latter are pale brown. On all four feet, the thenar and hypothenar are less prominent than the four interdigital pads (fig. 33A). The skull width relative to length is midsized at the braincase and interorbital region (figs. 10, 34A). The rostrum is long relative to skull length (fig. 10). The lambdoidal ridge is prominent and the lateral margins of the braincase are somewhat angular, forming a dull point at the squamosal-parietal suture (fig. 34A).

COMPARISONs: Crocidura brevicauda is considerably larger than all members of the Small-Bodied Group, larger than C. australis and C. pallida of the Rhoditis Group, has a much shorter tail than members of the Long-Tailed Group, is slightly smaller and has a narrower braincase than C. rhoditis and C. pseudorhoditis of the Rhoditis 
Group, is darker in color (pelage and feet) than all members of the Rhoditis Group, and is larger than all members of the Ordinary Group (detailed below) except $C$. nigripes. Crocidura nigripes, however, is usually very darkly colored, particularly on its feet, whereas $C$. brevicauda has pale brown to dark brown feet (fig. 33). Crocidura brevicauda also has a somewhat stockier body (fig. 17), much wider interorbital region (fig. 10), more rounded braincase, and a less robust dentition (fig. 34A) than C. nigripes. Crocidura brevicauda has a more luxuriant pelage than all other species except $C$. musseri and C. caudicrassa, the other member of the Thick-Tailed Group. Crocidura caudicrassa is generally similar to C. brevicauda, but can be distinguished by its even thicker fur, heavier body (fig. 17), longer skull, wider rostrum and braincase, and thicker tail (table 12).

Comments: The extent of montane habitats on Mt. Latimojong is fairly limited and isolated from other such areas (fig. 1). As such, the geographic range of Crocidura brevicauda may be quite small. See the next account for details of phylogenetic relationships and coalescent species delimitation results.

SPECIMENS EXAMINED: Mt. Latimojong (MVZ 237568, 237597, 237616, 237629-237631, 237633; MZB 43009).

\section{Crocidura caudicrassa, new species}

LSID: urn:lsid:zoobank.
org:act:8274BDB8-B7AF-46CC-A0A8-
5EC15DC347D3

Holotype: MZB 34795, an adult female collected on 28 October 2011 by K.C. Rowe and preserved as a cleaned skull (fig. 34B), fluid-preserved body (fig. 33B), and tissue sample (NMV Z21760). External measurements are $144 \mathrm{~mm} \times$ $62 \mathrm{~mm} \times 17 \mathrm{~mm} \times 10 \mathrm{~mm}=16.5 \mathrm{~g}$.

Type Locality: Indonesia, West Sulawesi Province, Kabupaten Mamasa, Desa Tondok Bakaru, Kampung Rantepangko, Mt. Gandang Dewata, Post 3; $2.84534^{\circ}$ S, $119.38216^{\circ}$ E, 2580$2640 \mathrm{~m}$ elevation.
Etymology: Caudicrassa is Latin for "thick tail," identifying this species' most distinctive trait.

Geographic Distribution: Known only from the type locality around $2600 \mathrm{~m}$ on $\mathrm{Mt}$. Gandang Dewata and from a single specimen collected by Luis Ruedas at 2120 m elevation from an area approximately $40 \mathrm{~km}$ ESE of Gandang Dewata in Rindingallo, of the west-central area of endemism (fig. 1; table 3).

Diagnosis: A large (tables 2, 12), stocky shrew (fig. 17) with chocolate dorsal pelage (more reddish brown in MSB 93104 from Rindingallo), slightly grayer ventral pelage, and an unusually thick tail (fig. 33B). The dorsal hairs are dark gray at the base, with the overall pelage color determined by the browner approximately $1 \mathrm{~mm}$ tip. The tips of ventral hairs are a paler brown. The tail is shorter than head-and-body length (fig. 9) and holds conspicuous bristles spread along nearly its entire length (fig. 33B). The bristles are pigmented proximally for roughly half their length in the series from Mt. Gandang Dewata, but only for approximately 1 $\mathrm{mm}$ on the specimen from Rindingallo (MSB 93104). The tail varies from pale brown to dark brown dorsally and is slightly paler on the ventral surface. The overall color of the tail is largely determined by the many applied hairs that cover the tail scales. The feet are similar in color to the tail, dorsally and ventrally and both the tail and feet are slightly paler than the dorsal pelage. The feet are small relative to body mass, but not body length (fig. 17). The interdigital pads are exceptionally prominent, but the thenar and hypothenar are not unusual (fig. 33B). The pelage is unusually thick, with hairs at the middorsum approximately $8-10 \mathrm{~mm}$ long. The skull is large and robust, with a broad interorbital region (figs. 10, 34B). The rostrum is long relative to skull length (fig. 10; table 12). From a dorsal view, the braincase appears narrow, largely from the effect of the broad interorbital region. In dorsal view, the anteriorly converging lines formed by the sinus canal, interorbital margin, and rostrum above the maxillary process are quite straight. In ventral view, the rostrum is 
TABLE 10

Results of Principal Components Analysis of Craniodental Measurements of the Thick-Tailed Group of Crocidura

\begin{tabular}{lcc}
\hline & Component 1 & Component 2 \\
Variables $^{\mathrm{a}}$ & & \\
\hline Condyloincisive length & 0.6837 & 0.3462 \\
Braincase breadth & 0.2291 & -0.3547 \\
Interorbital width & 0.1896 & -0.2052 \\
Rostral length & 0.3488 & -0.0117 \\
Postpalatal width & 0.1309 & -0.1335 \\
Rostral width & 0.0266 & 0.0543 \\
Postpalatal length & 0.3080 & 0.3563 \\
Condyle to glenoid fossa & 0.2077 & -0.0526 \\
Upper toothrow length & 0.2996 & -0.0421 \\
P4 to M3 length & 0.1698 & -0.1337 \\
M2 to M2 labial width & 0.1817 & -0.5521 \\
Palatal width & 0.1223 & -0.4870 \\
Proportion of variance & 0.7639 & 0.0682 \\
Cumulative proportion & 0.7639 & 0.8321 \\
\hline
\end{tabular}

a Table entries for variables are component loadings.

narrow relative to the broad posterior palate. The molar row is robust (fig. 34B).

COMPARIsOns: Crocidura caudicrassa is larger (as estimated from skull length) than most other species of shrew on Sulawesi. The exceptions are C. elongata and C. quasielongata of the Elongata Subgroup, C. nigripes of the Ordinary Group, and C. rhoditis of the Rhoditis Group. Among these relatively large animals, $C$. caudicrassa is much stockier than $C$. nigripes and all members of the Long-Tailed Group (fig. 17; table 2). Only C. rhoditis has a body form nearly as robust, but it is substantially paler in pelage and skin color, particularly on the feet, and has a longer hind foot and thinner tail than C. caudicrassa (fig. 9; table 2). Crocidura caudicrassa could be confused with C. nigripes, despite its stockier body. However, $C$. caudicrassa differs by having a wider interorbital region relative to both braincase breadth and skull length and a less robust dentition than C. nigripes. Crocidura caudicrassa could also be mistaken for C. brevicauda, the only other member of the Thick-Tailed Group, but the latter has a less stocky body form, less prominent interdigital pads, shorter skull length, narrower rostrum and interorbital region, lesser braincase height, and less elongate interorbital region (table 12). The most distinctive feature of C. caudicrassa is its thick tail, which has no equal among Sulawesi's Crocidura, but is approached by the somewhat thick tail of C. brevicauda (fig. 33). The pelage of $C$. caudicrassa is thick-only those of C. brevicauda and C. musseri, the latter of which is much smaller and does not have a particularly thick tail, are comparable.

Comments: We tested species limits between the two Thick-Tailed species using BPP on a small dataset containing 13 Crocidura caudicrassa and two C. brevicauda. Twelve of the C. caudicrassa specimens lack three of the five loci in this alignment, and thus it is only $54 \%$ complete. Nevertheless, BPP delimited these two species with posterior probability of 1.0 in all replicates.

The area around Mt. Gandang Dewata is an expansive region of montane habitat that is almost entirely unexplored by mammalogists. 
TABLE 11

Results of Principal Components Analysis of External Measurements of the Thick-Tailed Group of Crocidura

\begin{tabular}{lcc}
\hline & Component 1 & Component 2 \\
Variables $^{\mathrm{a}}$ & & \\
\hline Total & 0.8975 & 0.4228 \\
Tail & 0.4113 & -0.9001 \\
Hind foot & 0.0584 & -0.0341 \\
Ear & 0.1018 & -0.0962 \\
Mass & 0.1072 & 0.0238 \\
Proportion of variance & 0.6588 & 0.1931 \\
Cumulative proportion & 0.6588 & 0.8519 \\
\hline
\end{tabular}

a Table entries for variables are component loadings.

Although we describe Crocidura caudicrassa as a montane endemic, it may have a somewhat larger geographic range in this area. The single specimen from Rindingallo ( $40 \mathrm{~km}$ from Mt. Gandang Dewata) hints at this possibility.

We inferred a sister relationship between Crocidura caudicrassa and C. brevicauda in our analyses of UCEs (figs. 7, 8) and nuclear exons (supplementary data S6), but not in our analyses of mitochondrial DNA (figs. 4, 5). These two phenotypically similar species each appear to be montane endemics restricted to neighboring areas of high elevation, and thus we suspect that our UCE inferences reflect the correct relationship. Jukes-Cantor cytochrome $b$ distances between these two species averaged 0.12 , close to the mode of interspecific divergences among Sulawesi shrews and more than twice the median of intraspecific differences (fig. 6; supplementary data S4). Their morphological differences and presumed isolation by lowland habitats between Mts. Gandang Dewata and Latimojong further support their distinction.

Specimens examined: Mt Gandang Dewata (MZB 34792-34798, 34801-34805), Rindingallo, Tana Toraja (MSB 93104).

\section{OrdinARY Group}

We place five species that have medium body sizes, typical tail proportions (thickness and length), and integuments that are not especially pale in the Ordinary Group. The group includes Crocidura musseri, C. nigripes, and three new species. Crocidura nigripes is a distant relative of all other Sulawesi shrews (fig. 7), but the remaining four species also do not form a clade in any of our phylogenetic analyses. However, two of the species in this group are sister taxa. The species of the Ordinary Group have head-and-body lengths generally between 65 and $85 \mathrm{~mm}$, average tail lengths range from 50 to $65 \mathrm{~mm}$, and hind-foot lengths nearly always fall between 12 and $16 \mathrm{~mm}$ (supplementary data S7). These species vary considerably in color and pelage density. The animals grouped here are, with few exceptions, smaller than Long-Tailed, Rhoditis, and Thick-Tailed group species, while being larger than Small-Bodied Group members. A PCA of 12 cranial measurements for this group shows that $C$. nigripes and $C$. normalis occupy largely unique multivariate morphospace, but the three other species have extensive overlap on the first two axes (fig. 35; table 13 ). The two closely related taxa (C. ordinaria and C. solita) occur in sympatry where they possess deeply divergent mitochondrial haplotypes but are morphologically very similar.

\section{Crocidura nigripes Miller and Hollister, 1921}

Crocidura nigripes Miller and Hollister, 1921: 101. Original description. 


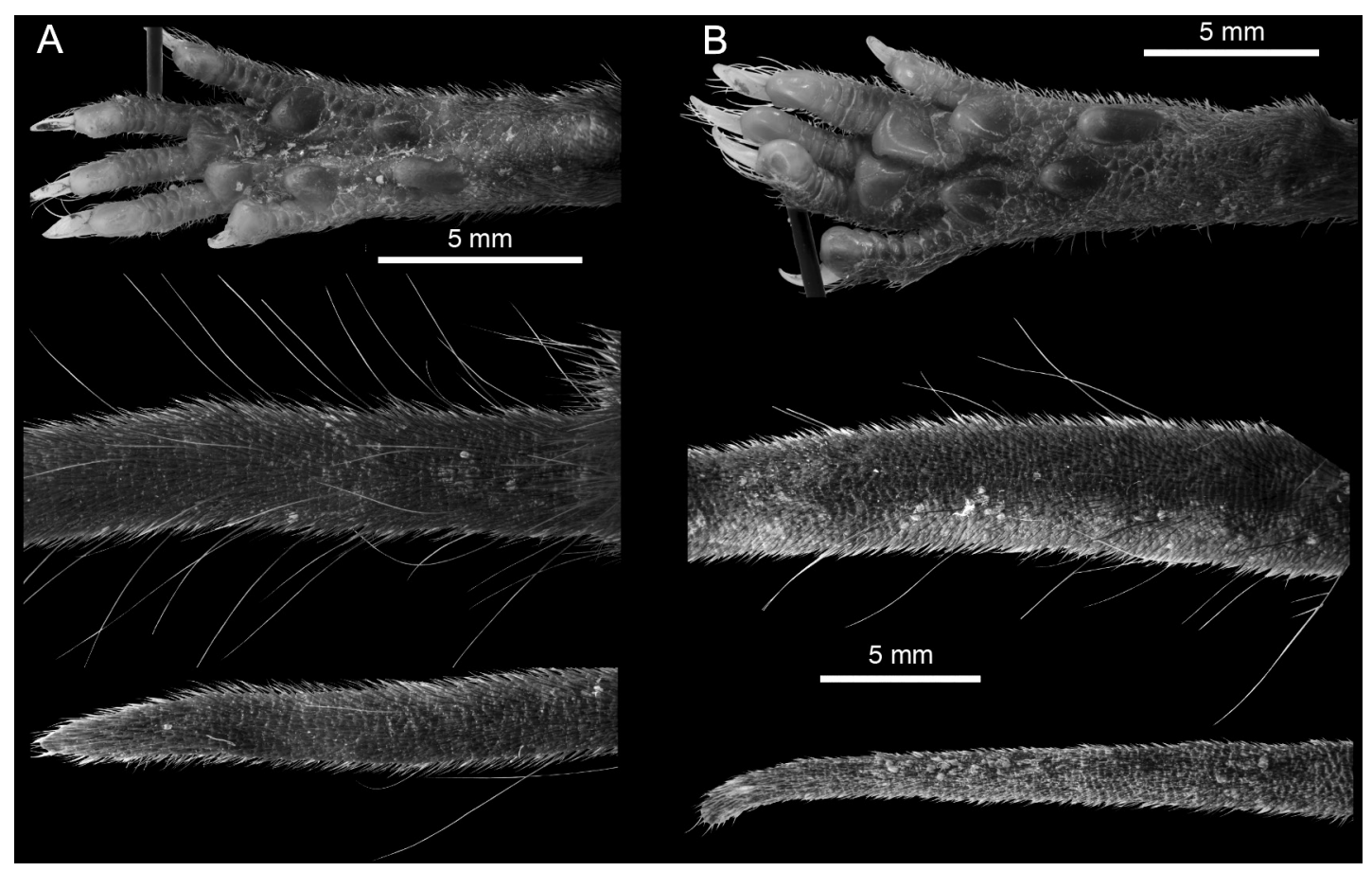

FIG. 33. Images showing the ventral surface of the hind foot and dorsal surfaces of the tail base (approximately $1 \mathrm{~cm}$ from rump) and tail tip from the two members of the Thick-Tailed Group: A, Crocidura brevicauda, MVZ 237632 (left hind foot); and B, C. caudicrassa, MZB 34795 (right hind foot). In B the upper scale bar applies to the foot and the lower to the tail.

\section{Crocidura nigripes lipara Miller and Hollister,}

1921: 101. Original subspecies description.

HolOtype: USNM 217545, an adult male collected by H.C. Raven on 4 August 1916 and prepared as a skin and skull. External measurements from the holotype are $131 \mathrm{~mm} \times 51 \mathrm{~mm} \times 14$ $\mathrm{mm}$; ear length and weight were not recorded.

Type Locality: "Temboan (southwest from Tondano Lake), northeastern Celebes” (Miller and Hollister, 1921: 101; fig. 1). We estimate Temboan is in the Southeast Minahasa Regency of North Sulawesi Province, $6 \mathrm{~km}$ south of Kalait, at $0.979^{\circ} \mathrm{N}, 124.605^{\circ} \mathrm{E}, 650 \mathrm{~m}$. See the gazetteer (appendix) for a full justification of our interpretation of Raven's notes.

Geographic Distribution: Crocidura nigripes is generally regarded as a Sulawesi endemic that occurs broadly across lowland areas of the island (fig. 1), but the species was tenta- tively reported from Obi Island by Fabre et al. (2018). This latter record is based solely on the similarity of cytochrome $b$ sequences between $C$. nigripes and a single specimen from Obi; we have not examined the Obi specimen. On Sulawesi, we recorded this species from the north-east (Mt. Ambang, Temboan, and Lembeh, North Sulawesi Province), north-central (Toraut, North Sulawesi Province), north-west (Mt. Buliohuto, Gorontalo Province and Mt. Dako, Central Sulawesi Province), west-central (Mts. Balease, Rorekatimbo, and Torompupu, Toare, Tolai, and Sungai Miu, Central Sulawesi Province; Mt. Gandang Dewata (including our lowland sample area at Salu Tiwo), West Sulawesi Province), and east-central areas of endemism (Mt. Katopasa and Peleng Island, Central Sulawesi Province). Notably, we did not record the species from the south-west or southeast areas of endemism. Similarly, Musser (1987) reported the species only from the west-central 


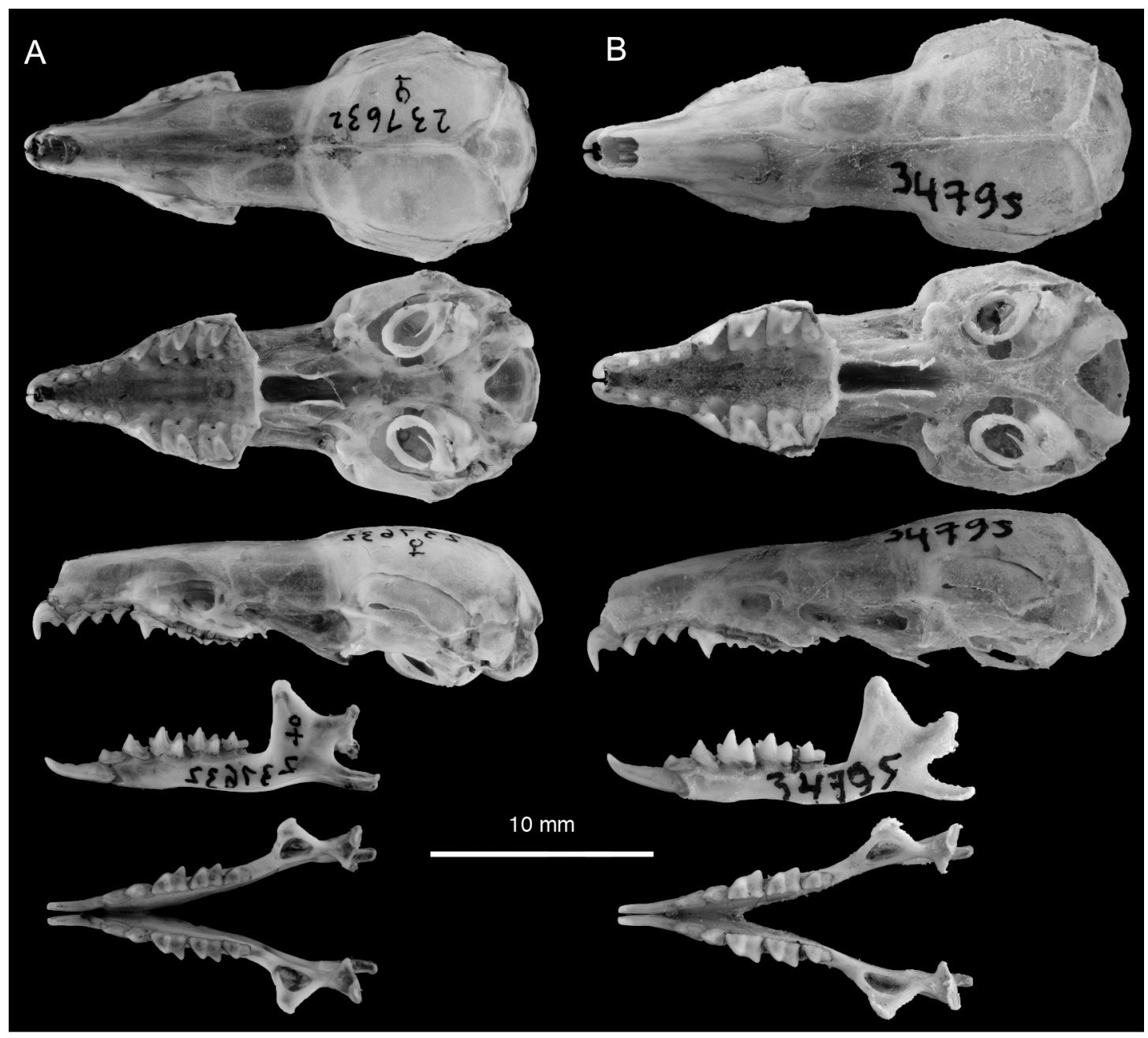

FIG. 34. Images showing dorsal, ventral, and lateral views of the skull and lateral and occlusal views of the dentary of the two members of the Thick-Tailed Group: A, Crocidura brevicauda, MVZ 237632; and B, C. caudicrassa, MZB 34795.

area of endemism and northern peninsula. The full elevational extent of $C$. nigripes records across these areas extends from near sea level to just over 2000 m (fig. 13; table 3).

Emended Diagnosis: A medium-sized shrew (tables 2,14) with a medium build and uniformly dark pelage, feet, and tail (light chocolate to black; fig. 36). The tail is shorter than head-andbody length. The hind foot is somewhat short relative to head-and-body length (fig. 17), and usually dark brown to black. The skull is broad, and quite angular, with a prominent maxillary process, broad palate, and dentition with a large occlusal area relative to palatal area (fig. 37B). The interorbital region is unusually narrow, which enhances the prominence of the braincase breadth and maxillary process (fig. 10). Rostral length makes up a large proportion of skull length (fig. 10).

COMPARISONS: Crocidura nigripes is generally very dark in color with a short tail and moderate body size, but there is substantial variation in size 
TABLE 12

Descriptive Statistics ${ }^{\mathrm{a}}$ for Craniodental Measurements $(\mathrm{mm})$ for Species of the Thick-Tailed Group of Sulawesi Crocidura

\begin{tabular}{lcc}
\hline & C. brevicauda & C. caudicrassa \\
\hline & $22.68 \pm 0.368$ & $23.29 \pm 0.548$ \\
Condyloincisive length & $(22.42-23.31) 5$ & $(22.33-24.19) 11$ \\
Braincase breadth & $10.2 \pm 0.243$ & $10.5 \pm 0.193$ \\
Interorbital width & $(9.92-10.48) 5$ & $(10.25-10.84) 11$ \\
& $5.2 \pm 0.088$ & $5.42 \pm 0.194$ \\
Rostral length & $(5.07-5.29) 5$ & $(5.14-5.7) 11$ \\
& $9.43 \pm 0.215$ & $9.75 \pm 0.287$ \\
Postpalatal width & $(9.21-9.71) 5$ & $(9.4-10.17) 11$ \\
Rostral width & $3.95 \pm 0.072$ & $4.12 \pm 0.123$ \\
Postpalatal length & $(3.87-4.02) 5$ & $(3.96-4.36) 11$ \\
& $2.89 \pm 0.102$ & $2.92 \pm 0.144$ \\
Condyle to glenoid fossa & $(2.75-3.03) 5$ & $(2.72-3.17) 11$ \\
Palatal width & $10.1 \pm 0.325$ & $10.4 \pm 0.267$ \\
Upper toothrow length & $(9.81-10.66) 5$ & $(10.0-11.04) 11$ \\
P4 to M3 length & $8.51 \pm 0.073$ & $8.75 \pm 0.195$ \\
M2 to M2 labial width & $(8.43-8.63) 5$ & $(8.44-9.07) 11$ \\
& $9.92 \pm 0.121$ & $10.2 \pm 0.26$ \\
& $(9.81-10.09) 5$ & $(9.78-10.67) 11$ \\
& $5.57 \pm 0.045$ & $5.76 \pm 0.147$ \\
& $(5.53-5.63) 5$ & $(5.48-6.02) 11$ \\
& $6.34 \pm 0.098$ & $6.63 \pm 0.191$ \\
& $(6.19-6.46) 5$ & $(6.41-6.95) 11$ \\
& $2.84 \pm 0.07$ & $3.17 \pm 0.119$ \\
& $(2.77-2.94) 5$ & $(3.03-3.36) 11$ \\
\hline
\end{tabular}

a The sample mean \pm one standard deviation, the observed range in parentheses, and the sample size.

and color. The feet are often nearly black, which will, in most cases, distinguish this species from all Sulawesi shrews except the darkest members of the Small-Bodied Group, which are much smaller. Typically, C. nigripes is smaller than C. elongata, $C$. quasielongata, C. caudicrassa, and C. rhoditis, comparable in size to C. microelongata, C. pseudorhoditis, C. brevicauda, and C. australis, and larger than the remaining species known from Sulawesi. It is the largest species in the Ordinary Group. These size differences can be observed using measures of skull length, head-and-body length, mass, or hind foot length (figs. 9, 17). Tail length is shorter than head-and-body length, which will distinguish $C$. nigripes from all similarly sized shrews (as judged by HBL, CIL, etc.) except the two Thick-Tailed species, which have greater relative hind-foot lengths (HF/HBL) and stockier bodies (figs. 9, 17). The skull of $C$. nigripes has a more angular braincase, more prominent maxillary process (enhanced by the narrow interorbital region), and more robust dentition (larger occlusal surface area) than all other Sulawesi shrews. The relative interorbital width (IOW/CIL) is substantially less than in all other species except C. elongata and C. quasielongata (fig. 10), two species with much longer skulls, tails, hind feet, and bodies.

Comments: Phylogenetically, Crocidura nigripes is more closely related to shrew species endemic to Sundaland than to any others that 


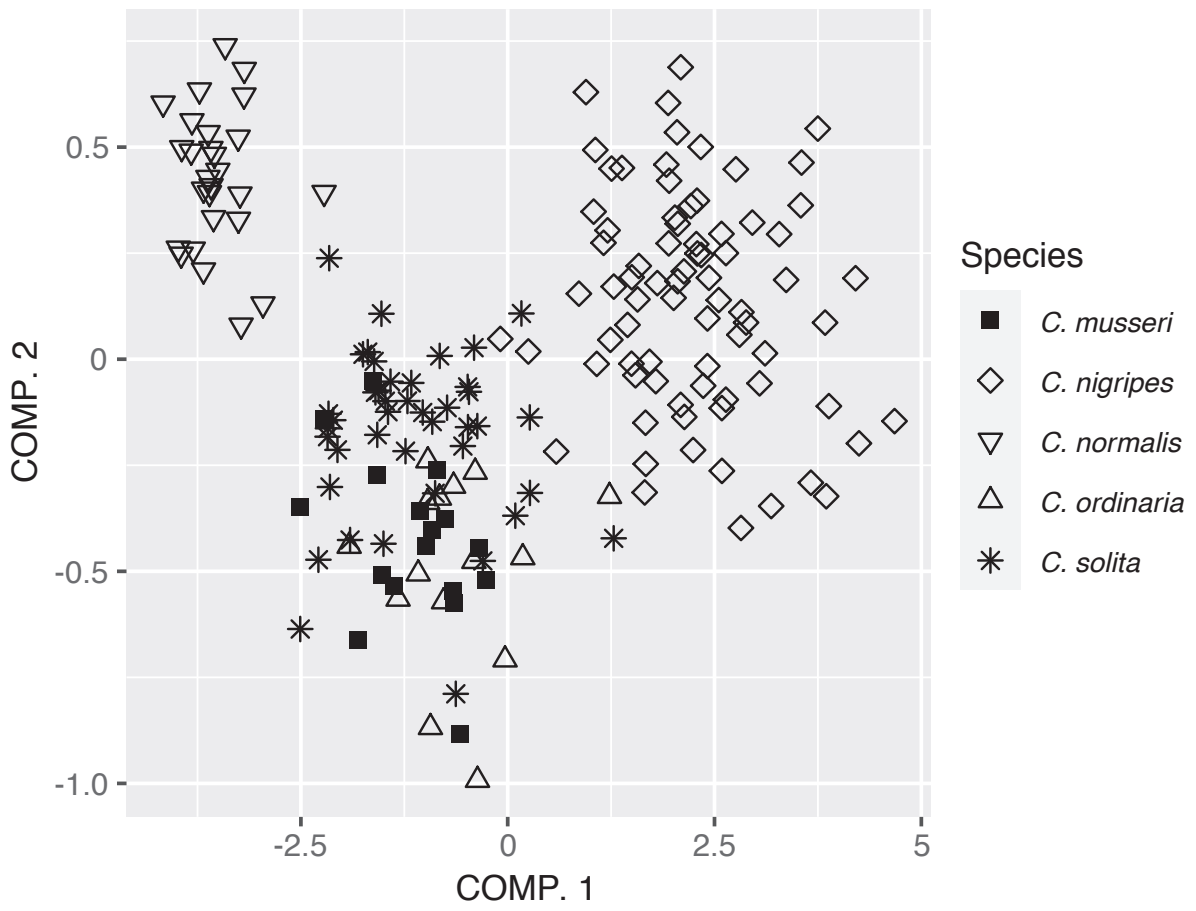

FIG. 35. Bivariate plot showing the results of principal components analysis of 12 cranial measurements from the five species in the Ordinary Group. Loadings and variance explained are given in table 13.

live on Sulawesi (Ruedi et al., 1998; Esselstyn et al., 2009, 2019; Hinckley et al. 2021). Our phylogenetic analyses conducted on far more species than previous studies reinforce this conclusion. We placed C. nigripes as sister to C. palawanensis, a species endemic to the Palawan Island group in the southwestern Philippines (figs. 7, 8). Hinckley et al. (2021) estimated C. nigripes as a close relative of $C$. foetida, a Bornean endemic that was not included in our analyses.

Miller and Hollister (1921) described two subspecies, Crocidura nigripes nigripes from Temboan and C. n. lipara from Gimpoe, in Central Sulawesi Province. Ruedi (1995) treated northern peninsula populations as $C$. $n$. nigripes and specimens from other parts of the island as $C$. $n$. lipara. He noted size differences with this geographic division, but also highlighted the limited sample of available specimens. We treat $C$. n. lipara as a synonym of $C$. nigripes because we have not identified any geographically partitioned morphological (fig. 38; tables 15, 16) or genetic diversity with our improved sampling. Jukes-Cantor cytochrome $b$ distances between specimens sampled from across Sulawesi are $<0.01$ (fig. 4; supplementary data S3). As such, we see no reason to maintain the subspecific distinction between C. $n$. nigripes and C. $n$. lipara.

Specimens examined: Mt. Ambang (LSUMZ 39044, 39279, 39320), Mt. Balease (MZB 38491; FMNH 210593, 210595, 210611), Mt. Buliohuto (LSUMZ 38279-38281, 38283, 38286, 38287, 38292-38295, 38297; NMV C37778), Mt. Dako (LSUMZ 37017-37019, 37022, 37025-37029, 37032, 37035-37049; NMV C37257, C37265, C37307, C37318, C37368, C37369), Mt. Gandang Dewata (FMNH 218708), Gimpoe (=Gimpu) (USNM 219444, 219446), Lake Lindu (USNM 218668, 501223), Mt. Katopasa (LSUMZ 40925; NMV C40227, C40229, C40230), Koelawi (= Kulawi) (FMNH 47361), Kuala Navusu (AMNH 226105, 226106, 226108, 226109, 226110, 226112), Peleng Island (AMNH 109215), Pinedapa (USNM 
TABLE 13

Results of Principal Components Analysis of Craniodental Measurements of the Ordinary Group of Crocidura

\begin{tabular}{lcc}
\hline & Component 1 & Component 2 \\
Variables $^{\mathrm{a}}$ & & \\
\hline Condyloincisive length & 0.6756 & 0.2490 \\
Braincase breadth & 0.1967 & -0.6930 \\
Interorbital width & 0.0579 & -0.4676 \\
Rostral length & 0.3475 & 0.1378 \\
Postpalatal width & 0.0985 & -0.3379 \\
Rostral width & 0.0910 & -0.1381 \\
Postpalatal length & 0.2585 & 0.0392 \\
Condyle to glenoid fossa & 0.1343 & -0.0332 \\
Upper toothrow length & 0.3736 & 0.1707 \\
P4 to M3 length & 0.2288 & -0.0378 \\
M2 to M2 labial width & 0.2824 & -0.2173 \\
Palatal width & 0.0790 & -0.0794 \\
Proportion of variance & 0.9380 & 0.0236 \\
Cumulative proportion & 0.9380 & 0.9616 \\
\hline
\end{tabular}

a Table entries for variables are component loadings.

219435), Mt. Rorekatimbo (FMNH 213190, 213191, 213252), Salu Tiwo (FMNH 218703, 218704, MZB 38488, 38489), Toraut (RMNH 38389 [= IZEA 4413], 38390 [= IZEA 4415]), Lembeh (FMNH 31844), Sungai Miu (AMNH 223989), Sungai Tolewonu, Tolai (AMNH 226537-226539), Temboan (FMNH 43859; USNM 217536, 217541217545), Toare (= Tuare or Toware) (FMNH 47362, USNM 219434, 219437-219440, 219443, 219447), Mt. Torompupu (LSUMZ 39469-39474).

\section{Crocidura musseri Ruedi, 1995}

\section{Crocidura musseri Ruedi, 1995: 254. Original} description.

Holotype: MZB 16791 (= IZEA 4397), an adult female caught 18 August 1991. Measurements from the holotype are TC (head-andbody length): $66 \mathrm{~mm} \times \mathrm{Q}$ (tail length): $57 \mathrm{~mm}$ $\times \mathrm{PP}$ (hind-foot length): $13.5 \mathrm{~mm}=\mathrm{Pds}$ (weight): $6.5 \mathrm{~g}$.
Type Locality: Mt. Rorekatimbo, Central Sulawesi, at $1^{\circ} 16^{\prime} \mathrm{S}, 120^{\circ} 15^{\prime} \mathrm{E}, 2230$ m elevation.

Geographic Distribution: Apparently restricted to high elevation areas $(>1800 \mathrm{~m})$ in the northern portions of the west-central area of endemism east of the Palu-Koro Fault in Central Sulawesi Province (figs. 13, 39; table 3). Ruedi (1995) reported specimens of this species from only the type locality on Mt. Rorekatimbo. We collected specimens that match Ruedi's description and are mitochondrially identical (based on cytochrome $b$ sequences from Ruedi et al., 1998) from the same mountain, at three nearby sites $\left(1.3093^{\circ} \mathrm{S}, 120.3092^{\circ} \mathrm{E}, 2020 \mathrm{~m} ; 1.2926^{\circ} \mathrm{S}\right.$, $120.3064^{\circ} \mathrm{E}, 2180 \mathrm{~m} ; 1.2884^{\circ} \mathrm{S}, 120.3104^{\circ} \mathrm{E}, 2250$ $\mathrm{m})$. Musser collected additional specimens from 1800-2300 m elevation on the neighboring Mt. Nokilalaki (ca. $15 \mathrm{~km} \mathrm{~W}$ of Mt. Rorekatimbo).

EMENDED Diagnosis: A medium-sized shrew (tables 2,14) with a thick, dark brown pelage that is only slightly paler on the venter. Foot, ear, tail, and rhinarium color closely match the pelage. Tail 
TABLE 14

Descriptive Statistics ${ }^{\mathrm{a}}$ for Craniodental Measurements $(\mathrm{mm})$ for Species of the Ordinary Group of Sulawesi Crocidura

\begin{tabular}{|c|c|c|c|c|c|}
\hline & C. musseri & C. nigripes & C. normalis & C. ordinaria & C. solita \\
\hline $\begin{array}{l}\text { Condyloincisive } \\
\text { length }\end{array}$ & $\begin{array}{c}20.13 \pm 0.446 \\
(19.17-20.78) 17\end{array}$ & $\begin{array}{c}22.47 \pm 0.733 \\
(20.91-24.32) 80\end{array}$ & $\begin{array}{c}18.73 \pm 0.276 \\
(18.29-19.66) 27\end{array}$ & $\begin{array}{c}20.38 \pm 0.491 \\
(19.47-21.59) 15\end{array}$ & $\begin{array}{c}20.13 \pm 0.584 \\
(19.25-21.55) 43\end{array}$ \\
\hline $\begin{array}{l}\text { Braincase } \\
\text { breadth }\end{array}$ & $\begin{array}{c}9.74 \pm 0.233 \\
(9.42-10.26) 18\end{array}$ & $\begin{array}{c}9.94 \pm 0.315 \\
(9.32-10.78) 77\end{array}$ & $\begin{array}{c}8.61 \pm 0.168 \\
(8.45-9.06) 27\end{array}$ & $\begin{array}{c}9.79 \pm 0.178 \\
(9.48-10.06) 15\end{array}$ & $\begin{array}{c}9.51 \pm 0.263 \\
(8.8-10.12) 43\end{array}$ \\
\hline $\begin{array}{l}\text { Interorbital } \\
\text { width }\end{array}$ & $\begin{array}{c}4.91 \pm 0.164 \\
(4.61-5.2) 18\end{array}$ & $\begin{array}{l}4.71 \pm 0.196 \\
(4.3-5.08) 85\end{array}$ & $\begin{array}{c}4.3 \pm 0.114 \\
(4.11-4.58) 28\end{array}$ & $\begin{array}{c}4.86 \pm 0.137 \\
(4.65-5.12) 16\end{array}$ & $\begin{array}{c}4.68 \pm 0.167 \\
(4.36-5.06) 43\end{array}$ \\
\hline Rostral length & $\begin{array}{c}8.16 \pm 0.205 \\
(7.76-8.39) 17\end{array}$ & $\begin{array}{c}9.31 \pm 0.337 \\
(8.45-10.09) 86\end{array}$ & $\begin{array}{c}7.36 \pm 0.163 \\
(7.09-7.75) 28\end{array}$ & $\begin{array}{c}8.25 \pm 0.285 \\
(7.77-8.95) 16\end{array}$ & $\begin{array}{l}8.15 \pm 0.363 \\
(7.2-9.17) 43\end{array}$ \\
\hline Postpalatal width & $\begin{array}{c}3.84 \pm 0.12 \\
(3.59-4.03) 18\end{array}$ & $\begin{array}{l}4.02 \pm 0.156 \\
(3.7-4.38) 85\end{array}$ & $\begin{array}{c}3.34 \pm 0.106 \\
(3.15-3.68) 28\end{array}$ & $\begin{array}{c}3.96 \pm 0.18 \\
(3.7-4.36) 16\end{array}$ & $\begin{array}{c}3.88 \pm 0.147 \\
(3.57-4.22) 43\end{array}$ \\
\hline Rostral width & $\begin{array}{c}2.65 \pm 0.147 \\
(2.46-3.03) 17\end{array}$ & $\begin{array}{c}3.02 \pm 0.17 \\
(2.62-3.58) 86\end{array}$ & $\begin{array}{c}2.47 \pm 0.172 \\
(2.08-2.71) 28\end{array}$ & $\begin{array}{c}2.96 \pm 0.139 \\
(2.73-3.18) 16\end{array}$ & $\begin{array}{l}2.73 \pm 0.198 \\
(2.31-3.2) 43\end{array}$ \\
\hline $\begin{array}{l}\text { Postpalatal } \\
\text { length }\end{array}$ & $\begin{array}{l}8.89 \pm 0.222 \\
(8.4-9.23) 18\end{array}$ & $\begin{array}{c}9.79 \pm 0.366 \\
(8.9-10.54) 80\end{array}$ & $\begin{array}{c}8.41 \pm 0.231 \\
(8.08-9.03) 27\end{array}$ & $\begin{array}{c}9.1 \pm 0.297 \\
(8.7-9.87) 15\end{array}$ & $\begin{array}{c}8.89 \pm 0.304 \\
(8.41-9.51) 44\end{array}$ \\
\hline $\begin{array}{l}\text { Condyle to gle- } \\
\text { noid fossa }\end{array}$ & $\begin{array}{c}7.93 \pm 0.186 \\
(7.52-8.24) 18\end{array}$ & $\begin{array}{l}8.37 \pm 0.281 \\
(7.78-8.9) 80\end{array}$ & $\begin{array}{c}7.72 \pm 0.134 \\
(7.47-8.01) 27\end{array}$ & $\begin{array}{c}8.09 \pm 0.194 \\
(7.77-8.43) 15\end{array}$ & $\begin{array}{c}7.93 \pm 0.224 \\
(7.35-8.49) 43\end{array}$ \\
\hline $\begin{array}{l}\text { Upper toothrow } \\
\text { length }\end{array}$ & $\begin{array}{c}8.84 \pm 0.229 \\
(8.35-9.19) 17\end{array}$ & $\begin{array}{c}10.2 \pm 0.359 \\
(9.24-11.02) 86\end{array}$ & $\begin{array}{c}8.07 \pm 0.211 \\
(7.69-8.7) 28\end{array}$ & $\begin{array}{c}9.04 \pm 0.254 \\
(8.63-9.68) 16\end{array}$ & $\begin{array}{c}8.91 \pm 0.327 \\
(8.07-9.89) 43\end{array}$ \\
\hline P4 to M3 length & $\begin{array}{l}5.08 \pm 0.182 \\
(4.7-5.34) 18\end{array}$ & $\begin{array}{c}5.82 \pm 0.238 \\
(5.17-6.24) 86\end{array}$ & $\begin{array}{c}4.49 \pm 0.163 \\
(4.23-5.02) 28\end{array}$ & $\begin{array}{c}5.24 \pm 0.167 \\
(4.99-5.62) 16\end{array}$ & $\begin{array}{c}5.11 \pm 0.195 \\
(4.72-5.67) 43\end{array}$ \\
\hline $\begin{array}{l}\text { M2 to M2 labial } \\
\text { width }\end{array}$ & $\begin{array}{c}5.86 \pm 0.238 \\
(5.44-6.16) 17\end{array}$ & $\begin{array}{c}6.84 \pm 0.253 \\
(6.37-7.52) 86\end{array}$ & $\begin{array}{c}5.12 \pm 0.152 \\
(4.85-5.63) 28\end{array}$ & $\begin{array}{c}6.08 \pm 0.286 \\
(5.69-6.77) 16\end{array}$ & $\begin{array}{c}5.9 \pm 0.217 \\
(5.53-6.61) 43\end{array}$ \\
\hline Palatal width & $\begin{array}{c}2.52 \pm 0.085 \\
(2.36-2.64) 18\end{array}$ & $\begin{array}{c}2.74 \pm 0.134 \\
(2.45-3.19) 85\end{array}$ & $\begin{array}{c}2.25 \pm 0.096 \\
(2.01-2.43) 28\end{array}$ & $\begin{array}{c}2.49 \pm 0.118 \\
(2.31-2.8) 16\end{array}$ & $\begin{array}{c}2.46 \pm 0.105 \\
(2.24-2.71) 43\end{array}$ \\
\hline
\end{tabular}

a The sample mean \pm one standard deviation, the observed range in parentheses, and the sample size.

length is shorter than head-and-body length. The tail has inconspicuous applied hairs that are visible with the naked eye only on the distal third of tail length and sparse bristle hairs spread from the tail base to at least its midpoint (fig. 36A). The braincase is notably inflated, with great width, giving an overall wedge-shaped appearance when viewed from the dorsal aspect (fig. 37A). The squamosal-parietal suture is often open, leaving a tear-drop-shaped opening anteriorly, directly below the anterior opening of the sinus canal (sensu McDowell, 1958).

COMPARISONS: Crocidura musseri is smaller than members of the Elongata Subgroup and all Rhoditis Group members except C. pallida. It is larger than all members of the Small-Bodied
Group. Within the Ordinary Group, C. musseri is smaller than $C$. nigripes, slightly larger than the sympatric C. normalis, and comparable to C. ordinaria and C. solita. Relative to head-and-body length, C. musseri has a shorter tail than all members of the Long-Tailed and Rhoditis groups, $C$. nigripes, and the sympatric C. solita. The pelage of C. musseri is thicker than that of any other shrew species we recognize from Sulawesi, except C. caudicrassa. Overall, the color of C. musseri is substantially darker than specimens from the Long-Tailed and Rhoditis groups, C. lea, and C. mediocris. Within the Ordinary Group, C. musseri is slightly darker than C. solita and C. normalis. Relative to skull length, skull width at both the braincase and interorbital region is greater than most other spe- 


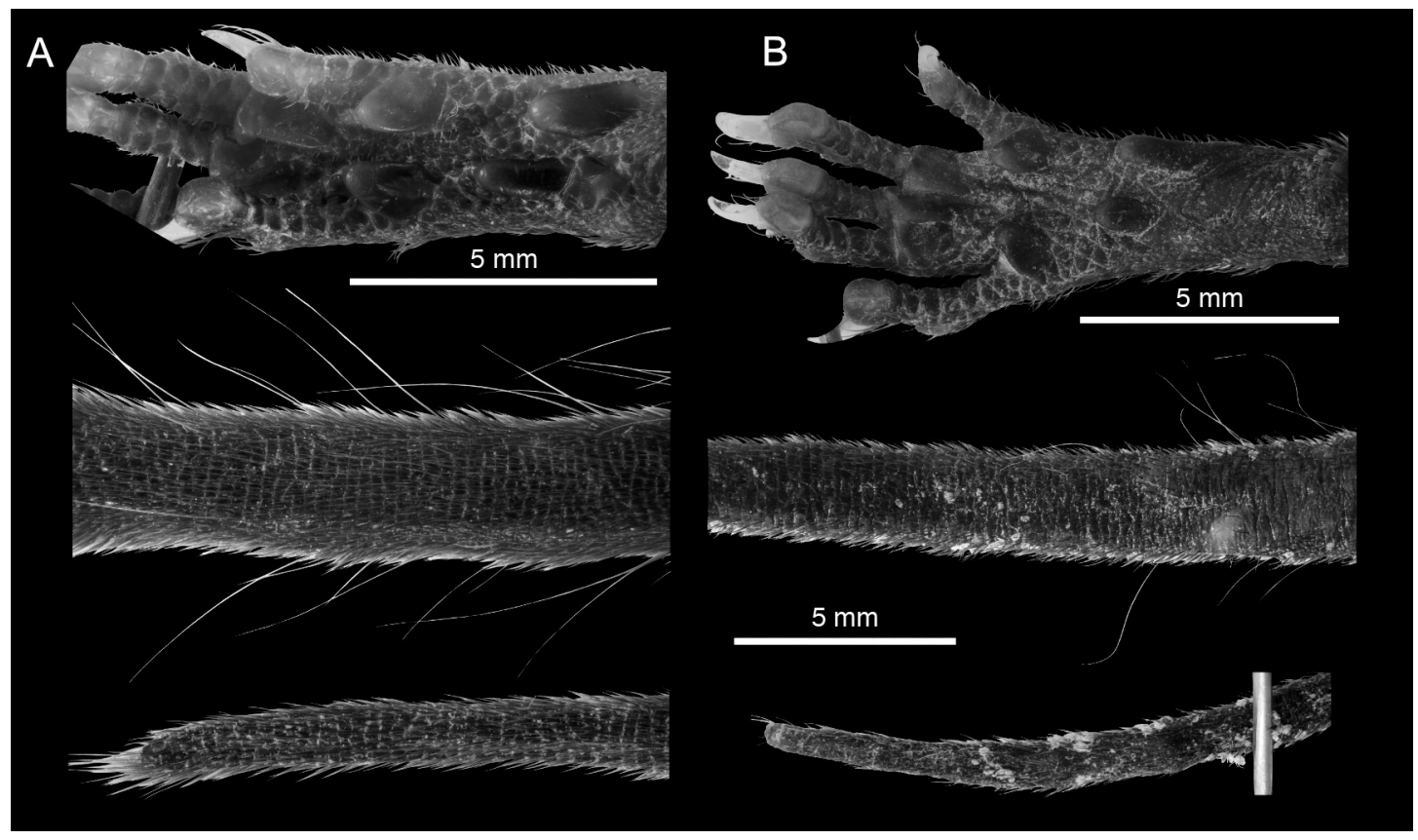

FIG. 36. Images showing the ventral surface of the right hind foot and dorsal surface of the tail base (approximately $1 \mathrm{~cm}$ from rump) and tail tip from two darkly pigmented members of the Ordinary Group: A, Crocidura musseri, FMNH 213267; and B, C. nigripes, LSUMZ 37018. Scale bars apply to all images in panel A and to foot (upper) and tail (lower) in panel B.

cies, including all members of the Ordinary Group (figs. 10, 37). The unusual width of the skull (table 14) gives $C$. musseri a more wedge-shaped appearance than any other species when viewed from the dorsal aspect (fig. 37A). Crocidura nigripes has a more angular braincase, a more robust dentition, and a much narrower relative interorbital region (IOW/CIL). Relative rostral length (RL/CIL) in $C$. musseri is less than in $C$. nigripes, but greater than in C. normalis (fig. 10). Crocidura musseri is distinguished from all sympatric shrews by a combination of its short tail length, thick and dark pelage, and wide, wedge-shaped skull with small teeth (figs. 9, 36, 40).

Comments: Our description of Crocidura musseri is based primarily on the series of specimens we collected in 2011 very near the type locality. This series matches the holotype (MZB 16791) and the description of Ruedi (1995). Cytochrome $b$ sequences from our series are identical to one from a paratype (IZEA 4403; Ruedi et al., 1998). None of our phylogenetic analyses supported a close relationship of $C$. musseri to any other species. Our mitogenome result placed C. musseri as sister to all other members of Sulawesi's endemic radiation with some support (fig. 5), while our UCE species tree placed it as sister to $C$. microelongata and $C$. pallida, but without statistical support (fig. 7).

SPECIMENS EXAMINED: Mt. Nokilalaki (AMNH 223495, 225516, 225517, 225521, 225525-225527, 225530, 225531), Mt. Rorekatimbo (FMNH 213249-213251, 213253-213256, 213258-213269, 213442, 213443; MZB 16791).

\section{Crocidura normalis, new species}

LSID: urn:lsid:zoobank. org:act:A639DEFB-7B56-4B2F-9916333Е95А 8 B499

HoLOTYPE: MZB 43010 (= FMNH 213437), an adult male, collected by J.A. Esselstyn on 27 


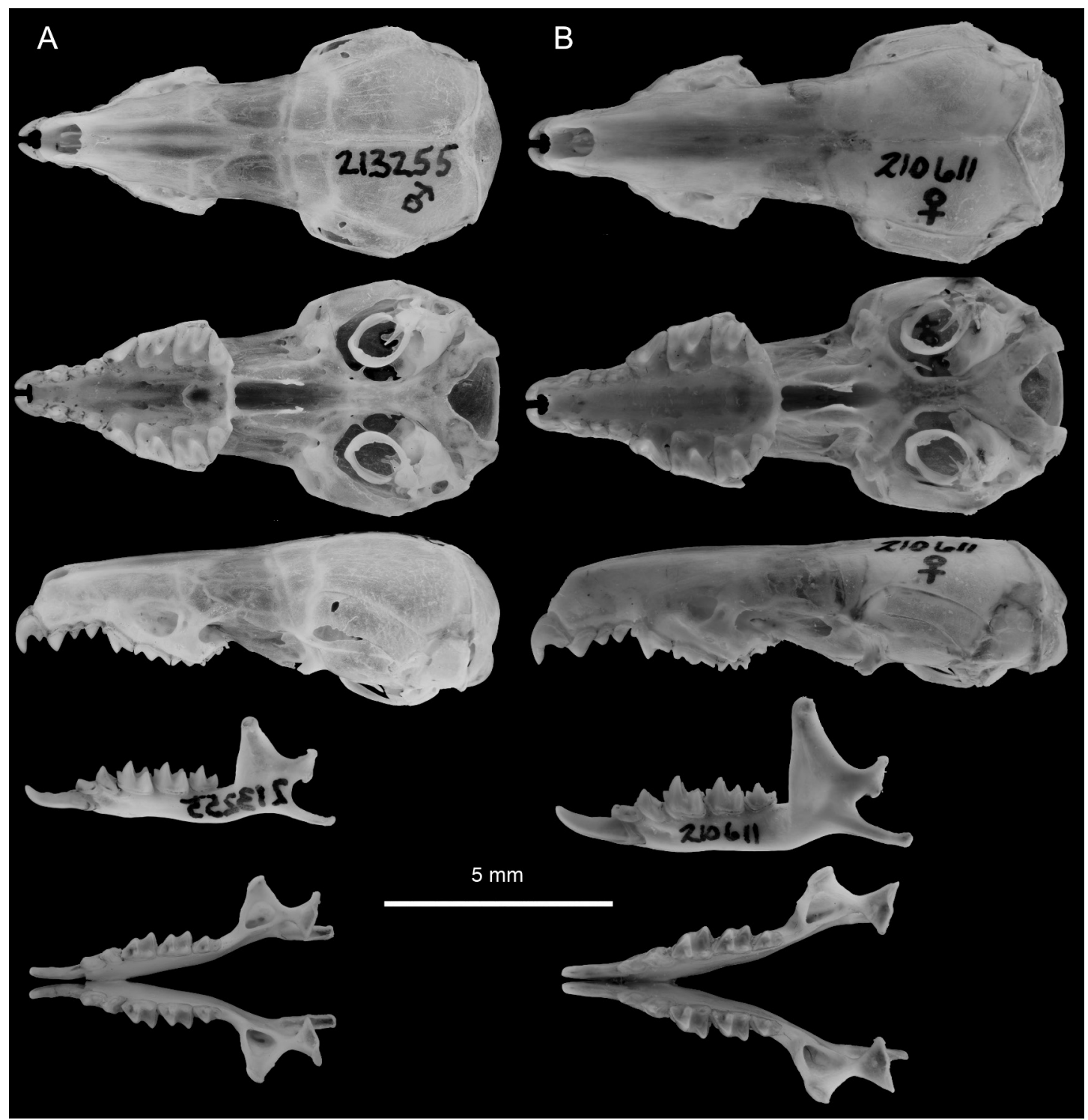

FIG. 37. Images showing dorsal, ventral, and lateral views of the skull and lateral and occlusal views of the dentary of two darkly pigmented members of the Ordinary Group: A, Crocidura musseri, FMNH 213255; and B, C. nigripes, FMNH 210611.

March 2011. The specimen was prepared as a study skin, cleaned skull (fig. 41A) and skeleton, and frozen tissues. External measurements from the holotype are: $124 \mathrm{~mm} \times 55 \mathrm{~mm} \times 13 \mathrm{~mm} \times 8$ $\mathrm{mm}=4.9 \mathrm{~g}$. The voucher specimen and a tissue sample will be permanently curated at MZB, with an additional tissue sample retained at FMNH.
Type Locality: Indonesia, Sulawesi Tengah, Poso, Huasa, Sedoa, Lore Lindu National Park, Mt. Rorekatimbo; $1.2884^{\circ} \mathrm{S}, 120.3104^{\circ} \mathrm{E}, 2250 \mathrm{~m}$.

Eтүмоlogy: Normalis is Latin for "normal," used in recognition that this is yet another species of shrew with no striking phenotypic traits worthy of attaching a descriptive name. 

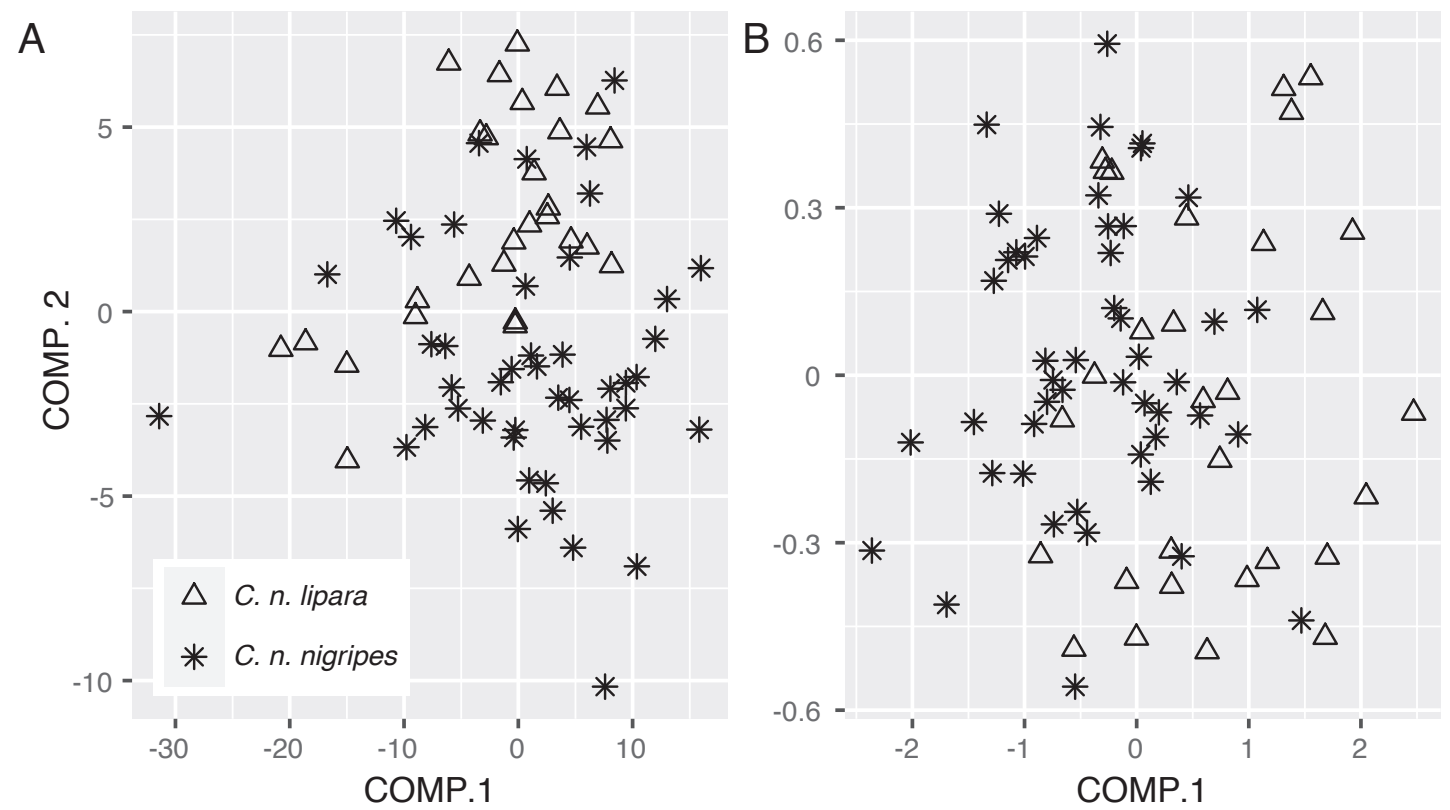

FIG. 38. Bivariate plot of the first two principal components from an analysis of A, five external measurements and B, 12 cranial variables from across the geographic distribution of Crocidura nigripes on Sulawesi. Specimens coded as C. $n$. nigripes are those from the northern peninsula and specimens from all other areas were designated as C. $n$. lipara, per the designations of Miller and Hollister (1921) and Ruedi (1995). Loadings and variance explained are given in tables 15 and 16.

GeOgRAPHiC Distribution: We recorded this species at relatively high-elevation sites in Sulawesi's west-central (Mt. Gandang Dewata, West Sulawesi Province; Mts. Latimojong and Rorekatimbo, Central Sulawesi Province), eastcentral (Mt. Katopasa, Central Sulawesi Province) and south-east areas of endemism (Mt. Mekongga, Southeast Sulawesi Province; figs. 13, 39). We found this species at sites ranging from 1400 to $2600 \mathrm{~m}$ (fig. 13, table 3).

Diagnosis: Crocidura normalis is a mediumsized shrew (tables 2, 14), with a light build (fig. 17) and dark brown pelage, feet, lips, pinna, and tail. Dorsoventrally, the color is relatively uniform. The mystacial vibrissae are short relative to body length and darkly pigmented proximally for about half of their length. The tail can be as long as head-and-body length but is usually shorter (fig. 9). It is relatively densely covered with bristles, many of which are darkly pigmented from the base of the tail along approxi- mately two-thirds of its length (fig. 40A). The small, applied hairs that typically cover the tail of Crocidura are less distinctly noticeable than in many other species. The feet are brown to black, usually uniformly so, including the digits and the thenar and hypothenar are subequal in area (fig. 40A). The claws are translucent. The skull is relatively gracile, being narrow across its entire length for a Crocidura of this size (fig. 10; table 14). Rostral length makes up a comparatively small proportion of skull length (fig. 10). The maxillary process is not prominent, the palate is narrow, and the occlusal surface area of the dentition is small relative to skull size (fig. 41A). The maxillary bridge is narrow.

COMPARISONS: Crocidura normalis is smaller than all members of the Long-Tailed, ThickTailed, and Rhoditis groups, and larger than all members of the Small-Bodied Group. As the smallest member of the Ordinary Group, C. normalis is only slightly larger than C. mediocris (the 
TABLE 15.

Results of Principal Components Analysis of Craniodental Measurements of Crocidura nigripes

\begin{tabular}{lcc}
\hline & Component 1 & Component 2 \\
Variables $^{\mathrm{a}}$ & & \\
\hline Condyloincisive length & 0.7122 & 0.2664 \\
Braincase breadth & 0.2566 & -0.4890 \\
Interorbital width & 0.1374 & -0.2795 \\
Rostral length & 0.2880 & 0.2761 \\
Postpalatal width & 0.0902 & -0.1729 \\
Rostral width & 0.0631 & -0.1442 \\
Postpalatal length & 0.3172 & -0.2060 \\
Condyle to glenoid fossa & 0.2488 & -0.1090 \\
Upper toothrow length & 0.3039 & 0.2937 \\
P4 to M3 length & 0.1800 & 0.0828 \\
M2 to M2 labial width & 0.1518 & -0.5245 \\
Palatal width & 0.0511 & -0.2497 \\
Proportion of variance & 0.7867 & 0.0681 \\
Cumulative proportion & 0.7867 & 0.8548 \\
\hline
\end{tabular}

a Table entries for variables are component loadings.

largest member of the Small-Bodied Group). It differs from C. mediocris in having a darker, denser pelage (individual hairs approximately 5 $\mathrm{mm}$ at middorsum) and longer tail both absolutely and relative to HBL (fig. 9). Within the Ordinary Group, C. musseri has a wider braincase relative to skull length, more robust body (fig. 17), longer rostrum relative to skull length (fig. 10), and paler feet than C. normalis. Crocidura nigripes has a short tail, like that of C. normalis, but is substantially larger, usually has darker feet, and the skull of $C$. nigripes shows a more prominent dentition, longer rostrum, and narrower interorbital region relative to skull length (fig. 10). Crocidura ordinaria and C. solita are slightly larger than $C$. normalis, have longer tails, both absolutely and relative to HBL, have hypothenar pads larger than thenar pads, and have greater relative rostral lengths (RL/CIL), braincase breadths $(\mathrm{BB} / \mathrm{CIL})$, and interorbital widths (IOW/CIL) (fig. 10).

Comments: In addition to the coalescent species delimitation analyses described above in the Crocidura parva account, we used BPP to test species limits between $C$. normalis and C. mediocris. The dataset consisted of 20 specimens of $C$. mediocris and 36 individuals of $C$. normalis. The sequence alignment is $93 \%$ complete. All replicates supported these species with 1.0 posterior probability. Unfortunately, we do not have nuclear exon data from the two specimens of C. normalis from Mt. Mekongga, which formed a clade independent of $C$. normalis from other localities in the cytochrome $b$ and mitogenome gene trees (figs. 4, 5). In our UCE inferences, the Mekongga specimens of $C$. normalis are represented and the species is monophyletic in both our species tree and concatenated estimates (figs. 7, 8). If specimens from additional localities from the south-east and west-central areas of endemism are collected, reexamining these populations would be worthwhile. In both UCE estimates, C. normalis is a member of a clade comprising several Small-Bodied Group members and C. caudipilosa (figs. 7, 8). 
TABLE 16

Results of Principal Components Analysis of External Measurements of Crocidura nigripes

\begin{tabular}{lcc}
\hline & Component 1 & Component 2 \\
Variables $^{\mathrm{a}}$ & & \\
\hline Total & 0.8466 & 0.4999 \\
Tail & 0.5281 & -0.8149 \\
Hind foot & 0.0580 & -0.0325 \\
Ear & 0.0135 & 0.1058 \\
Mass & 0.0277 & 0.2717 \\
Proportion of variance & 0.7943 & 0.1463 \\
Cumulative proportion & 0.7943 & 0.9406 \\
\hline
\end{tabular}

a Table entries for variables are component loadings.

Ruedi (1995) referred three specimens (IZEA 4393, 4394, 4042) to Crocidura lea and later Ruedi et al. (1998) sequenced a fragment of cytochrome $b$ in one of these individuals (IZEA 4394). That sequence is identical to our C. normalis cytochrome $b$ sequences from Mt. Rorekatimbo. Although we have not examined these three specimens, we presume they all represent C. normalis.

Specimens examined: Mt. Gandang Dewata (MZB 34809, 34810, 34812, 34821; FMNH 218604-218613, 218652-218658, 218973218975), Mt. Katopasa (NMV Z61813), Mt. Latimojong (FMNH 213006-213008, 213010, 213011, 213013, 213014, 213030, 213032; MVZ 237595, 237622-237624), Mt. Mekongga (MWFB 8151, 8154), Mt. Rorekatimbo (FMNH 213174213189, 213257, 213438; MZB 43010).

Crocidura ordinaria, new species

LSID: urn:lsid:zoobank. org:act:62BBDEF5-DF9F-45B8-BA4F0CCDDB65B8AD

Holotype: MZB 43011 (= FMNH 218726), an adult male, collected on 5 May 2012 by J.A. Esselstyn. The specimen comprises a skull (fig. 41B), formalin-fixed body, and frozen tissues. External measurements from the holotype are $142 \mathrm{~mm} \times 65 \mathrm{~mm} \times 16 \mathrm{~mm} \times 10 \mathrm{~mm}=11.0 \mathrm{~g}$.
The voucher specimen and a tissue sample will be permanently curated at MZB and an additional tissue sample will be retained at FMNH.

Type Locality: Indonesia, Sulawesi Barat, Mamasa, Mamasa, Tondok Bakaru, Rantepangko, Mt. Gandang Dewata; $2.8181^{\circ} \mathrm{S}$, $119.3823^{\circ} \mathrm{E}, 2200 \mathrm{~m}$ elevation.

Eтумоlogy: Ordinaria is Latin for "ordinary," used in recognition that this is yet another species of shrew with no striking or unique phenotypic traits worthy of a descriptive name.

Geographic Distribution: Crocidura ordinaria is found in the west-central area of endemism (Mt. Gandang Dewata, West Sulawesi Province and Mt. Torompupu, Central Sulawesi Province) (fig. 39). The species spans an unusually broad elevational range from approximately 200 to 2600 m (fig. 13; table 3).

Diagnosis: A moderately sized shrew (tables $2,14)$ with a somewhat stocky build. The pelage is medium to dark gray-brown and thick, with hairs at the middorsum typically 6-7 $\mathrm{mm}$ long. The venter is paler, with hairs that are pale gray at the tip, but dark gray at the base. In some specimens, the tips of some ventral hairs are reddish brown, giving the belly and chest pale cinnamon highlights. The mystacial vibrissae are short and darkly pigmented for at least half their lengths. Dorsally, the feet are nearly as dark as the pelage, but some specimens have much paler 


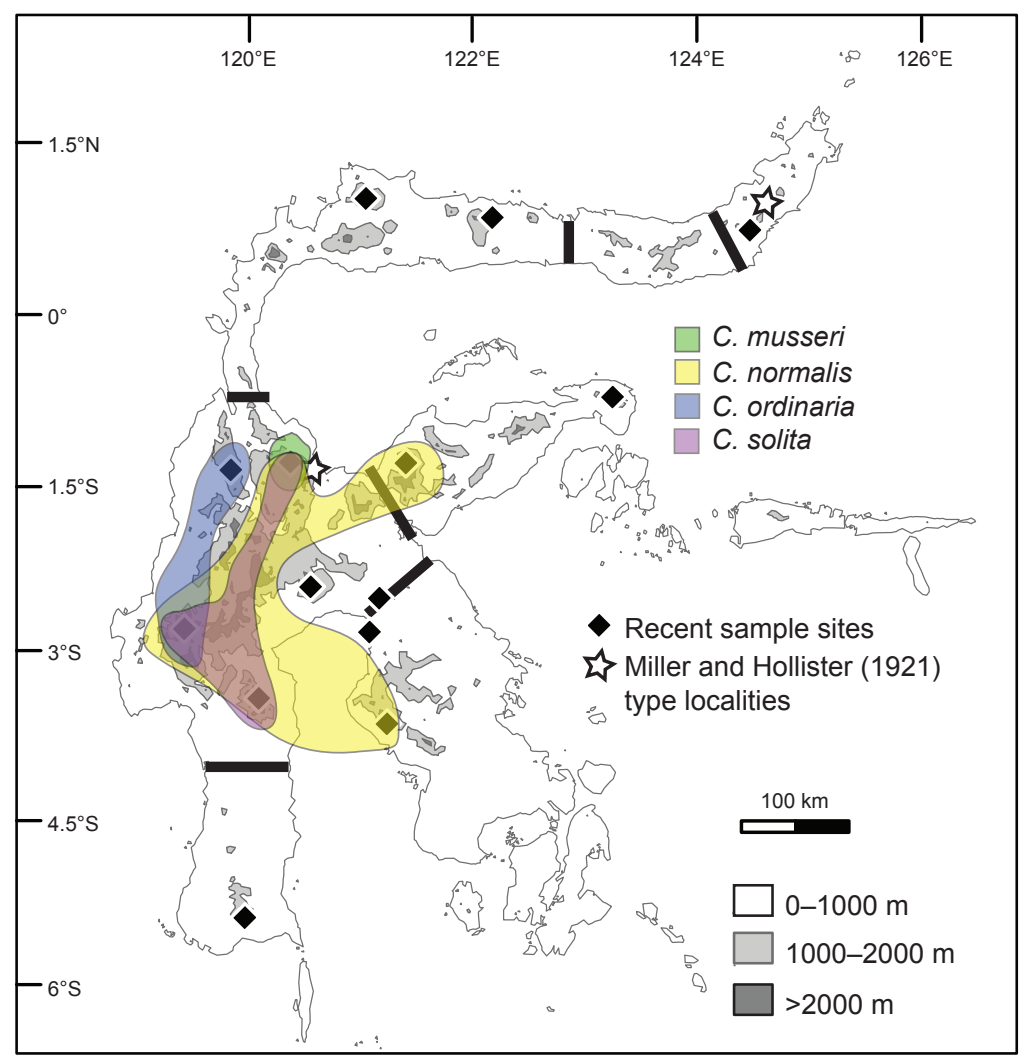

FIG. 39. Map of Sulawesi showing localities sampled for shrews. Colored areas enclose localities with known records of members of the Ordinary Group. To maintain clarity of presentation, the widespread Crocidura nigripes is not included.

digits (fig. 40B). The tail is shorter than head and body (fig. 9) and the abundance of tail bristles and applied hairs is variable. The skull of this species is typical in its length (relative to body size) for a Sulawesi shrew but is wide at the braincase and interorbital region relative to skull length (fig. 10; table 14). The braincase, though broad, is not especially inflated vertically. The dentition is more prominent than expected given the palatal width (fig. 41B), but, otherwise, the skull of Crocidura ordinaria is unremarkable.

Comparisons: Crocidura ordinaria is a moderately sized member of the Ordinary Group. The tail is shorter than head-and-body length (fig. 9; table 2). Members of the LongTailed Group are larger and have much longer tails. Rhoditis Group members C. rhoditis and
C. pseudorhoditis are larger. Crocidura pallida and $C$. australis, also members of the Rhoditis Group, are only slightly larger than C. ordinaria in head-and-body length. Compared to $C$. ordinaria, C. pallida has paler feet dorsally, a narrower relative braincase breadth $(\mathrm{BB} / \mathrm{CIL})$ and a narrower relative interorbital width (IOW/CIL) whereas C. australis has a narrower relative interorbital width, but wider relative braincase breadth than C. ordinaria (fig. 10). All members of the Small-Bodied Group are much smaller than $C$. ordinaria. Within the Ordinary Group, C. nigripes has darker feet and a relatively much narrower interorbital region and braincase than C. ordinaria. Compared to C. ordinaria, C. musseri has a thicker, darker pelage, and darker feet. Crocidura normalis is 


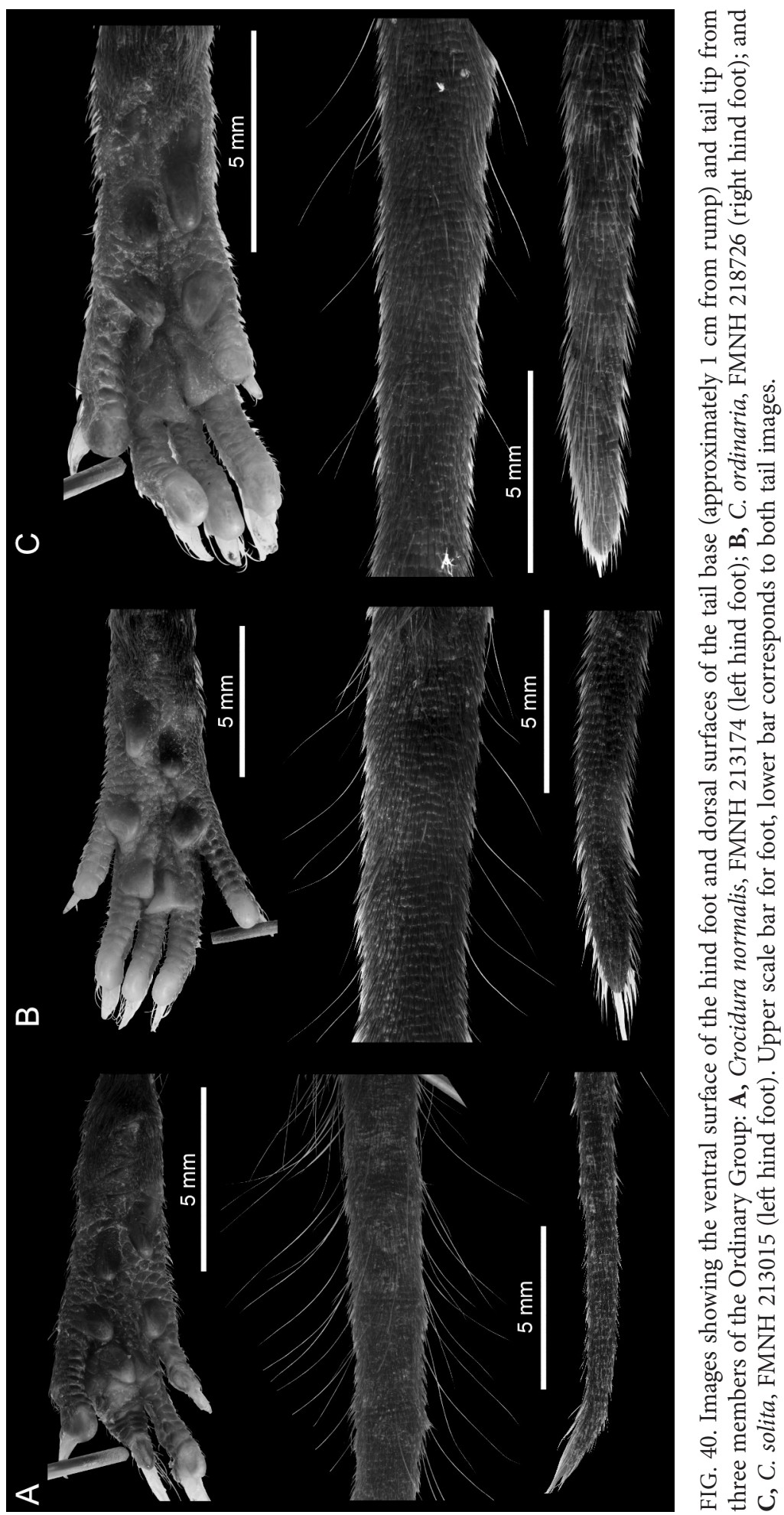




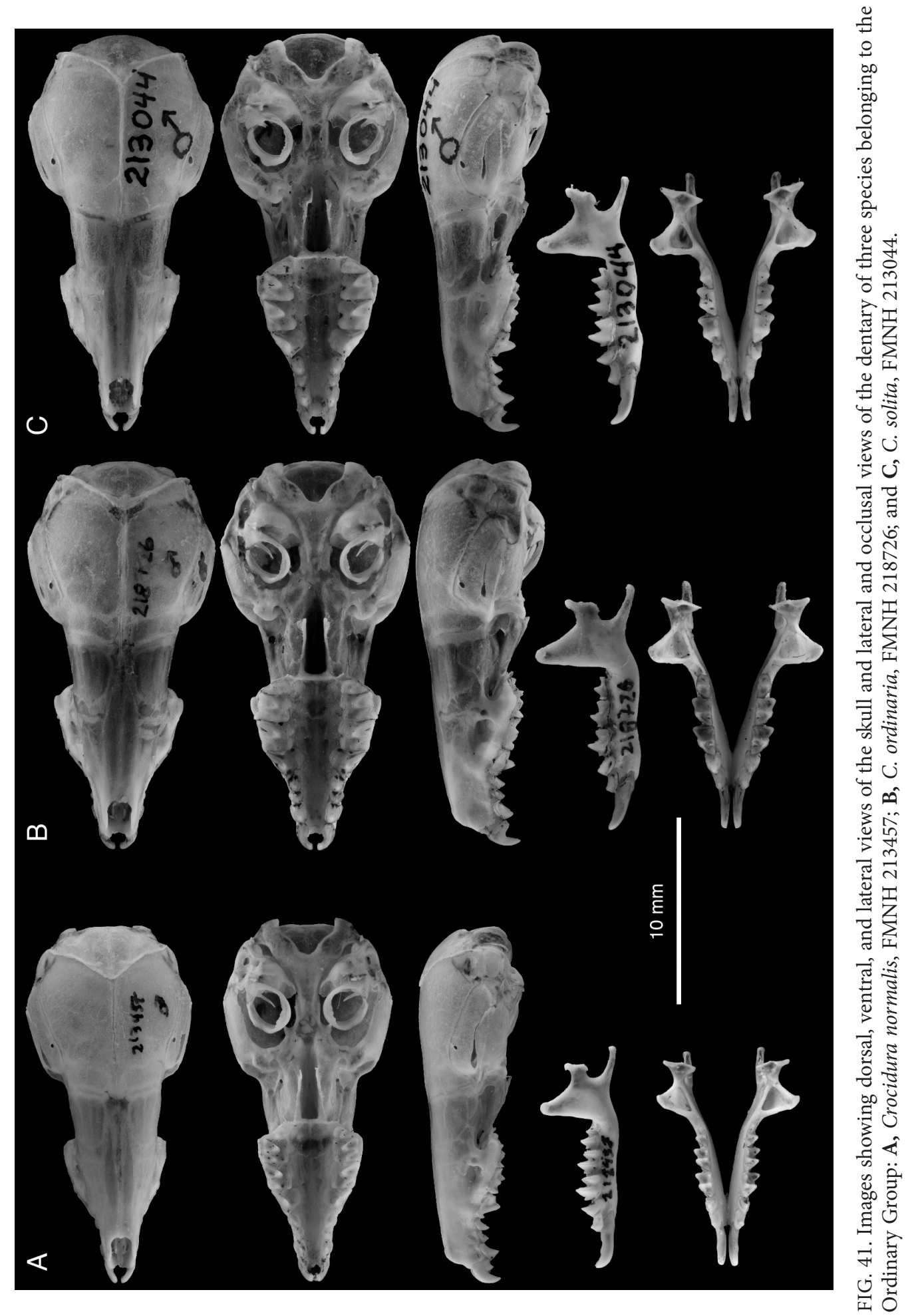



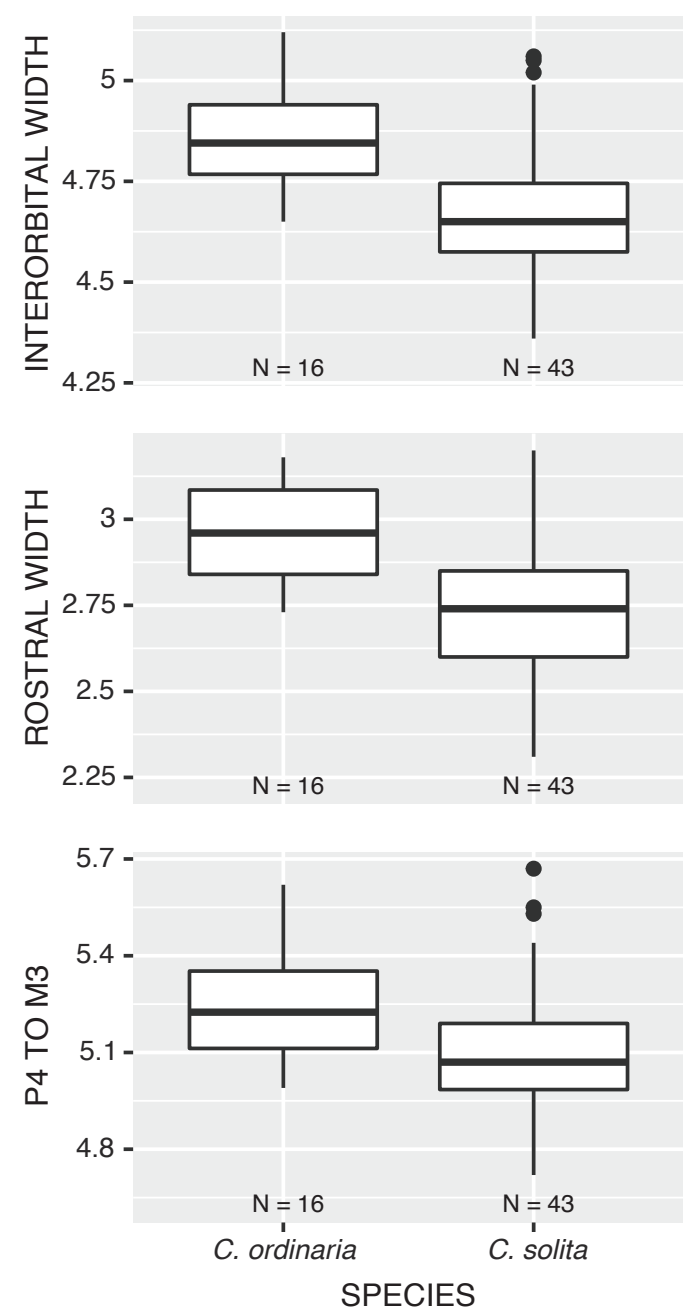

FIG. 42. Box plots showing subtle differences in cranial measurements between Crocidura solita and $C$. ordinaria, two members of the Ordinary Group. Plots show the median, 1 st and 3rd quartiles, the maximum value within $1.5 \times$ interquartile range (distance between 1st and 3rd quartiles; IQR), the minimum value within $1.5 \times \mathrm{IQR}$, and outliers (black circles). Sample sizes are shown along the $\mathrm{x}$-axis. All measurements in $\mathrm{mm}$. darker in color, smaller in body size, has more bristles on its darkly colored tail, and its skull is narrower with a shorter relative rostral length (RL/CIL) than C. ordinaria. Crocidura solita, another member of the Ordinary Group, is difficult to distinguish morphologically from $C$. ordinaria. External measurements are nearly identical between these two species (fig. 9), but C. ordinaria has a higher mass-to-length ratio (fig. 17). The pelage and feet of C. ordinaria are darker and have a smaller hypothenar (fig. 40), on average, than in C. solita. Cranially, $C$. ordinaria has a wider skull, observable in the absolute and relative breadths at the rostrum, interorbital region, and braincase (figs. 10, 42; table 14). Principal components analyses of external and cranial dimensions show that these two species overlap broadly in multivariate morphometric space, more so with external measurements than with cranial measurements (fig. 43; tables 17, 18).

Comments: See extensive comments detailing our decision to distinguish this species from Crocidura solita in the next species account.

Specimens examined: Mt. Gandang Dewata (FMNH 218727-218743, 218763-218767, 218769, 218771, 218772; MZB 34806, 34808, $34816,34820,34827,34833,34856,34870$, 34871, 34876, 34877, 34883, 43011; NMV Z21910, Z21911, Z21938), Salu Tiwo (FMNH 218744), Mt. Torompupu (LSUMZ 39480; NMV C40252, C40273).

\section{Crocidura solita, new species}

LSID: urn:lsid:zoobank. org:act:B8B27A48-E1C7-47F1-B0B8$938722284 \mathrm{C} 32$

Holotype: MZB 43012 (= FMNH 213044), an adult male collected 1 March 2011 by J.A. Esselstyn. The specimen consists of a cleaned skull, fluid preserved body, and frozen tissue samples. External measurements from the holotype are $147 \mathrm{~mm} \times 68 \mathrm{~mm} \times 16 \mathrm{~mm} \times 9 \mathrm{~mm}=$ $9.5 \mathrm{~g}$. The voucher specimen with a tissue sample 

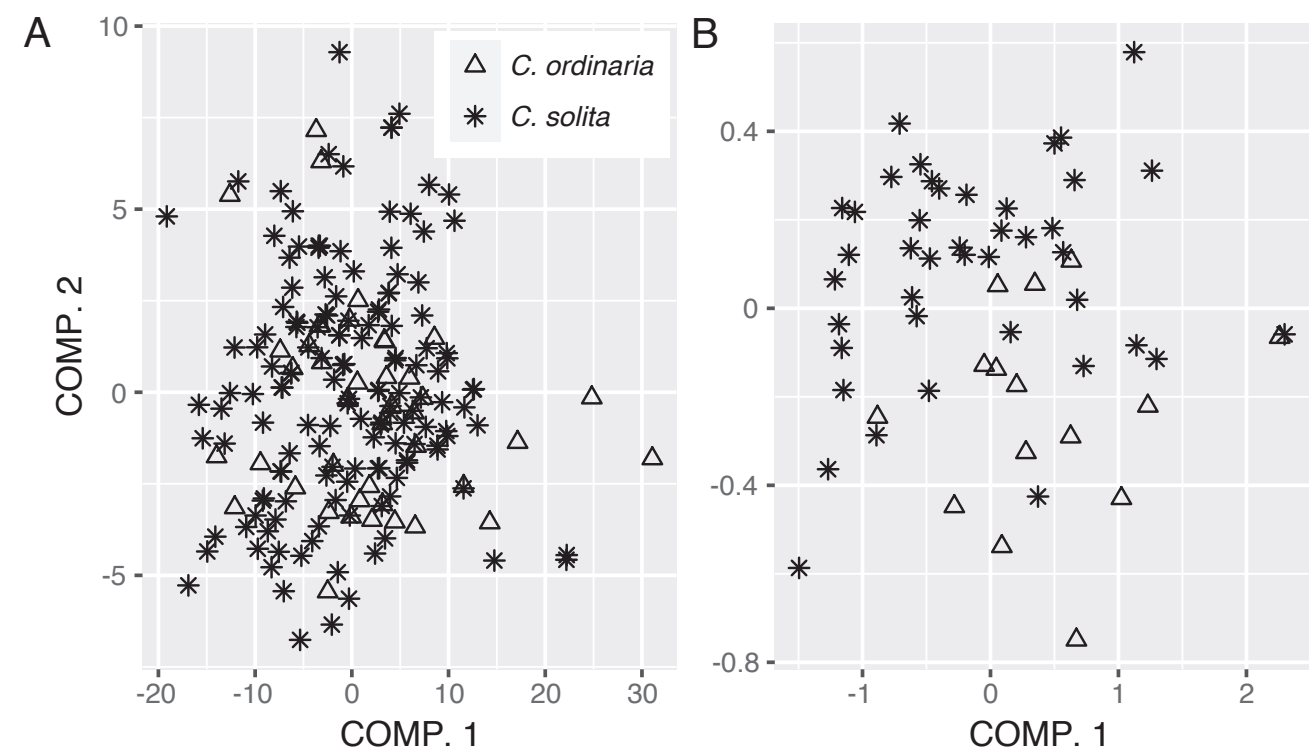

FIG. 43. Bivariate plots showing the first two axes from principal components analyses of A, five external and B, 12 cranial measurements from Crocidura solita and C. ordinaria, two members of the Ordinary Group. Loadings and variance explained are given in tables 17 and 18, respectively.

will be permanently curated at MZB, with an additional tissue sample retained at FMNH.

Type LOCALity: Indonesia; Sulawesi Selatan; Enrekang; Buntu Bato; Latimojong Village; Karangan; Mt. Latimojong, Bantanase; $3.40755^{\circ}$ S, $120.0078^{\circ}$ E, $2050 \mathrm{~m}$.

Eтymology: Solita is Latin for "usual," used in recognition that this is another species of shrew with no striking phenotypic traits worthy of attaching a descriptive name.

GEOGRAPHIC DISTRIBUTION: We recorded Crocidura solita on three mountains in the west-central area of endemism (Mts. Latimojong and Rorekatimbo, Central Sulawesi Province; and Mt. Gandang Dewata, West Sulawesi Province; fig. 39). Records of this species span a broad range of elevations, from 700 to $2600 \mathrm{~m}$. On Mt. Gandang Dewata, C. solita occurred syntopically with its sister species, C. ordinaria, at middle and high elevations (around 1600 and $2600 \mathrm{~m}$; fig. 13; table 3).

DiAgnosis: A medium-sized shrew (tables 2, 14) with a medium gray dorsal pelage and lighter gray ventral pelage. Tail length is slightly shorter than head-and-body length (fig. 9). The tail is only slightly bicolored, but some individuals have at least a few white applied hairs, giving it a somewhat silvery appearance, particularly near the tip. Dorsally, the feet are paler than the surrounding pelage, typically transitioning from light brown posteriorly to nearly white on the digits (fig. 40C). Ventrally, the feet are darker around the thenar and hypothenar pads than on the surrounding plantar and palmar surfaces; the hind feet tend to be darker than the forefeet. The external ears are slightly paler than the surrounding pelage. The mystacial vibrissae are short and mostly unpigmented, but a few of the longer, more posterior vibrissae are pigmented at their base. The skull is average in length (relative to HBL) for a Sulawesi shrew and slightly wide at the braincase and interorbital region relative to skull length (fig. 10). The braincase is rounded, but with a somewhat prominent lambdoidal crest (fig. 41C). The suture between the squamosal and parietal bones is often open, leaving a long slit below the sinus canal. The interorbital region is well tapered. The maxillary bridge is thin. 
TABLE 17

Results of Principal Components Analysis of Craniodental Measurements of Crocidura ordinaria and C. solita

\begin{tabular}{lcc}
\hline & Component 1 & Component 2 \\
Variables $^{\mathrm{a}}$ & & \\
\hline Condyloincisive length & 0.6484 & 0.2373 \\
Braincase breadth & 0.2346 & -0.4093 \\
Interorbital width & 0.1273 & -0.3353 \\
Rostral length & 0.3585 & 0.3436 \\
Postpalatal width & 0.1031 & -0.2452 \\
Rostral width & 0.0905 & -0.5550 \\
Postpalatal length & 0.3174 & -0.0198 \\
Condyle to glenoid fossa & 0.2210 & -0.1585 \\
Upper toothrow length & 0.3387 & 0.2051 \\
P4 to M3 length & 0.1900 & -0.0701 \\
M2 to M2 labial width & 0.2352 & -0.3234 \\
Palatal width & 0.0730 & -0.0226 \\
Proportion of variance & 0.7582 & 0.0779 \\
Cumulative proportion & 0.7582 & 0.8361 \\
\hline
\end{tabular}

a Table entries for variables are component loadings.

COMPARISONS: For comparisons to most species, see the Crocidura ordinaria comparisons section above. Compared to C. ordinaria, the pelage is less dense (i.e., shorter hairs on the dorsum) and both the pelage and feet are paler on average and the body is less stocky (fig. 17). The skull of C. solita is slightly smaller, and it is also narrower both absolutely and relative to skull length (figs. 10, 42), with a narrower palate and less robust dentition (table 14). The suture between the squamosal and parietal bones is often open, leaving a long slit in C. solita, but this suture is usually closed in C. ordinaria.

Comments: We posit that Crocidura solita and C. ordinaria are phenotypically similar sister species. Morphologically, we note subtle differences of body size, relative skull widths, and coloration. In the absence of other evidence, these slight morphological differences would be too little to justify dividing these specimens into two species, and we would not have suspected multiple taxa were represented by these specimens if it were not for our use of mitochondrial sequences. Syntopic specimens of these two species from Mt. Gandang Dewata are separated by a mitochondrial Jukes-Cantor distance of 0.064 ( 0.087 when all specimens are used in the calculation) and specimens of each species from the zone of parapatry is more closely related in the mitochondrial gene tree to conspecifics from other parts of the island (figs. 4, 5; supplementary data S2-S5). The mitochondrial distance between syntopic individuals and closer relatedness to allopatric populations suggests that these phenotypically similar animals are most likely evolving independently of each other.

In our mitochondrial gene trees, Crocidura ordinaria and C. solita are well-supported sister taxa and reciprocally monophyletic (figs. 4, 5). Our inferences using UCEs again indicate a close relationship with the two species forming a clade, but each species is reciprocally paraphyletic in our concatenated and species-tree inferences, the latter of which treated individuals as "species" and therefore did not force monophyly (figs. 7, 8). Our phylogenetic estimate from concatenated 
TABLE 18

Results of Principal Components Analysis of External Measurements of Crocidura ordinaria and C. solita

\begin{tabular}{lcc}
\hline & Component 1 & Component 2 \\
Variables $^{\mathrm{a}}$ & & \\
\hline Total & 0.9132 & 0.3972 \\
Tail & 0.3997 & -0.9128 \\
Hind foot & 0.0381 & -0.0278 \\
Ear & -0.0087 & -0.0835 \\
Mass & 0.0690 & 0.0352 \\
Proportion of variance & 0.8298 & 0.1263 \\
Cumulative proportion & 0.8298 & 0.9561 \\
\hline
\end{tabular}

a Table entries for variables are component loadings.

nuclear exons also inferred reciprocal paraphyly for this species pair (supplementary data S6).

We tested species delimitation models with BPP between Crocidura solita and C. ordinaria using a dataset that included 64 C. solita and 22 C. ordinaria sampled from across their ranges. The alignment of five exons is $82 \%$ complete. All analyses of this dataset supported species delimitation with 1.0 posterior probability.

Overall, we interpret the combination of subtle morphological differences (weak evidence), deep mitochondrial divergence in the face of syntopy (strong evidence), and our BPP results (modest evidence) as supporting species distinction. We conclude that the paraphyly in our UCE inferences is most likely the result of incomplete lineage sorting and ancestral polymorphism. In coming to this conclusion, we are admittedly leaning heavily on mitochondrial data. However, the great differences between the mitochondrial sequences where the two species cooccur provides strong evidence for differentiation, at least between females. If these specimens represented a single species, we presume that any substantive gene flow would lead to one of the divergent mitochondrial types being favored, either because it is independently superior to the other, or because it is superior in its integrative functioning with the relevant parts of the nuclear genome (sensu Sloan et al., 2017; Hill, 2019). Mitochondria are foundational to energy metab- olism; viewing them as a neutrally evolving locus would ignore their functional importance and extensive interactions with nuclear gene products (Nabholz et al., 2008; Lane, 2011; Sloan et al., 2017; Tobler et al., 2019). Although many cases of mitochondrial divergence within species have been documented, they rarely involve sympatry of the divergent mitochondrial types (but see Wayne et al., 1990; Morgan-Richards et al., 2017), and far more often than not, mitochondrial divergence is consistent with species limits (Hebert et al., 2003; Monaghan et al., 2005; Esselstyn et al., 2012a; Cao et al., 2016). Taking in all the evidence, we believe these two sets of samples represent independently evolving populations that should be recognized as species despite the limited evidence for phenotypic or nDNA differentiation.

Specimens examined: Mt. Gandang Dewata (FMNH 218770, 218773-218780, 218976; MZB $34807,34811,34813,34814,34823,34826$, 34828, 34829, 34831, 34881, 34885, 34887), Mt. Latimojong (MZB 41669-41677; FMNH 213009, 213012, 213015-213019, 213029, 213031, 213033-213037, 213039-213043, 213045213071; MVZ 237585-237593, 237596, 237598, 237599, 237611, 237617, 237619-237621, 237628, 237634, 238122; MZB 43012; NMV C38479, C38493, C38516), Mt. Rorekatimbo (FMNH 213163, 213194-213245, 213270), Rindingallo, Tana Toraja (MSB 93125). 


\section{DISCUSSION}

Through a combination of extensive biodiversity inventories, multiscale DNA sequencing efforts, and morphological study of over a thousand specimens, we identified support for the presence of 21 species of Crocidura on Sulawesi, tripling the previously known diversity (Esselstyn et al., 2019). Among the 21 species recognized in this report, most are supported by differences in mitochondrial sequences, nuclear DNA, and morphology. In cases where we found genetically divergent animals with modest or greater phenotypic differences, and partial sympatry, we considered the evidence for species differentiation incontrovertible (e.g., $C$. quasielongata and C. elongata; C. lea and C. baletei; and C. pseudorhoditis and C. rhoditis). However, other species required more careful judgement. These included genetically divergent but phenotypically similar allopatric populations (e.g., C. baletei and C. tenebrosa; C. brevicauda and C. caudicrassa; and C. mediocris and $C$. parva) and mitochondrially divergent sympatric populations with minimal phenotypic differentiation (C. ordinaria and C. solita). Among the divergent but allopatric populations, we divided them into species if we found consistent morphological differences, even if those differences were subtle. Our conclusions were often reinforced by our understanding of geography. Some species appear restricted to "islands" of montane habitat, and this geographic scenario gave us further confidence to split these populations (e.g., C. baletei and C. tenebrosa; C. brevicauda and C. caudicrassa). Crocidura mediocris and C. parva fit this pattern too, with the former present in the west-central and south-east areas of endemism and the latter identified only in the south-west area of endemism (fig. 25). However, unlike the previously mentioned pairs of species, these taxa were reciprocally paraphyletic in our UCE- and exon-based phylogenetic inferences (fig. 7; supplementary data S6). These nuclear loci evolve slowly compared with mitochondrial sequences, and paraphyly caused by incomplete lineage sorting is expected for recently diverged taxa (e.g., Patton and Smith, 1994). We concluded that the sum of mitochondrial divergence, geographic isolation, and subtle morphological differentiation presents stronger evidence for speciation than nDNA paraphyly presents against speciation, and thus we treated these as distinct species. We did not, however, divide all mitochondrially divergent populations into separate species. Several morphologically cohesive, but mitochondrially diverse species are diagnosed here, including C. pallida, C. mediocris, C. quasielongata, and $C$. normalis, among others (fig. 4; supplementary data S2, S3).

Another difficult case was that of Crocidura ordinaria and C. solita, which revealed distinct mitochondrial sequences in sympatric populations (fig. 39). In contrast to the mitochondrial clarity in support of speciation, we found few morphological differences between these taxa, which also exhibit reciprocal paraphyly in our UCE- and exon-based trees. Systematists often struggle with decisions over whether to consider geographically isolated populations with divergent mitochondrial DNA as distinct species (e.g., C. mediocris and C. parva), but when the divergent mitochondrial genotypes are found in sympatry, this provides much stronger evidence for a lack of gene flow. By describing C. ordinaria and C. solita, we attribute their UCE and exon paraphyly to incomplete lineage sorting, which, as stated above, is expected for relatively young species.

Gene flow can also produce paraphyly, but that would almost certainly result in a single mitochondrial genotype sweeping through the mixing populations. We expect this to be the case because mitochondrial DNA plays important functional roles, and many essential metabolic proteins are assembled from a combination of mitochondrial- and nuclear-encoded products (Alston et al., 2017; Pichaud et al., 2019). Effective energy conversion therefore requires cofunctioning mitochondrial and nuclear genomes (Lane, 2011; Wolff et al., 2014; Rank et al., 2020). We consider it unlikely that two deeply divergent 
mitochondrial genotypes would stably coexist in a population of freely mating individuals because a single nuclear genome is unlikely to function equally well with two such different mitochondrial genomes. While sympatric but divergent mitochondrial genotypes within species are not unheard of (e.g., Wayne et al., 1990; MorganRichards et al., 2017; Morales et al., 2018), this pattern appears to be rare in nature. Far more often than not, mitochondrial divergence is correlated with species boundaries, hence the general, though not complete, success of mitochondrial barcodes in species delimitation (e.g., Bradley and Baker, 2001; Monaghan et al., 2005; Esselstyn et al., 2012a; Cao et al., 2016; Hill, 2016), despite theoretical predictions that they would often fail (e.g., Hickerson et al., 2006; Sloan et al., 2017). Because divergent mitochondria combined with sympatry provides relatively strong evidence for a lack of gene flow, whereas nuclear paraphyly and limited morphological differentiation are weak forms of evidence consistent with multiple taxonomic hypotheses, we chose to follow the strong signal of the mitochondria and describe these as distinct species.

Our conclusions regarding species limits would have been difficult to achieve without a substantial, multifaceted effort. We conducted multimonth expeditions to Sulawesi nearly every year from 2010 to 2018, with up to six months of field time in some years. Our expansive inventories provided the specimen material needed to disentangle complex patterns of phenotypic variation. For example, dividing specimens from any single locality into morphospecies usually was comparatively simple, whereas assigning specimens from allopatric populations to the same species with morphology alone proved difficult. In general, the conservative morphology of shrews can mask the difference between interspecific boundaries and intraspecific geographic variation. However, the availability of large series of specimens with genetic data allowed us to detect subtle differences in quantitative and qualitative traits that might have otherwise gone unnoticed. Shrew systematists have faced similar challenges understanding systematic relationships in continental systems (e.g., Woodman and Timm, 1993; Stanley and Esselstyn, 2010; Baird et al., 2017). On Sulawesi, the apparent commonness of convergent or parallel evolution in this radiation further obfuscated the morphological nature of species boundaries. For instance, the three members of the Elongata Subgroup did not form a clade in any of our phylogenetic analyses, despite sharing multiple morphological traits that are otherwise unique among the island's 21 species. The challenge of identifying allopatric populations of any single species in the presence of an abundance of morphologically similar species that are not close relatives created another obstacle: the difficulty of knowing which of the preliminary species we had delimited represented species already described by Miller and Hollister (1921). Resurveying type localities probably would not have resolved our dilemma because these once forested habitats are now cleared and unlikely to hold the same shrew species they did a century ago. As such, obtaining genetic data from the type series was essential. Without this, we would have had a difficult time knowing which of our delimited species were already named. ${ }^{1}$

Despite the many challenges, the evidence is clear that Sulawesi's shrew diversity has been dramatically underestimated, and a lack of museum specimens was the foundational cause. Diversity in other taxonomic groups native to Sulawesi is also probably underestimated to a large degree (e.g., Giam et al., 2010). Our same inventories uncovered numerous new rodent species and genera (Esselstyn et al., 2012b, 2015; Musser, 2014; Rowe et al., 2014; Rowe et al., 2016b), and other systematic evaluations have revealed a wealth of previously unknown diversity among frogs (Setiadi et al., 2011), weevils

\footnotetext{
${ }^{1}$ See, for instance, Esselstyn et al. (2019), where we lacked sequence data from type series, and therefore used informal names for two members each of the Elongata Subgroup and the Small-Bodied Group because we did not know which, if either, represented Crocidura elongata and C. lea, respectively. In addition, we mistook C. pseudorhoditis for C. rhoditis in that paper, not recognizing it as an undescribed taxon.
} 
(Riedel and Narakusumo, 2019), begonias (Thomas et al., 2011), and other taxa from the island. These findings lend strong support for the need to build collections of Sulawesi's remarkable biodiversity, and numerous biologists have pleaded for such efforts globally (Remsen, 1995; Clemann et al., 2014; Malaney and Cook, 2018). In effect, the current taxonomy of life on Earth is heavily biased and woefully incomplete, with only a small fraction of insects, fungi, and many other massively diverse groups documented (e.g., Wu et al., 2019; Deng et al., 2020). Our discovery of 14 new shrews from Sulawesi should provide some perspective on the massive societal effort that would be needed to thoroughly document global biodiversity.

DATA COMPLETENESS: Although we identified an unusually large number of new mammal species in this analysis, our sampling remains incomplete. There are large geographic gaps between many of the mountains we sampled, and the extent of our elevational sampling on individual mountains varies widely. For instance, we have not trapped anywhere between Mts. Bawakaraeng and Latimojong, a distance of 215 $\mathrm{km}$. Similar distances exist between our sample sites on the eastern and northern peninsulas; on the latter, we have yet to obtain specimens from the north-central area of endemism (fig. 1) although Ruedi (1995) collected a few there. At a smaller geographic scale, our elevational sampling of individual mountains is also incomplete. For instance, on Mt. Gandang Dewata (including Salu Tiwo), we surveyed small mammals more thoroughly than on any other mountain, with sampling sites at roughly 200, 1600, 2200, and $2600 \mathrm{~m}$ (fig. 3, appendix). Aside from the obvious vertical gap between 200 and $1600 \mathrm{~m}$, this mountain is over $3300 \mathrm{~m}$ at its peak, and we do not know what species of shrews reside in the upper $700 \mathrm{~m}$ of elevation. This span of unsampled elevation often corresponds to a large range of climatic and habitat variation (Whitmore, 1984; Whitten et al., 1987), and on several mountains we found endemic species restricted to the highest areas we sampled (e.g., Crocidura brevi- cauda, C. caudicrassa, and C. baletei; table 3). At lower elevations, we found that sites separated by $1000 \mathrm{~m}$ or less of elevation often held somewhat different shrew faunas (e.g., on Mts. Latimojong and Buliohuto; table 3). Substantial spans of unsampled high-elevation habitats are also found on Mts. Latimojong (3478 $\mathrm{m}$ ) and Balease (3016 m; fig. 3). On these and other mountains, lowland forests are almost entirely cleared, and we have done little trapping in heavily disturbed habitats. On Mt. Ambang, for instance, we conducted no trapping below $1400 \mathrm{~m}$, nor did we find any previously obtained specimens from this mountain in museum collections. In summary, our sampling was limited at lower elevations due to forest loss and at higher elevations by difficulty of access. Considering the incompleteness of this sampling and the small geographic ranges of several of the species we document, we expect that additional species of shrews remain to be discovered on Sulawesi.

Phylogenetic Relationships and the TEMPO OF DIVERsification: All our phylogenetic estimates confirmed that all but one of Sulawesi's known shrew species are members of an endemic radiation, as previous analyses of many fewer taxa have suggested (Ruedi et al., 1998; Esselstyn and Brown, 2009; Esselstyn et al., 2009, 2019). Twenty species formed a well-supported clade, whereas Crocidura nigripes was placed sister to $C$. palawanensis, a Philippine endemic, in our UCE analyses, which included multiple outgroups (fig. 7). Although we did not include many outgroups in our mitochondrial analyses, these also showed $C$. nigripes to be a distant relative of all other Sulawesi species (figs. $4,5)$. This consistent topological pattern demonstrates the importance of in situ speciation following the colonization of Sulawesi by the ancestor of the endemic radiation.

Within the endemic radiation of Sulawesi's shrews, the overall tree shape in our phylogenetic results was one with tight, mostly well-supported tip clusters, but largely unresolved, very short branches along the backbone (figs. 4, 5, 7, 8; supplementary data S2, S6). Colonization of oce- 
anic islands is often thought to spur adaptive radiation (e.g., Setiadi et al., 2011), and the shape of our inferred trees is consistent with the hypothesis that the first shrew species to colonize Sulawesi spawned a rapid radiation. Rapid species diversification is often, though not always, associated with ecological diversification (Setiadi et al., 2011; Martin and Richards, 2019). In this case, we have little idea if or how these shrew species differ ecologically, aside from what can be guessed based on differences in body proportions, local community structure, and species' geographic ranges.

Previous studies have estimated the crown age of Sulawesi's endemic shrew radition to be between about two and 10 million years, with the younger estimates based on distant fossil calibrations and the older estimates derived from molecular clock analyses of mitochondrial data (Esselstyn and Brown, 2009; Esselstyn et al., 2009; Hinckley et al., 2021). Sulawesi has a very complex geological history involving the accretion and uplift of multiple substrates (Hall, 1998). Prior to about four million years ago, Sulawesi comprised a few neighboring islands with limited upland habitats (Nugraha and Hall, 2018). During the late Pliocene, there were dramatic increases in land area, connectivity between islands, and the extent of high elevation habitats (Nugraha and Hall, 2018), potentially providing the habitat variation and ecological opportunity needed to foster a rapid radiation. Given the limited available habitat around 8-10 million years ago (Nugraha and Hall, 2018), we suspect that the younger estimates of crown age (ca. 3-5 million years ago) for Sulawesi's endemic shrew radiation are more plausible.

LOCAL SPECIES RICHNESS AND SPECIES GEOGRAPHIC RANGES: Local shrew diversity on Sulawesi is remarkable. On individual mountains, we identified 4-10 cooccurring species of Crocidura (table 3). While some local shrew communities in tropical regions of Africa hold more than 10 shrew species belonging to several genera and up to 10 species of Crocidura (e.g., Ray and Hutterer, 1995; Lunde, 2007), no Eur- asian or North American shrew communities are comparable in local species richness (Medway, 1965; Berman et al., 2007; Smith and Xie, 2008; Hope, 2012). On Sulawesi, we found the greatest local diversity on Mt. Gandang Dewata, an area where we also found a remarkably rich murine rodent fauna (Esselstyn et al., 2012b; Rowe et al., 2014, 2016b). Mt. Gandang Dewata is one of the highest mountains on Sulawesi, and it is part of an expansive montane region in the west-central area of endemism. This mountain is also where we sampled the greatest elevational range (fig. 3), and that may partially explain why we found the highest diversity there. However, Mt. Gandang Dewata was not an outlier for shrew diversitywe found nine species on Mt. Torompupu and eight on Mt. Latimojong.

Multiple factors likely contribute to the variation in local shrew species richness on Sulawesi. First, the maximum elevation of a mountain should be positively correlated with local species richness (Heaney et al., 2016; Camacho-Sanchez et al., 2019). Elevational gradients are associated with major differences in temperature and precipitation, and this is reflected in the transitions in forest type from the lowlands to middle and higher elevations (Whitmore, 1984; Whitten et al., 1987). Forest-type transitions are commonly associated with shifts in small mammal communities in Southeast Asia (Heaney, 2001; Camacho-Sanchez et al., 2019), and the elevational distributions of Sulawesi shrews are no exception (fig. 13). Second, given Sulawesi's shape, we also expect the central portion of the island to hold more species than the habitats on the peninsulas (Preston, 1960; MacArthur and Wilson, 1967). The peninsular habitats obviously have only narrow land connections to other portions of the island, and this presumably limits dispersal opportunities. In addition, many mountains in the central part of the island are well connected to expansive montane regions, while peaks on the peninsulas are generally lower, smaller, and more isolated "islands" of montane habitat (fig. 1). Thus, maximum elevation and highland connectivity are not independent on Sulawesi. Per- 
haps not surprisingly, the three most species-rich mountains we surveyed are all located in the west-central area of endemism (Mts. Gandang Dewata, Torompupu, and Latimojong; table 3). Given the more isolated geography of montane habitats on peninsulas, we might expect to find more microendemic species in these areas. Indeed, we did find some species on only one mountain in the southwest (Crocidura australis and C. parva) and northern peninsulas (C. tenebrosa), but we did not survey other mountains in these species' respective areas of endemism, so we cannot say whether these are truly singlemountain endemics. However, we also found apparent microendemics in the west-central area of endemism, where we surveyed five mountains (e.g., C. caudicrassa, C. brevicauda, and C. musseri). While these local endemics appear to be restricted geographically, other species are quite widespread on the island (e.g., C. caudipilosa, $C$. pallida, and C. quasielongata). Among widespread taxa, some hold extensive, geographically structured mitochondrial variation (e.g., C. pallida and C. quasielongata), suggesting the presence of factors that limit gene flow across the island, but other widespread taxa are genetically homogeneous (e.g., C. nigripes and C. caudipilosa). Overall, the picture is complex and somewhat obscured by incomplete sampling, but one nevertheless consistent with elevational gradients and habitat connectivity interacting to generate within-island isolation and to foster rich local shrew communities with high spatial turnover. There is excellent potential for comparisons of geographic patterns between the shrews and murine rodents of Sulawesi to provide an improved understanding of geographic mechanisms promoting diversity within localized, yet species-rich radiations.

GEOGRAPHIC PATTERNS OF MORPHOLOGICAL DIVERSITY AND SYMPATRY: Niche theory predicts that if closely related species are to coexist in any particular habitat, they must differ in some ecologically important variable (Gause, 1934; Letten et al., 2016). Shrew communities are often structured by body size, and in some simple commu- nities, size differences reflect differences in feeding ecology and microhabitat use (Dickman, 1988; Fox and Kirland, 1992; Brannon, 2000). Consistent with the idea that shrew communities are structured by interspecific body-size differences, we found that each mountain we surveyed housed at least one of the smallest shrews (SmallBodied Group: Crocidura parva, C. tenebrosa, C. lea, C. levicula, C. baletei, and C. mediocris) and one of the largest shrews (e.g., C. rhoditis, $C$. pseudorhoditis, and C. quasielongata). Among the Small-Bodied Group, we found one representative of this size class on nine mountains and two members on three mountains (C. baletei and C. lea on Mts Buliohuto and Dako, and C. levicula and C. mediocris on Mt. Torompupu: table 3). On Mts. Buliohuto and Torompupu, the two Small-Bodied species had nonoverlapping elevational ranges, but on Mt. Dako we found two species cooccurring at high elevation (around $1600 \mathrm{~m}$ ), while only one was present at low elevation (table 3 ). The consistent presence of one small species, and the observation of parapatry in some cases, suggests that body size is indeed reflective of some ecologically important resource that limits cooccurrence. In other geographic settings, authors have suggested that shrews of different sizes exploit leaf litter with different textures (Brosset, 1988; Brannon, 2000), and this hypothesis is worth exploring in complex shrew communities. In addition to the body size differences, we speculate that interspecific variation in relative rostral lengths and perhaps relative skull widths (fig. 10) are somehow important for feeding ecology. Our analyses revealed that smallerbodied species and the Elongata Subgroup members tend to have a shorter rostrum relative to skull length, while among the larger species, C. rhoditis, C. pseudorhoditis, C. nigripes, C. brevicauda, and C. caudicrassa all have particularly long rostra. These anatomical differences may reflect differences in bite force and preferred prey types.

Tail length and hind-foot length vary greatly among Sulawesi shrews; in other tropical-forest small mammals, these traits correlate with differ- 
ences in the extent to which animals climb trees and shrubs (Nations et al., 2019). The extremely long tails and hind feet of Elongata Subgroup members (fig. 9) must be significant to locomotory mode, but with few direct observations it is difficult to say how. Crocidura caudipilosa also has a relatively long tail, but its hind feet are shorter than in Elongata Subgroup members. Two specimens of C. caudipilosa have indeed been observed climbing, one of which was caught climbing a vertical tree trunk (Esselstyn et al., 2019). We are aware of few other observations of the locomotory habits of Sulawesi shrews; Musser (1982) reported capturing a shrew in a tree on Sulawesi, but it is unclear to what species he was referring. Furthermore, making predictions from morphology alone is tricky because trait values often overlap between locomotor modes in small mammals (Samuels and Van Valkenburgh, 2008; Nations et al., 2019). A long tail, for instance, is characteristic of both arboreal and saltatorial small mammals (Hickman, 1979), but the combination of a long tail and long hind feet may be better explained by saltation (Brosset, 1988). If Elongata Subgroup members are indeed hoppers, this may be related more directly to avoiding predators such as owls, than it is to how these animals forage. Perhaps the foraging habits of Elongata Subgroup members give them more exposure to aerial predators. Despite the uncertain ecology of these species, the largely parapatric geographical distribution of Elongata Subgroup members suggests that they each occupy similar ecological niches, though at different elevational ranges (figs. 13, 16), as noted by Eldridge et al. (2018). We found one or two members of this subgroup (not a clade in any of our phylogenetic analyses) on every mountain we surveyed. On all four mountains where we found two members, elevational distributions of the two species were either separate or abutting at a middle elevation (table 3). In general, the frequency of elevational parapatry between phenotypically similar species suggests that these morphological traits are reflective of ecological similarities that hinder coexistence.
While it is fairly obvious that phenotypic differences indicate ecological differences, which in turn facilitate interspecific coexistence, we also found two phenotypically very similar sister species, Crocidura ordinaria and C. solita, occurring in syntopy on Mt. Gandang Dewata. The differences we observed in morphology between these two taxa are too slight to offer any clues as to how they might differ ecologically, assuming they do in fact differ. Of course, coexisting species such as these may differ in important physiological or behavioral traits that are not observable in their anatomy. Both species were abundant in the areas where we found them together (we identified 21 C. solita and 41 C. ordinaria from the zone of overlap; both species were found around 1600 and $2600 \mathrm{~m}$, but we only caught C. ordinaria around $2200 \mathrm{~m}$ ). With both species present at two widely separated elevational bands, we suspect their cooccurrence is more than an ephemeral interaction. We found a somewhat similar situation with the sister pair C. rhoditis and C. pseudorhoditis. Morphological differences in this species pair are more substantial, but individual specimens are still challenging to identify with morphology alone. Where C. rhoditis and C. pseudorhoditis occur together (Mt. Ambang), we observed slightly greater differences in their size-related morphological traits (fig. 23). This pattern is consistent with character displacement in body size in areas where phenotypically similar species are syntopic. Demos et al. (2017) found a similar phenomenon between C. umbra and C. monticola on Java, where these two close relatives were found occurring syntopically at middle elevations on Mt. Gede. We suspect that modest levels of character displacement, which is often noted in less speciesrich shrew communities (e.g., Malmquist, 1985), is common in Southeast Asian shrew communities, where similarly sized species have made secondary contact after a period of isolation. If our supposition is correct, the intraspecific geographic variation generated by character displacement in areas of range overlap would help explain why it can be so difficult to link allopatric populations of individual species using morphology alone. 
REGIONAL GEOGRAPHY OF SHREW DIVERSITY: The 21 species of Crocidura now known from Sulawesi dwarf the known shrew faunas of other islands. The major Sundaic islands that neighbor Sulawesi are somewhat smaller (Java) or considerably larger (Borneo and Sumatra) in land area and they all have higher mountains than Sulawesi (fig. 1A). In addition, these Sundaic islands were all connected to the mainland during glacial periods (Voris, 2000). Within the genus Crocidura, Borneo is known to have only three species, Sumatra eight, and Java seven (Esselstyn et al., 2014; Phillipps and Phillipps, 2016; Demos et al., 2017). However, recent discoveries of new species of Crocidura from Java (Esselstyn et al., 2014; Demos et al., 2017) and reports of undescribed species from Sumatra (Demos et al., 2016) suggest the Sundaic shrew fauna, as currently estimated (18 species excluding the Malay Peninsula), is also incompletely known (Hinckley et al., 2021). It is impossible to say whether these islands are likely to hold as many undescribed species as Sulawesi has until now, but Borneo's known shrew diversity is oddly low for such a massive island with exceptional diversity in many other groups. Two other shrew genera are known from Borneo, but neither is diverse (one species of Chimarrogale and two of Suncus are native; Medway, 1965; Phillipps and Phillipps, 2016). Much of what is known of Borneo's mammal fauna is based on surveys from Mt. Kinabalu and neighboring areas. This is by far the most mountainous portion of the island and will almost certainly hold the greatest small mammal diversity, but the island's vast areas of lowland habitats are largely unsampled, and phylogeographic studies have commonly documented divergent lineages of various vertebrate taxa despite limited sampling (Gorog et al., 2004; Lim et al., 2017). We suspect that none of these islands' shrew faunas are fully documented by the current taxonomy. In the Philippines, the shrew faunas of two oceanic islands (Luzon and Mindanao) that approach the land area of Sulawesi contain only one or two species each (Esselstyn and Brown, 2009; Esselstyn et al.,
2011). However, Crocidura appears to have arrived in the oceanic portions of the Philippine archipelago more recently than they arrived in Sulawesi (Esselstyn et al., 2009), and this may explain much of the difference in diversity.

If Sulawesi's shrew diversity is indeed unusually rich, the most obvious geographical differences from other Southeast Asian islands are isolation from the mainland (Sulawesi is an oceanic island; Sundaland has only been intermittently isolated from the mainland during the Quaternary [Voris, 2000]), Sulawesi's history as a complex of islands (the most recent island coalescent events occurred approximately 1-2 million years ago; Nugraha and Hall, 2018), and the island's peculiar K-shape. Geographic isolation is known to be a common cause of speciation and radiation (MacArthur and Wilson, 1967), and peninsulas also lead to isolation by limiting potential paths of dispersal between suitable habitats (e.g., Giarla et al., 2018). These geographical factors may be especially effective at fostering radiation, but we have little prospect of understanding these forces until comprehensive biodiversity inventories and thorough taxonomic revisions have been completed for many taxa across the region.

WITHIN-ISLAND DIVERSIFICATION PROCESSES: Explaining how Sulawesi's remarkable shrew diversity arose requires a speciation mechanism that operates quickly (although there is considerable uncertainty, we suspect the crown age for Sulawesi's endemic shrew radiation is $<5$ million years) and on a small spatial scale. We observed parapatric distributions among phenotypically similar taxa, an elevational influence on local community structure, and mitochondrial diversity largely consistent with species boundaries but also arising in some taxa with broad geographic distributions. Taken together, these observations suggest a speciation mechanism initiated by within-island geographic isolation and subsequently maintained upon secondary contact by some combination of competitive exclusion, character displacement, Bateson-Dobzansky-Muller incompatibilities (Bateson, 1909; 
Dobzhansky, 1937; Muller, 1940; see below), or perhaps behavioral incompatibilities. The numerous elevational gradients on Sulawesi, with varying degrees of connectivity to neighboring mountains, provide ample opportunity for isolation of forest-adapted species. Climatic fluctuations through the Quaternary probably shifted the elevational distributions of various forest types (Whitmore, 1984; Whitten et al., 1987), and populations adapted to, for instance, montane forest would have experienced varying degrees of isolation over the last few million years. Pleistocene sea-level fluctuations and Sulawesi's history as an archipelago prior to 1-2 million years ago (Nugraha and Hall, 2018) provided further opportunities for geographic isolation. Once a population had been isolated sufficiently long for genetic or behavioral incompatibilities to arise, gene flow would be hindered upon secondary contact and character displacement might alleviate resource competition.

Mitochondria are functionally critical and evolve rapidly, accumulating mildly deleterious mutations that are compensated for by interacting nuclear genes (e.g., Chou and Leu, 2010; Hoekstra et al., 2013; Adrion et al., 2015). This process offers a plausible mechanism for initial genetic incompatibilities to arise quickly in temporarily allopatric populations (e.g., Patel et al., 2016; Hill, 2019; Tobler et al., 2019; Rank et al., 2020). Upon secondary contact, gene flow would be prevented by the functional mismatch between interacting mitochondrial and nuclear genes, a form of Bateson-Dobzansky-Muller incompatibility. The importance of mito-nuclear compatibility to organismal fitness has been demonstrated in a diversity of motile animal taxa, including fruit flies (Montooth et al., 2010; Patel et al., 2016), copepods (Barreto and Burton 2013a, 2013b), beetles (Rank et al., 2020), and mice (Ma et al., 2016), and compensatory evolution of nuclear genes that interact with mitochondria has been found in primates (Osada and Akashi, 2012). Shrews, with their high activity level and fast metabolism, may be especially dependent on high-functioning mitochondria and thus perhaps also especially susceptible to the consequences of mito-nuclear interactions. While this proposed model of diversification is entirely speculative, it is consistent with available data, and offers a logical mechanism for generating high levels of species diversity and endemism on a short evolutionary time scale in a small geographic setting.

\section{CONCLUSION}

Discoveries of new mammal species remain common globally (e.g., Ceballos and Ehrlich, 2009; Giam et al., 2010; Percequillo et al., 2011; Heaney et al., 2011; Li et al., 2019), but reports of more than a couple new species in a single paper are rare. Our discovery of 14 new species from a single endemic clade undoubtedly stems from multiple factors, including those that likely fostered shrew diversity in the first place and those that reflect the efforts of biologists, such as the paucity of historical biodiversity inventories undertaken on the island. Further exploration of the evolutionary history of Sulawesi's shrew fauna may reveal fascinating details of the processes that produced such a rich radiation, but completing such studies will require continued dedication to growing the natural history collections that make ecological and evolutionary insights possible.

\section{ACKNOWLEDGMENTS}

This work would not have been possible without the many natural history museums that obtain and curate voucher specimens. In this work, we relied heavily on several institutions and their staff: American Museum of Natural History, United States National Museum of Natural History, Field Museum of Natural History, Louisiana State University Museum of Natural Science, University of California Museum of Vertebrate Zoology, Museums Victoria, Museum Zoologicum Bogoriense, Museum of Wildlife and Fish Biology, Museum of Southwestern Biology, Museum of Texas Tech University, Naturalis 
Biodiversity Center, and the University of Kansas Biodiversity Institute. We are grateful to the Government of Indonesia for access to source material. The Indonesian Ministry of Research and Technology, Ministry of Environment and Forestry, and the local governments on Sulawesi provided permit and logistical support. Our work was supported by grants from the U.S. National Science Foundation (OISE-0965856, DEB-1343517, DEB-1441634, DEB-1457654, and DEB-1754393), National Geographic Society (9025-11, WW-160R-17), and the Alfred L. Gardner and Mark S. Hafner Mammalogy Fund at LSUMZ. The collections at MWFB that we used were supported by Grant \#U01TW008160 from the Fogarty International Center, the Office of Dietary Supplements, the National Science Foundation, and the Department of Energy; the USDA Agricultural Food Research Initiative of the National Institute of Food and Agriculture, U.S. Department of Agriculture, Grant \#3562104750. LSU supported this work by granting sabbatical leave to J.A.E. Much of this work was completed during a long-term visit to FMNH, which was supported by a Bass Senior Fellowship and the Barbara Brown Fund for Mammal Research. FMNH staff, including Larry Heaney, John Phelps, Adam Ferguson, Lauren Smith, and the late Bill Stanley were especially generous with their time. Also at FMNH, Lauren Nassef expertly prepared the specimen images in this manuscript. We thank the Collaborative Invertebrate Laboratories at the Field Museum, and P. Sierwald and R. Bieler for use of the imaging equipment (funded by NSF). We also thank Stephanie Ware for equipment training and support. At Museum Zoologicum Bogoriense, we received extensive support from Maharadatunkamsi, Nanang Supriatna, Endah Dwi Jayanti, and Apandi. Amy Adams at NMV and Spenser Babb-Biernacki and Ryan Eldridge at LSUMZ contributed to genetic data collection. Ben Evans gave essential advice and encouragement in the early stages of this project, well before we appreciated the depth of this rabbit hole. We thank Larry Heaney, Rob Voss, and an anonymous reviewer for their constructive reviews of an earlier version of this manuscript. Finally, Jim and Carol Patton, Jim McGuire, Tri Haryoko, Mardin Sarkam, Pungki Lupiyaningdyah, Zulkurnia Irsaf, and Rizaldi Putra were all instrumental in completing many of the expeditions that underlie this work.

\section{REFERENCES}

Adrion, J.R., P.S. White, and K.L. Montooth. 2015. The roles of compensatory evolution and constraint in aminoacyl tRNA synthetase evolution. Molecular Biology and Evolution 33: 152-161.

Allio, R., et al. 2020. MitoFinder: efficient automated large-scale extraction of mitogenomic data in target enrichment phylogenomics. Molecular Ecology Resources 20: 892-905.

Alston, C.L., M.C. Rocha, N.Z. Lax, D.M. Turnbull, and R.W. Taylor. 2017. The genetics and pathology of mitochondrial disease. Journal of Pathology 241: 236-250.

Baird, A.B., et al. 2017. Molecular systematics and biodiversity of the Cryptotis mexicanus group (Eulipotyphla: Soricidae): two new species from Honduras supported. Systematics and Biodiversity 16: 108-117.

Barreto, F.S., and R.S. Burton. 2013a. Evidence for compensatory evolution of ribosomal proteins in response to rapid divergence of mitochondrial rRNA. Molecular Biology and Evolution 30: 310314.

Barreto, F.S., and R.S. Burton. 2013b. Elevated oxidative damage is correlated with reduced fitness in interpopulation hybrids of a marine copepod. Proceedings of the Royal Society B, Biological Sciences 280: 20131521.

Bateson, W. 1909. Heredity and variation in modern lights. In A.C. Seward (editor), Darwin and modern science: 85-101. Cambridge: Cambridge University Press.

Berman, J., T. McCay, and P. Scull. 2007. Spatial analysis of species richness of shrews (Soricomorpha: Soricidae) in North America north of Mexico. Acta Theriologica 52: 151-158.

Bolger, A.M., M. Lohse, and B. Usadel. 2014. Trimmomatic: a flexible trimmer for Illumina sequence data. Bioinformatics 30: 2114-2120.

Bradley, R.D., and R.J. Baker. 2001. A test of the genetic species concept: cytochrome-b sequences and mammals. Journal of Mammalogy 82: 960-973. 
Brannon, M.P. 2000. Niche relationships of two syntopic species of shrews, Sorex fumeus and S. cinereus, in the southern Appalachian Mountains. Journal of Mammalogy 81: 1053-1061.

Brosset, A. 1988. Le peuplement de mammifères insectivores des forêts du nord-est du Gabon. Revue d'Ecologie, La Terre et la Vie 43: 23-46.

Burgin, C.J., J.P. Colella, P.L. Kahn, N.S. Upham. 2018. How many species of mammals are there? Journal of Mammalogy 99: 1-11.

Cadena, C.D., F. Zapata, and I. Jiménez. 2017. Issues and perspectives in species delimitation using phenotypic data: Atlantean evolution in Darwin's finches. Systematic Biology 67: 181-194.

Camacho-Sanchez, M., M.T.R. Hawkins, F.T.Y. Yu, J.E. Maldonado, and J.A. Leonard. 2019. Endemism and diversity of small mammals along two neighboring Bornean mountains. PeerJ 7: e7858.

Cao, X., et al. 2016. Rapid dissemination of taxonomic discoveries based on DNA barcoding and morphology. Scientific Reports 6: 37066.

Ceballos, G., and P.R. Ehrlich. 2009. Discoveries of new mammal species and their implications for conservation and ecosystem services. Proceedings of the National Academy of Sciences of the United States of America 106: 3841-3846.

Chou, J.-Y., and J.-Y. Leu. 2010. Speciation through cytonuclear incompatibility: insights from yeast and implications for higher eukaryotes. BioEssays 32: 401-411.

Clemann, N., et al. 2014. Value and impacts of collecting vertebrate voucher specimens, with guidelines for ethical collection. Memoirs of Museum Victoria 72: $141-151$.

Demos, T.C., et al. 2016. Local endemism and withinisland diversification of shrews illustrate the importance of speciation in building Sundaland mammal diversity. Molecular Ecology 25: 5158-5173.

Demos, T.C., A.S. Achmadi, H. Handika, K.C. Rowe, and J.A. Esselstyn. 2017. A new species of shrew (Soricomorpha: Crocidura) from Java, Indonesia: possible character displacement despite interspecific gene flow. Journal of Mammalogy 98: 183-193.

Deng, J., Y. Guo, Z. Cheng, C. Lu, and X. Huang. 2020. The prevalence of single-specimen/locality species in insect taxonomy: an empirical analysis. Diversity 11: 106 .

de Queiroz, K. 2007. Species concepts and species delimitation. Systematic Biology 56: 879-886.

Dickman, C.R. 1988. Body size, prey size, and community structure in insectivorous mammals. Ecology 69: 569-580.
Dobzhansky, T.G. 1937. Genetics and the origin of species. New York: Columbia University Press.

Dubey, S., N. Salamin, S.D. Ohdachi, P. Barrière, and P. Vogel. 2007. Molecular phylogenetics of shrews (Mammalia: Soricidae) reveal timing of transcontinental colonizations. Molecular Phylogenetics and Evolution 44: 126-137.

Edgar, R.C. 2004. MUSCLE: multiple sequence alignment with high accuracy and high throughput. Nucleic Acids Research 32: 1792-1797.

Eldridge, R.A., A.S. Achmadi, T.C. Giarla, K.C. Rowe, and J.A. Esselstyn. 2018. Geographic isolation and elevational gradients promote diversification in an endemic shrew on Sulawesi. Molecular Phylogenetics and Evolution 118: 306-317.

Esselstyn, J.A., and R.M. Brown. 2009. The role of repeated sea-level fluctuations in the generation of shrew (Soricidae: Crocidura) diversity in the Philippine Archipelago. Molecular Phylogenetics and Evolution 53: 171-181.

Esselstyn, J.A., R.M. Timm, and R.M. Brown. 2009. Do geological or climatic processes drive speciation in dynamic archipelagos? The tempo and mode of diversification in Southeast Asian shrews. Evolution 63: 2595-2610.

Esselstyn, J.A., S.P. Maher, R.M. Brown. 2011. Species interactions during diversification and community assembly in an island radiation of shrews. PLoS ONE 6: e21885.

Esselstyn, J.A., B.J. Evans, J.L. Sedlock, F.A.A. Khan, and L.R. Heaney. 2012a. Single-locus species delimitation: a test of the mixed Yule-coalescent model, with an empirical application to Philippine roundleaf bats. Proceedings of the Royal Society B, Biological Sciences 279: 3678-3686.

Esselstyn, J.A., A.S. Achmadi, and K.C. Rowe. 2012b. Evolutionary novelty in a rat with no molars. Biology Letters 8: 990-993.

Esselstyn, J.A., Maharadatunkamsi, A.S. Achmadi, C.D. Siler, and B.J. Evans. 2013. Carving out turf in a biodiversity hotspot: multiple, previously unrecognized shrew species co-occur on Java Island, Indonesia. Molecular Ecology 22: 4972-4987.

Esselstyn, J.A., A.S. Achmadi, and Maharadatunkamsi. 2014. A new species of shrew (Soricomorpha: Crocidura) from West Java, Indonesia. Journal of Mammalogy 95: 216-224.

Esselstyn, J.A., A.S. Achmadi, H. Handika, and K.C. Rowe. 2015. A hog-nosed shrew rat (Rodentia: Muridae) from Sulawesi Island, Indonesia. Journal of Mammalogy 96: 895-907. 
Esselstyn, J.A., C.H. Oliveros, M.T. Swanson, and B.C. Faircloth. 2017. Investigating difficult nodes in the placental mammal tree with expanded taxon sampling and thousands of ultraconserved elements. Genome Biology and Evolution 9: 2308-2321.

Esselstyn, J.A., A.S. Achmadi, H. Handika, T.C. Giarla, and K.C. Rowe. 2019. A new climbing shrew from Sulawesi highlights the tangled taxonomy of an endemic radiation. Journal of Mammalogy 100: 1713-1725.

Evans, B.J., et al. 2003. Monkeys and toads define areas of endemism on Sulawesi. Evolution 57: 1436-1443.

Evans, B.J., J.A. McGuire, R.M. Brown, N. Andayani, and J. Supriatna. 2008. A coalescent framework for comparing alternative models of population structure with genetic data: evolution of Celebes toads. Biology Letters 4: 430-433.

Fabre, P.-H., A.H. Reeve, Y.S. Fitriana, K.P. Aplin, and K.M. Helgen. 2018. A new species of Halmaheramys (Rodentia: Muridae) from Bisa and Obi islands (North Maluku Province, Indonesia). Journal of Mammalogy 99: 187-208.

Faircloth, B.C. 2013. Illumiprocessor: a trimmomatic wrapper for parallel adapter and quality trimming. Online resource (http://dx.doi.org/10.6079/J9ILL).

Faircloth, B.C. 2016. PHYLUCE is a software package for the analysis of conserved genomic loci. Bioinformatics 32: 786-788.

Faircloth, B.C., et al. 2012. Ultraconserved elements anchor thousands of genetic markers spanning multiple evolutionary timescales. Systematic Biology 61: 717-726.

Fooden, J. 1969. Taxonomy and evolution of the monkeys of Celebes (Primates: Cercopithecidae). Biobliotheca Primatologica 10: 1-148.

Fox, B.J., and G.L. Kirkland, Jr. 1992. An assembly rule for functional groups applied to North American soricid communities. Journal of Mammalogy 73: 491-503.

Gause, G.F. 1934. The struggle for existence. Baltimore: Williams and Wilkins.

Giam, X., T.H. Ng, V.B. Yap, and H.T.W. Tan. 2010. The extent of undiscovered species in Southeast Asia. Biodiversity and Conservation 19: 943-954.

Giarla, T.C., and J.A. Esselstyn. 2015. The challenges of resolving a rapid, recent radiation: empirical and simulated phylogenomics of Philippine shrews. Systematic Biology 64: 727-740.

Giarla, T.C., et al. 2018. Isolation by marine barriers and climate explain areas of endemism in an island rodent. Journal of Biogeography 45: 2053-2066.
Gloger, C.W. 1833. Das Abändern der Vögel durch Einfluss des Klima's. Breslau: August Shultz.

Gorog, A.J., M.H. Sinaga, and M.D. Engstrom. 2004. Vicariance or dispersal? Historical biogeography of three Sunda shelf murine rodents (Maxomys surifer, Leopoldamys sabanus and Maxomys whiteheadi). Biological Journal of the Linnean Society 81: 91-109.

Grabherr, M.G., et al. 2011. Trinity: reconstructing a full-length transcriptome without a genome from RNA-seq data. Nature Biotechnology 29: 644-652.

Guindon, S., et al. 2010. New algorithms and methods to estimate maximum-likelihood phylogenies: assessing the performance of PhyML 3.0. Systematic Biology 59: 307-321.

Hall, R. 1998. The plate tectonics of Cenozoic SE Asia and distribution of land and sea. In R. Hall and J.D. Holloway (editors), Biogeography and geological evolution of SE Asia: 99-132. Leiden: Backhuys Publishers.

Handika, H., A.S. Achmadi, J.A. Esselstyn, and K.C. Rowe. 2021. Molecular and morphological systematics of the Bunomys division (Rodentia: Muridae), an endemic radiaton on Sulawesi. Zoologica Scripta 50: 141-154.

Hawkins, M.T.R., et al. 2016. Evolutionary history of endemic Sulawesi squirrels constructed from UCEs and mitogenomes sequenced from museum specimens. BMC Ecology and Evolution 16: 80.

Heaney, L.R. 2001. Small mammal diversity along elevational gradients in the Philippines: an assessment of patterns and hypotheses. Global Ecology and Biogeography 10: 15-39.

Heaney, L.R., et al. 2011. Seven new species and a new subgenus of forest mice (Rodentia: Muridae: Apomys) from Luzon Island. Fieldiana: Life and Earth Sciences 2: 1-60.

Heaney L.R., et al. 2016. Doubling diversity: a cautionary tale of previously unsuspected mammalian diversity on a tropical oceanic island. Frontiers of Biogeography 8: e29667.

Hebert, P.D.N., A. Cywinska, S.L. Ball, and J.R. deWaard. 2003. Biological identifications through DNA barcodes. Proceedings of the Royal Society of London B, Biological Sciences 270: 313-321.

Hickerson, M.J., C.P. Meyer, and C. Moritz. 2006. DNA barcoding will often fail to discover new animal species over broad parameter space. Systematic Biology 55: 729-739.

Hickman, G.C. 1979. The mammalian tail: a review of functions. Mammal Review 9: 143-157. 
Hill, G.E. 2016. Mitonuclear coevolution as the genesis of speciation and the mitochondrial DNA barcode gap. Ecology and Evolution 6: 5831-5842.

Hill, G.E. 2019. Mitonuclear ecology. Oxford: Oxford University Press.

Hinckley, A., et al. 2021. Evolutionary history of Sundaland shrews (Eulipotyphla: Soricidae: Crocidura) with a focus on Borneo. Zoological Journal of the Linnean Society. [doi: 10.1093/zoolinnean/zlab045]

Hoang, D.T., O. Chernomor, A. von Haeseler, B.Q. Minh, and L.S. Vinh. 2018. UFBoot2: improving the ultrafast bootstrap approximation. Molecular Biology and Evolution 35: 518-522.

Hoekstra, L.A., M.A. Siddiq, and K.L. Montooth. 2013. Pleiotropic effects of a mitochondrial-nuclear incompatibility depend upon the accelerating effect of temperature in Drosophila. Genetics 195: 11291139.

Hope, A.G. 2012. High shrew diversity on Alaska's Seward Peninusla: community assembly and environmental change. Northwestern Naturalist 93: 101-110.

Hutterer, R. 2005. Homology of unicuspids and tooth nomenclature in shrews. In J.F. Merritt, S. Churchfield, R. Hutterer, and B. Sheftel (editors), Advances in the biology of shrews II, 379-404. New York: International Society of Shrew Biologists.

Hutterer, R., D.S. Balete, T.C. Giarla, L.R. Heaney, and J.A. Esselstyn. 2018. A new genus and species of shrew (Mammalia: Soricidae) from Palawan Island, Philippines. Journal of Mammalogy 99: 518-536.

Kalyaanamoorthy, S., B.Q. Minh, T.K.F. Wong, A. von Haeseler, and L.S. Jermiin. 2017. ModelFinder: fast model selection for accurate phylogenetic estimates. Nature Methods 14: 587-589.

Katoh, K., and D.M. Standley. 2013. MAFFT multiple sequence alignment software version 7: improvements in performance and usability. Molecular Biology and Evolution 30: 772-780.

Kozlov, A.M., D. Darriba, T. Flouri, B. Morel, and A. Stamatakis. 2019. RaxML-NG: a fast, scalable, and user-friendly tool for maximum likelihood phylogenetic inference. Bioinformatics 35: 4453-4455.

Lane, N. 2011. Mitonuclear match: optimizing fitness and fertility over generations drives ageing within generations. BioEssays 33: 860-869.

Lanfear, R., B. Calcott, D. Kainer, C. Mayer, and A. Stamatakis. 2014. Selecting optimal partitioning schemes for phylogenomic datasets. BMC Evolutionary Biology 14: 82 .
Lanfear, R., P.B. Frandsen, A.M. Wright, T. Senfeld, and B. Calcott. 2017. PartitionFinder2: new methods for selecting partitioned models of evolution for molecular and morphological phylogenetic analyses. Molecular Biology and Evolution 34: 772-773.

Letten, A.D., P.-J. Ke, and T. Fukami. 2016. Linking modern coexistence theory and contemporary niche theory. Ecological Monographs 87: 161-177.

Li, Q., et al. 2019. Discovery and description of a mysterious Asian flying squirrel (Rodentia, Sciuridae, Biswamoyopterus) from Mount Gaoligong, southwest China. ZooKeys 864: 147-160.

Lim, H.C., et al. 2017. Sundaland's east-west rain forest population structure: variable manifestations in four polytypic bird species examined using RAD-seq and plumage analyses. Journal of Biogeography 44: 2259-2271.

Lunde, D.P. 2007. Record of a 17th species of shrew (Soricomorpha: Soricidae) from the Dzanga-Sangha Reserve, Central African Republic. Mammalia 71: 146.

Ma, H., et al. 2016. Incompatibility between nuclear and mitochondrial genomes contributes to an interspecies reproductive barrier. Cell Metabolism 24: 283-294.

MacArthur, R.H., and E.O. Wilson. 1967. The theory of island biogeography. Princeton: Princeton University Press.

Mace, G.M. 2004. The role of taxonomy in species conservation. Philosophical Transactions of the Royal Society B, Biological Sciences 359: 711-719.

Maddison, W.P. 1997. Gene trees in species trees. Systematic Biology 46: 523-536.

Malaney, J.L., and J.A. Cook. 2018. A perfect storm for mammalogy: declining sample availability in a period of rapid environmental degradation. Journal of Mammalogy 99: 773-778.

Malmquist, M.G. 1985. Character displacement and biogeography of the pygmy shrew in northern Europe. Ecology 66: 372-377.

Martin, C.H., and E.J. Richards. 2019. The paradox behind the pattern of rapid adaptive radiation: how can the speciation process sustain through an early burst. Annual Review of Ecology, Evolution, and Systematics 50: 569-593.

Mayr, E. 1942. Systematics and the origin of species from the viewpoint of a zoologist. Cambridge, MA: Harvard University Press.

Mayr, E. 1957. Species concepts and definitions. In E. Mayr (editor,) The species problem: 1-22. Washington, D.C.: American Association for the Advancement of Science. 
McDowell, S.B., Jr. 1958. The greater Antillean insectivores. Bulletin of the American Museum of Natural History 115 (3): 131-214.

Medway, L. 1965. Mammals of Borneo: field keys and an annotated checklist. Journal of the Malayan Branch of the Royal Asiatic Society 203: 1-193.

Merker. S., C. Driller, D. Perwitasari-Farajallah, J. Pamungkas, and H. Zischler. 2009. Elucidating geological and biological processes underlying the diversification of Sulawesi tarsiers. Proceedings of the National Academy of Sciences of the United States of America 106: 8459-8464.

Miller, G.S., and N. Hollister. 1921. Twenty new mammals collected by H.C. Raven in Celebes. Proceedings of the Biological Society of Washington 34: 93-104.

Miller, M.A., W. Pfeiffer, and T. Schwartz. 2010. Creating the CIPRES Science Gateway for inference of large phylogenetic trees. In Proceedings of the Gateway Computing Environments Workshop (GCE), 14 Nov. 2010, New Orleans. Piscataway, NJ: IEEE.

Minh, B.Q, et al. 2020. IQ-TREE 2: new models and efficient methods for phylogenetic inference in the genomic era. Molecular Biology and Evolution 37: 1530-1534.

Monaghan, M.T., M. Balke, T.R. Gregory, and A.P. Vogler. 2005. DNA-based species delineation in tropical beetles using mitochondrial and nuclear markers. Philosophical Transactions of the Royal Society B, Biological Sciences 360: 1925-1933.

Montooth, K.L., C.D. Meiklejohn, D.N. Abt, and D.M. Rand. 2010. Mitochondrial-nuclear epistasis affects fitness within species but does not contribute to fixed incompatibilities between species of Drosophila. Evolution 64: 3364-3379.

Morales, H.E., et al. 2018. Concordant divergence of mitogenomes and mitonuclear gene clusters in bird lineages inhabiting different climates. Nature Ecology and Evolution 2: 1258-1267.

Morgan-Richards, M., et al. 2017. Explaining large mitochondrial sequence differences within a population sample. Royal Society Open Science 4: 170730.

Mosey, V. 2015. Sejarah Desa Kalait Kecamatan Touluaan Selatan Tahun 1924-2014 [History of Kalait Village, South Touluaan District, 1924-2014]. Jurnal Fakultas Sastra Universitas Sam Ratulangi 3 (1): $1-21$.

Muller, H.J. 1940. Bearing of the Drosophila work on systematics. In J. Huxley (editor), The new systematics: 185-268. Oxford: Oxford University Press.
Musser, G.G. 1982. Results of the Archbold expeditions. No. 110. Crunomys and the small-bodied shrew rats native to the Philippine islands and Sulawesi (Celebes). Bulletin of the American Museum of Natural History 174 (1): 1-95.

Musser, G.G. 1987. The mammals of Sulawesi. In T.C. Whitmore (editor), Biogeographical evolution of the Malay archipelago: 73-91. Oxford: Clarendon Press.

Musser, G.G. 2014. A systematic review of Sulawesi Bunomys (Muridae, Murinae) with the description of two new species. Bulletin of the American Museum of Natural History 392: 1-313.

Nabholz, B., S. Glemin, and N. Galtier. 2008. Strong variations of mitochondrial mutation rate across mammals - the longevity hypothesis. Molecular Biology and Evolution 25: 120-130.

Nations, J.A, et al. 2019. A simple skeletal measurement effectively predicts climbing behaviour in a diverse clade of small mammals. Biological Journal of the Linnean Society 128: 323-336.

Nugraha, A.M.S., and R. Hall. 2018. Late Cenozoic palaeogeography of Sulawesi, Indonesia. Palaeogeography, Palaeoclimatology, Palaeoecology 490: 191-209.

Nurk, S., D. Meleshko, A. Korobeynikov, and P.A. Pevzner. 2017. metaSPAdes: a new versatile metagenomic assembler. Genome Research 27: 824-834.

Osada, N., and H. Akashi. 2012. Mitochondrial-nuclear interactions and accelerated compensatory evolution: evidence from the primate cytochrome c oxidase complex. Molecular Biology and Evolution 29: 337-346.

Paradis, E., and K. Schliep. 2019. ape 5.0: an environment for modern phylogenetics and evolutionary analyses in R. Bioinformatics 35: 526-528.

Patel, M.R., et al., 2016. A mitochondrial DNA hypomorph of cytochrome oxidase specifically impairs male fertility in Drosophila melanogaster. eLife 5: e16923.

Patterson, D.J., J. Cooper, P.M. Kirk, R.L. Pyle, and D.P. Remsen. 2010. Names are key to the big new biology. Trends in Ecology \& Evolution 25: 686-691.

Patton, J.L., and M.F. Smith. 1994. Paraphyly, polyphyly, and the nature of species boundaries in pocket gophers (genus Thomomys). Systematic Biology 43: 11-26.

Percequillo, A.R., M. Weksler, and L.P. Costa. 2011. A new genus and species of rodent from the Brazilian Atlantic Forest (Rodentia: Cricetidae: Sigmodontinae: Oryzomyini), with comments on oryzomyine biogeography. Zoological Journal of the Linnean Society 161: 357-390. 
Phillipps, Q., and K. Phillipps. 2016. Phillipps' field guide to the mammals of Borneo and their ecology. Princeton: Princeton University Press.

Pichaud, N., et al. 2019. Age dependent dysfunction of mitochondrial and ROS metabolism induced by mitonuclear mismatch. Frontiers in Genetics 10: 130.

Preston, F.W. 1960. Time and space and the variation of species. Ecology 41: 612-627.

Puillandre, N., A. Lambert, S. Brouillet, and G. Achaz. 2012. ABGD, automatic barcode gap discovery for primary species delimitation. Molecular Ecology 21: 1864-1877.

Rannala, B., and Z. Yang. 2013. Improved reversible jump algorithms for Bayesian species delimitation. Genetics 194: 245-253.

Ray, J.C., and R. Hutterer. 1995. Structure of a shrew community in the Central African Republic based on the analysis of carnivore scats, with the description of a new Sylvisorex (Mammalia: Soricidae). Ecotropica 1: 85-97.

R Core Team. 2019. R: A language and environment for statistical computing. Vienna: R Foundation for Statistical Computing. Online resource (https://www.Rproject.org/).

Rank, N.E., P. Mardulyn, S.J. Heidl, K.T. Roberts, N.A. Zavala, J.T. Smiley, and E.P. Dahloff. 2020. Mitonuclear mismatch alters performance and reproductive success in naturally introgressed populations of a montane leaf beetle. Evolution 74: 1724-1740.

Remsen, J.V. 1995. The importance of continued collecting of bird specimens to ornithology and bird conservation. Bird Conservation International 5: 146-180.

Riedel, A., and R.P. Narakusumo. 2019. One hundred and three new species of Trigonopterus weevils from Sulawesi. Zookeys 828: 1-153.

Rowe, K.C., A.S. Achmadi, and J.A. Esselstyn. 2014. Convergent evolution of aquatic foraging in a new genus and species (Rodentia: Muridae) from Sulawesi Island, Indonesia. Zootaxa 381: 541-564.

Rowe, K.C., A.S. Achmadi, and J.A. Esselstyn. 2016a. Repeated evolution of carnivory among Indo-Australian rodents. Evolution 70: 653-665.

Rowe, K.C., A.S. Achmadi, and J.A. Esselstyn. 2016b. A new genus and species of omnivorous rodent (Muridae: Murinae) from Sulawesi, nested within a clade of endemic carnivores. Journal of Mammalogy 97: 978-991.

Rowe, K.C., et al. 2019. Oceanic islands of Wallacea as a source for dispersal and diversification of murine rodents. Journal of Biogeography 46: 2752-2768.
Ruedi, M. 1995. Taxonomic revision of shrews of the genus Crocidura from the Sunda Shelf and Sulawesi with description of two new species (Mammalia: Soricidae). Zoological Journal of the Linnean Society 115: 211-265.

Ruedi, M., M. Auberson, and V. Savolainen. 1998. Biogeography of Sulawesian shrews: testing for their origin with a parametric bootstrap on molecular data. Molecular Phylogenetics and Evolution 9: 567-571.

Samuels, J.X., and B. Van Valkenburgh. 2008. Skeletal indicators of locomotor adaptations in living and extinct rodents. Journal of Morphology 269: 13871411.

Setiadi, M.I., et al. 2011. Adaptive radiation and ecological opportunity in Sulawesi and Philippine fanged frog (Limnonectes) communities. American Naturalist 178: 221-240.

Sikes, R.S., and the Animal Care and Use Committee of the American Society of Mammalogists. 2016. 2016 guidelines of the American Society of Mammalogists for the use of wild mammals in research and education. Journal of Mammalogy 97: 663-688.

Simpson, G.G. 1961. Principles of animal taxonomy. New York: Columbia University Press.

Sites, J.W., Jr., and J.C. Marshall. 2003. Delimiting species: a Renaissance issue in systematic biology. Trends in Ecology and Evolution 18: 462-470.

Sloan, D.B., J.C. Havird, and J. Sharbrough. 2017. The on-again, off-again relationship between mitochondrial genomes and species boundaries. Molecular Ecology 26: 2212-2236.

Smith, A.T., and Y. Xie. 2008. A guide to the mammals of China. Princeton: Princeton University Press.

Stanley, W.T., and J.A. Esselstyn. 2010. Biogeography and diversity among montane populations of mouse shrew (Soricidae: Myosorex) in Tanzania. Biological Journal of the Linnean Society 100: 669-680.

Stanley, W.T., R. Hutterer, T.C. Giarla, and J.A. Esselstyn. 2015. Phylogeny, phylogeography, and geographic variation in the Crocidura monax (Soricidae) species complex from the montane islands of Tanzania, with descriptions of three new species. Zoological Journal of the Linnean Society 174: 185-215.

Sukumaran, J., and L.L. Knowles. 2017. Multispecies coalescent delimits structure, not species. Proceedings of the National Academy of Sciences of the United States of America 114: 1607-1612.

Swanson, M.T., C.H. Oliveros, and J.A. Esselstyn. 2019. A phylogenomic rodent tree reveals the repeated evolution of masseter architectures. Proceedings of 
the Royal Society B, Biological Sciences 286: 20190672.

Thomas, D.C., W.H. Ardi, and M. Hughes. 2011. Nine new species of Begonia (Begoniaceae) from South and West Sulawesi, Indonesia. Edinburgh Journal of Botany 68: 225-255.

Thomson, S.A., et al. 2018. Taxonomy based on science is necessary for global conservation. PLoS Biology 16: e2005075.

Tobler, M., N. Barts, and R. Greenway. 2019. Mitochondria and the origin of species: bridging genetic and ecological perspectives on speciation processes. Integrative and Comparative Biology 59: 900-911.

Tsai, W.L.E., M.E. Schedl, J.M. Maley, and J.E. McCormack. 2020. More than skin and bones: comparing extraction methods and alternative sources of DNA from avian museum specimens. Molecular Ecology Resources 20: 1220-1227.

Voris, H.K. 2000. Maps of Pleistocene sea levels in Southeast Asia: shorelines, river systems and time durations. Journal of Biogeography 27: 1153-1167.

Waring, E., et al. 2020. skimr: compact and flexible summaries of data. $\mathrm{R}$ package version 2.1.2. Online resource (https://CRAN.R-project.org/ package $=$ skimr).

Wayne, R.K., et al. 1990. Large sequence divergence among mitochondrial DNA genotypes within populations of eastern African black-backed jackals. Proceedings of the National Academy of Sciences of the United States of America 87: 1772-1776.

Whitmore, T.C. 1984. Tropical rain forests of the Far East. Oxford: Clarendon Press.
Whitten, T., G.S. Henderson, and M. Mustafa. 1987. The ecology of Sulawesi. Ecology of Indonesia Series, vol. 4. Sunderland, MA: Sinauer Associates.

Wickham, H. 2016. ggplot2: elegant graphics for data analysis. New York: Springer-Verlag.

Wickham, H., R. Francois, L. Henry, and K. Muller. 2020. dplyr: a grammar of data manipulation. $\mathrm{R}$ package version 1.0.0. Online resource (https:// CRAN.R-project.org/package $=$ dplyr).

Wolff, J.N., E.D. Ladoukakis, J.A. Enríquez, and D.K. Dowling. 2014. Mitonuclear interactions: evolutionary consequences over multiple biological scales. Philosophical Transactions of the Royal Society B, Biological Sciences 369: 20130443.

Woodman, N., and R.M. Timm. 1993. Intraspecific and interspecific variation in the Cryptotis nigrescens species complex of small-eared shrews (Insectivora: Soricidae), with the description of a new species from Colombia. Fieldiana: Zoology (N.S.) 74: 1-30.

$\mathrm{Wu}, \mathrm{B}$., et al. 2019. Current insights into fungal species diversity and perspective on naming the environmental DNA sequences of fungi. Mycology 10:127-140.

Yang, Z. 2015. The BPP program for species tree estimation and species delimitation. Current Zoology 61: 854-865.

Yang, Z., and B. Rannala. 2010. Bayesian species delimitation using multilocus sequence data. Proceedings of the National Academy of Sciences of the United States of America 107: 9264-9269.

Zhang, C., M. Rabiee, E. Sayyari, and S. Mirarab. 2018. ASTRAL-III: polynomial time species tree reconstruction from partially resolved gene trees. BMC Bioinformatics 19: 153. 


\section{APPENDIX}

\section{Gazetteer of Specimens Examined}

Localities are grouped by their respective area of endemism. Individual localities are numbered and the English province name is given in parentheses. Within localities, geographic coordinates and elevations are given for individual sites, where available, and sites are sorted by elevation. Where no elevation is given, we were unable to estimate it with $<300 \mathrm{~m}$ of uncertainty. Individual specimens are listed following the geographic coordinates. We provide alternate spellings for some localities used in older literature.

\section{North-East Area of Endemism}

1. Mt. Ambang (North Sulawesi Province)

$\mathbf{0 . 7 6 3 8}^{\circ} \mathrm{N}$ 124.4119 ${ }^{\circ} \mathrm{E}, 1460 \mathrm{~m}$ (LSUMZ 39011, $39014,39045) ; \mathbf{0 . 7 6 4}^{\circ} \mathrm{N} \mathbf{1 2 4 . 4 1 1}^{\circ} \mathrm{E}, \mathbf{1 4 6 0} \mathrm{m}$ (LSUMZ 39008-39010, 39015-39017, 39019-39023, 39025, 39030-39044, 39050-39068); $\mathbf{0 . 7 6 3 8 4 5}^{\circ} \mathbf{~ N}$ 124.411884 ${ }^{\circ} \mathrm{E}, 1481 \mathrm{~m}$ (LSUMZ 39243-39251, 39257-39264, 39267-39274, 39278-39284, 39293, 39296-39298, 39300-39314, 39316-39322);

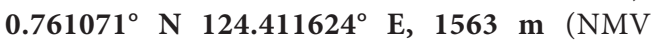
C37985, C37992, C37996, C38009, C38017, C38022, C38031, C38032); $\mathbf{0 . 7 5 8 9}^{\circ} \mathrm{N} \mathbf{1 2 4 . 4 0 9 5}^{\circ} \mathrm{E}, 1592 \mathrm{~m}$ (LSUMZ 39012, 39013, 39018, 39048, 39049).

2. Lembeh Island (North Sulawesi Province)

$\mathbf{1 . 4 3}^{\circ} \mathrm{S} \mathbf{1 2 5 . 2 2}^{\circ} \mathrm{E}$ (FMNH 31844).

3. Temboan (North Sulawesi Province)

$\mathbf{0 . 9 7 9}^{\circ} \mathrm{N} \mathbf{1 2 4 . 6 0 5}^{\circ} \mathrm{E}, \mathbf{6 5 0} \mathrm{m}$ (FMNH 43858, 43859, USNM 217534-217539, 217541-217545, 217547217557).

Raven's fieldnotes from 16 July 1916 (available at USNM) state, "Temboan (Kuala Kalait) [is] a new clearing of eight houses and lies from Mt. Sapoetan South, $55^{\circ}$ west and about six miles from Loboe." Musser (2014: 141) quoted this same statement but used a lower case "s" in "south." He placed this locality at $1.05^{\circ} \mathrm{N}, 124.55^{\circ} \mathrm{E}$, a hilly area just west of the Pamurapa River and exactly six miles west of Ronoketang (= Loboe), as Raven described. However, the compass bearing from this area to Mt. Soputan (= Sapoetan) is approximately $70^{\circ}$, and it is impossible to place a point on the map that is six miles west of Ronoketang and $55^{\circ}$ to Mt. Soputan. Furthermore, no villages named Temboan currently exist in the area. Rather, $1.05^{\circ} \mathrm{N}, 124.55^{\circ} \mathrm{E}$ is an area of scrubby secondary vegetation in hilly terrain and the nearest village is $4.7 \mathrm{~km}$ to the southeast, on the opposite side of the Pamurapa River. This nearest village is currently known as Kalait, which matches the parenthetical statement, "Kuala Kalait" in Raven's notes. An historical account of Kalait, which is in the South Touluaan District, Southeast Minahasa Regency, at $1.027^{\circ} \mathrm{N}, 124.586^{\circ} \mathrm{E}$, provides further clues. According to Mosey (2015), Kalait was established in 1924 by a few political refugees originally from Karimbow (a village about $20 \mathrm{~km}$ to the northwest). These refugees left Karimbow in 1914 and established a new village in 1916, which they named Temboan ("hilly terrain"). A newly established village matches Raven's 1916 statement of "a new clearing of eight houses." By 1924, Temboan's population had grown, and water was in short supply (Mosey, 2015). At this time, the entire village relocated by about $5 \mathrm{~km}$ (no direction was given) and established Kalait (Mosey, 2015). Musser's (2014) interpretation of Temboan puts the type locality very near the Pamurapa River, which seems unlikely given Mosey's (2015) account of a water shortage. Rather, we believe that Temboan lies south of Kalait, at a location $55^{\circ}$ to Mt. Manimporok, a peak $4 \mathrm{~km}$ south of Mt. Soputan. If this mountain was unlabeled on Raven's maps, he might have referred to it as "Mt. Sapoetan South." We suspect that the refugees that established Temboan named some small stream "Kuala Kalait," which translates roughly as the Desiring Peace (Kalait) River (Kuala) and carried the name "Kalait" with them when they abandoned Temboan in 1924. Given these inferences, we believe Raven's Temboan was located at $0.979^{\circ} \mathrm{N}, 124.605^{\circ} \mathrm{E}, 650 \mathrm{~m}$ elevation. This Temboan (there are many in North Sulawesi) is in the Southeast Minahasa Regency, North Sulawesi Province, $6 \mathrm{~km}$ south of Kalait and $9.5 \mathrm{~km}$ (6 miles) southwest of Ronoketang.

\section{North-Central Area of Endemism}

4. Toraut (Gorontalo Province)

$\mathbf{0 . 5 4}^{\circ} \mathrm{N} \mathbf{1 2 3 . 8 3}^{\circ} \mathrm{E}, 230 \mathrm{~m}$ (RMNH 38389, 38390).

\section{North-West Area of Endemism}

5. Mt. Buliohuto (Gorontalo Province) $\mathbf{0 . 9 1 3 3 9 3}^{\circ} \mathrm{N} 122.449845^{\circ} \mathrm{E}, 435 \mathrm{~m}$ (NMV C37692); $\mathbf{0 . 9 0 9 3 3}^{\circ} \mathrm{N} \mathrm{122.44994^{ \circ }}$ E, $480 \mathrm{~m}$ (LSUMZ 38254, $38257, \quad 38274-38279, \quad 38296) ; \quad \mathbf{0 . 9 1 0 1 3 6}^{\circ} \mathrm{N}$ $\mathbf{1 2 2 . 4 5 0 7 4 6}^{\circ}$ E, 520 m (NMV C37715, C37716, C37720, C37721, C37735); $\mathbf{0 . 9 0 7 4 1}^{\circ} \mathrm{N} \mathbf{1 2 2 . 4 5 3 2 5}^{\circ}$ 
E, 580 m (LSUMZ 38238, 38240, 38251, 38252, 38255 , 38256, 38271-38273, 38280, 38281, 38283,

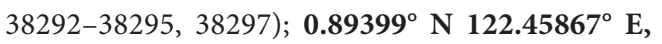
1200 m (LSUMZ 38243-38245, 38258-38262,

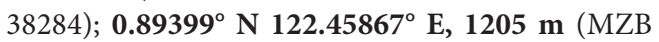
38656, NMV C37742, C37744, C37746, C37752, C37760, C37793, C37815, C37829); $\mathbf{0 . 8 9 0 7 1}^{\circ} \mathbf{N}$ 122.45802 ${ }^{\circ}$ E, 1375 m (LSUMZ 38246, 38247, $38265,38268,38270,38287-38291) ; \mathbf{0 . 8 8 7 2 9}^{\circ} \mathrm{N}$ 122.45496 ${ }^{\circ}$ E, 1390 m (LSUMZ 38253, 38264, 38286, MZB 38588, NMV C37777, C37778, C37794, C37800).

6. Mt. Dako (Central Sulawesi Province)

$\mathbf{1 . 1 0 9 9 8}^{\circ} \mathrm{N} \mathbf{1 2 0 . 9 0 3 3 9}^{\circ} \mathrm{E}, 410 \mathrm{~m}$ (LSUMZ 3693536939, 37039-37049); $\mathbf{1 . 1 0 6 4 2}^{\circ} \mathrm{N} \mathbf{1 2 0 . 9 1 0 6}^{\circ} \mathrm{E}, 512$ m (LSUMZ 36923, 36924, 36932, 36945, 3696836972, 37007, 37008, 37011-37016, 37026-37029, $37032-37038) ; \mathbf{1 . 1 0 6 3 1}^{\circ} \mathrm{N} \mathrm{120.91065^{ \circ }} \mathrm{E}, 630 \mathrm{~m}$ (NMV C37351, C37363, C37367-C37369); $\mathbf{1 . 1 0 9 7 8}^{\circ}$ N 120.937974 ${ }^{\circ}$ E, 1595 m (MZB 38558-38560, 38564-38566, NMV C37252, C37254, C37257, C37264, C37265, C37267, C37268, C37292, C37297, C37304-C37308, C37315, C37318, C37328$\mathrm{C} 37330) ; \mathbf{1 . 1 0 6 0 7}^{\circ} \mathrm{N} \mathbf{1 2 0 . 9 3 8 5 3}^{\circ} \mathrm{E}, \mathbf{1 6 0 0} \mathrm{m}$ (LSUMZ 36905-36907, 36909, 36916, 36919, 36921, 36940, 36942, 36946-36956, 36958-36966, 36973, 36978-36980, 36986, 36990, 36991, 36993, 36995, 36998, 37000, 37002, 37005, 37017-37019, 37022, 37025).

\section{West-Central Area of Endemism}

7. Mt. Balease (Central Sulawesi Province) $\mathbf{2 . 5 0 2 0 1}^{\circ} \mathrm{S} \mathbf{1 2 0 . 4 8 5 4}^{\circ} \mathrm{E}, \mathbf{8 1 7} \mathrm{m}$ (FMNH 210569$210571,210604) ; 2^{2.50273^{\circ}} \mathrm{S} \mathbf{1 2 0 . 4 8 4 7 9}^{\circ} \mathrm{E}, 830 \mathrm{~m}$

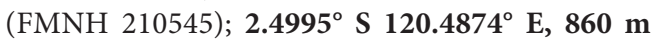
$(F M N H ~ 210546) ; \mathbf{2 . 5 0 0 2}^{\circ} \mathrm{S} \mathbf{1 2 0 . 4 8 6 2}^{\circ} \mathrm{E}, \mathbf{8 6 0} \mathrm{m}$ (FMNH 210564, 210580); 2.50002 ${ }^{\circ} \mathrm{S} \mathbf{1 2 0 . 4 8 7 2 6}^{\circ} \mathrm{E}$,

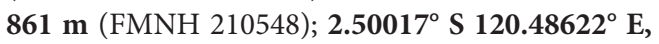
861 (FMNH 210565, 210602, 210605); $\mathbf{2 . 5 0 0 0 2}^{\circ} \mathrm{S}$ $\mathbf{1 2 0 . 4 8 7 2 6}^{\circ}$ E, 862 m (FMNH 210547, 210549, 210566-210568, 210572, 210583, 210590, 210592, $210599,210601,210603,210606) ; 2.49193^{\circ} \mathrm{S}$ 120.49022 ${ }^{\circ} \mathrm{E}, \mathbf{8 6 2} \mathrm{m}$ (FMNH 210556); 2.48834 ${ }^{\circ} \mathrm{S}$ $\mathbf{1 2 0 . 4 9 2 8 9}^{\circ} \mathrm{E}, \mathbf{8 6 2} \mathrm{m}(\mathrm{FMNH} 210550) ; \mathbf{2 . 4 8 9 1 8}^{\circ} \mathrm{S}$ $\mathbf{1 2 0 . 4 9 2 1 3}^{\circ} \mathrm{E}, \mathbf{8 9 7} \mathrm{m}(\mathrm{FMNH} 210558,210575)$; $\mathbf{2 . 5 0 0 2}^{\circ} \mathrm{S} \mathbf{1 2 0 . 4 8 6 2}^{\circ} \mathrm{E}, 900 \mathrm{~m}$ (FMNH 210563); $2.4995^{\circ} \mathrm{S} \mathbf{1 2 0 . 4 8 7 4}^{\circ} \mathrm{E}, 900 \mathrm{~m}$ (FMNH 210542, 210543, 210581, 210582, 210593, 210596, 210598, $210607-210609,210611) ; 2.4973^{\circ} \mathrm{S} 120.4879^{\circ} \mathrm{E}$, $913 \mathrm{~m}(\mathrm{FMNH} 210544,210597) ; \mathbf{2 . 4 9 1 9 3}^{\circ} \mathrm{S}$ 120.49022 ${ }^{\circ}$ E, 1005 m (FMNH 210555, 210588); $\mathbf{2 . 4 8 9 1 8}^{\circ} \mathrm{S} \mathbf{1 2 0 . 4 9 2 1 3}^{\circ} \mathrm{E}, \mathbf{1 1 0 7} \mathrm{m}$ (FMNH 210573, $210574,210595) ; \mathbf{2 . 4 8 9 1 8}^{\circ} \mathrm{S} \mathbf{1 2 0 . 4 9 2 1 3}^{\circ} \mathrm{E}, \mathbf{1 1 4 0} \mathrm{m}$ $(\mathrm{FMNH} 210554) ; \mathbf{2 . 4 8 8 3 4}^{\circ} \mathrm{S} \mathbf{1 2 0 . 4 9 2 8 9}^{\circ} \mathrm{E}, 1140 \mathrm{~m}$ (FMNH 210551-210553, 210557, 210559, 210584$210586,210589,210594,210600) ; \mathbf{2 . 4 8 4 8 6}^{\circ} \mathrm{S}$ $\mathbf{1 2 0 . 4 9 5 7 5}^{\circ} \mathrm{E}, \mathbf{1 2 4 4}_{\mathbf{~ m}}$ (FMNH 210587, 210591).

8. Donggala, Lake Lindu (Central Sulawesi Province) $\mathbf{1 . 3 2}^{\circ} \mathbf{S} \mathbf{1 2 0 . 0 8}^{\circ} \mathrm{E}$ (USNM 501223).

9. Mt. Gandang Dewata (West Sulawesi Province) $2.5415^{\circ} \mathrm{S} 119.3825^{\circ} \mathrm{E}, 170 \mathrm{~m}$ (Salu Tiwo) (FMNH 218548-218579, 218614-218651, 218703-218706, $218708,218744) ; 2.88311^{\circ} \mathrm{S} 119.38676^{\circ} \mathrm{E}, 1535 \mathrm{~m}$ (FMNH 218584, 218593-218603, 218653, 218654, 218656, 218657, 218687-218690, 218766, 218767, $218971,218973,218976,218983) ; \mathbf{2 . 8 8 3 9 4}^{\circ} \mathrm{S}$ $\mathbf{1 1 9 . 3 8 7 1}^{\circ}$ E, 1558 m (FMNH 218652, 218655, 218658, 218691, 218692-218695, 218699, 218700, 218761, 218763-218765, 218768, 218771, 218985); $\mathbf{2 . 8 8 2 0 4}^{\circ} \mathrm{S} \mathbf{1 1 9 . 3 8 4 4}^{\circ} \mathrm{E}, \mathbf{1 5 7 5} \mathrm{m}$ (FMNH 218975, 218986); $\mathbf{2 . 8 8 4 2 1}^{\circ} \mathrm{S} \mathbf{1 1 9 . 3 8 7 5 6}^{\circ} \mathrm{E}, \mathbf{1 5 8 1} \mathrm{m}(\mathrm{FMNH}$ 218696, 218697, 218702, 218769, 218770, 218974); $2.883946^{\circ} \mathrm{S} 119.386379^{\circ} \mathrm{E}, 1600 \mathrm{~m}(\mathrm{MZB} 34811$, $34828,34829,34872,34885-34890,34952)$; $\mathbf{2 . 8 8 2 0 4}^{\circ} \mathrm{S} \mathbf{1 1 9 . 3 8 4 4}^{\circ} \mathrm{E}, \mathbf{1 6 0 2} \mathrm{m}$ (FMNH 218762); $\mathbf{2 . 8 8 2 6 1}^{\circ} \mathrm{S} \mathbf{1 1 9 . 3 8 5 2 1}^{\circ} \mathrm{E}, \mathbf{1 6 0 2} \mathrm{m}$ (FMNH 218698, $218701,218772-218780,218972,218989)$; $2.883946^{\circ} \mathrm{S} 119.386379^{\circ} \mathrm{E}, 1630 \mathrm{~m}(\mathrm{MZB} 34751$, 34753, 34755-34757, 34823, 34826, 34827, 34831, 34833, 34876, 34877, 34881-34884, 34951); $\mathbf{2 . 8 1 8 1}^{\circ}$ S 119.3823 ${ }^{\circ}$ E, 2200 m (FMNH 218544-218547, 218604-218613, 218726-218743, 218759, 218760, $218969,218970,218984) ; \mathbf{2 . 8 4 5 3 4}^{\circ} \mathrm{S} 119.38216^{\circ} \mathrm{E}$, $2520 \mathrm{~m}$ (MZB 34749, 34821); $2.84534^{\circ} \mathrm{S} 1 \mathbf{1 9 . 3 8 2 1 6}^{\circ}$ E, 2610 m (MZB 34736-34748, 34790-34799, 34801-34810, 34812-34814, 34816, 34820, 34856, 34870, 34871).

10. Gimpoe (= Gimpu) (Central Sulawesi Province) $\mathbf{1 . 6 0}^{\circ} \mathrm{S} \mathbf{1 1 9 . 8 8}^{\circ} \mathrm{E}, \mathbf{4 0 0} \mathbf{m}$ (USNM 219444, 219446).

11. Koelawi (= Kulawi) (Central Sulawesi Province) $\mathbf{1 . 4 5}^{\circ} \mathrm{S} 119.98^{\circ} \mathrm{E}$ (FMNH 47361).

12. Kuala Navusu (Central Sulawesi Province) $\mathbf{0 . 9 8}^{\circ} \mathrm{S} \mathbf{1 2 0 . 4 3}^{\circ} \mathrm{E}, 30 \mathrm{~m}$ (AMNH 226105, 226106); $\mathbf{0 . 9 8}^{\circ} \mathrm{S} \mathbf{1 2 0 . 4 3}^{\circ} \mathrm{E}, 43 \mathrm{~m}$ (AMNH 226108, 226109); $\mathbf{0 . 9 8}^{\circ} \mathrm{S} \mathbf{1 2 0 . 4 3}^{\circ} \mathrm{E}, 46 \mathrm{~m}$ (AMNH 226110, 226112).

13. Mt. Latimojong (South Sulawesi Province)

3.38897 ${ }^{\circ} \mathrm{S} 120.19717^{\circ} \mathrm{E}, 683 \mathrm{~m}$ (MVZ 237573, 237611, MZB 40936, 40937); 3.40866 ${ }^{\circ} \mathrm{S}$ $\mathbf{1 2 0 . 0 9 1 1 6}^{\circ} \mathrm{E}, \mathbf{1 3 7 6} \mathrm{m}$ (MVZ 237618, 237619, MZB 41669-41672); 3.415 ${ }^{\circ} \mathrm{S} \mathbf{1 2 0 . 0 9 8 7 1}^{\circ} \mathrm{E}, 1697$ m (MVZ 237574, 237586, 237620, 237621, 237628, MZB 41649, 41673-41677); $\mathbf{3 . 4 2 7 5 1 6}^{\circ} \mathrm{S}$ 
$\mathbf{1 2 0 . 0 9 2 3 7 5}^{\circ} \mathrm{E}, \mathbf{1 8 5 0} \mathrm{m}$ (MZB 40938); 3.420665 S $120.094371^{\circ}$ E, 2015 m (MVZ 237570, 237571, 237587-237592, 237612, 237622-237624, NMV C38479, C38493, C38516, C38534); 3.40755 $\mathrm{S}$ $\mathbf{1 2 0 . 0 0 7 8}^{\circ}$ E, 2050 m (FMNH 212990-213002, 213006-213013, 213015-213018, 213020-213023, 213025, 213029, 213030, 213034-213037, 213039213058, 213426); 3.40564 ${ }^{\circ} \mathrm{S} \mathbf{1 2 0 . 0 1 0 5 2}^{\circ} \mathrm{E}, \mathbf{2 2 5 0}$ m (FMNH 213031, 213032, 213059, 213060); $3.40513^{\circ} \mathrm{S} 120.01154^{\circ} \mathrm{E}, 2300 \mathrm{~m}$ (FMNH 213003213005, 213014, 213019, 213024, 213026-213028, $213033,213061-213071,213427) ; 3^{4.43051^{\circ}} \mathrm{S}$ $\mathbf{1 2 0 . 0 8 8 9 5}^{\circ}$ E, $2322 \mathrm{~m}$ (MVZ 237569, 237629237631, 238122, MZB 40935); 3.427516 ${ }^{\circ} \mathrm{S}$ $120.092375^{\circ} \mathrm{E}, 2380 \mathrm{~m}$ (MVZ 237568, 237572, 237593-237599, 237613-237617, NMV C38591);

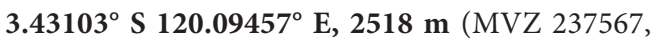

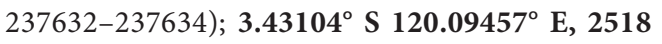
m (MVZ 237585); $3.43445^{\circ} \mathrm{S} 120.09039^{\circ} \mathrm{E}, 2535$ m (MVZ 238121).

14. Mt. Nokilalaki (Central Sulawesi Province) $1.26^{\circ} \mathrm{S} 120.17^{\circ} \mathrm{E}, 1829 \mathrm{~m}$ (AMNH 223495); $\mathbf{1 . 2 6}^{\circ}$ S $120.17^{\circ}$ E, $2195 \mathrm{~m}$ (AMNH 225516); $1.26^{\circ} \mathrm{S}$ $120.17^{\circ}$ E, $2255 \mathrm{~m}$ (AMNH 225517, 225521); 1.26 S $\mathbf{1 2 0 . 1 7}^{\circ}$ E, 2286 m (AMNH 225525-225527, 225530, 225531).

15. Sungai Miu (Central Sulawesi Province) $1.35^{\circ} \mathrm{S} 119.97^{\circ} \mathrm{E}, 350 \mathrm{~m}$ (AMNH 223989).

16. Sungai Tolewonu (Central Sulawesi Province) $\mathbf{1 . 0 8}^{\circ} \mathrm{S} 120.45^{\circ} \mathrm{E}, 122 \mathrm{~m}$ (AMNH 226537); $\mathbf{1 . 0 8}^{\circ} \mathrm{S}$ 120.45 ${ }^{\circ}$ E, 137 m (AMNH 226538, 226539).

17. Pinedapa (Central Sulawesi Province) $\mathbf{1 . 4 1}^{\circ} \mathrm{S} \mathbf{1 2 0 . 6 2}^{\circ} \mathrm{E}, 31 \mathrm{~m}$ (USNM 219435, 219450).

18. Mt. Rorekatimbo (Central Sulawesi Province) $1.30934^{\circ} \mathrm{S} 120.30919^{\circ} \mathrm{E}, 2020 \mathrm{~m}$ (FMNH $213146-$ 213167, 213174, 213175, 213184, 213190-213216, 213218-213220, 213223-213226, 213228, 213229, 213246, 213247, 213249, 213250, 213252, 213253, 213258, 213269-213271, 213435); $\mathbf{1 . 2 9 2 5 5}^{\circ} \mathrm{S}$ $\mathbf{1 2 0 . 3 0 6 3 9}^{\circ}$ E, 2180 m (FMNH 213168, 213169, 213171, 213173, 213178, 213179, 213186-213188, 213221, 213222, 213227, 213231-213239, 213241$213245,213265,213441) ; \mathbf{1 . 2 6 7}^{\circ} \mathrm{S} \mathbf{1 2 0 . 2 5}^{\circ} \mathrm{E}, \mathbf{2 2 3 0}$ m (MZB 16791, RMNH 38409); $\mathbf{1 . 2 8 8 4}^{\circ} \mathrm{S}$ $\mathbf{1 2 0 . 3 1 0 3 9}^{\circ}$ E, 2250 m (FMNH 213170, 213172, 213176, 213177, 213180-213183, 213185, 213189, $213217,213230,213240,213248,213251,213254-$ 213257, 213259-213264, 213266-213268, 213436213438, 213442, 213443).

19. Tana Toraja, Rindingallo (Central Sulawesi Province) $2.9312^{\circ} \mathrm{S} 119.7123^{\circ} \mathrm{E}, 1609 \mathrm{~m}$ (MSB 93256); $2.9022^{\circ} \mathrm{S} 119.6973^{\circ} \mathrm{E}, 2120 \mathrm{~m}$ (MSB 93104); $\mathbf{2 . 9 0 2 2}^{\circ} \mathrm{S} 119.6973^{\circ} \mathrm{E}, 2150 \mathrm{~m}$ (MSB 93125).

20. Toare (= Tuare or Toware) (Central Sulawesi Province)

$\mathbf{1 . 9 0}^{\circ} \mathrm{S} \mathbf{1 2 0 . 1 7 ^ { \circ }}$ E, $800 \mathrm{~m}$ (USNM 219434, 219437219440, 219443, 219447, FMNH 47362).

21. Tomado, Lindoe Lake (= Lake Lindu) (Central Sulawesi Province):

$1.32^{\circ} \mathrm{S} 120.05^{\circ} \mathrm{E}, 1000 \mathrm{~m}$ (USNM 218668).

22. Mt. Torompupu (Central Sulawesi Province)

$1.40291^{\circ} \mathrm{S} 119.9445^{\circ} \mathrm{E}, 663 \mathrm{~m}$ (LSUMZ 39418, 39455); $1.403264^{\circ} \mathrm{S} 119.944928^{\circ} \mathrm{E}, 670 \mathrm{~m}$ (MVZ 238109-238111); $\mathbf{1 . 4 0 5 7 4 1}^{\circ} \mathrm{S} \mathbf{1 1 9 . 9 4 0 3 4 6}^{\circ} \mathrm{E}, 739$ m (MVZ 238112-238114, NMV C40245-C40247, C40251-C40254, C40259-C40262, C40273, C40274, C40278); $\mathbf{1 . 4 0 4 7 5 9}^{\circ} \mathrm{S} 119.944928^{\circ}$ E, 765 m (NMV C40240, C40241); $\mathbf{1 . 4 0 0 7 9}^{\circ}$ S $119.94241^{\circ}$ E, 790 m (LSUMZ 39419-39422, 39426,-39428, 39452, 39453, 39456, 39457, 39469, 39471-39473, 39480, 39555); $\mathbf{1 . 4 0 0 7 9}^{\circ} \mathrm{S} \mathbf{1 1 9 . 9 4 2 4 1}^{\circ} \mathrm{E}, 793 \mathrm{~m}$ (LSUMZ 39358); $\mathbf{1 . 4 0 7 3 8 3}^{\circ} \mathrm{S} \mathbf{1 1 9 . 9 4 4 4 7 8}^{\circ} \mathrm{E}, 838$ m (NMV C40243, C40244, C40281, C40282, Z62199); $1.40813^{\circ} \mathrm{S} 119.94427^{\circ} \mathrm{E}, 854 \mathrm{~m}$ (LSUMZ $39454,39470) ; 1^{1.40813^{\circ}} \mathrm{S} 119.94427^{\circ} \mathrm{E}, 862 \mathrm{~m}$ (LSUMZ 39359); 1.42115 $^{\circ} \mathrm{S} 119.898646^{\circ} \mathrm{E}, 1371$ m (LSUMZ 39429, 39430, 39446-39449, 39474); $1.421367^{\circ} \mathrm{S} 119.895122^{\circ} \mathrm{E}, 1455 \mathrm{~m}$ (NMV C40288, C40311); $1.419193^{\circ} \mathrm{S} 119.886327^{\circ} \mathrm{E}, 1455 \mathrm{~m}$ (NMV C40292-C40294); $\mathbf{1 . 4 2 1 3 6 7}^{\circ} \mathrm{S} 119.895122^{\circ}$ E, $1655 \mathrm{~m} \mathrm{(NMV} \mathrm{Z63365);}$. $^{419193^{\circ}} \mathrm{E}$, $\mathbf{1 1 9 . 8 8 6 3 2 7 ^ { \circ }}$ E, $1655 \mathrm{~m}$ (MVZ 238107, 238108, MZB 43014, NMV C40307, C40308); $\mathbf{1 . 4 1 9 1 9 3}^{\circ} \mathrm{S}$ $119.886327^{\circ} \mathrm{E}, 1840 \mathrm{~m}(\mathrm{NMV} \mathrm{C} 40306) ; 1^{\circ} 416503^{\circ}$ S $119.875666^{\circ}$ E, $2032 \mathrm{~m}$ (NMV C40139); $\mathbf{1 . 4 1 2 6 3 1 ~}^{\circ} \mathrm{S} 119.868257^{\circ} \mathrm{E}, 2218 \mathrm{~m}$ (MZB 43013).

23. Wasponda (South Sulawesi Province)

$\mathbf{2 . 5 0 3 6 8}^{\circ} \mathrm{S} \mathbf{1 2 1 . 0 9 0 1 2}^{\circ} \mathrm{E}, 455 \mathrm{~m}$ (FMNH 210560 210562, 210578, 210579).

\section{East-Central Area of Endemism}

24. Mt. Katopasa (Central Sulawesi Province)

$1.136766^{\circ} \mathrm{S} 121.444346^{\circ} \mathrm{E}, 407 \mathrm{~m}$ (NMV Z62311); $1.132712^{\circ} \mathrm{S} 121.4354^{\circ} \mathrm{E}, 450 \mathrm{~m}$ (LSUMZ 39486$39490,39537,39538) ; \mathbf{1 . 3 2 4 1}^{\circ} \mathrm{S} \mathbf{1 2 1 . 4 3 7 0 1}^{\circ} \mathrm{E}, 450$

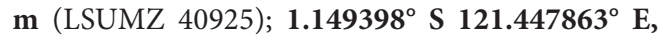
755 m (NMV C40229, C40230); 1.152636 $^{\circ} \mathrm{S}$ $121.44891^{\circ} \mathrm{E}, 837 \mathrm{~m}$ (NMV C40227); $1.17133^{\circ} \mathrm{S}$ $121.44636^{\circ} \mathrm{E}, 1352 \mathrm{~m}$ (LSUMZ 39357); $\mathbf{1 . 1 7 1 3 3}^{\circ} \mathrm{S}$ 121.44636 ${ }^{\circ}$ E, 1365 m (LSUMZ 39514, 39515, $39531,39535,39536) ; \mathbf{1 . 1 4 4 3 9}^{\circ} \mathrm{S} \mathbf{1 2 1 . 4 4 6 9 9}^{\circ} \mathrm{E}$, 
$1364 \mathbf{m}$ (LSUMZ 39355, 39356); $\mathbf{1 . 1 7 4 3 9}^{\circ} \mathrm{S}$ 121.44699 ${ }^{\circ}$ E, 1365 m (LSUMZ 39483, 39512, 39513 , 39527, 39529, 39530, 39532- 39534); $\mathbf{1 . 1 8 8 6 3 1}^{\circ} \mathrm{S} \mathbf{1 2 1 . 4 4 2 6 4 8}^{\circ} \mathrm{E}, 1495 \mathrm{~m}$ (MVZ 238115238118, MZB 39840, 39871, 39922, NMV C40177, C40180, C40181, C40186, C40187, C40199-C40203, C40206, C40207, C40214, C40217, C40219, C40220, Z55557, Z61754, Z61792, Z61813, Z61815, Z62366, Z62413-Z62415, Z62422); $\mathbf{1 . 1 9 1 0 8 5}^{\circ} \mathrm{S} \mathbf{1 2 1 . 4 3 9 8 4 2}^{\circ}$ E, 1532 m (NMV Z56723); $1.199932^{\circ} \mathrm{S} 121.434823^{\circ}$ E, 1700 m (LSUMZ 39492, 39516).

25. Peleng Island (Central Sulawesi Province) $\mathbf{1 . 3 3}^{\circ} \mathrm{S} \mathbf{1 2 3 . 0 4}^{\circ} \mathrm{E}$ (AMNH 109215).

26. Mt. Tompotika (Central Sulawesi Province) $\mathbf{0 . 6 5 0 0 8}^{\circ} \mathrm{S} \mathbf{1 2 3 . 1 2 8 6 8}^{\circ} \mathrm{E}, 350$ m (FMNH 213339213344, 213346-213350, 213358, 213361, 213362, 213365-213368); $\mathbf{0 . 6 6 2 8 7}^{\circ} \mathrm{S} \mathbf{1 2 3 . 1 3 1 7 5}^{\circ} \mathrm{E}, \mathbf{6 0 0} \mathrm{m}$ (FMNH 213345, 213351-213357, 213359, 213360, 213363, 213364, 213369).

\section{South-East Area of Endemism}

27. Mt. Mekongga (Southeast Sulawesi Province) 3.98422 ${ }^{\circ} \mathrm{S} 121.57144^{\circ} \mathrm{E}, 150 \mathrm{~m}$ (MWFB 8195, 8196 ); $3.63052^{\circ} \mathrm{S} 121.22073^{\circ} \mathrm{E}, 1366 \mathrm{~m}$ (MWFB 8151 ); $3.63086^{\circ} \mathrm{S} 121.21967^{\circ} \mathrm{E}, 1366 \mathrm{~m}$ (MWFB $8154) ; 3.63655^{\circ} \mathrm{S} 121.19427^{\circ} \mathrm{E}, 1366 \mathrm{~m}$ (MWFB $8091) ; 3^{6} 6381^{\circ} \mathrm{S} 121.19513^{\circ} \mathrm{E}, 1471 \mathrm{~m}$ (MWFB $8092,8094,8113-8115,8121,8122) ; 3.6381^{\circ} \mathrm{S}$ $121.19513^{\circ} \mathrm{E}, 1515 \mathrm{~m}$ (MWFB 8104); 3.63158 $\mathrm{S}$ 121.20397 ${ }^{\circ}$ E, 1710 m (MWFB 13507, 13508, $13512,13513) ; \mathbf{3 . 6 3 2 1 1}^{\circ} \mathrm{S} \mathbf{1 2 1 . 2 0 8 3 1}^{\circ} \mathrm{E}, \mathbf{1 7 1 7} \mathrm{m}$ (MWFB 13509-13511, 13514); 3.63052 ${ }^{\circ} \mathbf{S}$ 121.22073 ${ }^{\circ} \mathrm{E}, \mathbf{1 8 5 0} \mathbf{~ m}$ (MWFB 8139, 8152, 8153); $3.63086^{\circ} \mathrm{S} 121.21967^{\circ} \mathrm{E}, 1881 \mathrm{~m}$ (MWFB 8148, $8150) ; 3^{63086^{\circ} \mathrm{S}} \mathbf{1 2 1 . 2 1 9 6 7}^{\circ} \mathrm{E}, 1899 \mathrm{~m}$ (MWFB

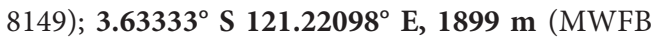
$8059,8130-8133,8135,8136,8140-8142) ; 3^{6344^{\circ}}$ S 121.22208 ${ }^{\circ} \mathrm{E}, 1936 \mathrm{~m}$ (MWFB 8125, 8134, 8144, 8145 ); $3.65041^{\circ} \mathrm{S} 121.23684^{\circ} \mathrm{E}, 2536 \mathrm{~m}$ (MWFB 8158 ); $3.652216^{\circ} \mathrm{S} 121.23657^{\circ} \mathrm{E}, 2578 \mathrm{~m}$ (MWFB $8161,8162,8438,8439)$.

28. Tolala (Southeast Sulawesi Province)

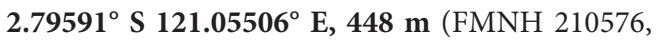
210577).

\section{South-West Area of Endemism}

29. Mt. Bawakaraeng (South Sulawesi Province) $\mathbf{5 . 2 8 6 8 1 5}^{\circ} \mathrm{S} \mathbf{1 1 9 . 9 6 1 4 0 6}^{\circ} \mathrm{E}, 1733 \mathrm{~m}$ (MVZ 237575237581, NMV Z56280, Z56302, Z56314, Z57129, $\mathrm{Z} 57152, \mathrm{Z} 57156) ; \mathbf{5 . 2 8 7 2 2}^{\circ} \mathrm{S} \mathbf{1 1 9 . 9 5 7 1 2}^{\circ} \mathrm{E}, \mathbf{1 7 6 0} \mathrm{m}$
$(\mathrm{MVZ} 237604,237605) ; \mathbf{5 . 2 9 1 3 8 5}^{\circ} \mathrm{S} 119.95757^{\circ} \mathrm{E}$, $1800 \mathrm{~m}$ (NMV Z56319, Z57377); 5.28722 ${ }^{\circ} \mathrm{S}$ 119.95712 ${ }^{\circ}$ E, 1850 m (MVZ 237600-237603, 237606-237609, 237625); 5.287222 S $\mathbf{1 1 9 . 9 5 7 1 1 9}^{\circ}$ E, 1850 m (NMV Z56801, Z56995, Z57008, Z57012, Z57013, Z57043-Z57047, Z57057, Z57061, Z57064);

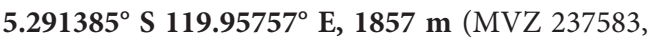

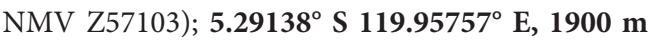
(MVZ 237627); 5.291385 ${ }^{\circ} \mathrm{S} 119.95757^{\circ} \mathrm{E}, 2072 \mathrm{~m}$ (MVZ 237584); $5.308463^{\circ} \mathrm{S} \mathbf{1 1 9 . 9 4 8 6 6 1}^{\circ} \mathrm{E}, \mathbf{2 4 7 0} \mathrm{m}$ (MZB 40991, 41027, NMV Z57200, Z57208); $5.31623^{\circ} \mathrm{S} 119.945107^{\circ} \mathrm{E}, 2470 \mathrm{~m}$ (NMV Z57223); $5.31623^{\circ} \mathrm{S} 119.94511^{\circ} \mathrm{E}, 2470 \mathrm{~m}$ (MVZ 237610); $5.30846^{\circ} \mathrm{S} 119.94866^{\circ} \mathrm{E}, 2550 \mathrm{~m}$ (MVZ 237626). 


\section{Scientific Publications of the American Museum of Natural History}

AMERICAN MUSEUM NOVITATES

Bulletin of the American Museum of Natural History

anthropological Papers of the American Museum of natural History

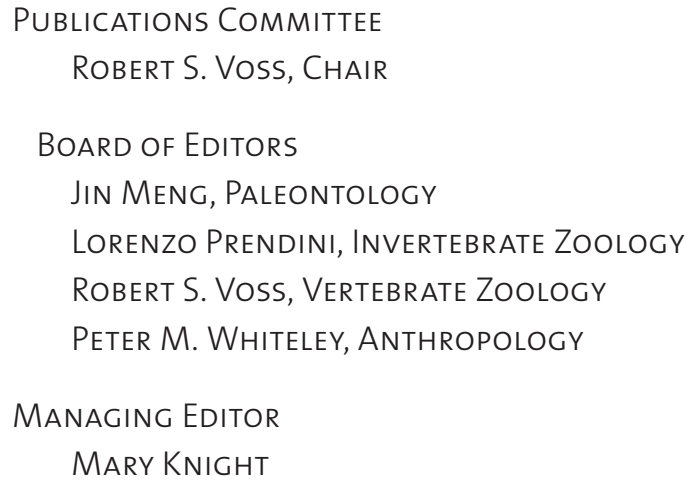

All issues of Novitates and Bulletin are available on the web (https://digitallibrary. amnh.org/dspace/handle/2246/5). Order printed copies on the web from: https://shop.amnh.org/books/scientific-publications.html or via standard mail from:

American Museum of Natural History-Scientific Publications Central Park West at 79th Street

New York, NY 10024

(0) This paper meets the requirements of ANSI/NISO Z39.48-1992 (permanence of paper).

On the cover: Two species of Crocidura from Sulawesi. ILLUSTRATION by SUbir SHAKYa. 